\title{
Effect of Water Harvesting Techniques on Hydrological Processes and Sediment Yield in Northern Ethiopia
}




\section{Thesis committee}

\section{Promotors}

Prof. Dr V. Geissen

Personal chair, Soil Physics and Land Management Group

Wageningen University \& Research

Prof. Dr C.J. Ritsema

Professor of Soil Physics and Land Management Group

Wageningen University \& Research

\section{Co-promotors}

Dr R. Hessel

Senior Scientist

Wageningen University \& Research

Dr. C.A. Kessler

Assistant professor, Soil Physics and Land Management Group

Wageningen University \& Research

\section{Other members}

Prof. Dr J. Wallinga, Wageningen University \& Research

Dr L.H.E. Cammeraat, University of Amsterdam, Netherlands

Dr Z. Adimassu, International Water Management Institute, Addis Ababa, Ethiopia

Dr O. Gonzalez Pelayo, University of Aveiro, Portugal

This research was conducted under the auspices of the Research School for SocioEconomic and Natural Sciences of the Environment (SENSE) 


\title{
Effect of Water Harvesting Techniques on Hydrological Processes and Sediment Yield in Northern Ethiopia
}

\author{
Berhane Grum Woldegiorgis
}

Thesis

submitted in fulfilment of the requirements for the degree of doctor at Wageningen University

by the authority of the Rector Magnificus

Prof. Dr A.P.J. Mol

in the presence of the

Thesis Committee appointed by the Academic Board

to be defended in public

on Tuesday 9 May 2017

at 4 p.m. in the Aula. 
Berhane Grum Woldegiorgis

Effect of Water Harvesting Techniques on Hydrological Processes and Sediment Yield in Northern Ethiopia,

156 pages.

PhD thesis, Wageningen University, Wageningen, NL (2017)

With references, with summary in English

ISBN: 978-94-6343-168-2

DOI: $10.18174 / 412142$ 


\section{Table of contents}

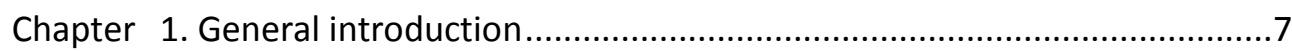

Chapter 2. A decision support approach for the selection and implementation of water harvesting techniques in arid and semiarid regions

Chapter 3. Improving on-site water availability by combining in-situ water harvesting techniques in semi-arid northern Ethiopia

Chapter 4. Effect of in-situ water harvesting techniques on soil and nutrient losses in semi-arid northern Ethiopia...

Chapter 5. Assessing the effect of water harvesting techniques on eventbased hydrological responses and sediment yield at a catchment scale in northern Ethiopia using LISEM

Chapter 6. Synthesis 117

Literature cited .131

English summary. 147

Acknowledgements 151

Curriculum Vitae 


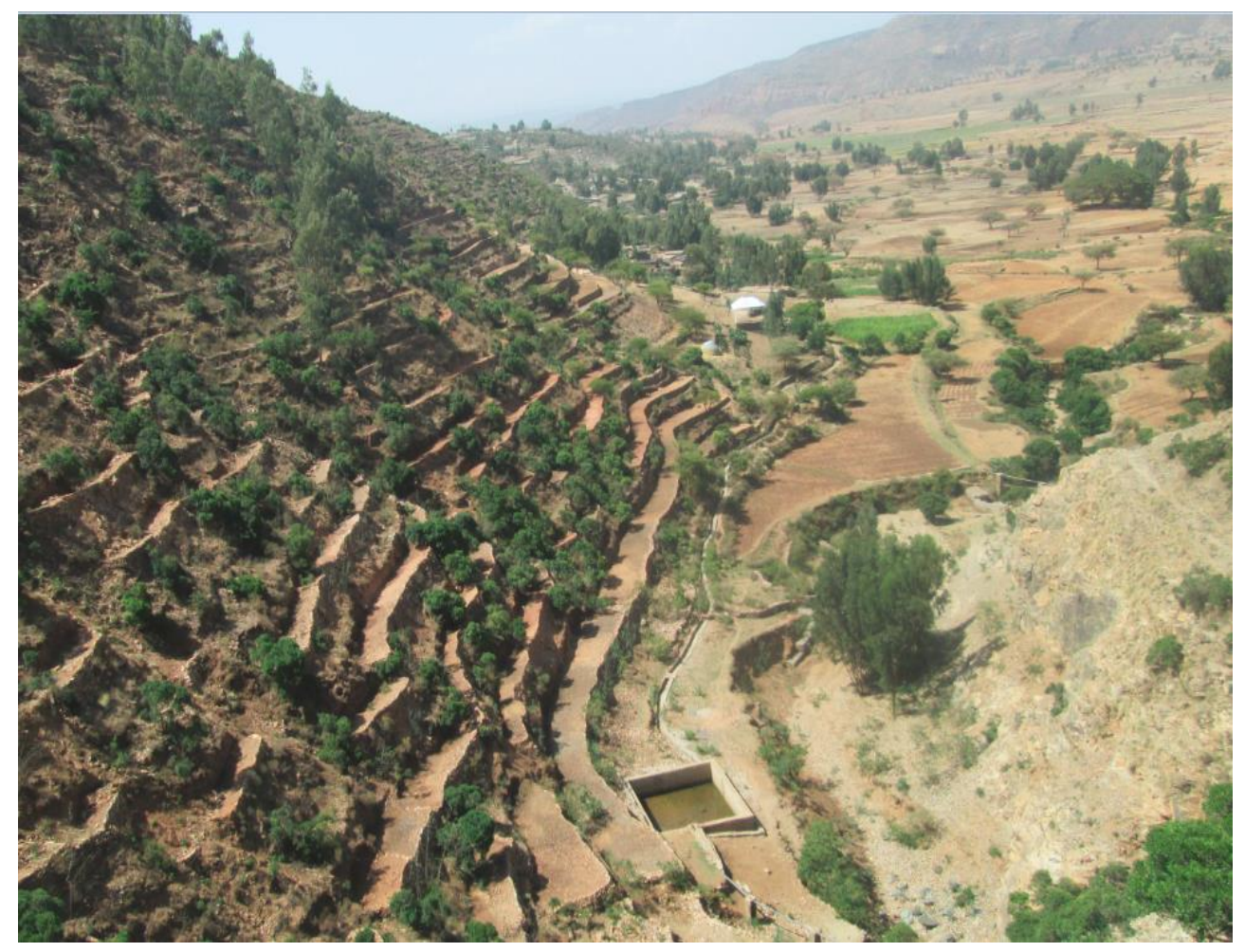




\section{General introduction}




\subsection{Water shortage and the need for water harvesting techniques}

Recent studies show that the global water resource availability will be stressed due to climate change, population growth and other socio-economic variables (Alcamo et al., 2007; Gerten et al., 2011; Vörösmarty et al., 2000). Many modelling-based findings predict that the future water stress conditions will be worse than today. The increase in water stress is mainly caused by an increase in domestic water use driven by the growth of per capita income (Alcamo et al., 2007). Therefore, without proper and planned use of the available water, more severe water shortages, unsustainable use of water, and conflicting interests regarding water use can be expected. This makes improving water use efficiency in all sectors of water applications inevitable. In arid and semi-arid regions, the main challenges in rainfed agriculture are dry spells, short periods of water stress and temporal rainfall variability causing crop failures, which are main constraints to crop production in these regions of the world (Enfors and Gordon, 2008; Fox and Rockström, 2003).

A good strategy to deal with water stress is to maximize water productivity by improving the efficiency of different rainwater applications of rainfed agricultural systems in arid and semi-arid regions (Biazin et al., 2012; Oweis and Hachum, 2006). Large scale irrigation systems have been the focal point as agronomic solutions to tackle crop water deficit, but nowadays many activities are focused on interventions such as water harvesting techniques (WHTs) and supplemental irrigation (UNDP, 2006). Supplemental irrigation is the application of limited amount of water when rainfall is insufficient for crop growth (Oweis et al., 1999). Supplemental irrigation is applied when there is water deficit and helps to stop crop failures during the absence or shortage of rainfall, while WHTs help to effectively use harvested water during the entire plant growth period as well as to bridge moisture-stress during dry spells. From the different water management practices, WHTs are also highly promoted by governments, non-governmental agencies and agricultural extensions in many parts of the world particularly in African countries and India (Batchelor et al., 2002; Stroosnijder, 2003; Vohland and Barry, 2009).

WHTs are very diverse and have been used for many years in different parts of the world. WHTs, however, share common characteristics as they depend on local runoff sources and are generally applied in arid and semi-arid climates (Boers and Ben-Asher, 1982; Prinz, 1996). Water harvesting is defined as the collection of water for its productive use (Critchley and Siegert, 1991). WHTs are primarily used for crop production; however they are also used for domestic and animal consumption with the provision of necessary storage facilities. WHTs may be pivotal in dry areas but are also necessary for using/optimising the available water for additional uses, even in areas with sufficient water resources. Generally, WHTs (Figure 1.1) are classified into in-situ, micro-catchment 
and macro-catchment techniques, mainly based on the relative ratio of catchment to cropping area (Liniger et al., 2011; Ngigi, 2003; Oweis et al., 2001). Micro- and macrocatchment systems are ex-situ WHTs that require water storage structures for runoff generated from larger catchments while in-situ techniques store water where it falls. Other classifications of WHTs are based on type of use or storage facility (Oweis et al., 2001).

In-situ WHTs enhance the collection of rainwater on the surface where it falls and store it in the soil (Helmreich and Horn, 2009). The availability of water in the soil is improved through different agronomic measures such as modifying the soil structure, vegetation cover and density by enhancing infiltration while surface runoff and evaporation losses from the soil surface are reduced (Vohland and Barry, 2009). This technology does not need a runoff generation area, instead it is a technique mainly used to efficiently utilize rainwater where it falls. It is one of the simplest and cheapest technologies that can be implemented in a wide variety of land use systems (Ngigi, 2003). The most widely used insitu WHTs are tied ridges, mulching, conservation tillage and various furrow systems (Biazin et al., 2012).

Micro-catchment WHTs collect surface runoff from the vicinity of an agricultural/cropping area mainly from sheet flow either to be applied within the field or externally in small reservoirs for later use. The catchment area is relatively small (less than $1000 \mathrm{~m}^{2}$ ) and so is the catchment to cropping area ratio ( $C: C A$ ), with values in the range of 1:1 to 10:1 (Liniger et al., 2011). The catchments that provide runoff are normally farmlands, but nowadays rooftops of buildings, courtyards and rock catchments are also used. On-farm microcatchment systems have been extensively used in different part of the world especially in arid and semi-arid regions. The main advantage of these systems is that the farmer has a control over the catchment and the cropping/storage area. The disadvantage of microcatchment systems could be that part of the crop land need to be sacrificed to collect water. This depends on whether or not suitable areas for collecting water are available outside and nearby to the crop land. The fact that micro-catchment WHTs are constructed with low cost and the adoption of a simple design makes them easily adaptable and replicable to different environments (Oweis et al., 2001; Reij et al., 1988).

Macro-catchment and flood WHTs are characterized by a large runoff catchment area. Examples are flood storm collected from gullies, ephemeral streams or roads directed to a storage area or arable land. The runoff is stored in surface/subsurface reservoirs or it may be stored in the soil profile where it can be used for crop growth or pasture. These systems are characterized by a large catchment area with a C:CA of 10:1 to 1000:1 (Liniger et al., 2011). The advantage of such systems is that large volumes of water can be stored 
and used. The limitation of these WHTs is a poor runoff collection efficiency compared to micro-catchments and the farmer has little control over the runoff collection area (Oweis et al., 2001). Macro-catchment and flood water diversion techniques include small farm reservoirs, check dams, water diversion channels, percolation ponds, cisterns, hillside conduits, etc.

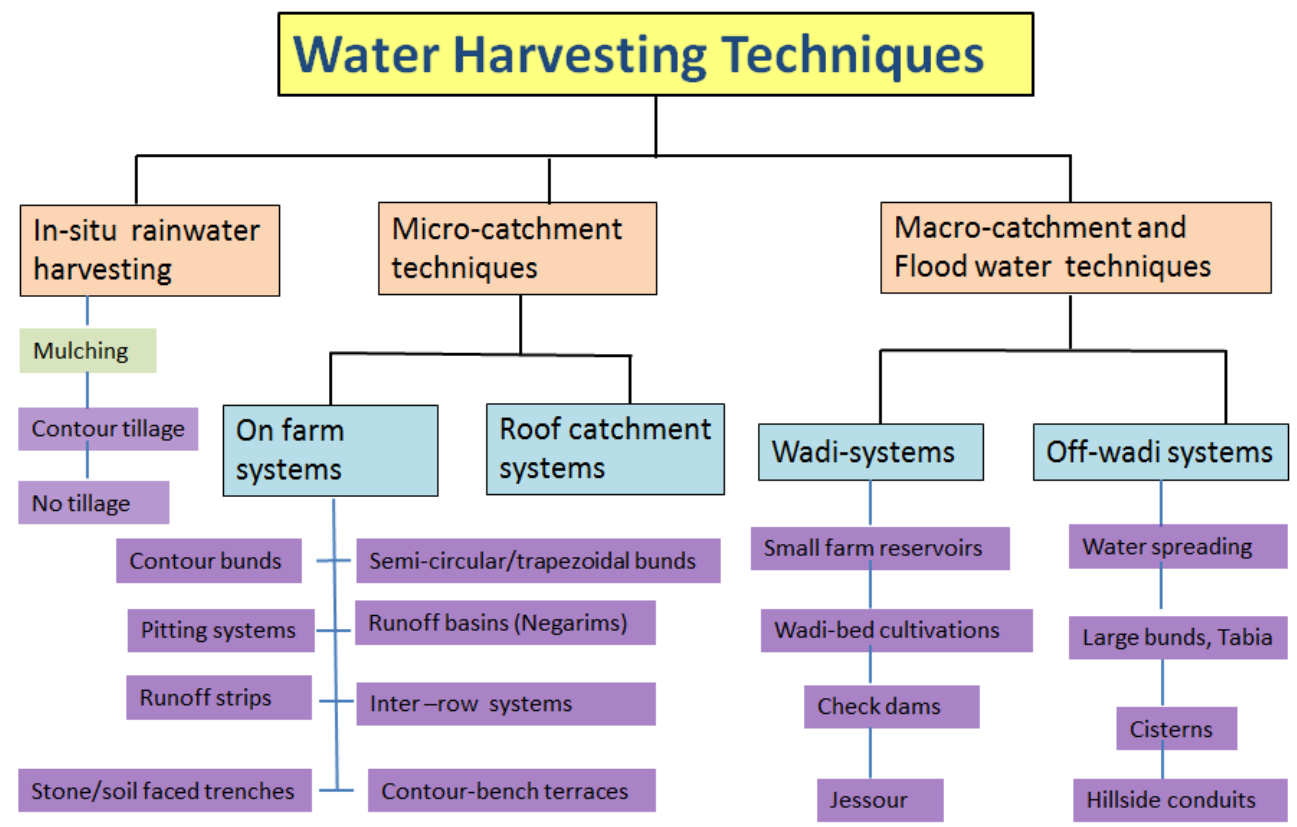

Figure 1.1: Classification of water harvesting techniques, adapted from Oweis et al. (2001).

Practical field practices show that WHTs have been beneficial in maintaining agroecological ecosystems. WHTs minimize runoff, enhance soil infiltration (e.g. Al-Seekh and Mohammad, 2009; Wakindiki and Ben-Hur, 2002), improve soil-moisture availability (e.g. Ibraimo and Munguambe, 2007; Zougmoré et al., 2003), and reduce temporal variability of water available for plant growth (e.g. Rockström et al., 2002). Hence, there is ample evidence that WHTs can improve on-site water availability. However, one should also consider that increased on-site use of water may have off-site effects downstream.

\subsection{Agricultural practice and water harvesting techniques in northern Ethiopia}

The majority of the world population, primarily in sub-Saharan Africa, rely to large extent on smallholder subsistence rainfed agriculture for food production and livelihood security (Cooper et al., 2008; World Bank, 2007). Rural communities are faced with the challenge 
of improving the productivity of arable land and water resources in order to feed their ever growing population (Rockström et al., 2000). Agricultural systems in (semi-) arid areas are also vulnerable to environmental adversities such as climate change, extended droughts and the occurrence of dry spells.

Agriculture is the economic back-bone of Ethiopia and still constitutes the major livelihood base for the rural community. Agricultural practice in Ethiopia, which dates back to the Axumite period, mainly involves the tillage of the land using oxen-driven maresha, and the cropping systems are adapted to existing soil catena (Nyssen et al., 2008). Grains, mainly teff, wheat, barley, maize, sorghum, and millet are the most commonly grown field crops and are the principal sources of food for most Ethiopians.

Rainfed agriculture has been widely practiced in northern Ethiopia and $85 \%$ of the livelihood of the population is dependent on subsistence agriculture mainly on crop production (Araya et al., 2011). Crop production in the semi-arid northern Ethiopia, is low because of erratic and insufficient rainfall for crop growth (Meze-Hausken, 2004) and high losses of water by runoff and evaporation (Yosef and Asmamaw, 2015).

The occurrence of dry spells, especially in drought-prone areas such as the northern Ethiopian highlands, hampers crop growth and is usually the primary cause for crop failures and low yields (Rockström et al., 2002, McHugh et al., 2007). The negative effects of these environmental adversities can only be minimized by improving the efficiency of water use in agricultural systems (Biazin et al., 2012; Oweis and Hachum, 2006). As rain is the primary source of water for subsistence agriculture in northern Ethiopia, water management options should be focused on the efficient use of rainwater (Araya and Stroosnijder, 2010). Therefore, it becomes imperative to rely on rainwater strategies that bridge water deficiency and improve water productivity through the use of innovative and cost effective water management techniques in order to minimize the effects of water stresses on crop growth.

With the current problem of water shortage in (semi-) arid areas, the direction towards the use of WHTs to improve water use efficiency has been rejuvenated and hence the adoption rate has increased. As the suitability of WHT in a particular site depends on local bio-physical and socio-economic conditions, as well as on policies, the selection of most appropriate techniques is often difficult.

There have been on-going efforts by the government and others to rehabilitate the land and improve agricultural productivity in northern Ethiopia by implementing WHTs such stone bunds, exclosures, farm ponds, etc. (Nyssen et al., 2015; Vancampenhout et al., 
2006; Walraevens et al., 2015). Despite the government led endeavours to implement WHTs in the region, the adoption rate for some of these techniques was not satisfactory. For example, farm pond, which was implemented at household level in northern Ethiopia, was not successful because it was implemented with a top-down approach, in which farm ponds were constructed at household level without considering local bio-physical conditions. Many of the constructed farm ponds failed to store water for irrigation because of excessive infiltration, and the loss of water by evaporation. It is, however, recommended that farm ponds need to be constructed in soils with moderate infiltration rate and terrain slopes between 0 and 10\% (Singh et al., 2009). Given the rugged and often steep landscape of northern Ethiopia, hydrology is to a large extent determined by landscape morphology. As a result, position in the landscape is an important factor to consider in the selection of WHTs. Distinctions can be made between, for example, slopes and valley-floors as well as upstream and downstream parts of watersheds. Therefore, it is, in this region, especially important to look at on-site as well as off-site effects of WHTs. The implementation of different techniques for efficient crop production requires knowledge of site-specific conditions, optimal design, and an appropriate selection procedure involving local farmers and other stakeholders (Mengistie, 1997). The work related to WHTs in northern Ethiopia carried out until now lacks a decision support system to select the most suitable WHT given local conditions.

\subsection{On-site effects of in-situ water harvesting techniques}

In-situ WHTs have a great potential to improve the availability of water for agricultural use by enhancing infiltration of rainwater into the soil layer, where it is stored, but simultaneously reducing water losses through runoff and evaporation (Vohland and Barry, 2009). Although in-situ WHTs are primarily implemented to improve the efficiency of water use in (semi-) arid areas, they can also contribute to minimizing soil loss from farmlands.

Several researchers report the benefit of in-situ WHTs such as tied ridges, mulching, conservation tillage, and furrow systems in improving on-site water availability for plant growth. There is evidence that in-situ WHTs such as tied ridges and furrow systems are efficient in reducing runoff from agricultural fields (e.g. Araya et al., 2011; Araya and Stroosnijder, 2010; Gebreegziabher et al., 2009; McHugh et al., 2007). McHugh et al. (2007) reported a decrease of runoff by $75 \%$ using tied ridges compared to conventional tillage. Tied ridges can also improve soil-moisture content (SMC) in the soil layer due to increased infiltration of ponded water from ridge depressions (e.g. Araya and Stroosnijder, 2010; Motsi et al., 2004). Field investigations showed that conservation 
agriculture with crop residue with at least $30 \%$ left on the soil surface (Kongo and Jewitt, 2006; Rockström, 2000), tillage operation with sub-soiler and tie-ridger (Temesgen et al., 2009) and combination of no tillage, furrows and retention of crop residue (Araya et al., 2011) can substantially reduce runoff losses from farmlands.

In-situ WHTs such as mulching also decrease soil loss by absorbing the energy of raindrop in detaching soil particles from the soil surface (Cerdà et al., 2016; Donjadee and Tingsanchali, 2016). Mulching also slows down surface flow velocity thereby delaying or disrupting the connectivity of runoff flow pathways (Cerdà et al., 2016). The effect of mulching on decreasing soil loss from farmlands is well documented (e.g. Adekalu et al., 2007; Gholami et al., 2013; Mwango et al., 2015; Prosdocimi et al., 2016b; Sadeghi et al., 2015a). Other techniques such as tied ridges and furrowing systems decrease the loss of runoff from agricultural fields, enabling the retention of detached soil particles in the depressions. There is ample evidence that shows the benefit of tied ridges and furrow systems in reducing soil loss from farmlands (e.g. Araya et al., 2011; Gebreegziabher et al., 2009; Jie et al., 2013; McHugh et al., 2007). Some researchers also report the decrease of nutrient losses by the use of in-situ WHTs as a result of reduced soil loss from agricultural fields (Adimassu et al., 2014; Baptista et al., 2015a; Okeyo et al., 2014; Zougmoré et al., 2009), emphasizing that any measure taken to control soil loss would also minimize nutrient depletion (Jie et al., 2013).

Despite the proven benefits of in-situ WHTs in increasing SMCs and decreasing runoff, soil and nutrient losses, the efficiency can be improved by combining some of these techniques. Some researchers have already indicated an increase in SMC due to combined use of plastic film with ridges and gravel/sand mulch with planting furrows (Li et al., 2001; Li et al., 2000; Wang et al., 2009) and crop residues with ridges/furrows (Ramesh and Devasenapathy, 2006). The integrated use of plastic mulch with ridges increased runoff efficiency (higher runoff) while the coverage of planting furrows with sand/gravel mulch decreased the loss of the harvested water by evaporation (Wang et al., 2009). Combining in-situ WHTs ensures high-level and reliable crop production, benefiting from enhanced soil-water storage and water-use efficiency (Li et al., 2000). The combined use of mulch with organic amendments resulted in the reduction of runoff loss by $84-99 \%$ in the Cabo Verde drylands (Baptista et al., 2015b).

Some tested combinations of in-situ WHTs for controlling soil and nutrient losses are cropresidue mulching with organic amendments (Baptista et al., 2015a), runoff barriers with nutrient management (Zougmoré et al., 2009) and tillage with mulching (Jin et al., 2008). Other researchers also suggest the integration of in-situ WHTs with soil-fertility improvement measures (e.g. nutrient applications, organic amendments, effective micro- 
organisms (EMs), etc.) to improve crop yield as well as increasing the efficiency of water harvesting (Miriti et al., 2007; Nyamadzawo et al., 2013). The application of EMs on agricultural soils can, for example, improve soil structure thereafter increasing infiltration rate and water-holding capacity hence increasing SMC in the soil (Ismail, 2013; Lee et al., 2008). There is some evidence (e.g. Araya et al., 2011; Araya and Stroosnijder, 2010; Gebreegziabher et al., 2009; McHugh et al., 2007) on the effect of individual WHTs such as mulch, tied ridges, furrow systems, conservation tillage, etc. on runoff and soil loss in northern Ethiopia. Despite some tested combination of WHTs, there is still a lack of information about the effect of combining tied ridges, mulch and EMs on soil properties, on-site water availability, soil and nutrient losses in northern Ethiopia. Therefore, there is a need to explore the benefit of combining in-situ WHTs (tied ridges, mulch and EMs) in terms of improving soil properties, soil-moisture, runoff reduction, soil and nutrient reduction in semi-arid northern Ethiopia.

\subsection{Effect of WHTs on catchment-scale hydrological and erosion processes}

Hydrological processes at catchment scale are controlled by many physical and climatic factors. Any significant change in land management within a catchment is expected to trigger hydrological responses. Land use change, for example, is understood to influence the amount of evapotranspiration, water infiltration, runoff in catchments and the magnitude of discharge in rivers (Rust et al., 2014). Hydrological processes such as runoff, infiltration, groundwater recharge, etc. are also likely to change following the treatment of catchments with different WHTs.

WHTs installed in a catchment are expected to affect hydrological and erosion processes at field or catchment level. These techniques could also affect hydrological processes beyond the field or micro-catchment scale. A study by Dagnew et al. (2015) in Debre Mawi catchment (95 ha) in Ethiopia, for example, showed a significant reduction in runoff volume and sediment yield at the catchment outlet after the construction of earth bunds with trenches. Catchment management with different WHTs such as stone bunds and check dams in a small catchment (187 ha) in northern Ethiopia has resulted in reduction of runoff and sediment yield at the catchment outlet (Nyssen et al., 2009a). Several other studies also confirm that WHTs in large catchments affect catchment hydrology and sediment transport processes (e.g. Betrie et al., 2011; Gates et al., 2011; Glendenning and Vervoort, 2011; Ouessar et al., 2009; Wang et al., 2013). These studies were, however, carried out at relatively coarse temporal scales (e.g. daily or annual) and could miss to capture small-scale runoff and erosion processes in events with varying rain intensity and 
duration (Kandel et al., 2004). There are still research gaps on the effect of WHTs on event-based runoff and sediment yield at catchment scale (Hessel and Tenge, 2008).

Runoff and erosion processes at catchment scale are complex to understand because of their non-linearity and scale dependency (Lesschen et al., 2009). Runoff and sediment yield are also characterized by high temporal and spatial variability within a catchment (Mohamadi and Kavian, 2015; Rai and Mathur, 2008). Erosion processes in semi-arid regions are, moreover, highly influenced by high-magnitude but less frequent rain events, and the low soil surface protection due to sparse vegetation cover (Medeiros et al., 2010). Therefore, extreme runoff events need to be carefully assessed because these events can control sediment yield in the long term (White, 2005). The design of strategies to combat the negative effects of runoff and soil loss from hillslopes often requires understanding the characteristics of individual rain events in order to quantify the magnitude and timing of peak water and sediment discharges (Ramsankaran et al., 2013).

Several studies were conducted worldwide to understand event-based runoff and sediment yield at catchment level (e.g. Baartman et al., 2012; Gao and Jesefson, 2012; Hessel et al., 2006; Medeiros et al., 2010; Rai and Mathur, 2008; Ramsankaran et al., 2013). Some modelling studies were also carried out in Ethiopia to understand processbased runoff and sediment transport at catchment level (e.g. Betrie et al., 2011; Gebreyohannes et al., 2013; Haregeweyn et al., 2013). These studies were, however, conducted at larger temporal scales and event-based hydrological studies are lacking in Ethiopia. There is still a research gap to understand the effect of extreme rain events on catchment hydrological responses and sediment yield, especially under the influence of different WHTs. Event-based runoff and soil erosion models can be used to assess the effect of WHTs on catchment hydrology and sediment yield.

\subsection{Research questions and thesis outline}

The main objectives of the study were to develop a decision support approach for selection of WHTs and investigate the on-site and off-site effects of WHTs in semi-arid northern Ethiopia.

Based on the discussion in the previous sections, which described what knowledge gaps exist in relation to the use and adoption of WHT in northern Ethiopia, the following research questions are formulated:

- How can appropriate site-specific WHTs be selected in arid and semi-arid areas? 
- What is the role of in-situ WHTs such as tied ridges and straw mulch in improving on-site water availability in semi-arid areas?

- Can in-situ WHTs help to mitigate land degradation by reducing soil and nutrient losses from farmlands?

- What is the effect of catchment-scale WHTs on catchment hydrological responses and sediment yield in northern Ethiopia?

Figure 1. 2. demonstrates how the research was conducted and links the different topics with the chapters of the thesis. A decision support approach was used to select in-situ and catchment-scale WHTs, which were implemented and tested in northern Ethiopia. A key part of the decision support approach was a GIS-based multi-criteria analysis (MCA), which was used to identify suitable areas for WHTs using database of suitability indicators for WHTs, which was developed by reviewing worldwide practices of WHTs (Chapter 2). The performance of in-situ WHTs was evaluated at field level using runoff-plots established on farmland to monitor the effect of in-situ WHTs on soil properties, runoff and SMC (Chapter 3). The field experiment was also used to monitor the effect of the in-situ WHTs on soil and nutrient losses from farmland (Chapter 4). The effect of WHTs at catchment scale was also assessed using an event-based Limburg Soil Erosion Model (LISEM), based on measured runoff and sediment yield in the catchment (Chapter 5).

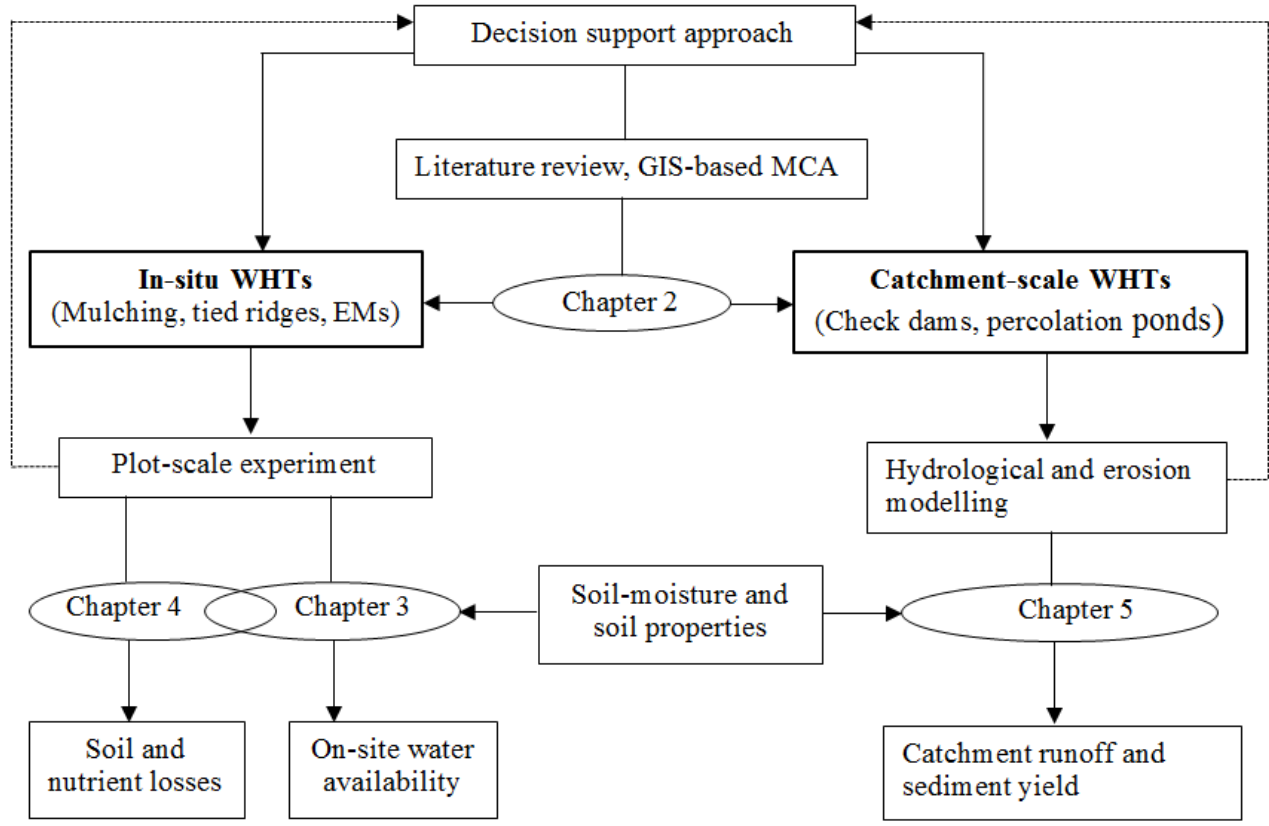

Figure 1.2 Thesis outline relating the different topics and the chapters. MCA: multi-criteria analysis, WHTs: Water harvesting techniques, EMs: effective micro-organisms. 
The objectives and research questions of the study are addressed in the following four chapters (Chapter 2 to 5). Chapter 2 deals with the methodology to select appropriate WHTs that suit specific site conditions with different bio-physical and socio-economic conditions. The chapter also deals with bio-physical suitability analysis of WHTs based on a developed database of suitability indicators of WHTs and using GIS-based MCA.

Chapter 3 addresses the benefit of combined use of in-situ WHTs (e.g. tied ridges, mulches, EMs) on on-site water availability. The chapter studies the effects of individual and combined use of WHTs on runoff and SMC. To study these effects, runoff and soil moisture were continuously measured for two successive years (2013 and 2014) in a plotscale experiment which was installed in the Gule catchment, in northern Ethiopia.

Chapter 4 is related to the previous chapter and addresses the role of in-situ WHTs in reducing soil and nutrient losses from farmland. The study was carried out using the same experimental setup as explained in chapter 3. For this chapter, soil and nutrient losses were monitored for two years in 2013 and 2014 in the field experiment during runoff events.

Chapter 5 deals with the effect of catchment-scale WHTs on catchment hydrological response and sediment yield. The effect of catchment-scale WHTs on hydrological responses and sediment yield is studied using the event-based runoff and soil erosion model LISEM. The model was applied to the Gule catchment in northern Ethiopia. The model was calibrated using measured discharges and sediment yield at two outlets in the catchment. The model was then used to simulate the effect of existing WHTs on hydrological responses and sediment yield of the Gule catchment.

\subsection{Study area}

The on-site and off-site effects of different WHTs were particularly investigated in the upper Geba catchment, which is part of the northern Ethiopian highlands, located between $13^{\circ} 32^{\prime} 43^{\prime \prime}-14^{\circ} 15^{\prime} 13.6^{\prime \prime} \mathrm{N}$ and $39^{\circ} 18^{\prime} 13.5^{\prime \prime}-39^{\circ} 47^{\prime} 4^{\prime \prime} \mathrm{E}$ (Figure 1.3). The upper Geba catchment has a total catchment area of $2380 \mathrm{~km}^{2}$. It is characterized by mountainous and undulating topography and altitudes of 1760-3300 m a.s.I. The upper Geba catchment has a semi-arid climate with dry (October to May) and wet (June to September) seasons. Annual rainfall in the upper Geba catchment ranges between 520 and $680 \mathrm{~mm}$ and shows high spatial and inter-annual variations. The upper Geba catchment was selected for the study because of existing water shortage problems due to seasonal variability of rainfall. 


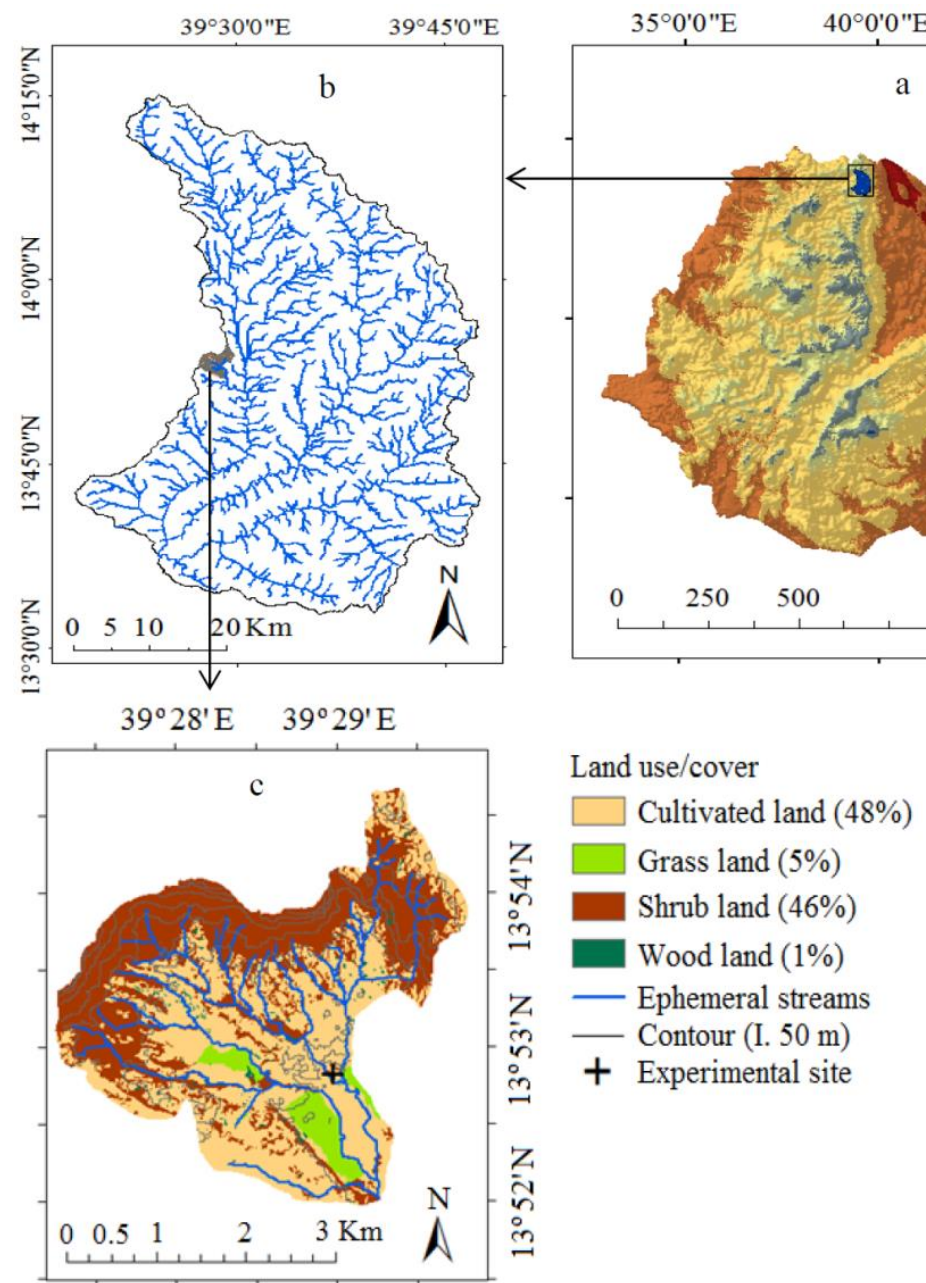

Figure 1.3 Location map of the study area (a). Altitude of Ethiopia (b). Drainage of the upper Geba catchment (c). Land uses of the Gule catchment and location of the field experiment site.
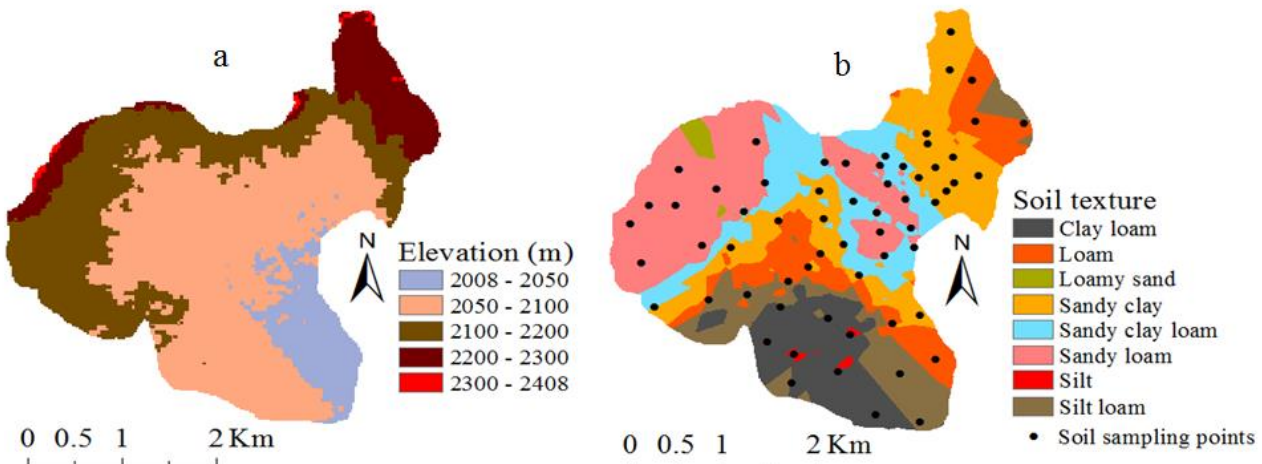

Figure 1.4 Topography (a) and soil texture (b) of the Gule catchment, northern Ethiopia. 
Detail study on on-site and off-site effects of WHTs was concentrated in Gule catchment (Figure 1.3c). The Gule catchment has a total area of around $12 \mathrm{~km}^{2}$ and has a rugged topography with mountains and flat valley floors whose altitudes (Figure 1.4) range between 2008 and $2408 \mathrm{~m}$ a. s. I. The land uses (Figure 1.3c) and soil types of the Gule catchment are typical for the northern Ethiopian highlands. The catchment is characterized by fine to coarse textured soils (Figure 1.4). 


\section{A decision support approach for the selection and implementation of water harvesting techniques in arid and semi-arid regions}

Water harvesting techniques improve the availability of water, which is essential for growing crops, especially in arid and semi-arid areas. A decision support approach can help in the selection of water harvesting techniques suitable under site-specific biophysical and socio-economic conditions. This paper describes a participatory approach for the selection of suitable water harvesting techniques in watersheds in (semi-) arid regions. It builds on a database of suitability indicators for water harvesting techniques, which was developed by integrating worldwide knowledge on their suitability. Once developed, the approach was applied on a case study for water harvesting techniques in the upper Geba watershed in northern Ethiopia. First, based on evaluation criteria and participants' scientific and local knowledge, a pre-selection of most promising water harvesting techniques took place in a multi-stakeholder workshop. Next, the suitability indicators and a GIS-based multi-criteria analysis were used to identify suitable areas for these water harvesting techniques. The results of the multi-criteria analysis were presented to stakeholders during a second stakeholder workshop. At this workshop, a final selection of water harvesting techniques to test was made based on a participatory ranking of water harvesting techniques using economic, ecological and socio-cultural criteria. The multi-criteria analysis approach was validated by comparing the predicted suitable areas with the already existing water harvesting techniques in the watershed. This led to the result that 90\% of the existing check dams and 93\% of the percolation ponds were correctly identified by the approach. We conclude therefore that this approach can be successfully applied for the participatory selection of water harvesting techniques and the identification of suitable areas for their implementation. Given that this approach is based on the newly developed database of water harvesting techniques, it can be easily applied in other (semi-) arid regions.

Based on:

Grum, B., Hessel, R., Kessler, A., Woldearegay, K., Yazew, E., Ritsema, C.J., Geissen, V., 2016. A decision support approach for the selection and implementation of water harvesting techniques in arid and semi-arid regions. Agricultural Water Management 173, 35-47. 


\subsection{Introduction}

Population growth and changes in lifestyle put high pressure on existing water resources. The main challenges associated with water use in dryland agriculture around the world are droughts, short periods of water stress, and temporally variable rainfall that can cause crop failures (Enfors and Gordon, 2008; Rockström et al., 2003). Rainfed agriculture, despite its challenges, remains the dominant source of staple food production and livelihood for many agriculturally based countries, especially in sub-Saharan Africa (Cooper et al., 2008; World Bank, 2007). A proper and planned use of the available water and the improvement of water-use efficiency in all sectors of water applications are thus indispensable. Water harvesting techniques (WHTs) can improve the availability of water and are already highly promoted by governments and non-governmental and agricultural extension agencies in many parts of the world, particularly in African countries and India (Batchelor et al., 2002; Stroosnijder, 2003; Vohland and Barry, 2009).

WHTs are very diverse and have been used for many years in different parts of the world. WHTs in arid and semi-arid areas are mainly associated with agricultural uses but are also suitable for domestic purposes. Water harvesting in a broader context is defined as the collection of runoff for its productive use (Critchley and Siegert, 1991). WHTs may be pivotal in dry areas but are also necessary for using/optimising the available water for additional uses, even in areas with sufficient water resources.

Various WHTs are used in different parts of the world (Liniger et al., 2011; Mekdaschi Studer and Liniger, 2013; Oweis et al., 2001; WOCAT, 2007), and their methods of application differ with the local conditions (Boers and Ben-Asher, 1982; Vohland and Barry, 2009). Various organisations have tried to share experiences and to transfer knowledge of the WHTs implemented in different parts of the world (Liniger et al., 2011; Oweis et al., 2001; WOCAT, 2007). These efforts, however, have been fragmented, and comprehensive information is still lacking on the practices of different WHTs and their suitability for various applications under different bio-physical and socio-economic conditions. A review of WHTs (indigenous and non-indigenous) and indicators of biophysical suitability (applicability limits) is necessary to help stakeholders select and evaluate the WHTs that could potentially be suitable for the physical conditions of a site.

Some approaches and tools have been developed for appraising and selecting WHTs (Mbilinyi et al., 2005; Schwilch et al., 2009) and for assessing the potential of WHTs at larger scales (Ouessar et al., 2013). A decision support tool was also developed to evaluate the success of out-scaling of some agricultural water management technologies at basin level (SEI, 2013). The establishment of a system of decision support that could simplify the 
selection of WHTs to be implemented at a specific site, however, is urgently needed, given the variability of bio-physical and socio-economic conditions. The implementation of different techniques for efficient crop production requires knowledge of the site-specific conditions, optimal design, and an appropriate selection procedure involving local farmers and other stakeholders (Mengistie, 1997). The selection and implementation of WHTs should be designed to find appropriate WHTs that suit site-specific bio-physical and socioeconomic conditions and that can be achieved using proper scientific expertise integrated with existing local knowledge. This integration of scientific and local knowledge is necessary, because it enables the development of sustainable solutions to local problems (Mbilinyi et al., 2005; Ngigi, 2003; Schwilch et al., 2009), and creates a common understanding and shared experience amongst stakeholders towards sustainable development (Schwilch et al., 2009).

The bio-physical suitability assessment of WHTs in large watersheds can be achieved by using multi-criteria analyses (MCAs) embedded in geographic information systems (GISs). GIS-based MCAs have been applied in various parts of the world to identify potential sites for WHT application (Elewa et al., 2012; Pandey et al., 2011; Saptarshi and Raghavendra, 2009; Singh et al., 2009). Maps produced from suitability analyses deliver good spatial visualisation, provide an understanding of potentially suitable areas, and can be presented and explained to the participants of a WHT selection workshop.

The objective of the study is to develop and validate an approach for selecting WHTs that are suitable to be applied in specific bio-physical and socio-economic conditions. The approach combines site-specific indicators of bio-physical suitability in a GIS-based MCA for identifying potential WHTs and the participation of multi-stakeholders in the selection and implementation of the WHTs. The approach was validated in a case study in the northern Ethiopian highlands.

\subsection{The developed decision support approach}

The purpose of most WHTs is to improve production in agricultural systems, and the choice of the techniques should be targeted to meet that objective. Many WHTs are available globally, so the selection of most appropriate techniques is often difficult. A simplified system of decision support can facilitate WHT selection and would create a better understanding amongst the stakeholders involved in the selection of most appropriate techniques. 
The approach (Figure 2.1) developed and validated in this study is based on the approach used by the EU-funded DESIRE project for the selection of conservation measures (Schwilch et al., 2009). A GIS-based MCA, a key part of the approach, is used to identify suitable locations for specific WHTs based on the developed database of WHTs and their suitability indicators.

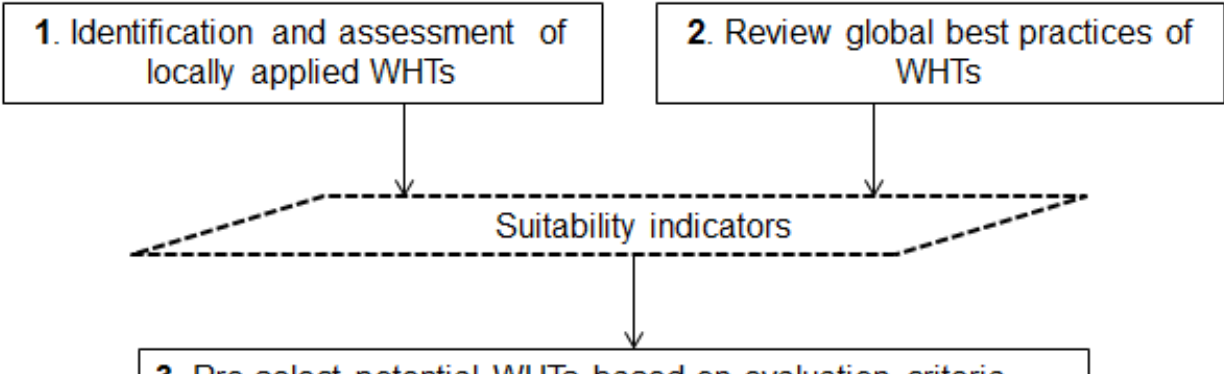

3. Pre-select potential WHTs based on evaluation criteria

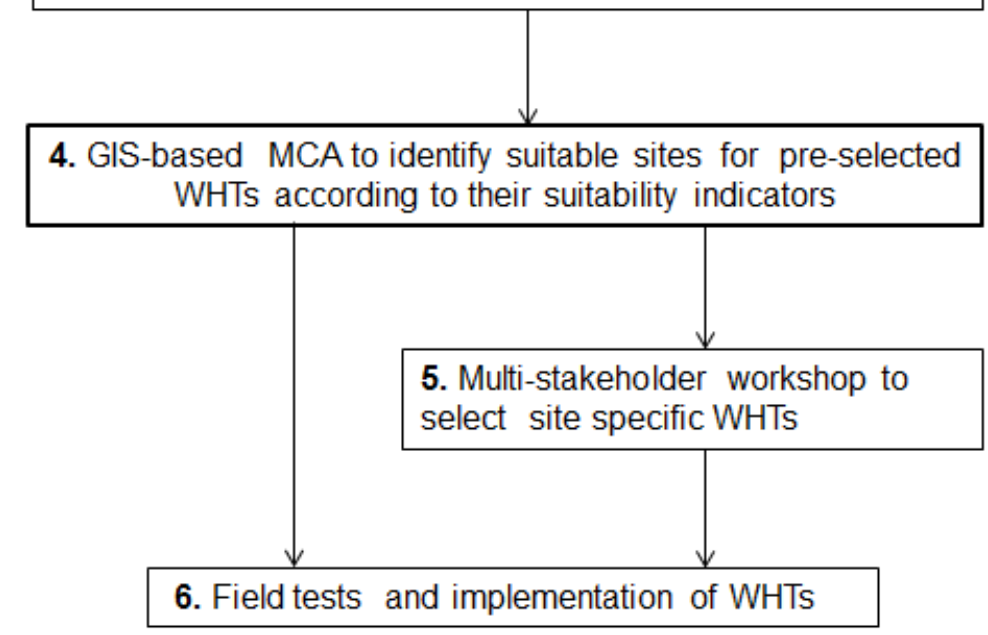

Figure 2.1 Overview of the approach for the selection and implementation of water harvesting techniques (WHTs).

The first step in our approach is to identify and assess locally applied WHTs in a stakeholder workshop. Various participants, such as researchers, farmers, nongovernmental organisations (NGOs), extension workers, and development agents, meet in a common discussion forum such as a stakeholder workshop to assess potential WHTs that they would like to consider for selection.

The second step is to make a literature review of global WHTs from the developed database for WHTs and their suitability indicators (Table 2.1). Suitability indicators for WHTs are specified to evaluate the suitability of the target WHTs to a specific area. 
Combining steps 1 and 2 provides a long-list of potentially suitable WHTs. As part of the approach a detailed database of WHTs and their suitability indicators was prepared to provide input information about bio-physical suitability of WHTs. To create the database, a literature review was made for global WHTs used in arid and semi-arid regions. The list of reviewed WHTs from global best practices and their suitability indicators is presented in Table 2.1.

The WHTs were classified into in-situ, micro-catchment, and macro-catchment systems based on a classification used in the literature (e.g. Ibraimo and Munguambe, 2007; Liniger et al., 2011; Ngigi, 2003; Oweis et al., 2001). Most of the suitability indicators for WHTs were retrieved from available guidelines (Critchley and Siegert, 1991; Liniger et al., 2011; Oweis et al., 2001; Prinz, 1996). The guidelines in these reports were not identical and some WHTs were not available in these sources. Hence, a comprehensive set of suitability indicators was defined for an extended list of WHTs applied in arid and semiarid regions. We included land use and common WHT limitations as indicators to characterize WHTs. We searched for more specific information about the values of suitability indicators from other sources for WHTs which were not available in these literatures (Critchley and Siegert, 1991; Liniger et al., 2011; Mekdaschi Studer and Liniger, 2013; Oweis et al., 2001; Prinz, 1996; WOCAT, 2007).

The suitability indicators used in our study were slope, land use, soil properties, annual rainfall, topography, C:CA (ratio of catchment (C) to cropping area (CA)), and WHT limitations. These indicators were assigned to specific WHTs separately, so the practitioners could use them to evaluate the suitability of an area for WHT application. The suitability indicators for WHTs reported in this study only belong to bio-physical characteristics which help to locate suitable sites for WHTs. For most cases, the suitability indicators were indicated in ranges, which allow a considerable range of possible locations of suitable areas for WHTs. Similar suitability indicators have been reported by Prinz (1996) but were few in number and considered only slope, annual precipitation, and C:CA. The guidelines reported by Oweis et al. (2001) were general and considered the range of the indicators on a wider scale (e.g. low, medium, and steep for slope) instead of an optimal specific range for each WHT. The WHTs mentioned in the guidelines also belong to dry (arid) climates so do not consider annual rainfall as a suitability indicator. In other reports (Liniger et al., 2011; Mekdaschi Studer and Liniger, 2013; WOCAT, 2007), different ecologic and socio-economic WOCAT (World Overview of Conservation Approaches and Technologies) guidelines are used to characterize sustainable land management (SLM) practices, in which information is only available for some WHTs. 


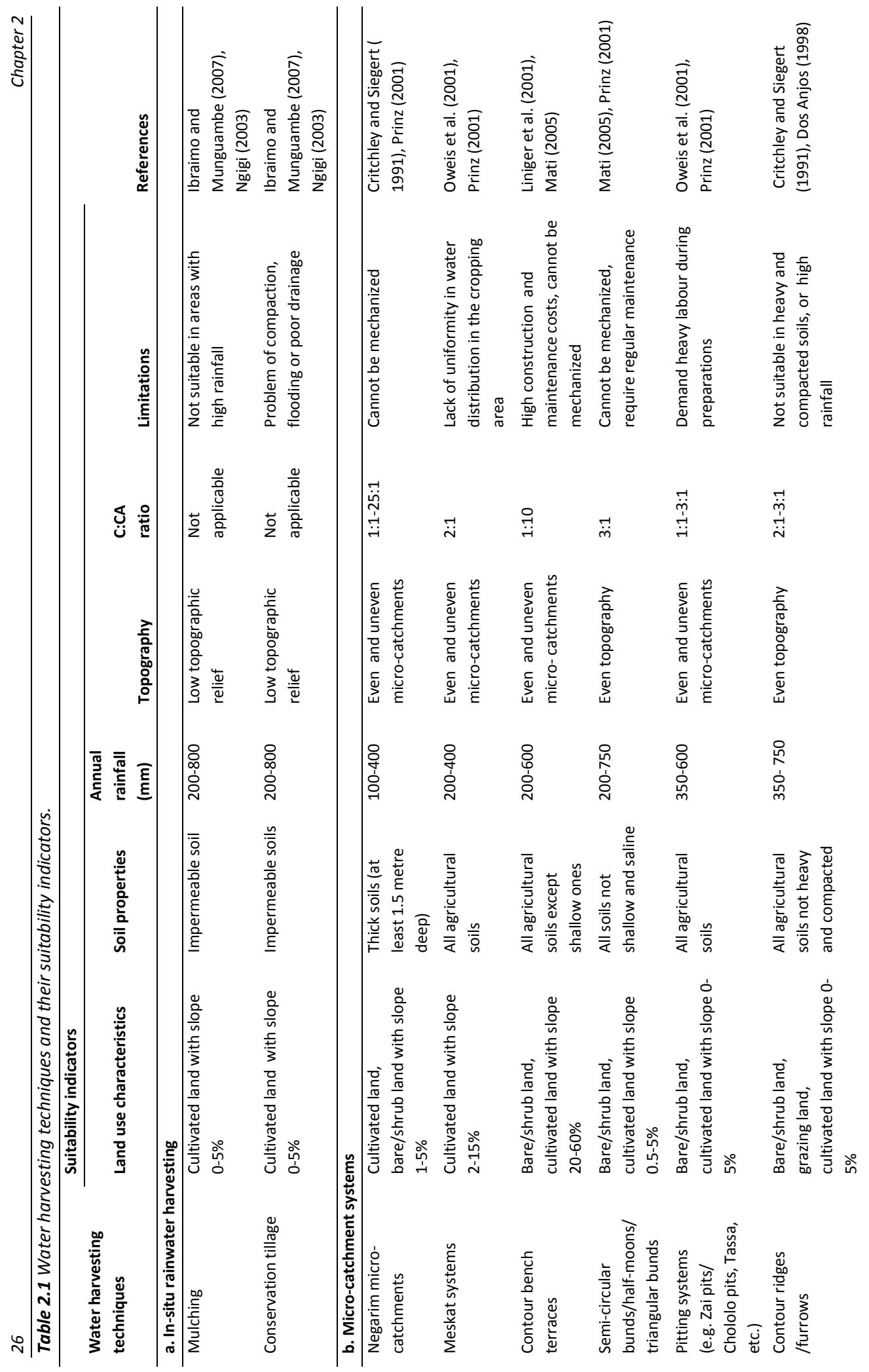




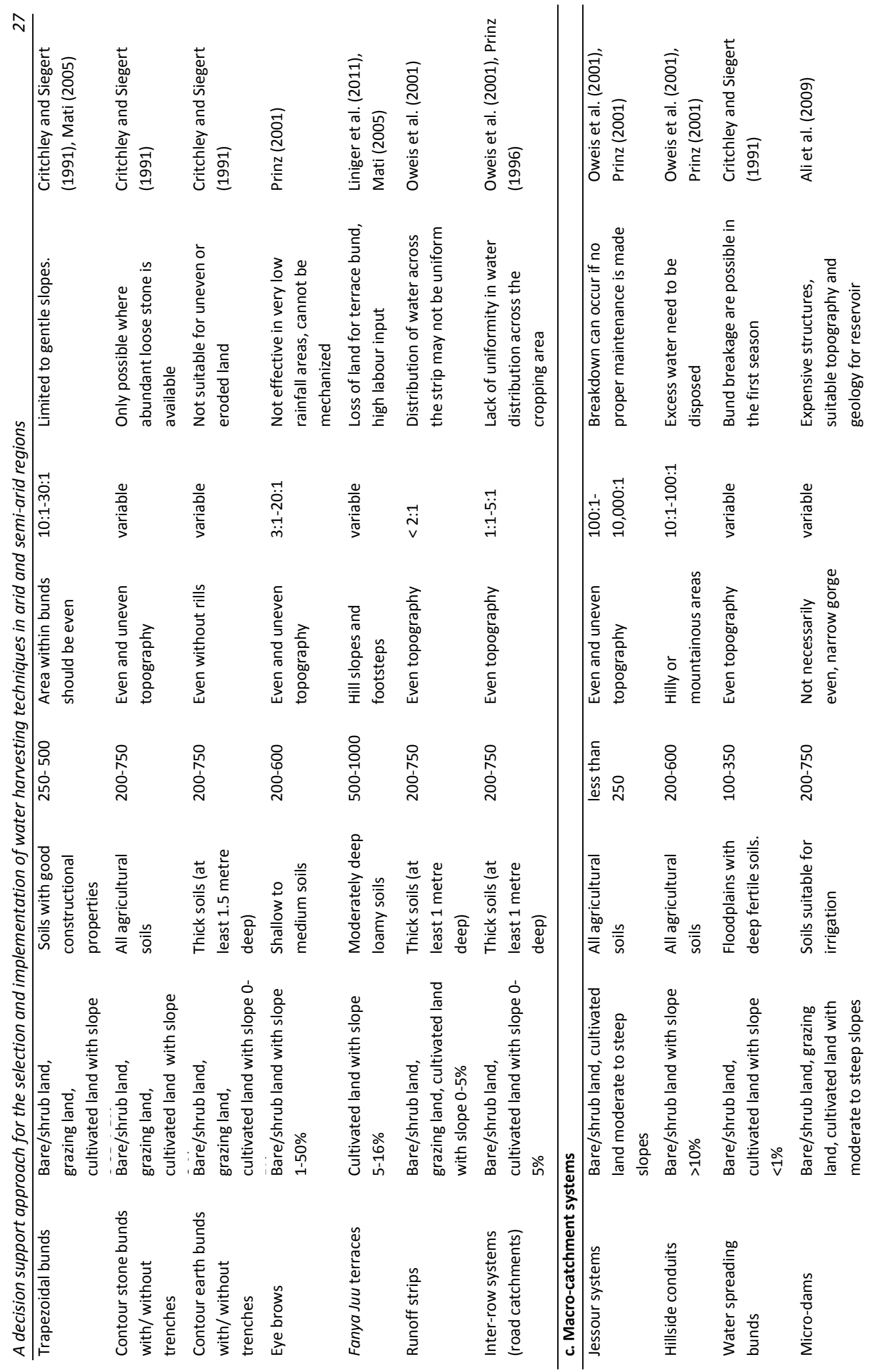




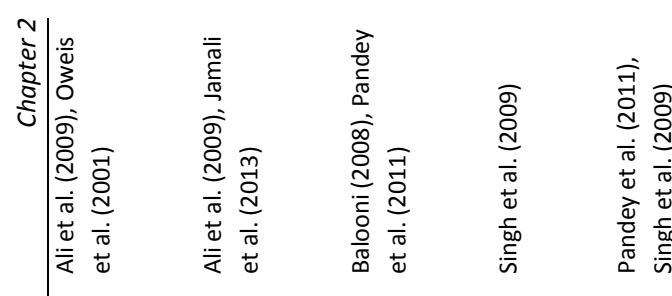

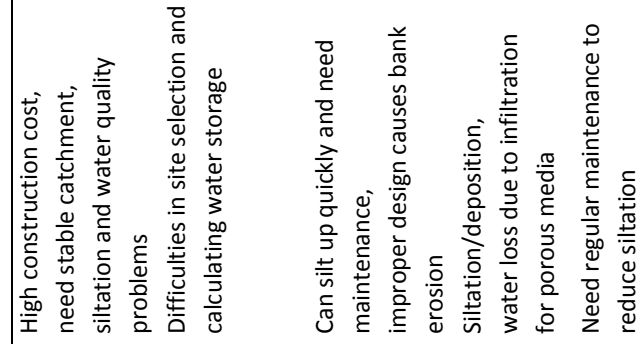

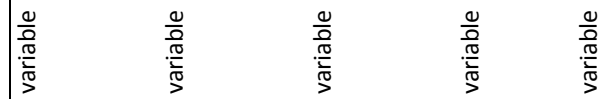

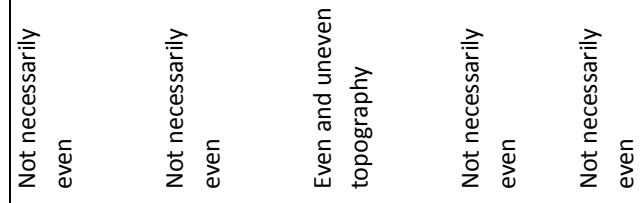

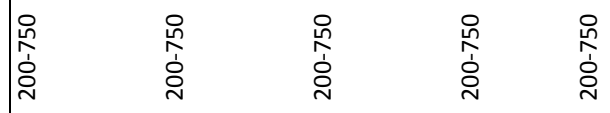

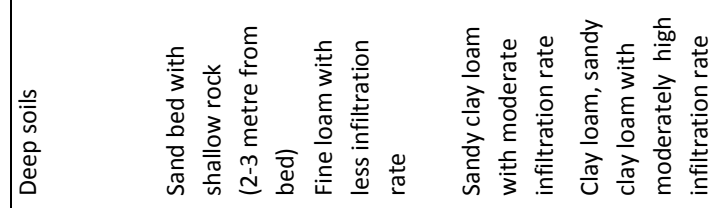

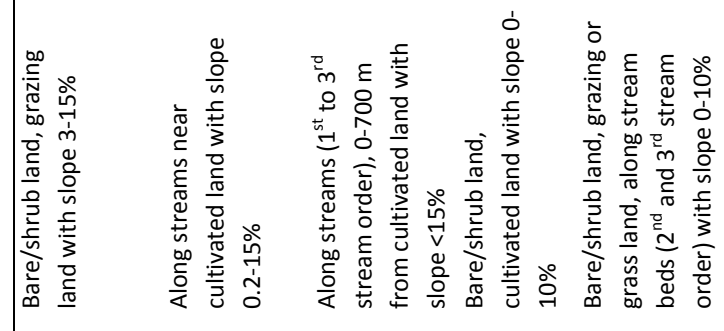

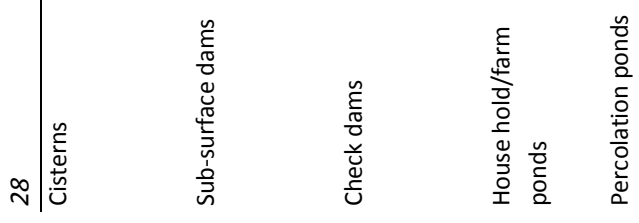


The suitability indicators reported in Table 2.1 are relevant throughout all arid and semiarid regions and can be used to determine potential areas for specific WHTs. However, for specific cases in an area, it might be necessary to add site-specific suitability indicators or slightly modify the suitability thresholds recommended in Table 2.1. For example, during adaptation of WHTs to a specific location, design modifications might be needed to make them optimally suitable for site specific physical conditions.

Once the potential WHTs are identified from local and global sources (steps 1 and 2), it is necessary to limit the number of WHTs to be considered for final selection (step 5) in order to properly manage and simplify the selection process. The pre-selection process is then carried out in a pre-selection multi-stakeholder workshop which consists of local stakeholders and researchers. Pre-selection of potential WHTs is achieved by using biophysical and socio-economic evaluation criteria in line with the target area/watershed (step 3). This results in a short-list of potentially suitable WHTs to a specific area. Indigenous WHTs might be the easiest to apply and adapt to suit site specific conditions, especially if these conditions are similar to the conditions for which the WHT has so far been applied. During pre-selection, however, the inclusion of innovative WHTs from other areas might be crucial if these techniques can potentially improve agricultural productivity. Such innovative WHTs might be more difficult to adapt and apply, but once this is done, the benefits might be greater. To optimize benefits from WHTs applications, it might be necessary to combine some of the WHTs. The combinations should however be done for WHTs that supplement each other and improve the efficiency of water harvesting without causing any significant additional cost in developing the system. The list of WHTs which was gathered from local and worldwide practices should be evaluated based on some evaluation criteria to pre-select potential WHTs. These criteria can vary from one place to the other depending on the existing bio-physical and socio-economic conditions. For example, WOCAT questionnaires were used by Schwilch et al. (2009), for assessment of SLM practices.

The database of suitability indicators for WHTs is also used in step 4 to identify potential areas where each pre-selected WHT could be applied. A GIS-based MCA, an essential part of the decision support approach, is used to assess the suitability of pre-selected WHTs in a specific area. The MCA requires spatial databases as input to carry out the suitability analysis. Suitability indicators for the pre-selected WHTs are extracted from Table 2.1. Specific WHTs may have different suitability indicators, so an overall assessment of all WHTs combined could be misleading. Therefore, the MCA should be done separately for each WHT by considering its suitability indicators. The spatial databases are then modified in GIS to create thematic maps based on the extracted suitability indicators for each WHT. The maps with suitability indicators are overlaid in GIS to perform MCA, which results in 
identification of suitable areas for the different WHTs separately. In step 5, the MCA information is provided to stakeholders as input to the participatory selection of WHTs. The final selection of WHTs for later testing and implementation is achieved in a participatory multi-stakeholder workshop which involves farmers, local extension workers, NGOs, development agents, researchers, and governmental representatives. The participants of the workshop are able to define selection criteria based on economic, ecological and socio-cultural benefits to rank the pre-selected WHTs. For ranking the WHTs based on the selection criteria, the choice of an analysis tool for a given situation could be challenging. It is recommended that the tool used for decision-making in the selection workshop should not be too complex, time-taking, costly and data intensive (Schwilch et al., 2012a).

Once selected, the WHTs can be implemented in step 6. This study focused on steps 1-5, which are described within the frame-work of the upper Geba case study to illustrate the approach.

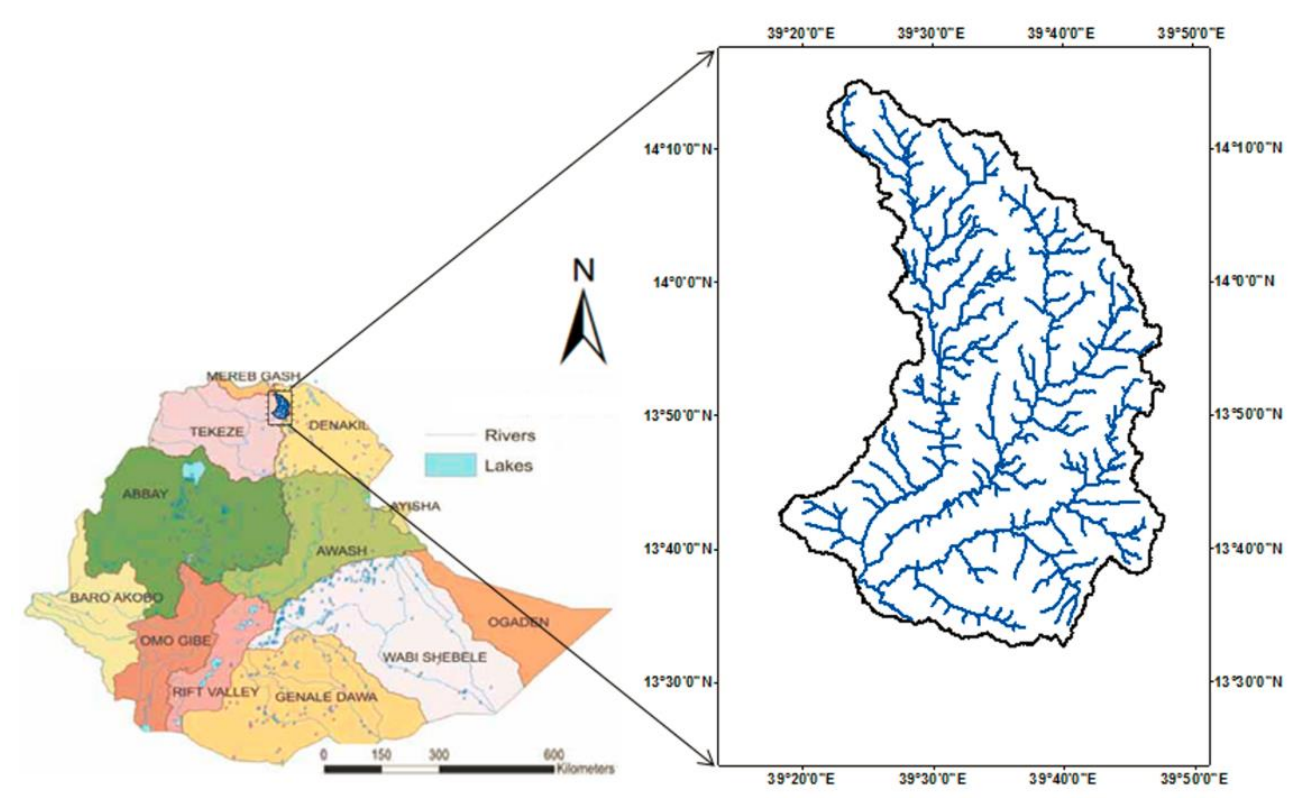

Figure 2.2 Location and drainage network of the case study area. Map on the left shows drainage basins of Ethiopia. 


\subsection{Implementation in the upper Geba watershed}

\subsubsection{Case study area description}

The Geba catchment in the regional state of Tigray in the northern highlands of Ethiopia drains into the Tekeze River basin (Figure 2.2). The study area is the upper part of the Geba catchment between $13^{\circ} 32^{\prime} 43^{\prime \prime}-14^{\circ} 15^{\prime} 13.6^{\prime \prime} \mathrm{N}$ and $39^{\circ} 18^{\prime} 13.5^{\prime \prime}-39^{\circ} 47^{\prime} 4^{\prime \prime} \mathrm{E}$ with a total basin area of $2380 \mathrm{~km}^{2}$. The upper Geba watershed is generally characterised by a mountainous and undulating topography and altitudes of 1760-3300 m a.s.l. The major land uses/covers for the upper Geba watershed are cultivated land (51.9\%) and shrub land (45.9\%). The remaining land uses include grass land $(1.2 \%)$, bare land $(0.6 \%)$ and water bodies $(0.1 \%)$. The major soil types in the watershed based on the FAO (1998) soil classification and the study by Hunting (1974) are Leptosols (37\%), Cambisols (21\%) and Luvisols (17\%). Other soils types include Calcisols (10\%), Vertisols (9\%), Alisols (3\%) and Arenosols (3\%).

The upper Geba watershed has a semi-arid climate with a dry (October to May) and a wet (June-September) season. The rainfall pattern is erratic and is highly spatially and temporally variable. The watershed receives an average annual rainfall of 520-680 mm. The temperature in the upper Geba watershed is relatively constant throughout the year $\left(16-20{ }^{\circ} \mathrm{C}\right)$, with diurnal variations being larger than seasonal changes. The livelihood of the people in the study area is mainly dependent on a subsistent agriculture with mixed farming system, i.e. rainfed crop production and livestock. The main crops grown in the rainy season are barley, wheat, teff (Eragrostis tef), maize, sorghum, and vegetables. The livestock mainly consists of cattle, sheep, goats, poultry, donkeys, camels, horses, and mules.

\subsubsection{Identification and pre-selection of potential WHTs (steps 1-3)}

Locally applied WHTs were inventoried and assessed in a pre-selection stakeholder workshop conducted in the study area with the active participation of the EU-funded WAHARA (www.wahara.eu) project team (Mekelle University) and other stakeholders in the watershed. The WAHARA project research team documented the information obtained in the workshop regarding local WHT practices (step 1, Figure 2.1).

Moreover, the team reviewed best WHTs from other parts of the world, potentially suitable to the study site. The review was aimed at exploring innovative WHTs which have 
been successfully applied in other areas and having the potential to introduce new technology to the study site (step 2, Figure 2.1).

The research team then used criteria to assess and evaluate the potential WHTs gathered from local and global sources. The evaluation criteria used in the assessment of the WHTs were availability of local knowledge, innovativeness, cost, adaptability, suitability to local environments, and socio-economic benefits. The research team used these criteria to compile the final list of pre-selected WHTs (step 3, Figure 2.1).

Many WHTs have been used within the area of this case study, especially in the last two decades. Some techniques were indigenous, but most were recently introduced to the area and to the regional state in general. Indigenous techniques included ridging systems, conservation tillage, and contour earth/stone bunds with or without trenches. Other techniques such as household ponds, percolation ponds, check dams, bench terraces, micro-dams, cisterns, semi-circular bunds, and eye brows have been recently introduced but are currently widely used in the watershed.

Some of the techniques were combined during pre-selection to maximise benefits. The combination of WHTs was made for these techniques which would potentially improve the efficiency of water harvesting and productivity. For example, a series of community ponds used locally were integrated with the new technique of hillside conduits, and hillside cisterns were combined with bench terraces. Eight WHTs were pre-selected based on the evaluation criteria stated above. These eight techniques were deep stone/soil faced trenches, hillside cisterns on bench terraces, hillside conduits with a series of community ponds, check dams, percolation/sediment storage ponds with hand-dug wells, infiltration pits coupled with biological measures, soil-improvement methods (e.g. use of mulch, compost, or effective micro-organisms), and sub-surface dams.

The selection and implementation of WHTs should start by identifying local techniques and indigenous knowledge. The use of indigenous knowledge helps to change and improve existing agricultural or water management systems such as WHTs (Mbilinyi et al., 2005). The meeting of stakeholders in a pre-selection workshop helps to generate substantial knowledge about existing WHT practices. Moreover, the workshop creates a shared understanding amongst actors involved and lays a platform for future development of WHTs (Schwilch et al., 2009). 


\subsubsection{GIS-based MCA for bio-physical suitability assessment of WHTs} (step 4)

The GIS-based MCA was used to assess the bio-physical suitability of the pre-selected WHTs in the case study area. Spatial databases, which were necessary for the MCA, were prepared in GIS. Based on the extracted suitability indicators, the spatial databases were modified to thematic maps so as to use them in the MCA to locate suitable areas for WHTs.

Application of the MCA to locate suitable areas for WHTs

The suitability analysis was carried out within the GIS interface using the weighted linear combination procedure (Eq. (2.1)) described by Eastman et al. (1995). The weighted linear combination is the most commonly used decision rule in GIS-based land suitability analysis because it is simple to understand and easy to apply within the GIS environment (Malczewski, 2000).

The suitability of sites for WHTs was analysed by combining thematic maps with various attributes and by using a set of decision rules applied to the maps. The thematic maps of land use, soil, drainage, and rainfall were prepared in ArcGIS, and necessary classifications were applied to suit the defined suitability indicators for each WHT. The attributes of all maps were scaled to a range of 1-9, similar to the methods by Mbilinyi et al. (2007) and Saptarshi and Raghavendra (2009). The values for each suitability indicator in a map attribute were assigned based on the database of WHTs suitability indicators (Table 2.1). All maps were then overlaid in an ArcGIS weighted overlay to produce a suitability map based on a composite suitability score for each WHT. The composite suitability score is a score of all attributes of the thematic maps of a given cell in the overlay for each WHT. The composite suitability score of each area using the multi-criteria evaluation decision rule is described in Eq. (2.1).

$\mathrm{S}=\sum \mathrm{W}_{\mathrm{i}} \mathrm{X}_{\mathrm{i}} \times \prod_{\mathrm{c}_{\mathrm{j}}}$

where $S$ is composite suitability score, $W_{i}$ is weight assigned to each criterion, $X_{i}$ is criterion score (cells), $\Pi$ is products of constraints (1-suitable, 0-unsuitable), $c_{j}$ is constraints or Boolean criteria, and $\Sigma$ is sum of weighted criteria (suitability indicators).

After the weighted overlay, each cell in the map was classified into highly suitable, moderately suitable, and unsuitable based on the composite suitability score of each area/cell for each WHT separately. The overall conceptual framework of the suitability analysis (step 4, Figure 2.1) is shown in Figure 2.3. 


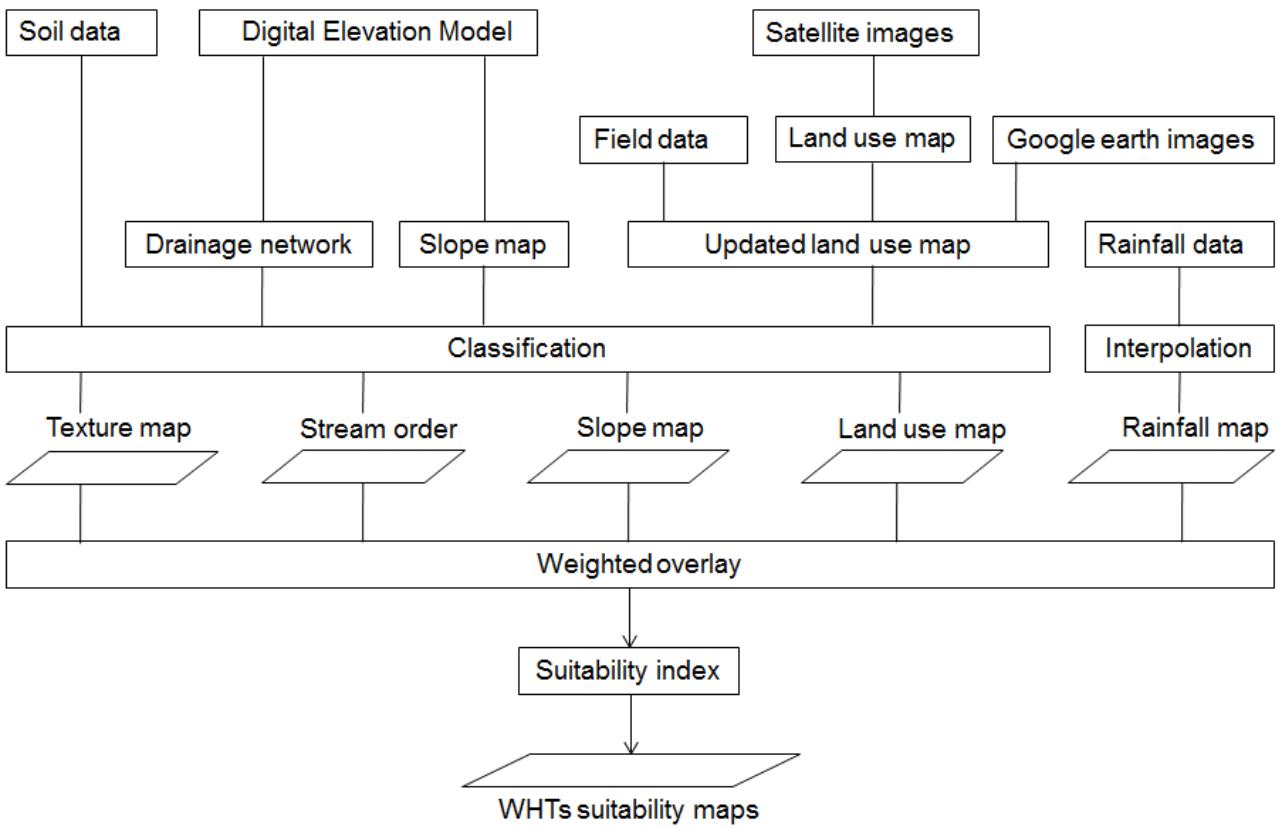

Figure 2.3 Conceptual framework for identifying suitable areas for water harvesting techniques (WHTs).
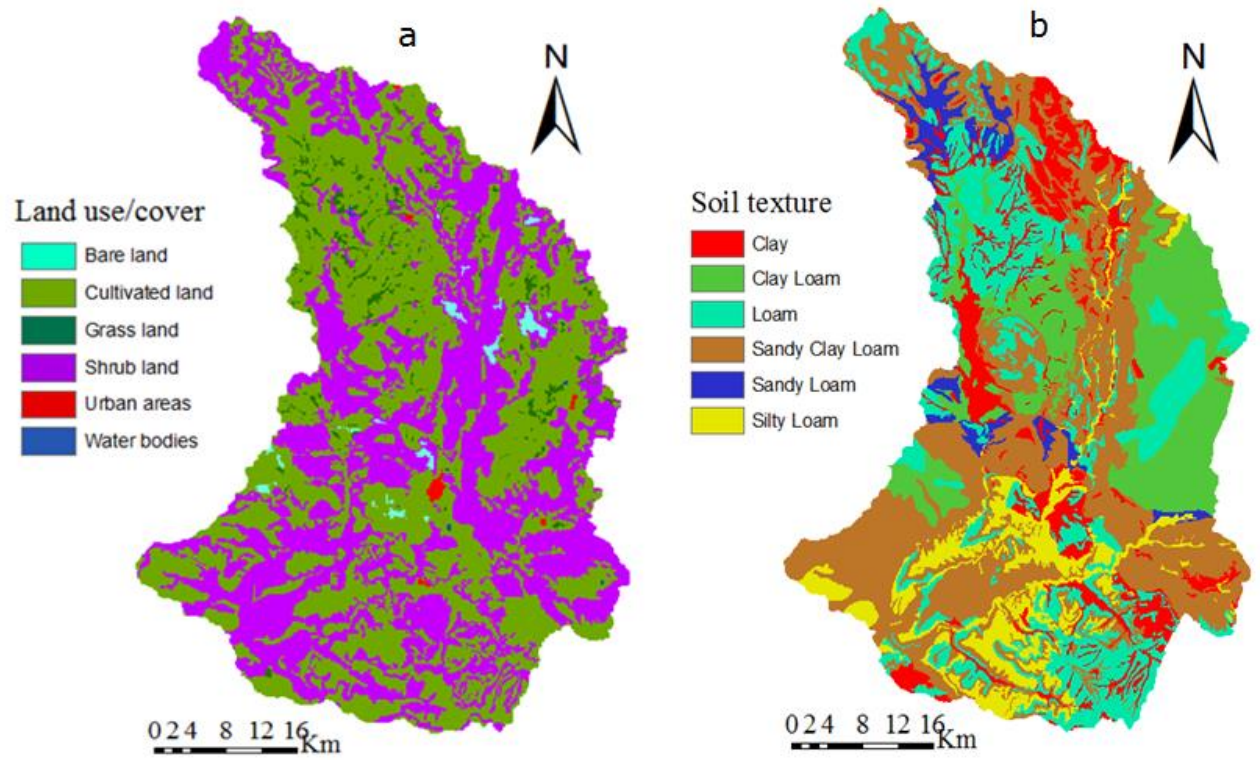

Figure 2.4 Land use/cover (a) and soil texture (b) map for the upper Geba watershed. 


\section{Preparation of spatial databases}

The GIS-based MCA requires spatial databases to test bio-physical suitability of preselected WHTs in the case study. Spatial data from GISs were processed for parameters such as land use/cover, soil texture, slope, drainage networks, and rainfall maps. The data for land use/cover of the study area were adopted from NEDECO (1998) as a shape file and were then modified in ArcGIS using ground observations and the latest (2011 and 2013) Google Earth images (Figure 2.4a). The high spatial resolution of the Google Earth images provided detailed mapping information for the classification of land use/cover (Hu et al., 2013; Mering et al., 2010).

A soil map of the study area was provided by the Bureau of Agriculture and Rural Development of Ethiopia, prepared using the FAO (1998) soil classification, and was digitised in ArcGIS from the detailed regional soil and land classification study by Hunting (1974). A soil-texture map (Figure 2.4b) of the study area was then generated by collecting descriptions of the textures of the major soils of the world, available from FAO (2001). A spatial annual rainfall map of the watershed was produced using the annual records (1994-2012) of seven meteorological stations (Adigrat, Hawzien, Sinkata, Edagahamus, Wukro, Mekelle and Hagereselam) within or near the watershed (Figure 2.5a). The spatial rainfall data were generated in ArcGIS using Inverse Distance Weighting (IDW) interpolation.

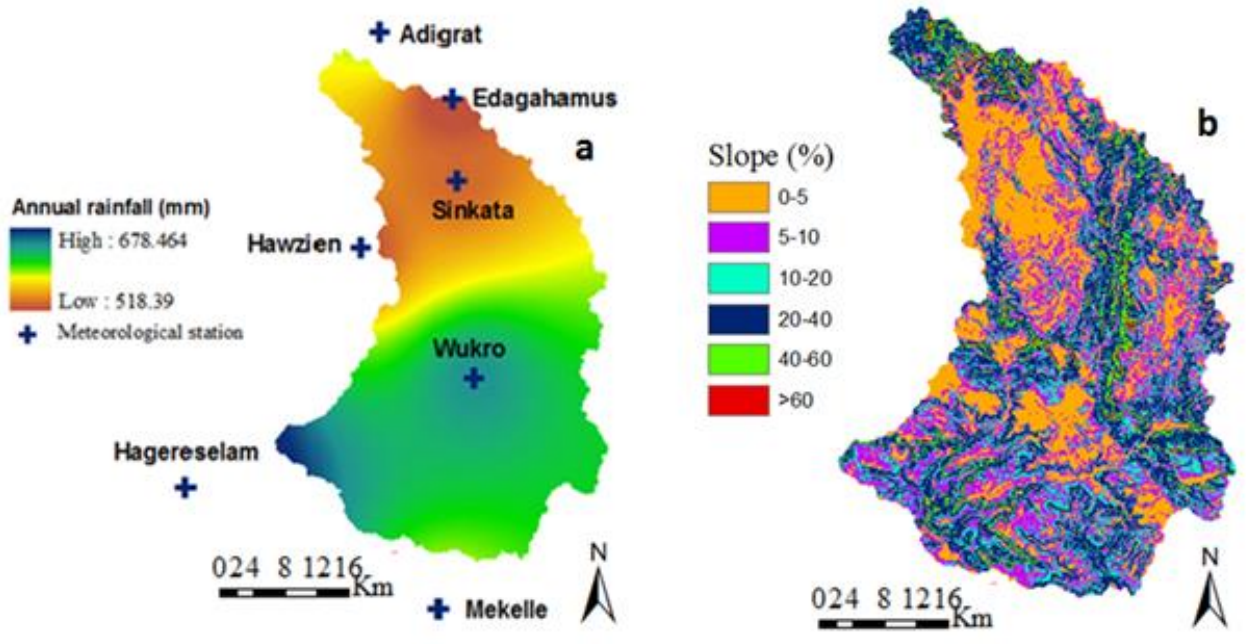

Figure 2.5 Annual rainfall (a) and slope class (b) map for the upper Geba watershed. 


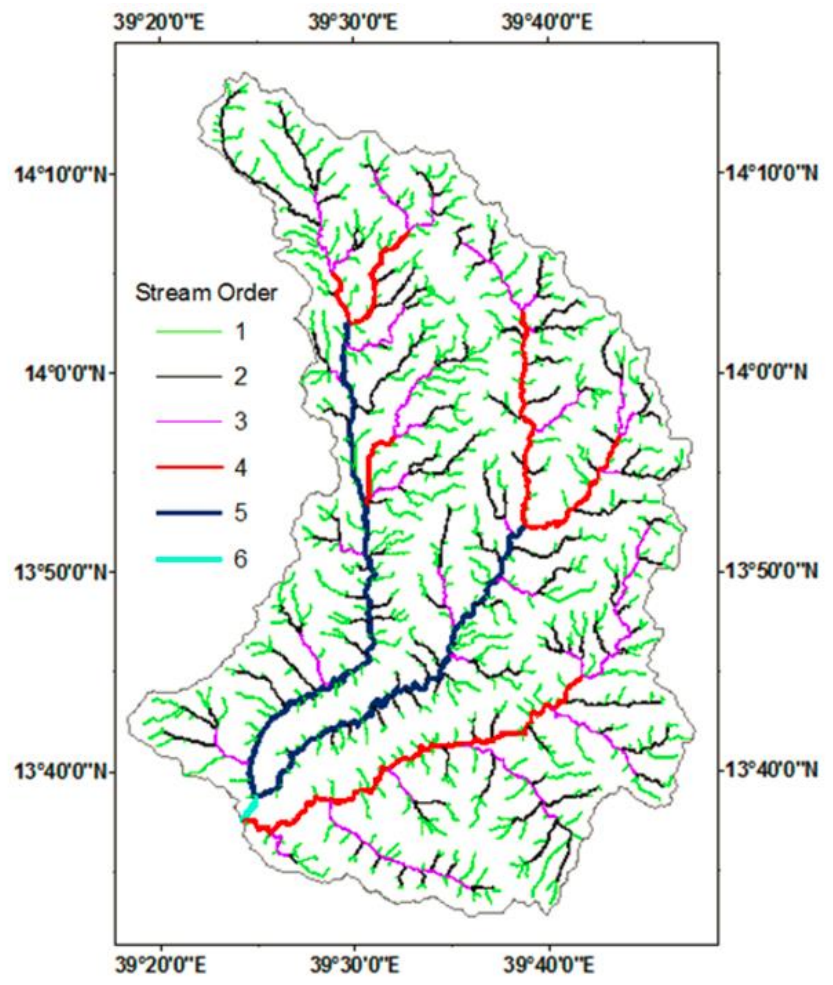

Figure 2.6 Drainage network and stream order classes for the upper Geba watershed.

A Digital Elevation Model (DEM) with a resolution of $90 \mathrm{~m}$ was downloaded from Jarvis et al. (2006). The DEM was used to generate slope gradients (Figure 2.5b) and to identify a drainage network with notations of stream (drainage) order. The drainage network was generated using 5 ha as a threshold for the upstream area of the smallest streams in the network. The drainage network was further classified into stream orders (Strahler, 1957) using the ArcGIS interface for hydrological analysis, which produced six classes (Figure 2.6).

Extraction of suitability indicators for the pre-selected WHTs in the case study Suitability indicators indicate if a given area can be potentially used for WHTs. Based on the suitability indicators available in Table 2.1, the suitability analysis was made for each WHT separately. Eight potential WHTs for the case study were shortlisted in the preselection stakeholder workshop for consideration for final selection. Potential sites for all these pre-selected techniques can be identified using the available suitability indicators for the specific WHTs. A detailed suitability exercise was carried out for three techniques (check dams, percolation ponds and bench terraces) from the eight pre-selected WHTs to demonstrate the methodology. Most of the suitability indicators for these three 
techniques were extracted from Table 2.1 and are summarized in Table 2.2. Stream order was considered as a suitability indicator particularly for check dams and percolation ponds because these two WHTs can be located along stream beds with a specific stream order. The specific requirement of distance to cultivated land for check dams is already indicated under the land use suitability indicator in Table 2.1.

Table 2.2 Suitability indicators adopted to locate suitable areas in the study area for check dams, percolation ponds and bench terraces.

\begin{tabular}{|c|c|c|c|c|c|}
\hline $\begin{array}{l}\text { Water } \\
\text { harvesting } \\
\text { techniques }\end{array}$ & $\begin{array}{l}\text { Slope } \\
\text { (\%) }\end{array}$ & Soil properties & Land use/cover & $\begin{array}{l}\text { Annual } \\
\text { rainfall } \\
(\mathrm{mm})\end{array}$ & Stream order \\
\hline Check dams & $<15$ & $\begin{array}{l}\text { Fine loam with less } \\
\text { infiltration rate }\end{array}$ & $\begin{array}{l}\text { River streams } \leq 700 \mathrm{~m} \\
\text { from cultivated land }\end{array}$ & $250-750$ & $1^{\text {st }}$ to $3^{\text {rd }}$ \\
\hline $\begin{array}{l}\text { Percolation } \\
\text { ponds }\end{array}$ & $<10$ & $\begin{array}{l}\text { (Sandy) clay loam with } \\
\text { moderately high infiltration } \\
\text { rate }\end{array}$ & $\begin{array}{l}\text { Bare/shrub land, grass } \\
\text { land, along stream beds }\end{array}$ & $250-750$ & $2^{\text {nd }}$ and $3^{\text {rd }}$ \\
\hline Bench terraces & $20-60$ & $\begin{array}{l}\text { All agricultural soils except } \\
\text { shallow ones }\end{array}$ & $\begin{array}{l}\text { Bare/shrub land, } \\
\text { cultivated land }\end{array}$ & $200-600$ & Not applicable \\
\hline
\end{tabular}

Check dams are small barriers constructed in shallow rivers and streams for harvesting water and controlling erosion (Balooni et al., 2008). These structures supplement irrigation in dry periods and improve overall water availability in sub-watersheds. The potential sites for check dams are streams of the $1^{\text {st }}$ to $3^{\text {rd }}$ orders at a maximum of $700 \mathrm{~m}$ from cultivated land. The land use/cover map was thus buffered to a distance up to $700 \mathrm{~m}$ around cultivated land using Arclnfo.

Percolation ponds are formed by structures constructed across small streams $\left(2^{\text {nd }}\right.$ and $3^{\text {rd }}$ orders) or other places to collect surface runoff during rainy periods. Infiltration and percolation raise the level of the groundwater, which can then be harvested during dry seasons. The soils where percolation ponds are located must have medium to high infiltration rates to ensure good infiltration, but the infiltrated water should not be quickly lost downstream to higher order streams (above $3^{\text {rd }}$ ) where harvesting of the water would be difficult.

Bench terraces are banks of structures across long slopes used to convert mountainous areas to arable land. They can be located on steep slopes (20-60\%) but are also sometimes used on more gently sloping agricultural land to disrupt long slopes. Shallow soils are not suitable for bench terraces due to the small volume of soil for bench formation. 


\subsubsection{Participatory selection of WHTs based on socio-economic and ecological criteria (step 5)}

The final selection of WHTs was carried out in a multi-stakeholder workshop based on socio-economic and ecological selection criteria defined by the participants. The participants of the selection workshop included farmers, local extension workers, NGOs, development agents, researchers, and governmental representatives. A total of 63 participants from four local administrative areas (Woredas) were involved. Information and MCA results of the pre-selected WHTs were presented to the participants of the workshop. The participants accepted the eight proposed techniques and added two others.

The participants defined the criteria to be used for ranking and final selection from the list of WHTs. The proposed criteria were categorized into economic, socio-cultural, and ecological benefits. The list of criteria was long, so the number to be used in the final selection was reduced. An effort was made to consider at least one criterion from each of the three benefit categories, some of the criteria were modified, and similar criteria were combined.

The local participants were divided into four groups based on their geographical locations (Woredas), and the stakeholders, consisting of representatives from NGOs and the government, development agents, and the researchers, were randomly distributed to these groups. The groups rated the selection criteria on a scale of 1-10.

Each group ranked the criteria, and the rates assigned by each group were averaged to produce the final ranking. The same group of participants evaluated each of the preselected WHTs by each of the selection criteria on a scale of 1-10. The evaluation of the WHTs by the four groups was combined and analysed to rank the techniques to be selected.

The Analytical Hierarchy Process (AHP) of decision making (Saaty, 1980, 2004) was then used to rank the proposed selection criteria and the ten WHTs. First, the six selection criteria were com-pared pairwise to rank or determine the weighted score of each criterion. Once the ten proposed WHTs were rated on a scale of 1-10 by each of the six criteria, then the ten WHTs were compared pair-wise taking into account the weighted score of each criterion. The rank of each WHT was then determined by the outcome of the weighted score of the WHTs after the AHP analysis. 
The description and suitability maps of the pre-selected WHTs provided valuable information about the applicability of the proposed WHTs to the study area. It also bridged knowledge gaps among the participants of the workshop regarding the proposed WHTs. With the aid of the suitability maps and the description of the WHTs, the stakeholders were able to easily evaluate the WHTs based on the agreed selection criteria. The suitability maps can also be used by land users to locate suitable areas for selected WHTs.

In addition to the eight pre-selected WHTs presented in the selection workshop, two other techniques, namely large semi-circular bunds and on-farm (in-situ) conservation measures, were added to the list of techniques or technologies to be considered for selection. The participants insisted that if selected and implemented the two new techniques could be important to improve productivity while improving soil and water conservation. The participants emphasised that in-situ WHTs such as infiltration pits and soil-improvement methods need further research to allow introduction of new practices of soil management at the field level. The participants were also strongly interested in contributing to the scientific research on some of the locally practised techniques, such as percolation ponds and check dams.

Table 2.3 Proposed potential water harvesting techniques selection criteria

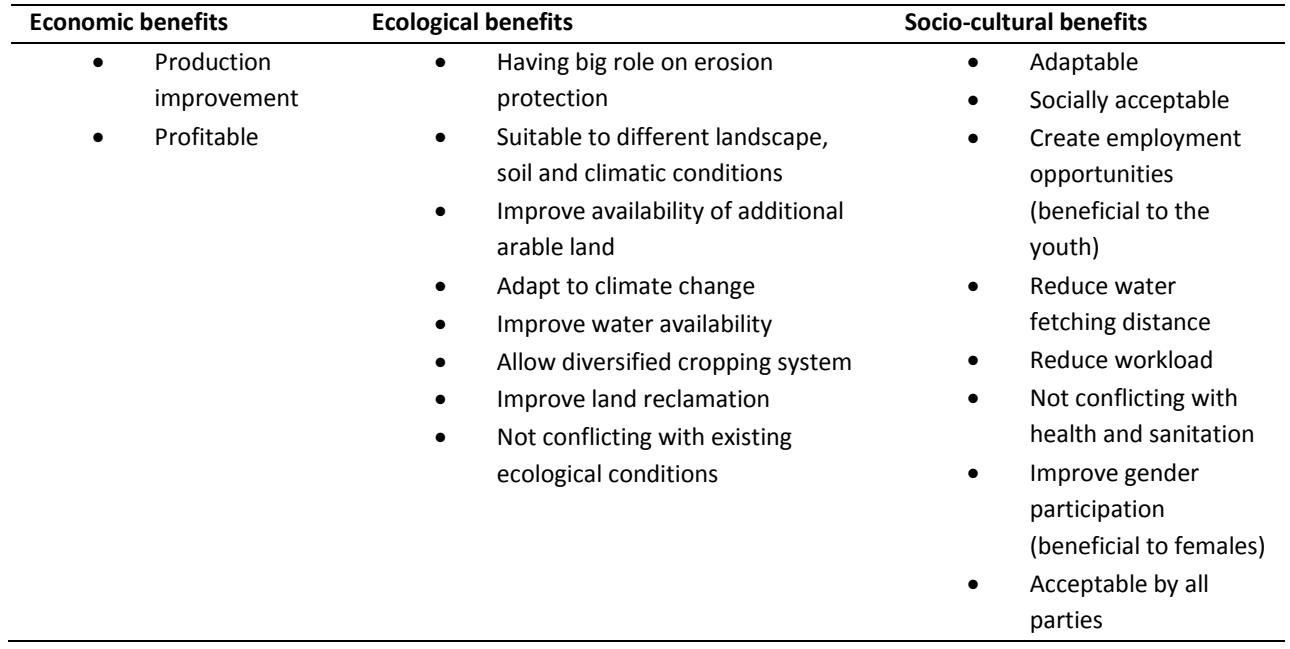

The selection criteria proposed by the participants of the workshop based on the ecological, economic, and socio-cultural benefits are shown in Table 2.3. These criteria reflected the socio-economic and ecological problems in the area of the case study and anticipated the criteria to be considered to foster the adoption of these technologies. Most of the criteria listed in Table 2.3 would also be relevant for other areas. The full list 
of criteria in Table 2.3 provided much insight, but the workshop agreed to limit the number of selection criteria to prevent the selection procedure from becoming too complex. The selection criteria and their AHP weighted scores are presented for the study area (Table 2.4).

Based on the criteria and their weights defined in Table 2.4, the selection and ranking of the WHTs techniques are described in Table 2.5. The top four WHTs were proposed for testing and evaluation with field research. The workshop emphasised that the performance evaluation of the selected WHTs in the field research should involve the local farmers, government, and development agencies to make use of the outcomes and to promote the adoption and expansion of the techniques.

Table 2.4 Prioritized selection criteria and their analytical hierarchy process (AHP) weighted scores.

\begin{tabular}{lll}
\hline Objective & Criteria & AHP weighted score \\
\hline Improve production & Crop production & 0.191 \\
Profitable & Profitability & 0.162 \\
Reduce erosion, increase arable land and reclaim & Land rehabilitation & 0.177 \\
plantation & & \\
Suitable to different ecological conditions & Ecological suitability & 0.148 \\
Adaptable and socially acceptable & Adaptability & 0.171 \\
Beneficial to females and the youth & Job opportunity & 0.150 \\
\hline
\end{tabular}

The participants of the workshop finally agreed with the AHP results and the ranking of the WHTs. The participants emphasised that the results reflected their rating of the proposed WHTs and the selection criteria and promised to cooperate during the testing of the selected techniques. Most of the selected WHTs have recently been partly or fully applied in the region. Even though the implementation of WHTs in the region was good, the results from previous interventions were not satisfactory due to the lack of involvement of appropriate stakeholders in the selection and implementation of the techniques. The field practices were also not supported by scientific research.

The selection criteria used for the selection of WHTs should suit to existing ecological and socio-economic conditions of the specific site. The criteria chosen were supposed to bring ecological, economic and socio-cultural benefits to the study site. Similar selection criteria were recommended by Schwilch et al. (2009), to facilitate a sustainable selection of SLM options. In addition to the selection criteria proposed by the stakeholders (Table 2.3) in the study area, other criteria such as land and water ownership, implementation costs (installation, operation and maintenance) can influence the suitability of different WHTs. Some WHTs (e.g. mulches and ridges) can be owned by farmers and applied at farm level while others such as micro-dams and sub-surface dams should be implemented at community level, as they are too expensive to be implemented by individual farmers. 
It is helpful to use an analysis tool to accomplish the ranking of the pre-selected WHTs based on the selection criteria. The AHP used in the selection workshop was simple and efficient where the tool was able to quickly sort out the ranking of WHTs and the results were easily communicated to the participants. The workshop created a co-learning process in which the stakeholders were able to share their experiences and choices about WHTs to be implemented in the study site. Similar collaborations were achieved in other studies, e.g. in the DESIRE project (Schwilch et al., 2012b). The WAHARA workshop resulted in a common understanding amongst the participants in which they promised to collaborate and participate in the testing and implementation of the selected WHTs, thus paving the way for field tests and implementation (step 6, Figure 2.1).

Table 2.5 Ranking and the analytical hierarchy process (AHP) weighted score of the proposed water harvesting techniques after the selection workshop.

\begin{tabular}{|c|c|c|c|c|}
\hline \multirow[b]{2}{*}{ No. } & \multirow[b]{2}{*}{ Water harvesting technique } & \multicolumn{3}{|c|}{ AHP weighted } \\
\hline & & score & Rank & Remark \\
\hline 1 & T1: Series of hillside cisterns on bench terraces & 0.112 & 3 & To be tested \\
\hline 2 & T2: Stone/soil faced trench bunds & 0.104 & 5 & \\
\hline 3 & T3: Hillside conduits with series of community ponds & 0.100 & 6 & \\
\hline 4 & $\begin{array}{l}\text { T4: Percolation/sediment storage ponds with hand-dug } \\
\text { wells }\end{array}$ & 0.114 & 1 & To be tested \\
\hline 5 & T5: Check dams & 0.113 & 2 & To be tested \\
\hline 6 & T6: Infiltration trenches coupled with biological measures & 0.097 & 7 & \\
\hline 7 & $\begin{array}{l}\text { T7: Soil-improvement methods (e.g. mulching, compost, } \\
\text { effective micro-organisms) }\end{array}$ & 0.108 & 4 & To be tested \\
\hline 8 & T8: Sub-surface dams & 0.072 & 10 & \\
\hline 9 & T9: Large semi-circular bunds & 0.089 & 9 & \\
\hline 10 & $\begin{array}{l}\text { T10: On-farm (in-situ) conservation measures (e.g. deep } \\
\text { tillage) }\end{array}$ & 0.091 & 8 & \\
\hline
\end{tabular}

\subsection{Validation of the developed approach}

The developed approach was in a general sense validated by its application in the upper Geba watershed, which showed that the approach did result in selection of WHTs for testing and implementation in step 6 (Figure 2.1).

A more detailed validation of part of the approach was performed by comparing the areas that were, according to the application of the MCA, suitable for check dams, percolation ponds and bench terraces with sites in which these WHTs are currently already implemented.

The bio-physical suitability of WHTs to the case study was carried out by a GIS-based MCA, the core part of the proposed decision support approach. To ascertain the validity of the 
suitability analysis, suitability indexes produced from the GIS-based MCA were superimposed with the locations of existing structures in ArcGIS. The resulting maps of the MCA for check dams and percolation ponds were compared with existing locations of the structures. The suitability maps were validated with 80 and 92 existing locations of check dams and percolation ponds, respectively. The results of the validation were reported in percent showing locations of existing structures coinciding with the suitability indexes. Of the three techniques for which suitable areas were identified, check dams and percolation ponds were already widely implemented in the study area, and bench terraces were used on steep slopes.

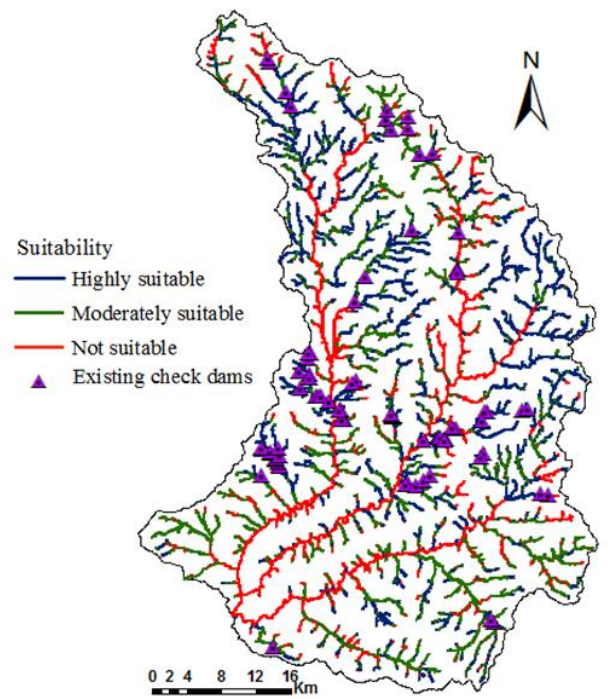

Figure 2.7 Suitability map for check dams in the upper Geba watershed.

The GIS-based MCA for check dams is depicted in Figure 2.7. The validation of the suitability map with existing check dams in the study area showed that $48 \%$ of the check dams were in highly suitable streams, $42 \%$ were in moderately suitable streams, and only $10 \%$ were in unsuitable streams. The suitability mapping for check dams was generally satisfactory and could be used for further prioritisations of locations for the construction of check dams.

The suitability map indicated that the study area contained many potential areas for percolation ponds (Figure 2.8). Nine percent of the total area of the watershed was highly suitable for the construction of percolation ponds, and $14 \%$ was moderately suitable. The potential areas were mainly on grass land, but some were on bare land and shrub land. The study area contains much shrub land (Figure $2.4 a$ ), which is not ideal for percolation 
ponds because most of it has steep slopes. Agricultural areas had a high potential for percolation ponds but were excluded because they are used for cultivation.

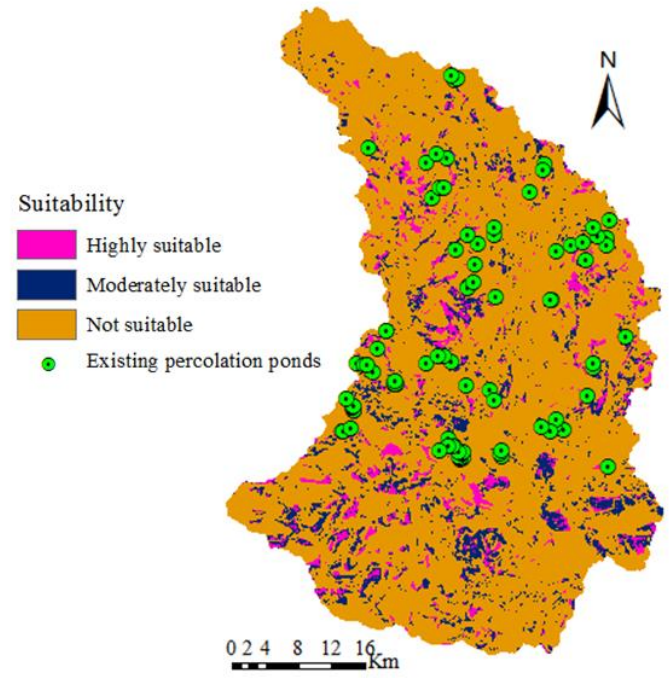

Figure 2.8 Suitability map for percolation ponds in the upper Geba watershed.

The validation of the suitability map (Figure 2.8) showed that $63 \%$ of the 92 existing percolation ponds were in highly suitable areas, $30 \%$ were in moderately suitable areas, and only $7 \%$ were in unsuitable areas. This distribution indicated that the suitability mapping worked well for identifying suitable areas for percolation ponds and could be used for the future planning and development of percolation ponds.

The use of percolation ponds is increasing in the study area. Most existing percolation ponds are on grass land, because grass land is within or in close proximity to agricultural areas. Hand-dug wells within the grass land or the adjacent crop land are then used to extract groundwater for irrigation. The construction of a series of percolation ponds upslope of cultivated areas makes use of bare land and shrub land identified suitable areas in the analysis. This is advised to enhance groundwater recharge and hence maximise the amount of water that can be sustainably extracted in the downstream cultivated areas.

Nine percent of the study area was highly suitable for the construction of bench terraces, and $26 \%$ was moderately suitable (Figure 2.9). The installation of bench terraces on hillsides is potentially economically feasible, because bench terraces are constructed on steep slopes that are generally unsuitable for conventional farming and because they increase the availability of arable land. Proper construction of terraces on steep slopes also decreases the rate of soil loss in runoff. Other benefits include the improvement of 
water availability in the benched areas and their surroundings, especially downstream, because the terraces improve infiltration. The study area currently contains few bench terraces but has considerable potential for more. The existing government policy in support of technologies that increase the availability of farm land should encourage the construction of more bench terraces on hillsides.

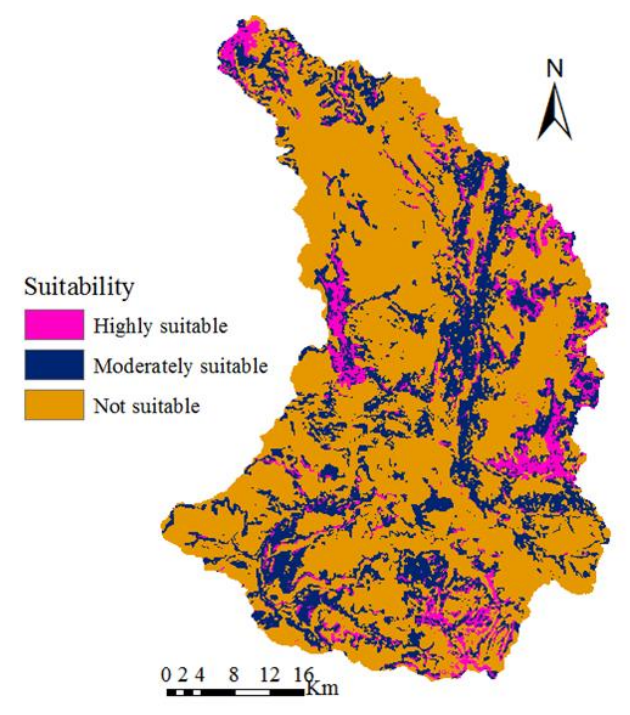

Figure 2.9 Suitability map for bench terraces in the upper Geba watershed.

The suitability analysis for these three WHTs satisfactorily located suitable areas for future development. Similar GIS-based MCAs have been used in other regions to identify potential suitable areas for WHTs (Elewa et al., 2012; Saptarshi and Raghavendra, 2009; Singh et al., 2009). The analyses in these regions showed that GIS-based MCAs are valuable because they can identify potential sites for WHTs in large areas and under a number of suitability criteria. The proposed potential sites in these analyses (Elewa et al., 2012; Saptarshi and Raghavendra, 2009; Singh et al., 2009), however, were not validated with the existing locations of WHTs. In other studies (Mbilinyi et al., 2007; Pandey et al., 2011), remote sensing and GIS-based analysis for identifying suitable sites for soil and water conservation structures and validated with existing locations and site conditions was able to match the existing and proposed structures. The same MCA can also be applied to other WHTs by utilizing the newly developed database of WHTs and their suitability indicators (Table 2.1) to identify potential areas in other regions of the world.

The application and validation of the developed approach in the upper Geba watershed indicated that it can be applied in similar regions in the country with similar bio-physical and socio-economic conditions, but some modifications may be necessary if these 
conditions vary significantly. Identifying generic criteria for the selection of WHTs in different ecological, economic, and socio-cultural conditions would be useful, although the weight of the criteria might differ. WHTs that improve the availability of arable land and hence create job opportunities for youths would be beneficial in the study area and similar regions in Ethiopia with high population growth and a dependence on agriculture by the majority of the society. Other WHTs may be used in other parts of the world where sitespecific conditions may differ. The WHTs database in this paper, however, has been compiled from many parts of the world, and their suitability indicators have also been defined. The approach presented here can thus be used for other areas with arid and semi-arid climates provided that necessary modifications are made to comply with the site-specific conditions.

The decision support approach is helpful to facilitate the selection and implementation of appropriate WHTs in a given area to improve agricultural production. The decision support approach however did not consider the impacts of existing and new WHTs on water availability and water demands of various uses at different watershed scales. The current adoption rate of WHTs is low and hence the resulting marginal impacts are minimum (Ngigi, 2003; Oweis and Hachum, 2006). It is however probable that the widespread application of WHTs at a watershed or basin level would improve water availability for downstream users (Rockström et al., 2003) but it could also have negative implications for other water users (Ngigi, 2003; Rockström et al., 2003). Therefore, there is a need to carryout hydrological modelling to assess the impacts of WHTs at a watershed or basin level before these techniques can be up-scaled (Ngigi, 2003; SIWI, 2001).The developed decision support approach in general and the GIS-based MCA in particular will be however very useful in identifying suitable areas for specific WHTs in large watershed with different bio-physical settings. The resulting WHTs suitability maps from the MCA provide valuable information for land users and stakeholders who intend to select and apply specific WHTs for a given area.

\subsection{Conclusions}

Water harvesting techniques are widely applied in arid and semi-arid climates to improve the availability of water for various uses. Selecting appropriate techniques is crucial for optimising the impact of water harvesting, given site-specific bio-physical and socioeconomic conditions. Our approach which combined a GIS-based multi-criteria analysis and a participatory multi-stakeholder workshop proved to assist the selection of appropriate water harvesting techniques because it integrated bio-physical knowledge/tools with socio-economic criteria. The inclusion of selection criteria relevant 
to ecological, economic, and socio-cultural benefits was crucial in the multi-stakeholder selection workshop, so similar criteria should also be considered in other parts of the world. Combining water harvesting techniques can maximise benefits, and the possibilities for such combinations should thus be explored. A key tool in this approach is the GISbased multi-criteria analysis for identifying suitable areas for water harvesting techniques. The GIS-based multi-criteria analysis, which was successfully validated in the case study, was also an important tool for identifying potential water harvesting techniques in large watersheds constrained by a number of decision criteria (e.g. suitability indicators).The multi-criteria analysis generates suitability maps that provide valuable information on the types of water harvesting techniques that could be applied at a specific site, facilitating decision making for land-use planners. The same approach could be used in other parts of the world with arid and semi-arid climates. The extensive list of water harvesting techniques and their suitability indicators from this study should provide valuable inputs for multi-criteria analyses and should thus simplify decision making for applying water harvesting techniques for stakeholders and land-use planners. 


\section{Improving on-site water availability by combining in-situ water harvesting techniques in semi-arid northern Ethiopia}

Crop production in arid and semi-arid environments is strongly affected by temporal variation of water availability during the growth period. In-situ water harvesting techniques such as tied ridges and mulching improve water availability over time and may improve crop yield. A field experiment was conducted in 2013 and 2014 in the Gule sub-watershed, northern Ethiopia to study the effect of combining in-situ water harvesting techniques on on-site water regime, i.e., runoff and soil-moisture content. Five treatments with tied ridges, straw mulch, and effective micro-organisms, alone or in combination, and an untreated control were tested. Combined tied ridges and straw mulch with and without effective micro-organisms significantly reduced average runoff per event by 78 and 88\%, respectively, compared to the control. Tied ridges alone reduced runoff by $56 \%$ and straw mulch with and without effective micro-organisms reduced runoff by 49 and 53\%, respectively. Average soil-moisture content over the two years was significantly higher (22.4\%) in combined tied ridges and straw mulch than the control (19.9\%). Tied ridges or straw mulch alone significantly reduced runoff and improved soil-moisture content, but the two combined were more efficient. Based on the results of field experiment in 2014, multiple regression models were formulated to predict runoff using rainfall, 30-minute rain intensity, soil-moisture content, slope, soil organic-matter and saturated and unsaturated hydraulic conductivities for the treatments. The regression analysis indicated that the models predicted runoff well $\left(r^{2}=0.63-0.83\right)$. The regression also showed that runoff could be estimated from rainfall, rain intensity, and soil-moisture content for farmlands when runoff data was not available. The findings suggest that combined straw mulch and tied ridges enhance water infiltration into the soil and improve water availability during the growing season, thereby protecting crops from dry periods.

Submitted as:

Grum, B., Assefa, D., Hessel, R., Woldearegay, K., Ritsema, C.J., Aregawi, B., Geissen, V. Improving on-site water availability by combining in-situ water harvesting techniques in semi-arid northern Ethiopia. Agricultural Water Management. 


\subsection{Introduction}

The efficient use of water in agricultural systems is needed to improve crop production and resilience to environmental adversities that may be caused by climate change and extended droughts, especially in arid and semi-arid areas. Marginal and erratic rainfall aggravated by the loss of water by runoff and evaporation are the main causes of low crop production in these areas (Yosef and Asmamaw, 2015). Ethiopia has been dependent on subsidence rainfed agriculture for centuries, and crop production has thus been heavily reliant on the availability of rainwater (Araya and Stroosnijder, 2010; Yosef and Asmamaw, 2015). Most of the cultivation in Ethiopia is in the highlands, which have fragile natural resources and often coarse-textured soils low in organic-matter and water holding capacity that are prone to wind and water erosion (Boelee et al., 2013). Water harvesting techniques (WHTs) have played a key role in improving the efficient use of rainwater and have increased the sustainability and reliability of rainfed agriculture (Biazin et al., 2012).

In-situ WHTs such as tied ridges, mulching, conservation tillage, and the application of compost and manure (Mati, 2005) improve the availability of water in the soil profile to decrease the effects of dry periods caused by the seasonal variation of rainfall. Soils can temporarily hold water, so in-situ water harvesting prolongs the availability of water in the root zone by reducing runoff and evaporation losses (Vohland and Barry, 2009). Some techniques (e.g. ridges and furrows) can conserve water in the soil profile mainly by reducing net runoff, and others (e.g. mulching) can conserve water by reducing evaporation.

The effect of mulch on soil properties, soil-water storage, and crop yield is well documented (Chakraborty et al., 2008; Cook et al., 2006; Li et al., 2007; Ramakrishna et al., 2006). Several other studies have focused on the effect of conservation agriculture (e.g. contour furrows and soil tillage) on soil and water conservation (Abrisqueta et al., 2007; Araya et al., 2011; Gebreegziabher et al., 2009; McHugh et al., 2007; Mesfine et al., 2005; Temesgen et al., 2009). The effects of individual tied ridges and mulching on water availability and crop production have also been evaluated in different parts of the world (Araya and Stroosnijder, 2010; Mudatenguha et al., 2014; Wang et al., 2009).

Combining WHTs (e.g. mulching and tied ridges) ensures high-level and reliable crop production, benefiting from enhanced soil-water storage and decreased net runoff ( $\mathrm{Li}$ et al., 2000). Integrating in-situ water harvesting techniques and soil fertility improvement measures is needed not only to improve yield but also to increase the efficiency of water harvesting (Miriti et. al, 2007; Nyamadzawo et al., 2013). The application of effective 
micro-organisms (EMs) to the soil can enhance soil properties such as infiltration rate and water holding capacity hence increase soil-moisture (Ismail, 2013; Lee et al., 2008).

Combinations of in-situ WHTs such as wood-chip mulch and ridges substantially improved the growth and straw yield of sorghum (Chiroma et al., 2006a). Moreover, combined application of wood-shavings mulch with ridge tillage improved soil fertility and slowed down the acidification of a coarse-textured soil (Chiroma et al., 2006b). Similarly, combined use of ridges and furrows with gravel/plastic mulch improved runoff and water use efficiency, and significantly increased corn yield (Li et al., 2000; Li et al., 2001). Positive effects of ridges and mulch on cowpea physiological responses have been demonstrated (Ramesh and Devasenapathy, 2006). Little information, however, is available on the effect of in-situ WHTs (e.g. ridges and straw mulch) integrated with soil fertility improvement methods (e.g. EMs) on runoff retention and soil-moisture content (SMC). Therefore, this study tests the efficacy of individual and combined application of straw mulch, tied ridges, and EMs in reducing runoff and increasing SMC to improve water availability for plant growth and recommend improved soil-water management for (semi-) arid regions.

\subsection{Materials and Methods}

\subsubsection{Study site description}

The study was conducted in the Gule sub-watershed in the upper Geba watershed, part of the Tekeze River basin in northern Ethiopia $\left(13^{\circ} 52^{\prime} 49^{\prime \prime} \mathrm{N}, 39^{\circ} 28^{\prime} 59^{\prime \prime} \mathrm{E}\right.$; Figure 3.1). The subwatershed has a catchment area of around $12 \mathrm{~km}^{2}$. It is characterized by a rugged topography with mountains and flat valley floors whose altitudes range between 2008 and $2408 \mathrm{~m}$ a.s.l. The study area has a semi-arid climate with two major seasons, a rainy season in the summer, often June to September, and a dry season from October to May. Rain is rare during the dry season, except for some showers towards the beginning of the rainy season. Average daily temperature for the sub-watershed is $20{ }^{\circ} \mathrm{C}$. The minimum and maximum temperatures are 11 and $31{ }^{\circ} \mathrm{C}$ respectively. The sub-watershed was chosen based on criteria set during a stakeholder workshop for selection of WHTs (Grum et al., 2016).

The experiment was conducted at a farmer training center located on the flat valley floor of the sub-watershed whose mean altitude is $2050 \mathrm{~m}$ a.s.l. The field experiment had a total size of $1750 \mathrm{~m}^{2}$ and a field slope ranging between 1.8 and $3.4 \%$. The experiment site has Eutric Cambisols (IUSS Working Group WRB, 2015) soil type with a sandy clay loam soil texture. The initial soil properties at the experimental site are summarized in Table 3.1. 
Table 3.1 Selected initial soil properties at the experimental site.

\begin{tabular}{ll}
\hline Property & Mean \pm SD \\
\hline Soil texture & - \\
$0.063-2 \mathrm{~mm}$, sand (\%) & $64.6 \pm 4.7$ \\
$0.002-0.063 \mathrm{~mm}$, silt (\%) & $12.6 \pm 3.5$ \\
$<0.002 \mathrm{~mm}$, clay (\%) & $22.8 \pm 1.9$ \\
Slope (\%) & $2.4 \pm 0.4$ \\
Bulk density, Bd $\left(\mathrm{g} \mathrm{cm}^{-3}\right)$ & $1.6 \pm 0.0$ \\
$\mathrm{pH}\left(\mathrm{H}_{2} \mathrm{O}\right)$ & $6.8 \pm 0.2$ \\
Soil organic-matter, SOM ( $\left.\mathrm{g} \mathrm{kg}^{-1}\right)$ & $8.3 \pm 2.6$ \\
Unsaturated hydraulic conductivity, Ks $\left(\mathrm{m} \mathrm{d}^{-1}\right)$ & $1.8 \pm 1.0$ \\
Saturated hydraulic conductivity, Ksat $\left(\mathrm{m} \mathrm{d}^{-1}\right)$ & $4.2 \pm 1.7$ \\
\hline
\end{tabular}

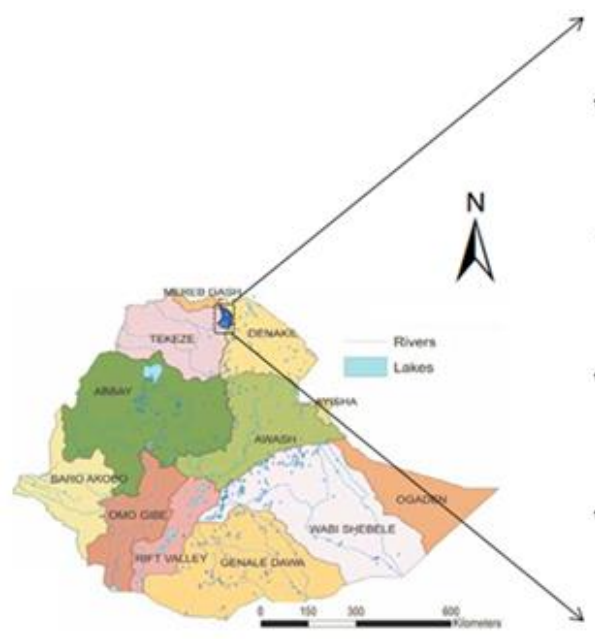

(a)

\section{$L$ and uses}

$\square$ Cultivated land
Grass land
Shrub land
Wood land
$\square$ Streams
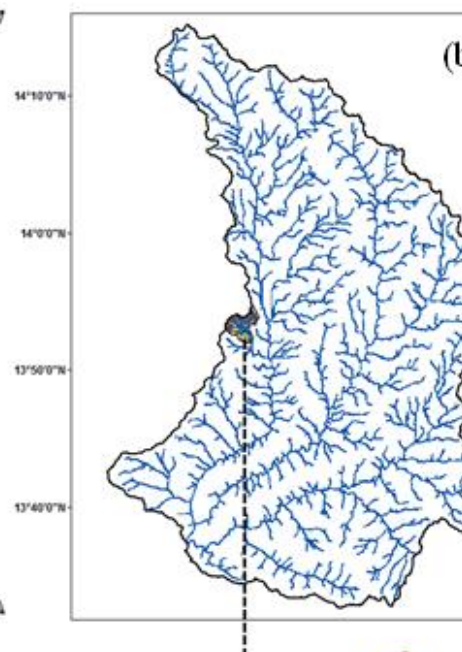

(b)
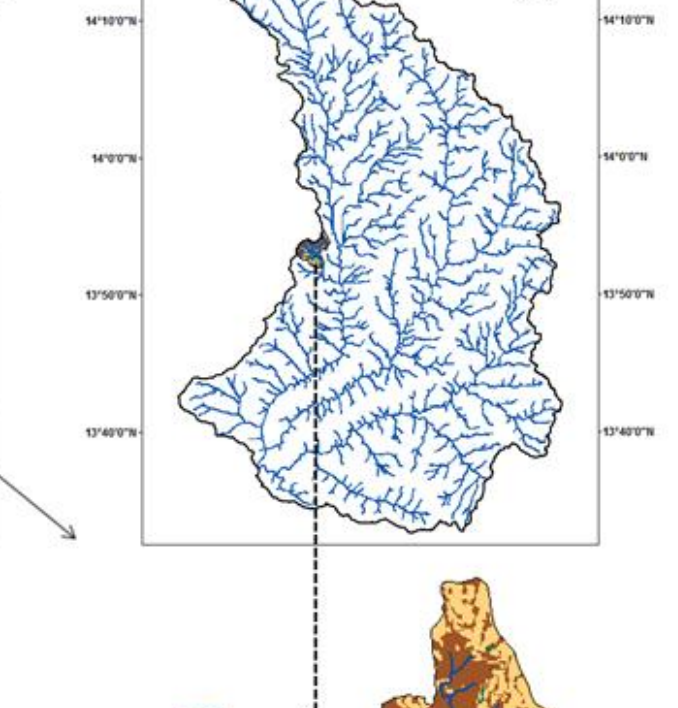


\subsubsection{Experimental design}

The experiment was conducted during the rainy seasons in 2013 and 2014 . The in-situ WHTs used in the field experiment were selected by stakeholders in a participatory WHT selection workshop (Grum et al., 2016). The experiment site was established in May 2013. The experiment had a completely randomized block design with five treatments and a control, with three replicates, for a total of 18 plots. The treatments consisted of single and combined WHTs (Table 3.2). Each plot was $3 \times 15 \mathrm{~m}$ (Figure 3.2).

After significant rain, the experimental field was ploughed twice by oxen-driven maresha a month and a week before sowing. The experiment plots were then established by hand. The plots in each replicate were separated by earth bunds $50 \mathrm{~cm}$ wide and $40 \mathrm{~cm}$ high to prevent water flow from neighboring plots and to provide access to the plots. The runoff from the plots was collected in a corrugated iron gutter and then directed into 300-400 L sub-surface barrels buried at the end of each plot. The crop used in the experiment was maize (Zea mays L.). Maize seeds were planted in each plot with $30 \mathrm{~cm}$ between plants and $60 \mathrm{~cm}$ between rows. The distance between rows in the plots with ridges, however, was $70 \mathrm{~cm}$ to allow enough space for the tied ridges. The tied ridges were $3 \mathrm{~m}$ long, $1.9 \mathrm{~m}$ apart, center to center, and had a mean height of $20 \mathrm{~cm}$.

Table 3.2 Description of the treatments in the field experiment.

\begin{tabular}{ll}
\hline Treatment & Description \\
\hline T0 (control) & Basal fertilization ${ }^{\text {a }}$ \\
T1 & Basal fertilization + Tied ridges \\
T2 & Basal fertilization + Straw mulch $\left(15 \mathrm{Mg} \mathrm{ha}^{-1}\right)$ \\
T3 & Basal fertilization + Straw mulch $\left(15 \mathrm{Mg} \mathrm{ha}^{-1}\right)$ and tied ridges \\
T4 & Basal fertilization + Straw mulch $\left(15 \mathrm{Mg} \mathrm{ha}^{-1}\right)$ and $4 \mathrm{~L} \mathrm{ha}^{-1}$ of EMs \\
T5 & Basal fertilization + Straw mulch $\left(15 \mathrm{Mg} \mathrm{ha}^{-1}\right)$, tied ridges, and $4 \mathrm{~L} \mathrm{ha}^{-1}$ of EMs \\
\hline${ }^{\mathrm{a}}$ Basal fertilization: $100 \mathrm{~kg} \mathrm{ha}^{-1}$ urea $(46 \% \mathrm{~N})$ and $100 \mathrm{~kg} \mathrm{ha}^{-1}$ diammonium phosphate $(18 \% \mathrm{~N}, 46 \% \mathrm{P})$ applied to the \\
\multicolumn{2}{c}{ entire field experiment. EMs: effective micro-organisms. }
\end{tabular}

\subsubsection{Field measurements}

Composite soil samples were collected to a depth of $20 \mathrm{~cm}$ for characterizing the physical and chemical properties of the experimental site before the beginning of the rainy season in 2013 and 2014 (Table 3.1). Soil physical properties such as bulk density, soil organicmatter (SOM), saturated (Ksat) and unsaturated (Ks) hydraulic conductivities were also measured after crop harvest both in 2013 and 2014. Bulk density was determined by core method and Ksat was determined by a laboratory permeameter using the constant-head 
method. Ks was measured in the field using a mini-disk infiltrometer after crop harvest in 2013 and 2014, both under dry conditions.
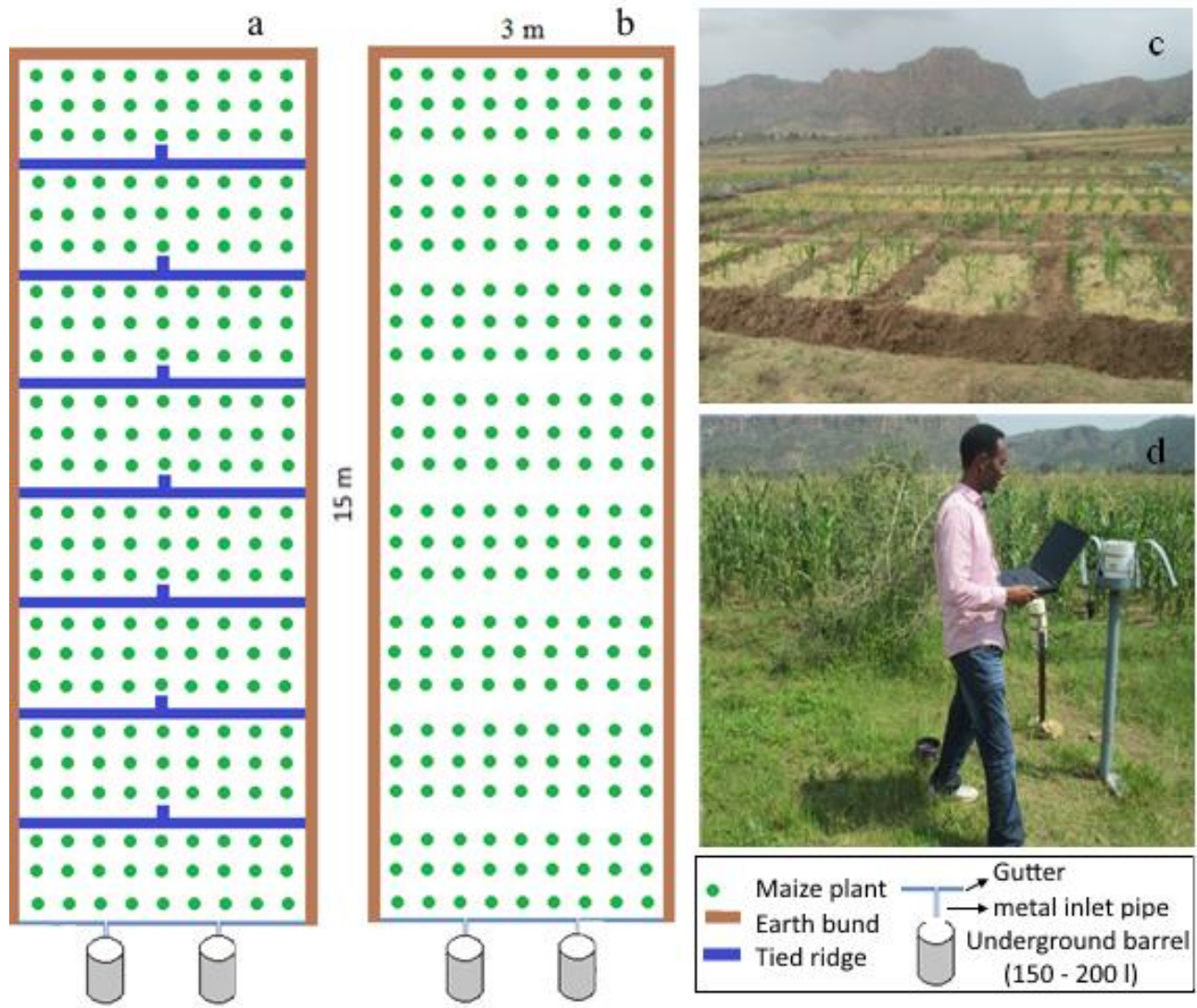

Figure 3.2 Layout of the experimental runoff plots. (a) Typical plot with tied ridges. (b) Typical plot without tied ridges. (c) Photograph of the field layout. (d). Rainfall and temperature measurement using an RG3-M rain gauge and a hobo pendant temperature data logger.

Rainfall and temperature were continuously monitored using a tipping-bucket datalogging rain gauge (RG3-M, precision $0.2 \mathrm{~mm}$ per tip) and a hobo pendant temperature data logger, respectively, installed at the experimental site (Figure 3.2). A standard rain gauge was also installed at the site to measure rainfall. Rainfall in 2013 was only measured using the standard rain gauge, because the data logger was not ready for use. Runoff volume after each rain event was determined by measuring the volume of water collected in the subsurface barrels. SMC was measured daily in 2013 and 2014 using a Trime-PICO64 (time-domain reflectometer or TDR method) soil-moisture sensor (Eijkelkamp, Giesbeek, the Netherlands) to a depth of $15 \mathrm{~cm}$ at six sampling points per plot. 


\subsubsection{Data analysis}

Statistical analysis was carried out using SPSS 22 (IBM Corporation, New York, USA). Normality of data was tested using the Kolmogorov-Smirnov test. The normally distributed data were analyzed using least squares one-way analyses of variance to identify significance differences between treatments. The homogeneity of the variances for the measured data was checked using Levene's test. The data that failed the normality test were analyzed using non-parametric tests for statistical differences. The Kruskal-Wallis $\mathrm{H}$ test was used to identify if a treatment had a significant effect on a measured variable. The pairwise Mann-Whitney U-test was used to determine if a measured variable differed significantly between treatments.

Total seasonal (for the rainy season) runoff was derived from rain events that generated runoff. Average seasonal SMC was generated from daily soil-moisture measurements in the plots for all treatments.

Runoff reduction per event of a treatment was calculated by:

$R(\%)=\frac{Q_{c}-Q_{t}}{Q_{c}} \times 100$

where $R$ is the reduction in runoff by a treatment compared to the control (\%), $Q_{c}$ is the measured runoff $(\mathrm{mm})$ in the control, and $Q_{t}$ is the measured runoff $(\mathrm{mm})$ in a treatment. Runoff coefficient $(C)$ was estimated from the total seasonal runoff during the rainy season by:

$C(\%)=\frac{Q}{P} \times 100$

where $Q$ is total seasonal runoff $(\mathrm{mm})$ and $P$ is total seasonal rainfall $(\mathrm{mm})$ for rain events producing runoff.

Rainfall and rain intensity thresholds for runoff generation were estimated using the method by Fu et al. (2013). Rainfall or rain intensity was plotted against runoff and regression lines were fitted by least square method. Thresholds were determined at three SMC levels (<20\%, 20-30\% and >30\%) for all treatments using measured runoffs in 2014 .

Principal component analysis (PCA) was performed to identify the main factors affecting runoff and SMC. Two PCAs were performed separately for two groups, the hydrological and soil parameters (runoff, SMC, slope, SOM, Ksat, and Ks) and the hydro-meteorological 
variables (runoff, rainfall, 30-minute rain intensity (I30) and SMC). For the hydrological and soil parameters group, runoff per treatment was total of seasonal runoff and SMC was average of seasonal daily measurements in 2013 and 2014. For SOM, Ksat and Ks, data were taken from measurements at the end of the rainy season (after crop harvest) in 2013 and 2014 per treatment $(n=36)$. For the hydro-meteorological variables, the PCA was performed based on runoff, rainfall and rain intensity events and daily SMC in 2013 and $2014(n=630)$. Rainfall and rain intensity were not included in the first PCA, because total seasonal rainfall was the same for all treatments. Therefore, we formulated the second PCA to demonstrate the relationships amongst the hydro-meteorological variables.

Extracted components with eigenvalues $>1$ were chosen to explain the associations amongst the variables. A factor analysis for the related variables was carried out after testing the normality of the data used in the analysis. Most of the data were not normally distributed, so we used Spearman's rank correlation to identify correlations amongst variables.

Regression models were formulated to predict runoff per event using predictor variables such as rainfall, 130, SMC, slope, SOM, Ksat, and Ks for different treatments. Runoff per treatment, rainfall and rain intensity data were based on event-based measurements in 2014. SMC data per treatment was based on daily measurements in 2014. SOM, Ksat and Ks data per treatment were taken from measurements after crop harvest in 2014.

Regression analysis was performed after confirming the assumptions of linearity between the dependent and independent variables, the statistical independence, homoscedasticity, and normality of the predictor errors. The degree of multicollinearity amongst predictor variables was tested using tolerance (Eq. 3.3). Multicollinearity refers to a near perfect linear combination amongst predictor variables and disrupts the uniqueness of parameter estimates of a regression model. Tolerance was calculated by:

Tolerance $_{\mathrm{j}}=1-\mathrm{r}_{\mathrm{j}}^{2}$

where $r_{j}^{2}$ is the coefficient of determination of a regression of predictor variable $j$ on all other predictor variables. A tolerance near 1 indicates no multicollinearity and a tolerance $<0.1$ indicates that further assessment is required. Multicollinear predictor variables were excluded from the regression analysis. Statistical independence amongst predictor variables was evaluated using the Durbin-Watson test. A Durbin-Watson value <2 indicates no significant dependence amongst predictor variables. 
The multiple regression model to estimate runoff was:

$Y=\beta_{0+} \beta_{1} X_{1}+\beta_{2} X_{2}+\beta_{3} X_{3}+\cdots \cdots+\beta_{n} X_{n}+\varepsilon$

where $Y$ is dependent variable, i.e., runoff per event $(m m), X_{1}, X_{2}, X_{3}$ and $X_{n}$ are predictor variables, $b_{0}$ is a constant, $b_{1}, b_{2}, b_{3} \ldots .$. and $b_{n}$ are parameter estimates of the predictor variables, $\varepsilon$ is the residual error.

The performance of the regression models was evaluated using the coefficient of determination $\left(r^{2}\right)$ and the Nash-Sutcliffe efficiency (NSE) coefficient (Nash and Sutcliffe, 1970). The coefficient of determination describes how well the regression line of observed and predicted data pass through each data point. $R^{2}$ ranges between 0 and 1 , with 0 indicating no correlation and 1 indicating a balanced dispersion between model predictions and observations.

$$
r^{2}=\left(\frac{\sum_{i=1}^{n}\left(O_{i}-\bar{O}\right)\left(P_{i}-\bar{P}\right)}{\sqrt{\sum_{i=1}^{n}\left(O_{i}-\bar{O}\right)^{2}} \sqrt{\sum_{i=1}^{n}\left(P_{i}-\bar{P}\right)^{2}}}\right)^{2}
$$

where $O_{i}$ is observed runoff $(\mathrm{mm}), \bar{O}$ is average observed runoff $(\mathrm{mm}), P_{i}$ is predicted runoff $(\mathrm{mm})$, and $\bar{P}$ is average predicted runoff $(\mathrm{mm})$.

NSE measures the goodness of fit between a model prediction and the measured data. It measures how well the observed and predicted data fit the regression line with a slope of 1. NSE ranges from $-\infty$ to 1 , and a value of 1 indicates perfect agreement between predicted and observed data. A value of 0 indicates that the model is able to predict as well as the mean observed data and a value $<0$ indicates that the mean of the observed data is a better estimate than the model output.

$N S E=1-\frac{\sum_{i=1}^{n}\left(O_{i}-P_{i}\right)^{2}}{\sum_{i=1}^{n}\left(O_{i}-\bar{O}\right)^{2}}$

where $O_{i}$ is observed runoff $(\mathrm{mm}), \bar{O}$ is average observed runoff $(\mathrm{mm})$, and $P_{i}$ is predicted runoff ( $\mathrm{mm})$. 


\subsection{Results}

\subsubsection{Characteristics of rainfall and soil hydro-physical properties}

The sub-watershed has a semi-arid climate with temperature varying more diurnally than seasonally. The average daily temperature range during the 2014 rainy season was $16-23$ ${ }^{\circ} \mathrm{C}$, with a mean of $19^{\circ} \mathrm{C}$. The minimum and maximum daily temperatures were 10 and 38 ${ }^{\circ} \mathrm{C}$, respectively. The distribution of rainfall was good throughout the 2013 rainy season, except for low rainfall in September (Figure 3.3a). The main rainy season in 2014 began in June, but rainfall was low for nearly three weeks in July (Figure 3.3b). Rainfall was well distributed in the other months.
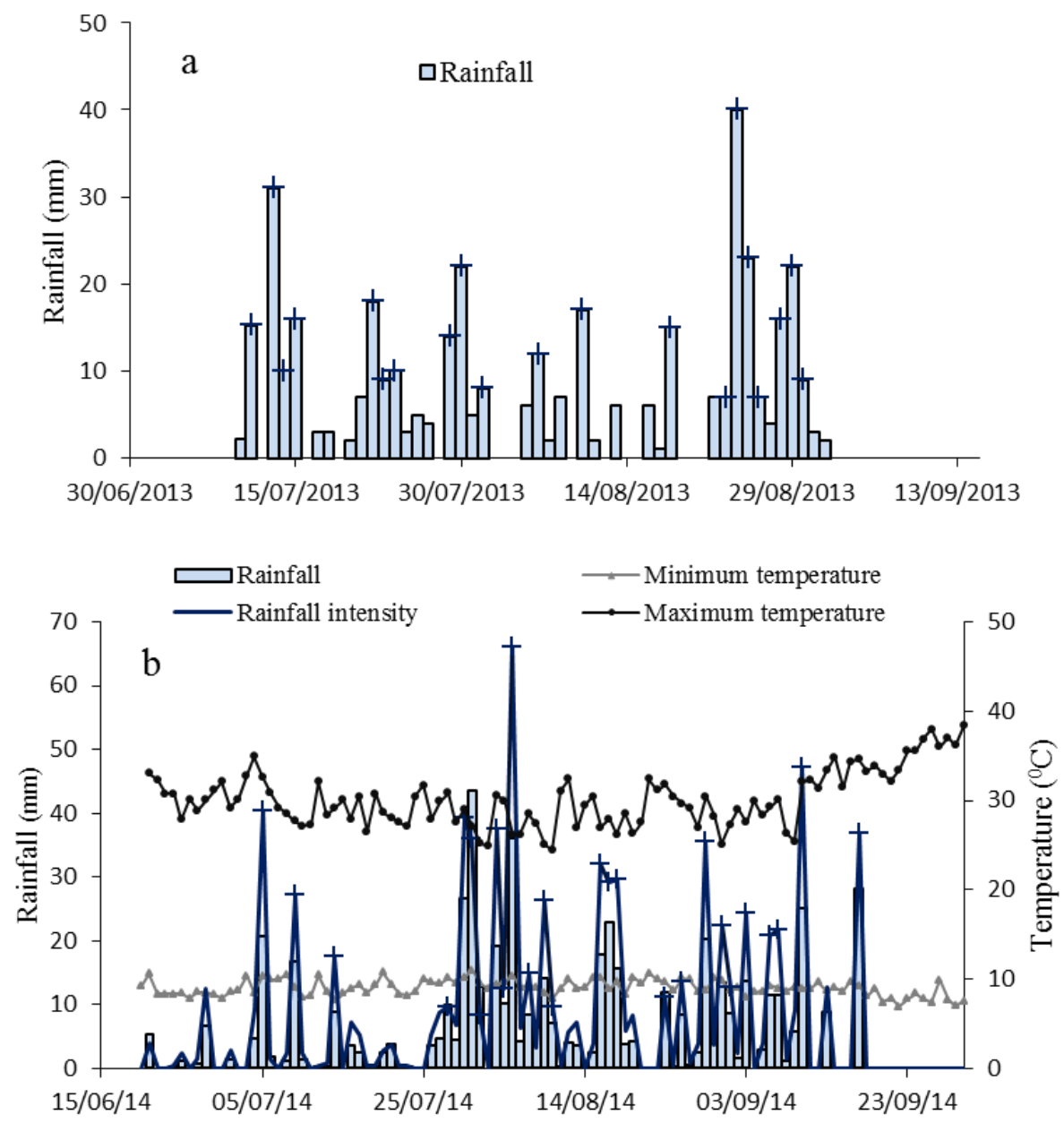

Figure 3.3 Rainfall in 2013 (a) and rainfall, rain intensity, and temperature at the experimental site in 2014 (b). Plus (+) indicates a rain that generated runoff. 
The total rainfalls for the 2013 and 2014 rainy seasons were 402 and $552 \mathrm{~mm}$, respectively. The main rains fell in July and August. Most of the rains in 2013 and 2014 produced runoff in the plots (Figure 3.3), 49\% of the 41 rains in the 2013 rainy season and $46 \%$ of the 57 rains in 2014. Rain intensity was not measured in 2013 so is shown in Figure $3.3 \mathrm{~b}$ only for 2014. Rainfall and I30 were closely correlated (Figure 3.4), so the rainfall for 2013 was likely a good indicator of runoff for that year.

Soil physical properties such as bulk density and SOM did not vary significantly $(p>0.05)$ amongst the treatments over the two seasons of experiment. SOM was generally low in the experiment field and did not significantly $(p>0.05)$ improve after the application of straw mulch despite some variations in magnitude. Ksat and Ks showed little variation $(p>0.05)$ among treatments. Generally, the magnitude of Ksat was significantly $(p<0.05)$ higher than Ks for all treatments (Table 3.3).

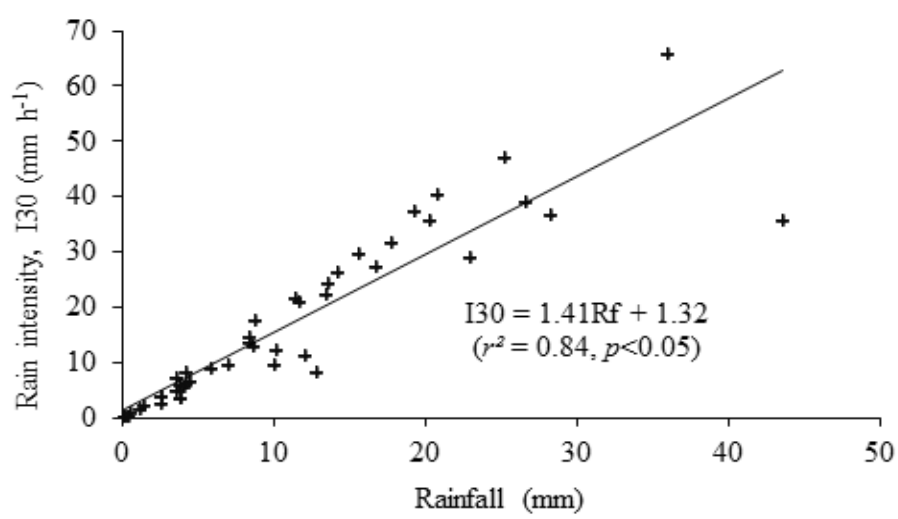

Figure 3.4 Relationship between rain intensity (I30) and rainfall (Rf).

Table 3.3 Average bulk density (Bd), soil organic-matter (SOM), saturated (Ksat) and unsaturated (Ks) hydraulic conductivities for different treatments over two years of experiment. All measurements were made after crop harvest in 2013 and 2014.

\begin{tabular}{|c|c|c|c|c|}
\hline Treatment & $\begin{array}{l}\text { Bd }\left(\mathrm{g} \mathrm{cm}^{-3}\right) \\
\text { Median }(\min , \max )^{b} \\
(n=6)\end{array}$ & $\begin{array}{l}\text { SOM }\left(\mathrm{g} \mathrm{kg}^{-1}\right) \\
\text { Mean } \pm \mathrm{SD}^{\mathrm{a}} \\
(n=6)\end{array}$ & $\begin{array}{l}\text { Ksat }\left(\mathrm{m} \mathrm{d}^{-1}\right) \\
\text { Mean } \pm S D^{a} \\
(n=6)\end{array}$ & $\begin{array}{l}\text { Ks }\left(\mathrm{m} \mathrm{d}^{-1}\right) \\
\text { Median }(\min , \max )^{b} \\
(n=6)\end{array}$ \\
\hline TO & $1.53(1.48,1.57)$ & $8.60 \pm 1.64$ & $4.68 \pm 2.32$ & $1.48(0.71,3.03)$ \\
\hline $\mathrm{T} 1$ & $1.59(1.56,1.59)$ & $7.92 \pm 3.69$ & $3.77 \pm 1.17$ & $1.74(0.68,3.61)$ \\
\hline $\mathrm{T} 2$ & $1.59(1.49,1.61)$ & $10.02 \pm 3.77$ & $3.06 \pm 1.13$ & $1.49(0.81,4.12)$ \\
\hline T3 & $1.56(1.50,1.64)$ & $9.11 \pm 3.90$ & $4.75 \pm 1.96$ & $1.28(0.61,3.33)$ \\
\hline T4 & $1.60(1.51,1.65)$ & $7.81 \pm 2.50$ & $3.28 \pm 1.08$ & $1.25(0.90,4.58)$ \\
\hline T5 & $1.60(1.46,1.80)$ & $6.53 \pm 4.46$ & $5.33 \pm 2.99$ & $1.18(0.53,3.94)$ \\
\hline
\end{tabular}

${ }^{a}$ Normally distributed data, ${ }^{b}$ not normally distributed data. T0: Control, T1: Tied ridges, T2: Straw mulch, T3: Tied ridges + straw mulch, T4: Straw mulch + EMs, T5: Tied ridges + straw mulch + EMs. 


\subsubsection{Effect of treatment on runoff}

Runoff per event was significantly lower $(p<0.05)$ in all treatments compared to the control (Table 3.4). The order of magnitude of runoff for all treatments was $\mathrm{T} 0>\mathrm{T} 4=\mathrm{T} 2>\mathrm{T} 1 \geq \mathrm{T} 5=\mathrm{T} 3$ in 2013 and $\mathrm{T} 0>\mathrm{T} 1>\mathrm{T} 2=\mathrm{T} 3=\mathrm{T} 4=\mathrm{T} 5$ in 2014. Runoff was thus lowest in T3 in both years.

T3 and T5 were most efficient at reducing runoff in both years. T3 reduced runoff by 91 and $84 \%$ compared to the control in 2013 and 2014, respectively. T5, reduced runoff by 78\% in both 2013 and 2014. T2 and T4 also reduced runoff, but the efficiency of reduction was significantly higher in 2014 than in 2013, perhaps due to the cumulative effect of mulch application in the two experimental seasons.

Table 3.4 Average runoff per event, runoff reduction, seasonal runoff coefficient, and daily soil-moisture content for the treatments. Different letters indicate significant differences $(p<0.05)$ between treatments, $a<b<c<d$.

\begin{tabular}{|c|c|c|c|c|}
\hline Treatment & $\begin{array}{l}\text { Runoff } \\
\text { (mm) }\end{array}$ & $\begin{array}{l}\text { Runoff reduction } \\
\text { (\%) }\end{array}$ & $\begin{array}{l}\text { Seasonal runoff } \\
\text { coefficient (\%) }\end{array}$ & $\begin{array}{l}\text { Soil-moisture } \\
\text { content (\%) }\end{array}$ \\
\hline 2013 & Median $(\min , \max )^{\mathrm{b}}(n=24)$ & $\begin{array}{l}\text { Median }(\min , \max )^{b} \\
(n=24)\end{array}$ & $\begin{array}{l}\text { Median }(\min , \max )^{\mathrm{b}} \\
(n=3)\end{array}$ & $\begin{array}{l}\text { Mean } \pm S D^{a} \\
(n=30)\end{array}$ \\
\hline T0 & $4.33(1.8,9.5) d$ & $0(0,0)$ & $34.7(30.8,35.8)$ & $20.4 \pm 2.6$ a \\
\hline $\mathrm{T} 1$ & $1.20(0.4,4.5) b$ & $65(-16,93)$ & $12.2(11.1,14.1)$ & $21.1 \pm 2.7 \mathrm{ab}$ \\
\hline $\mathrm{T} 2$ & $3.00(0.3,6.8) \mathrm{c}$ & $23(-9,92)$ & $22.5(17.9,27.7)$ & $19.9 \pm 2.6 \mathrm{a}$ \\
\hline T3 & $0.38(0.0,3.2) a$ & $91(11,100)$ & $4.2(2.9,6.4)$ & $22.6 \pm 3.3 \mathrm{c}$ \\
\hline $\mathrm{T} 4$ & $3.13(1.0,8.6) \mathrm{c}$ & $20(-19,89)$ & $21.4(18.9,27.8)$ & $20.5 \pm 1.3 \mathrm{a}$ \\
\hline T5 & $0.98(0.0,4.1) a b$ & $78(-12,100)$ & $7.1(6.8,11.4)$ & $22.0 \pm 3.6 \mathrm{bc}$ \\
\hline 2014 & $\begin{array}{l}\text { Median }(\min , \max )^{b} \\
(n=81)\end{array}$ & $\begin{array}{l}\text { Median }(\min , \max )^{b} \\
(n=81)\end{array}$ & $\begin{array}{l}\text { Median }(\min , \max )^{b} \\
(n=3)\end{array}$ & $\begin{array}{l}\text { Median }(\min , \max )^{b} \\
(n=180)\end{array}$ \\
\hline T0 & $5.21(0.3,11.2) \mathrm{c}$ & $0(0,0)$ & $30.2(28.4,32.1)$ & $19.3(5.5,40.8) \mathrm{a}$ \\
\hline $\mathrm{T} 1$ & $2.62(0.2,9.2) b$ & $46(-29,87)$ & $16.2(15.5,17.5)$ & $20.3(6.9,40.4) a b$ \\
\hline $\mathrm{T} 2$ & $0.66(0.0,8.9) \mathrm{a}$ & $82(6,100)$ & $7.9(6.1,8.6)$ & $21.4(8.8,40.1) b c$ \\
\hline T3 & $0.57(0.0,8.8) \mathrm{a}$ & $84(14,100)$ & $6.7(6.0,6.8)$ & $22.9(8.2,46.2) d$ \\
\hline $\mathrm{T} 4$ & $0.77(0.0,8.8) a$ & $78(-14,100)$ & $10.1(6.8,11.2)$ & $20.6(7.1,42.7) b$ \\
\hline T5 & $0.86(0.0,8.6) \mathrm{a}$ & $78(-8,100)$ & $9.3(6.5,9.6)$ & $22.1(7.8,44.3) \mathrm{cd}$ \\
\hline
\end{tabular}

${ }^{a}$ Normally distributed data, ${ }^{b}$ not normally distributed data. T0: Control, T1: Tied ridges, T2: Straw mulch, T3: Tied ridges + straw mulch, T4: Straw mulch + EMs, T5: Tied ridges + straw mulch + EMs.

The seasonal runoff coefficient was higher in 2013 than 2014 for T0, T2 and T4 (Table 3.4). The control (TO) had the highest runoff coefficients of 34.7 and $30.2 \%$ in 2013 and 2014, respectively. T3 had the lowest runoff coefficients of 4.2 and $6.7 \%$ in 2013 and 2014, respectively. 

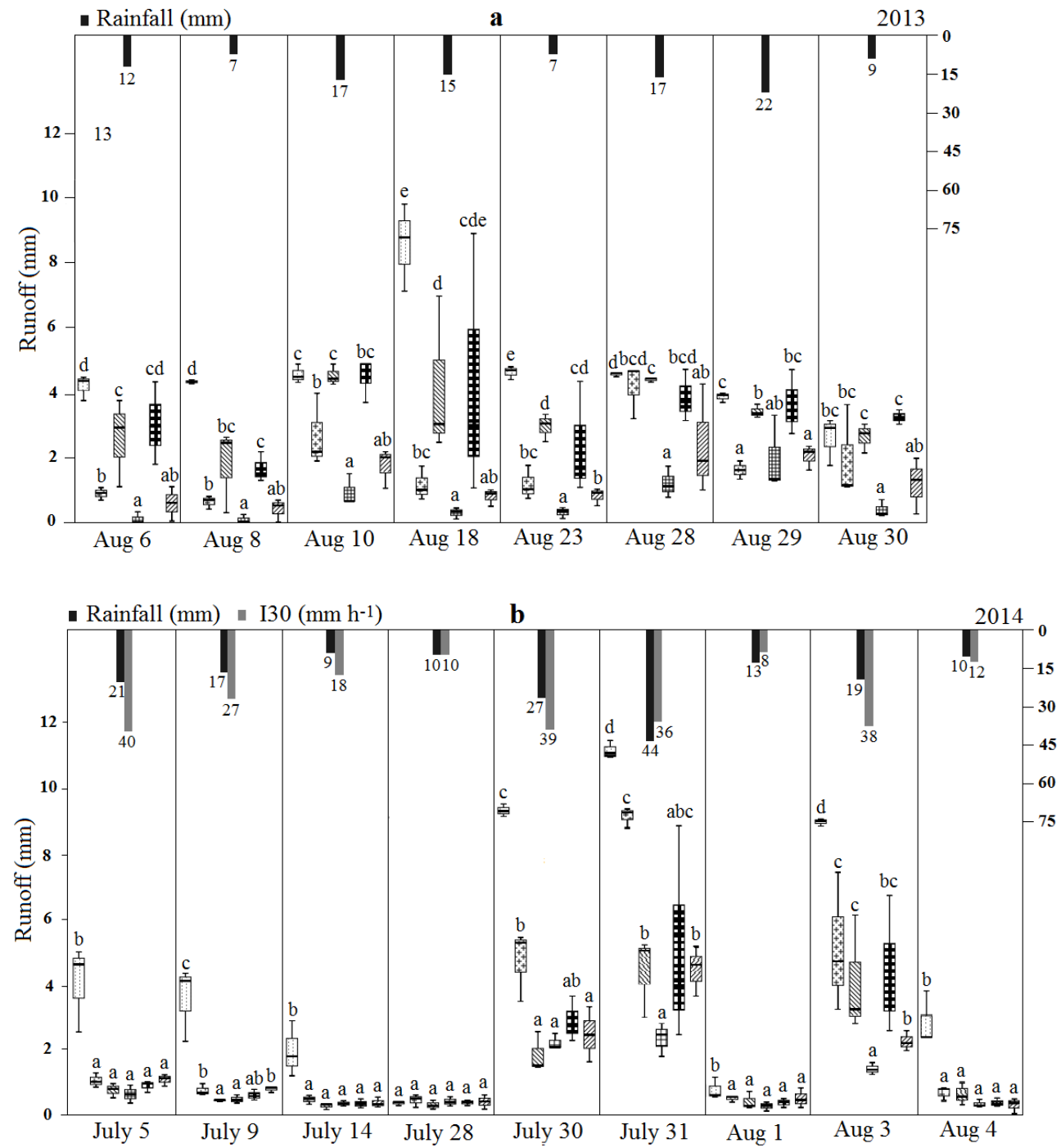

Figure 3.5 To be continued on next page 
Figure 3.5 Continued
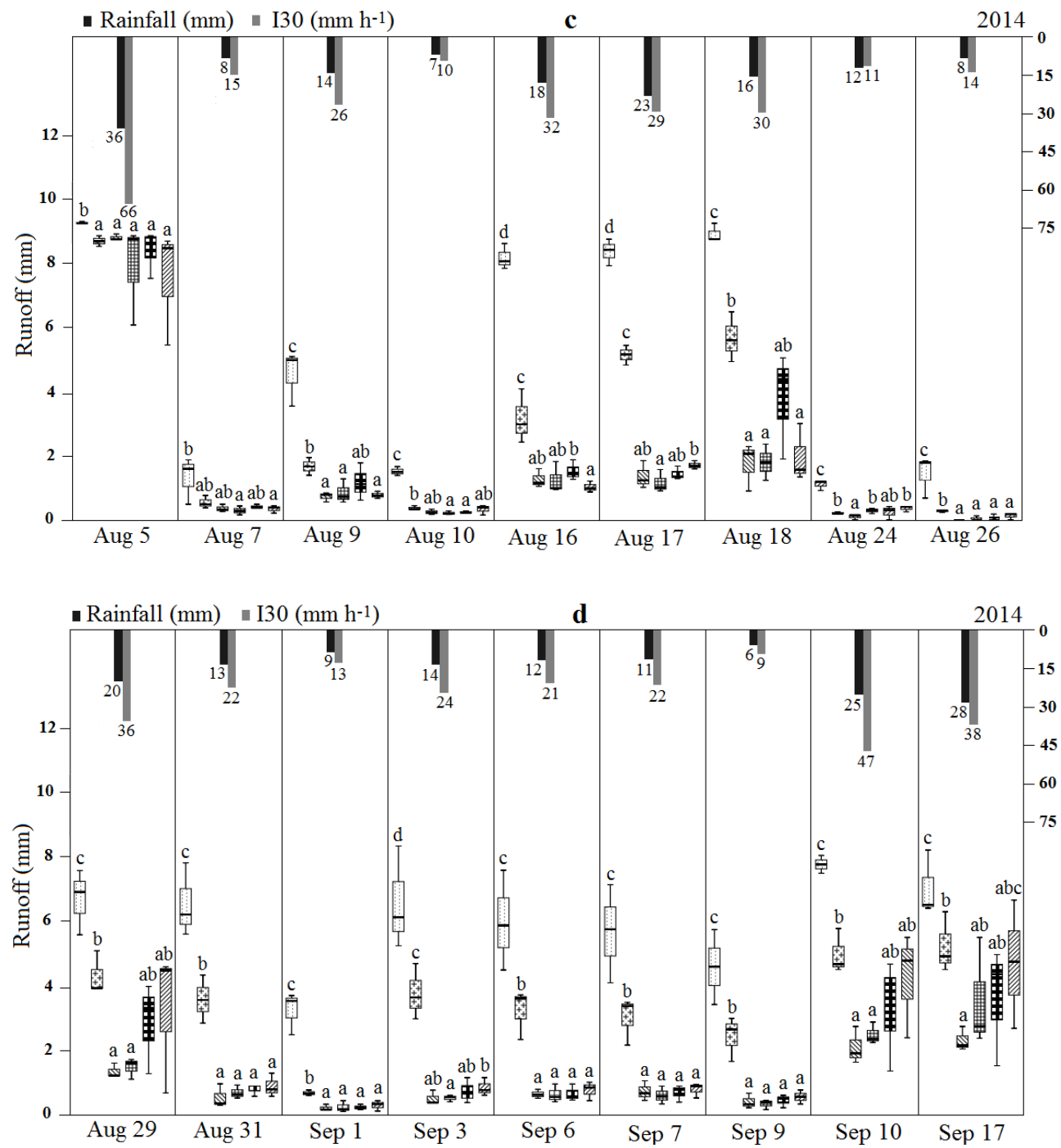

\section{周进田 \\ T0 T1 12 T2 3 T4 T5}

Figure 3.5 Rainfall and runoff for the treatments in 2013 (a), rainfall, rain intensity (130), and runoff for the treatments in 2014 ( $b$ to d). Different letters indicate significant differences between treatments (MannWhitney U-test, $p<0.05), a<b<c<d<e$. T0: Control, T1: Tied ridges, T2: Straw mulch, T3: Tied ridges + straw mulch, T4: Straw mulch + EMs, T5: Tied ridges + straw mulch + EMs. 


\subsubsection{Characteristics of runoff per rain events}

The amount of runoff was high in both 2013 and 2014 (Figure 3.5). Nearly half of the rains in 2013 and 2014 produced runoff in the plots (Figure 3.3). Runoff was highest in the control (T0) for most rains in August 2013. T3 produced the lowest runoff, followed by T1. T0 generated significantly $(p<0.05)$ more runoff in 2014 than the other treatments for all runoff-generating rains except for those on 28 July, 7 August and 17 September. Runoff was relatively higher in all treatments after the relatively high rainfall $(36 \mathrm{~mm})$ at the highest rain intensity $\left(I 30=66 \mathrm{~mm} \mathrm{~h}^{-1}\right)$ on 5 August 2014 compared to the other rains. Runoff in TO was highest on 31 July at $10.9 \mathrm{~mm}$, for which the rainfall and 130 were $44 \mathrm{~mm}$ and $36 \mathrm{~mm} \mathrm{~h}^{-1}$, respectively.

The amount of runoff generated from the plots was relatively lower in July 2014, especially in the first weeks, compared to similar rains in August (Figure 3.5). For example, the rains on 5 July (rainfall=21 mm, I30=40 $\mathrm{mm} \mathrm{h}^{-1}$ ) and 3 August (rainfall=19 mm, I30=mm $\mathrm{h}^{-1}$ ) were similar. Runoff in the control was however significantly lower on 5 July $(4.1 \mathrm{~mm})$ than on 3 August $(9.1 \mathrm{~mm})$. The difference in runoff between these two events is mainly attributed to soil- moisture differences in July and August. Runoff was significantly $(p<0.05)$ lower in the other treatments (T1-T5) than the control on 5 July but was relatively higher on 3 August except in T3 and T5. Runoff tended to be higher with higher 130, although the effect was more apparent in the control. Runoff was, for example, significantly higher $(p<0.05)$ in the control than the other treatments on 14 July (rainfall=9 $\mathrm{mm}, \mathrm{I} 30=18 \mathrm{~mm} \mathrm{~h}^{-1}$ ) but was relatively lower in all treatments, including the control, on 28 July (rainfall $=10 \mathrm{~mm}, \mathrm{I} 30=10 \mathrm{~mm} \mathrm{~h}^{-1}$ ).

Rainfall threshold for runoff generation varied with treatments and antecedent SMC. Rainfall threshold refers to the minimum rainfall above which runoff will be generated. Rainfall and rain intensity (in terms of 130) threshold computations are illustrated by the correlation plots as shown in Figure 3.6. Generally, rainfall thresholds decreased with increasing antecedent SMC for all treatments (Table 3.5). Rainfall thresholds were lower in the control (T0) than the other treatments (T1-T5) for similar SMCs. Rainfall threshold for TO was $4.3 \mathrm{~mm}$ when SMC was below 20\%. Rainfall threshold for T0 was $4 \mathrm{~mm}$ when antecedent SMC was between 20 and $30 \%$ and slightly decreased to $3.8 \mathrm{~mm}$ when SMC exceeded 30\%. The highest rainfall threshold was recorded by tied ridges (T1) with $4.8 \mathrm{~mm}$ when SMC was below 20\%. TO had the lowest rain intensity threshold with $5.4 \mathrm{~mm} \mathrm{~h}^{-1}$ when SMC exceeded 30\%. Rain intensity threshold decreased when antecedent SMC was increased. Rain intensity thresholds were similar for T1-T5 for similar SMCs. 

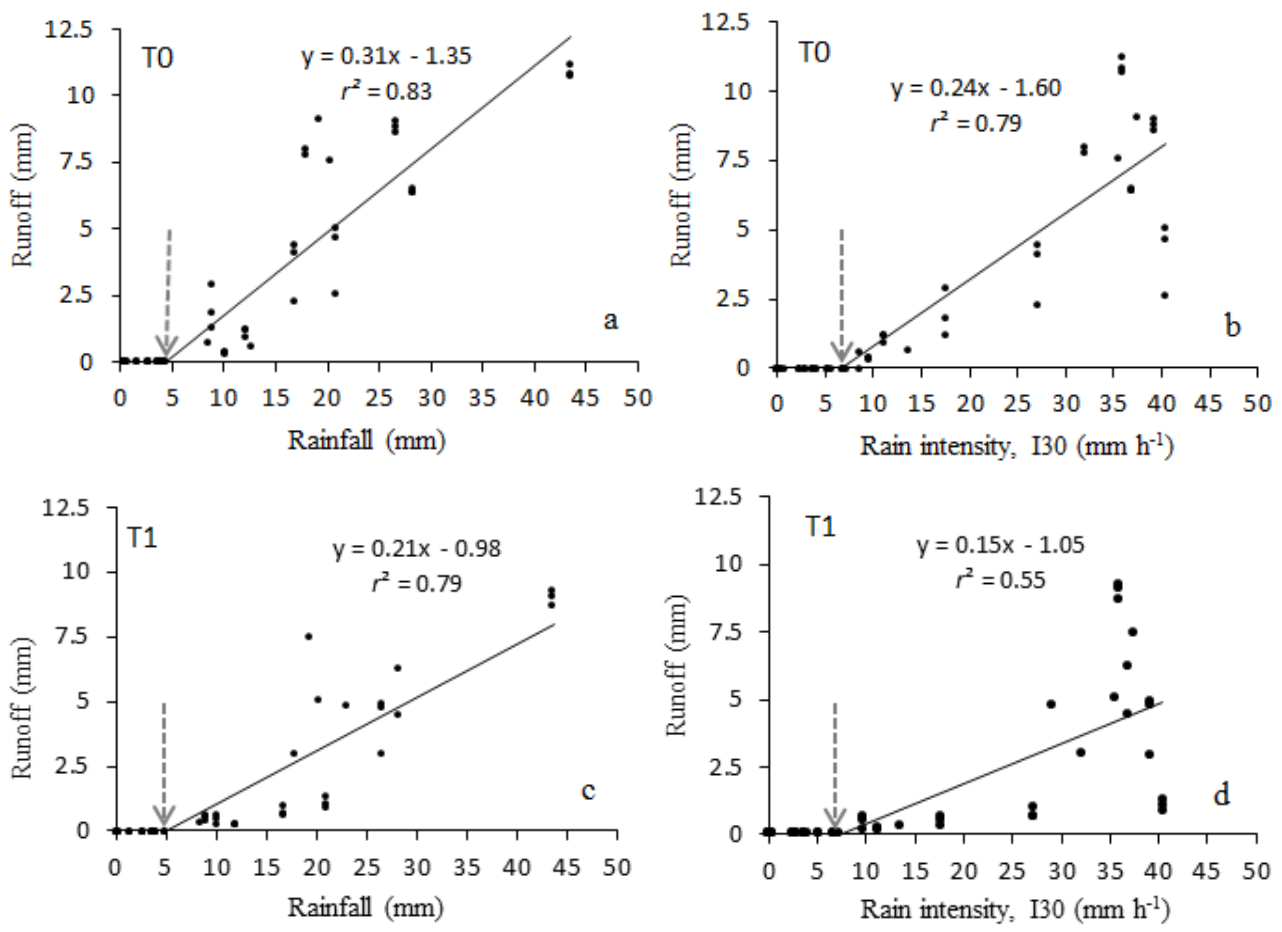

Figure 3.6 Examples of determination of rainfall and rain intensity (130) thresholds (arrow) at 0-20\% antecedent soil-moisture content. Correlations (a) between runoff and rainfall for TO (control) (b) between runoff and rain intensity (I30) for TO (c) between runoff and rainfall for $T 1$ (tied ridges), (d) between runoff and rain intensity (130) for $T 1$.

Table 3.5 Rainfall and rain intensity thresholds for runoff generation at different soil-moisture contents for various treatments.

\begin{tabular}{llll}
\hline Treatment & Soil-moisture content (\%) & Rainfall $(\mathbf{m m})$ & $\begin{array}{l}\text { Rain intensity, } \\
\mathbf{1 3 0}\left(\mathbf{m m ~ h}^{-1}\right)\end{array}$ \\
\hline \multirow{2}{*}{ T0 } & $<20$ & 4.3 & 6.6 \\
& $20-30$ & 4.0 & 5.8 \\
& $>30$ & 3.8 & 5.4 \\
\hline \multirow{2}{*}{ T1 } & $<20$ & 4.8 & 7.1 \\
& $20-30$ & 4.2 & 7.0 \\
& $>30$ & 4.1 & 6.4 \\
\hline \multirow{2}{*}{ T2-T5 } & $<20$ & 4.5 & 7.2 \\
& $20-30$ & 4.3 & 7.0 \\
\hline
\end{tabular}




\subsubsection{Effect of treatments on soil-moisture content}

SMC in 2013 was significantly $(p<0.05)$ higher in T3 (tied ridges + straw mulch) and T5 (straw mulch + tied ridges + EMs) than TO (Table 3.4), with mean SMCs of 22.6 and $22.0 \%$, respectively. SMC in 2014 was significantly $(p<0.05)$ higher in all treatments except T1 than the control and was highest in T3 and T5, similar to 2013, with medians of 22.9 and 22.1\% respectively. SMC was slightly higher in T2 and T4 in 2014 than 2013, and only T3 and T5 had significantly higher contents $(p<0.05)$ than T1. SMC was significantly $(p<0.05)$ higher in T3 than all other treatments except T5.

SMC was higher in all treatments when rainfall peaked (Figure 3.7). SMC was relatively higher throughout the 2014 rainy season in T3 and T5 compared to the other treatments and was lowest in T0 and T1. The difference in SMC amongst the treatments was smallest during heavy rains and largest at the beginning (July) and end (September) of the rainy season.

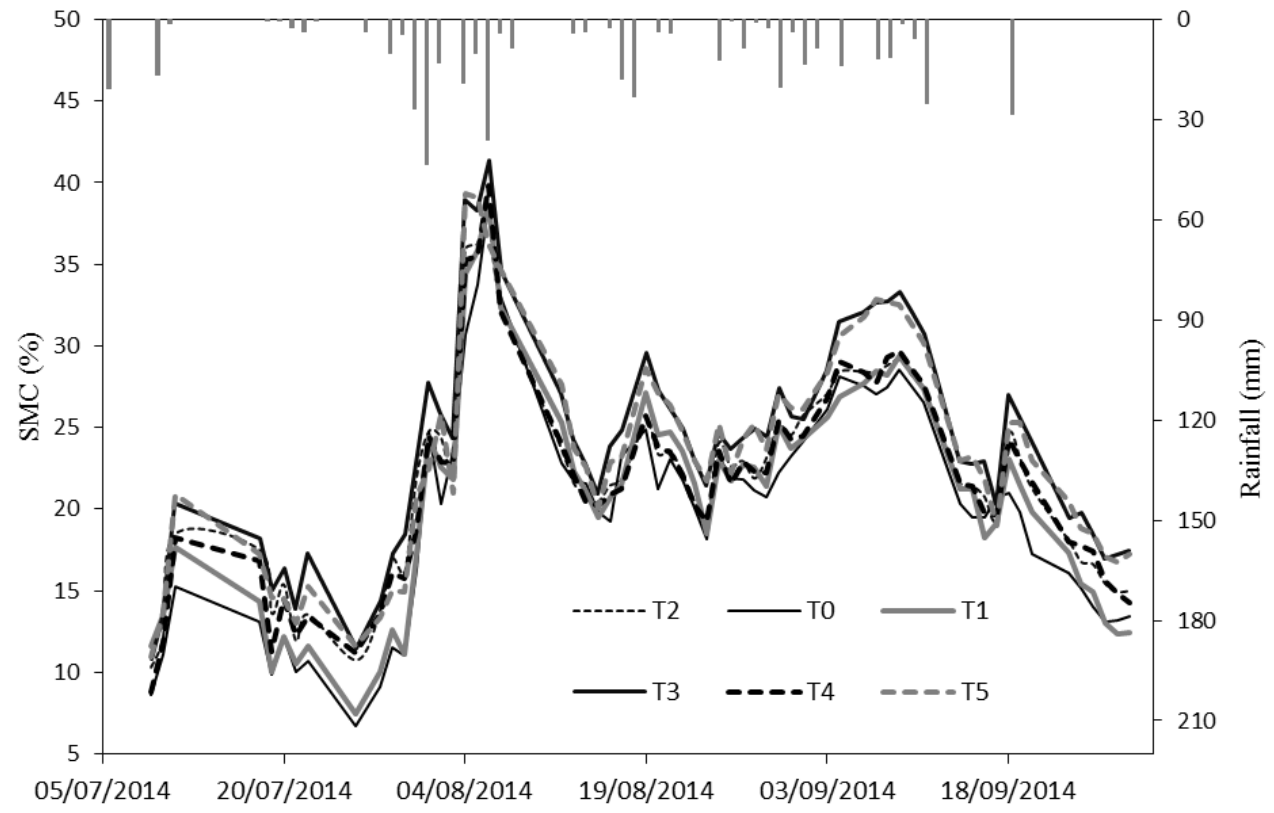

Figure 3.7 Soil-moisture content (SMC) for the treatments and rainfall during the 2014 rainy season. TO: Control, T1: Tied ridges, T2: Straw mulch, T3: Tied ridges + straw mulch, T4: Straw mulch + EMs, T5: Tied ridges + straw mulch + EMs. 


\subsubsection{Relationships amongst the hydro-meteorological and soil parameters}

\section{Factors affecting runoff and soil-moisture content}

The PCA for the hydrological and soil parameters indicated that the first two PCs explained $57.3 \%$ of the total variance (Figure 3.8). PC1 described $35.9 \%$ of the total variance and had strong positive loadings for SMC (0.89) and Ks (0.88). The high and positive loadings in PC1 of these two factors may be due to their strong correlation $(r=0.80, p<0.01)$. PC2 accounted for $21.4 \%$ of the total variance and was mainly associated with runoff and slope, with moderate factor loadings of 0.63 and 0.67 , respectively.

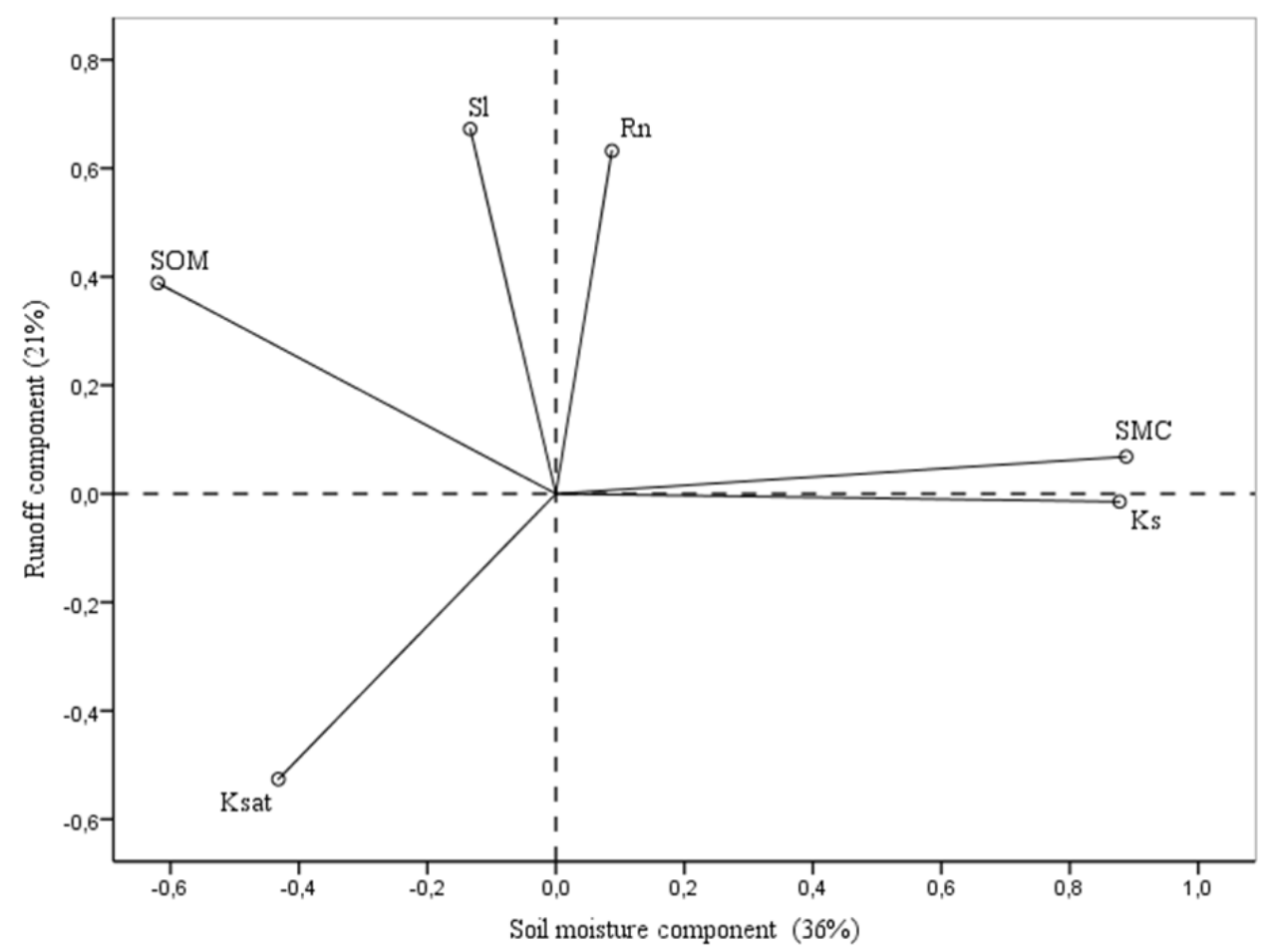

Figure 3.8 Principal component analysis of the hydrological and soil parameters: runoff (Rn), soil-moisture content (SMC), slope (SI), soil organic-matter (SOM), saturated (Ksat), and unsaturated (Ks) hydraulic conductivities. The PCA was based on total seasonal runoff, average seasonal SMC, and SOM, Ksat and Ks taken from measurements after crop harvest.

The PCA for the hydro-meteorological data obtained from event-based measurements identified two components that explained $86.7 \%$ of the total variation. PC1 accounted for $61.3 \%$ of the total variation (Figure 3.9 ) and was mainly associated with 130 , rainfall, and runoff, with factor loadings of $0.96,0.94$, and 0.80 , respectively. The positive and high loadings for the three variables may be attributed to the link between runoff and both 
rainfall and 130 . Runoff was moderately correlated with rainfall $(r=0.59, p<0.01)$ and 130 $(r=0.70, p<0.01)$. PC2 was strongly linked with SMC and accounted for $25.4 \%$ of the total variance in the hydro-meteorological data.

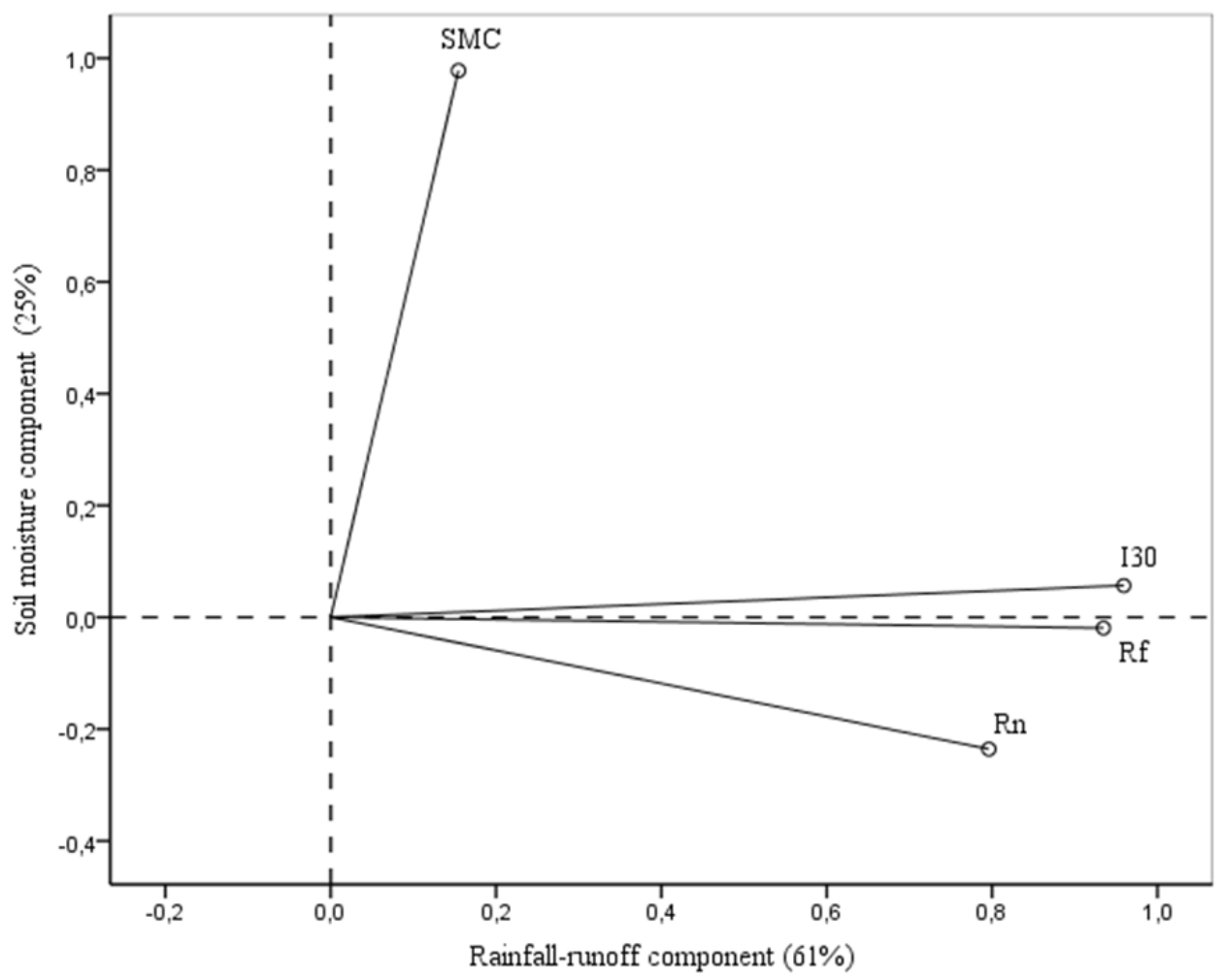

Figure 3.9 Principal component analysis of the hydro-meteorological parameters: runoff (Rn), rainfall (Rf), rain intensity (I30), and soil-moisture content (SMC). The PCA was performed based on event data for rainfall, rain intensity and runoff, and daily measurements for SMC (n=630) for 2013 and 2014.

\section{Establishing multiple regression to estimate runoff}

PC1 (rainfall-runoff component) of the PCA for the hydro-meteorological group indicated that runoff was closely associated with rainfall and 130 , and PC2 (runoff component) of the PCA for the hydrological and soil parameters group indicated that runoff was moderately associated with slope. We thus used multiple linear regressions to determine if runoff could be predicted using meteorological, hydrological, and soil physical parameters. Rainfall and I30 (Figure 3.9) and SMC and Ks (Figure 3.8) were closely associated, so the problem of multicollinearity was examined using the magnitude of the tolerance in the regression analysis.

The multiple linear regression analysis for estimating runoff per event from the measured rainfall, 130, SMC, slope, SOM, Ksat, and Ks resulted in a significant $(p<0.05)$ overall model 
fit for all treatments (Table 3.6). The regression models performed well for all treatments, with $r^{2}$ of $0.63,0.77$, and $>0.8$ for T0, T1, and T2-T5, respectively. The NSEs for the regression models also indicated good agreement between estimated and measured runoff, with values ranging from 0.62 to 0.81 for the various treatments (Figure 3.10 ).
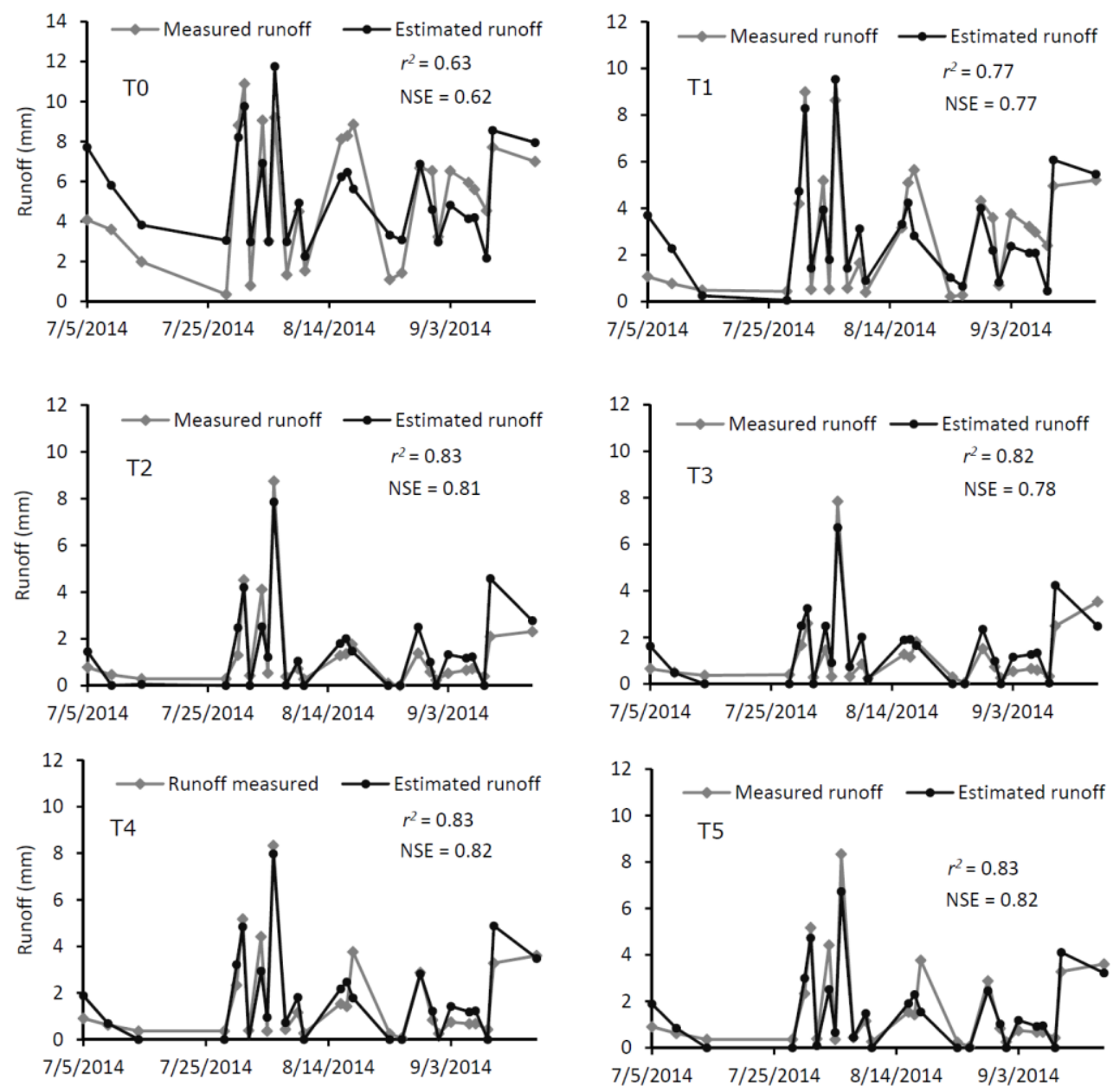

Figure. 3.10 Relationship between estimated and measured runoff for the treatments in 2014. TO: Control, T1: Tied ridges, T2: Straw mulch, T3: Tied ridges + straw mulch, T4: Straw mulch + EMs, T5: Tied ridges + straw mulch + EMs.

Slope and Ksat were excluded from the regression model for T0 because these two variables were highly multicollinear (tolerance near 0 ) with the other predictors. The variables excluded from the regression models for the other treatments are identified (-) in Table 3.6. 
Parameter estimates for rainfall and 130 were positive and significant $(p<0.05)$ for all treatments, except rainfall for T3. The parameter estimates for SMC were positive and significant $(p<0.05)$ for all treatments except T0 (control). Rainfall, 130, and SMC were thus positively correlated with runoff, indicating that runoff tended to increase as these predictor variables increased. The regression model for the control performed moderately but significantly $(p<0.05)$ well $\left(r^{2}=0.63\right.$, NSE=0.62) compared to the other treatments, which showed relatively better model performance $\left(r^{2}=0.77-0.83, \mathrm{NSE}=0.77-0.82\right)$. The runoff regression model for the control was less influenced by SMC, with a non-significant $(p>0.05)$ and small parameter estimate $\left(\beta_{3}=-0.02\right)$.

Runoff was generally less affected by slope, SOM, Ksat, and Ks, demonstrated by the nonsignificant $(p>0.05)$ parameter estimates in all treatments, except for Ksat in T5 and SOM in T4. These results indicate that runoff can basically be predicted using rainfall, rain intensity, and SMC at the field scale where slope and soil properties are generally less variable.

Table 3.6 Linear regression analysis for runoff $(n=54)$ and model parameter estimates for different treatments. Regression model: Runoff $=\beta_{0+} \beta_{1} R f+\beta_{2} I_{30}+\beta_{3} S M C+\beta_{4} S l+\beta_{5} K s a t+\beta_{6} K s+\beta_{7} S O M$. Data for runoff, rainfall and I30 belong to event-based measurements and SMC on a daily basis. SOM, Ksat and Ks were based on measurements after crop harvest in 2014.

\begin{tabular}{lllllll}
\hline & \multicolumn{3}{l}{ Parameter estimate $\left(\beta_{\mathrm{i}}\right)$} & & & \\
\cline { 2 - 7 } Predictor variable & T0 & T1 & T2 & T3 & T4 & T5 \\
\hline Constant, $\beta_{0}$ & 6.05 & 3.81 & $-5.75^{\mathrm{a}}$ & $-3.18^{\mathrm{a}}$ & $-8.09^{\mathrm{a}}$ & $-1.96^{\mathrm{a}}$ \\
Rainfall, $\mathrm{Rf}(\mathrm{mm}), \beta_{1}$ & $0.12^{\mathrm{a}}$ & $0.19^{\mathrm{a}}$ & $0.08^{\mathrm{a}}$ & 0.04 & $0.10^{\mathrm{a}}$ & $0.10^{\mathrm{a}}$ \\
Rain intensity, I30 (mm), $\beta_{2}$ & $0.11^{\mathrm{a}}$ & $0.05^{\mathrm{a}}$ & $0.09^{\mathrm{a}}$ & $0.09^{\mathrm{a}}$ & $0.08^{\mathrm{a}}$ & $0.06^{\mathrm{a}}$ \\
Soil-moisture content, SMC (\%), $\beta_{3}$ & -0.02 & $0.07^{\mathrm{a}}$ & $0.12^{\mathrm{a}}$ & $0.07^{\mathrm{a}}$ & $0.08^{\mathrm{a}}$ & $0.05^{\mathrm{a}}$ \\
Slope, SI (\%), $\beta_{4}$ & - & -0.62 & - & -0.76 & -1.33 & - \\
Saturated hydraulic conductivity, Ksat $\left(\mathrm{m} \mathrm{d}^{-1}\right), \beta_{5}$ & - & - & - & - & - & $-0.11^{\mathrm{a}}$ \\
Unsaturated hydraulic conductivity, Ks $\left(\mathrm{m} \mathrm{d}^{-1}\right), \beta_{6}$ & -0.76 & - & 0.17 & - & - & - \\
Soil organic-matter, SOM (g kg $\left.{ }^{-1}\right), \beta_{7}$ & -0.48 & -0.55 & 0.06 & 0.12 & $0.73^{\mathrm{a}}$ & -0.06 \\
\hline \multicolumn{1}{c}{$r^{2}$} & $0.63^{*}$ & $0.77^{*}$ & $0.83^{*}$ & $0.82^{*}$ & $0.83^{*}$ & $0.83^{*}$ \\
\hline
\end{tabular}

${ }^{a}$ Parameter estimate significant $(p<0.05),{ }^{*}$ Model fit significant $(p<0.05)$. T0: Control, T1: Tied ridges, T2: Straw mulch, T3: Tied ridges + straw mulch, T4: Straw mulch + EMs, T5: Tied ridges + straw mulch + EMs.

\subsection{Discussion}

\subsubsection{Effect of treatments on soil hydro-physical properties, runoff and soil- moisture content}

The non-significant variation of bulk density, SOM, Ksat and Ks shows the uniformity of soil physical properties in the field and less effect of the treatments on significantly 
altering these properties. Non-significant effect of straw mulch on SOM and bulk density might be attributed to the application rate or a significant effect might be revealed in the long term under successive applications. Lower values of Ks than Ksat in the plots is most probably due to a slower rate of water conductivity in unsaturated soils than saturated soil conditions (FAO, 2001).

T1 (tied ridges) reduced average runoff per event moderately well, by 65 and $46 \%$ in 2013 and 2014, respectively. Runoff was significantly lower than normal agricultural practices without treatment. This result is consistent with previous studies (Araya and Stroosnijder, 2010; McHugh et al., 2007). The very low runoff for T3 (straw mulch+ tied ridges) and T5 (straw mulch + tied ridges + EMs) in both experimental seasons demonstrated that combining mulch and tied ridges can potentially be effective in reducing runoff in farmlands. Mulch combined with various soil conservation measures such as compost, pigeon-pea hedges, and manures has produced similar results, in which runoff was reduced by $84-99 \%$ (Baptista et al., 2015b).

All treatments significantly reduced runoff in 2014 relative to the control. The higher reduction for T2 (straw mulch) and T4 (straw mulch + EMs) in the second year of the experiment demonstrated that annual additions of straw mulch may be nearly as effective as combined straw mulch and tied ridges. Runoff did not differ significantly between mulch alone and combined mulch and tied ridges. Tied ridges alone were less effective in reducing runoff compared to combined straw mulch and tied ridges. Low runoff at the beginning of the 2014 rainy season may have been due to the unsaturated state of the soil profile (Araya et al., 2011). Runoff is primarily generated when rain intensity exceeds the infiltration capacity of the soil (Beven, 2004).

The higher soil-water storage of the combined mulch and tied ridges compared to either alone was attributed to the cumulative effect of reduced runoff and evaporation and enhanced infiltration. Tied ridges can reduce runoff and enhance infiltration but are less effective in preventing the loss of water from the soil by evaporation (Mudatenguha et al., 2014). Mulching can reduce runoff and evaporation and so helps to retain water in the soil profile (Stroosnijder, 2003). Our results, however, indicated that the efficiency of mulching in retaining water was enhanced when combined with tied ridges, because the ridges were able to prolong infiltration of the water they temporarily stored. Higher SMCs were reported when various mulching systems such as gravel/sand, plastic, and groundnut crop residue were combined with ridges or furrows, compared to ridges or furrows without mulching (Ramesh and Devasenapathy, 2006; Wang et al., 2009). 
The rainfall thresholds for runoff generation were generally low for all treatments even though the threshold values slightly increased in the in-situ WHTs (Table 3.5). Our result corroborated other studies (Descheemaeker et al., 2006a; Girmay et al., 2009) in northern Ethiopia. Descheemaeker et al. (2006a) reported rainfall thresholds which range between 5 to $8 \mathrm{~mm}$ for young enclosures and $3 \mathrm{~mm}$ for grazing lands. Girmay et al. (2009) found rainfall threshold for cultivated land as low as $2 \mathrm{~mm}$. The low rainfall threshold in semiarid (including our study) areas is attributed to the lower infiltration capacity of soils in dry environments (Descheemaeker et al., 2006a). The slight increase in rainfall thresholds in the in-situ WHTs (straw mulch and tied ridges) compared to the control is most probably due to the ponding of water in tied ridges and improved infiltration capacity of the soil by straw mulch.

Our experimental design was most suitable to in-situ WHTs such as tied ridges and mulches. Other systems such as micro- and macro-catchment WHTs demand large areas and investments and hence are not convenient to study on the plot scale. The size of our plots was dictated by the availability of land to accommodate the replicates, and installation and operational cost of the experiment. Water was forced to flow across the ridge terraces by the earth bunds, whereas water might flow along the terraces under normal field conditions. The tied ridges, however, were small, so the deviation from normal conditions may have been small. Plot experiments are also not suitable for studying the effects of large WHTs such as bench terraces and check dams, because these techniques require evaluation at larger scales.

\subsubsection{Relationships amongst the hydro-meteorological and soil parameters}

High correlation and significant factor loadings of SMC and $\mathrm{Ks}$ in the principal components of the hydro-meteorological and soil parameters indicated that SMC was highly influenced by the existing Ks of the soil. This was consistent with other studies that reported a positive effect of Ks on SMC (Abrisqueta et al., 2006; Schuhmann et al., 2011). Our study found that SMC and Ksat were poorly correlated, indicating that SMC is weakly associated with Ksat when the soil is saturated.

Runoff was positively correlated with the hydro-meteorological parameters. Runoff was mainly affected by rainfall, rain intensity, and SMC and was positively correlated with slope, even though slope was slightly different in the plots. Other physical factors such as soil type and land cover can affect the amount of runoff produced from farmlands (Baptista et al., 2015b). Our regression equations indicated that slope and soil properties 
did not significantly affect runoff, because they varied little within the experimental design but should be taken into account for larger areas where variations may be larger.

The positive and significant parameter estimates of SMC for T1-T5 in the runoff regression models, unlike for T0 (control), substantiated the role of straw mulch and tied ridges, individually or combined, in controlling the amount of runoff generated in the plots. The regression models were able to estimate runoff per event with good performance using measured rainfall, rain intensity, and daily SMC for the various in-situ WHTs. In areas where runoff data are not readily available, regression models can be useful for predicting runoff using hydro-meteorological input data for different in-situ WHTs, provided that variations in field slope and soil properties are not large. In large areas, where variations in slope and soil properties are expected, runoff can also be greatly affected by slope and soil properties.

\subsection{Conclusions}

In coarse-textured soils with gentle slopes, tied ridge combined with straw mulch was the most efficient technique for in-situ water harvesting. Tied ridge combined with straw mulch significantly increased soil-moisture content in the farmlands by limiting water losses via runoff and evaporation thereby improving temporal soil-water distribution. Insitu water harvesting was substantiated during low rainfall or dry periods because of prolonged water availability for crops. An improved soil-moisture distribution over dry periods helps the resilience of crops to environmental adversities such as climate change and drought.

Regression models are provided to estimate runoff from farmlands based on available data for rainfall, rain intensity and daily soil-moisture content when field variations for slope and soil properties are minimal. Knowing the amount of runoff generated from farmlands under different in-situ water harvesting techniques helps to properly manage the available water. 


\section{Effect of in-situ water harvesting techniques on soil and nutrient losses in semi-arid northern Ethiopia}

Land degradation, mainly due to soil erosion and nutrient losses, is a global problem for sustainable agriculture. Farmlands in the Ethiopian highlands are susceptible to water erosion because of steep slopes and extensive cultivation. A field experiment was conducted in the Gule sub-watershed in northern Ethiopia to assess the efficacy of in-situ water harvesting techniques in reducing soil and nutrient losses. The research was carried out on a sandy clay loam soil under semi-arid conditions. Soil erosion and nutrient losses were monitored during the rainy season (June to September) in 2013 and 2014. Five treatments with tied ridges, wheat-straw mulch, and effective microorganisms, alone or in combination, and an untreated control were tested. Combined tied ridges and straw mulch, with and without effective micro-organisms significantly reduced average soil loss over the two rainy seasons by 82 and 90\%, respectively, compared to the control. Tied ridges alone reduced average soil loss by $60 \%$. Straw mulch with and without effective micro-organisms decreased average soil loss by 81 and 85\%, respectively. Combined tied ridges and straw mulch significantly decreased average total nitrogen and total phosphorus losses by 82 and 83\%, respectively. Average nutrient losses were also significantly decreased by tied ridges (59\% for nitrogen, 52\% for phosphorus) and straw mulch (63\% for nitrogen, 68\% for phosphorus). Our results indicated that in-situ water harvesting techniques can effectively reduce soil and nutrient losses from farmland and were more efficient when the techniques were combined.

Based on:

Grum, B., Assefa, D., Hessel, R., Woldearegay, K., Kessler, A., Ritsema, C.J., R., Geissen, V., 2016. Effect of in-situ water harvesting techniques on soil and nutrient losses in semiarid northern Ethiopia. Land Degradation and Development. DOI: 10.1002/Idr.2603. 


\subsection{Introduction}

Land degradation is considered as the main global problem preventing future sustainable agricultural production (Zougmoré et al., 2009). Accordingly, soil erosion is a serious problem due to its severe impacts on agricultural productivity, ecosystem services and environmental balances (Panagos et al., 2015). Soil loss from farmland is aggravated by inappropriate soil management and tillage practices and the absence of erosion control measures (Cerdà et al., 2009; Rodrigo Comino et al., 2015; Prosdocimi et al., 2016a).

Farmlands in the Ethiopian highlands are often located on steep slopes and are extensively cultivated; therefore they are highly susceptible to water erosion in the rainy seasons (Damene et al., 2013; Taddese, 2001; Teshome et al., 2013). Moreover, farmer's decision to invest on sustainable land management practices is highly constrained by existing land quality, land fragmentation and land tenure systems (Teshome et al., 2016). Soil loss in the Ethiopian highlands is reported to be around 1.9 billion $\mathrm{Mg} \mathrm{yr}^{-1}$ and $80 \%$ of the loss comes from cultivated areas (FAO, 1986). Land degradation, mainly by water erosion, is a primary cause of low and declining soil productivity in Ethiopia (Araya et al., 2011). Water erosion causes the removal of soil from farmland, which results in the loss of valuable plant nutrients with the eroded soil (Kraaijvanger and Veldkamp, 2015; Taddese, 2001).

Land degradation in the Tigray region of northern Ethiopia became so critical that it hampered agricultural productivity, so the government and others endeavoured to rehabilitate the land using soil and water conservation measures (Nyssen et al., 2015; Vancampenhout et al., 2006; Walraevens et al., 2015), mainly stone bunds and area exclosures (Descheemaeker et al., 2006b; Desta et al., 2005; Nyssen et al., 2007). According to Desta et al. (2005), stone bunds reduced annual soil losses from sheet and rill erosion by $68 \%$. Runoff, however, spilt over these structures because in-situ water harvesting techniques (WHTs) were rarely used in the agricultural fields (Gebreegziabher et al., 2009). A new paradigm of soil conservation and land rehabilitation by in-situ soil and water management is therefore needed (Nyssen et al., 2009b).

In-situ WHTs enhance the collection of rainwater on the surface where it falls and store it in the soil layer (Helmreich and Horn, 2009). The most widely used in-situ WHTs are tied ridges, mulching, conservation tillage and various furrow systems (Biazin et al., 2012).

Some studies in Tigray and other parts of Ethiopia have focused on the role of conservation agriculture (e.g. contour furrows, conservation tillage, terwah and derdero) in reducing soil loss from farmland (Araya et al., 2011; Gebreegziabher et al., 2009; McHugh et al., 2007). The effect of different soil management practices on soil erosion 
have also been studied in other parts of the world (Adekalu et al., 2007; Fernández and Vega, 2016; Mekonnen et al., 2015b; Mwango et al., 2015; Prosdocimi et al., 2016b). Insitu WHTs have been applied in a variety of climates and landscapes, mainly to improve on-site soil-water regimes and to reduce soil and nutrient losses in runoff (Adimassu et al., 2014; Al-Seekh and Mohammad, 2009; Okeyo et al., 2014).

The effects of combining different measures of soil management, such as crop-residue mulching with organic amendments (Baptista et al., 2015a), runoff barriers with nutrient management (Zougmoré et al., 2009) and tillage with mulching (Donjadee and Tingsanchali, 2016; Jin et al., 2008), on soil and/or associated nutrient losses have been studied. Other researchers also investigated the effect of combined use of rice-straw compost with phosphogypsum (Mahmoud and Abd El-Kader, 2015) and crushed maizestraw residue with urea (Tejada and Benítez, 2014) on improving soil chemical and biological properties. Little information, however, is available on the effect of combining in-situ WHTs such as tied ridges and straw mulch on the reduction of soil and nutrient losses from farmland. Combining different in-situ WHTs helps to reduce runoff, soil and associated nutrient losses (Baptista et al., 2015a). Integrating WHTs with nutrient management can also help to ensure higher and more sustainable agricultural productivity (Miriti et al., 2007). For example, the application of bio-fertilisers such as effective microorganisms (EMs) to the soil enhances the physical properties of the soil such as infiltration rate and water-holding capacity (Ismail, 2013).

Therefore the aims of this study were (i) to assess the effect of in-situ WHTs on soil and nutrient losses and maize yield (ii) to evaluate the efficacy of combining in-situ WHTs (straw mulch, tied ridges and EMs) for controlling soil erosion .

\subsection{Materials and methods}

\subsubsection{Description of the study area}

The study was conducted at a farmer-training centre in the Gule sub-watershed of the upper Geba catchment in northern Ethiopia $\left(13^{\circ} 52^{\prime} 49^{\prime \prime} \mathrm{N}, 39^{\circ} 28^{\prime} 59^{\prime \prime} \mathrm{E}\right.$; Figure 4.1). The subwatershed has a rugged topography with mountains and flat valley floors and with altitudes ranging between 2008 and $2408 \mathrm{~m}$ a.s.l. It has a semi-arid climate, with two major seasons, a rainy and a dry season. The rainy season is often from June to September, and the dry season is from October to May (Nyssen et al., 2010). Rainfall measurements of three successive years (2013-2015) using a meteorological station that was installed for the purpose of this study showed an average annual rainfall of $465 \mathrm{~mm}$. 
The temperature is relatively constant throughout the year. Average daily temperature ranges between 15 and $25^{\circ} \mathrm{C}$, with a mean of $20^{\circ} \mathrm{C}$. The study area was selected based on a set of criteria established during a stakeholders' workshop for selecting WHTs (Grum et al., 2016). The experimental site was on the flat valley floor of the sub-watershed at a mean altitude of $2050 \mathrm{~m}$ a.s.l. The site had a total area of $1750 \mathrm{~m}^{2}$, and slopes ranged between 1.8 and $3.4 \%$. The experiment was conducted on a Eutric Cambisols soil type (IUSS Working Group WRB, 2015) with a sandy clay loam texture.
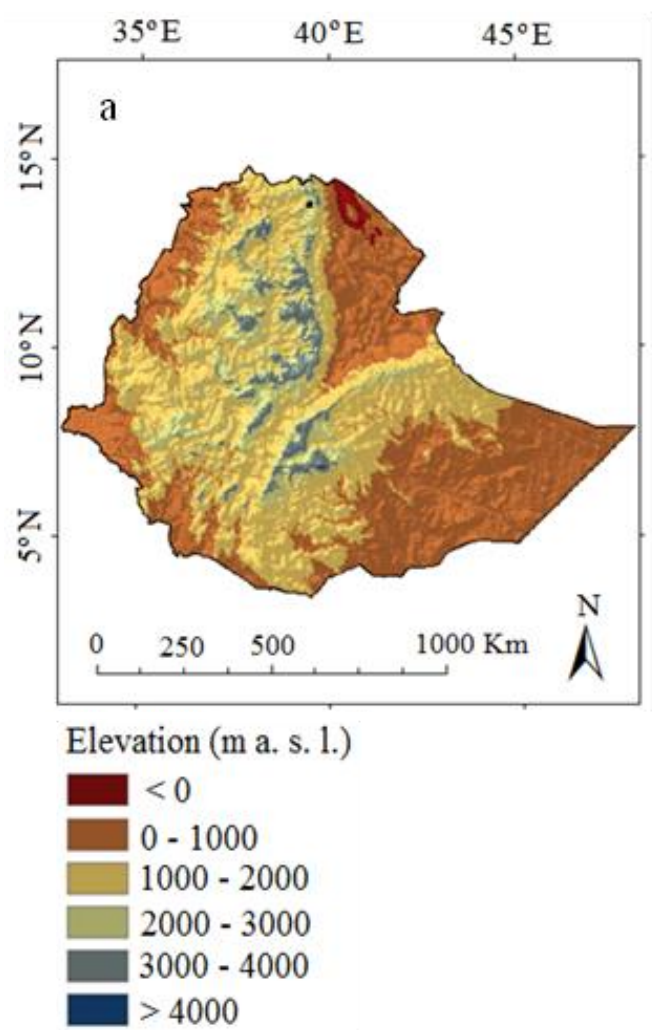

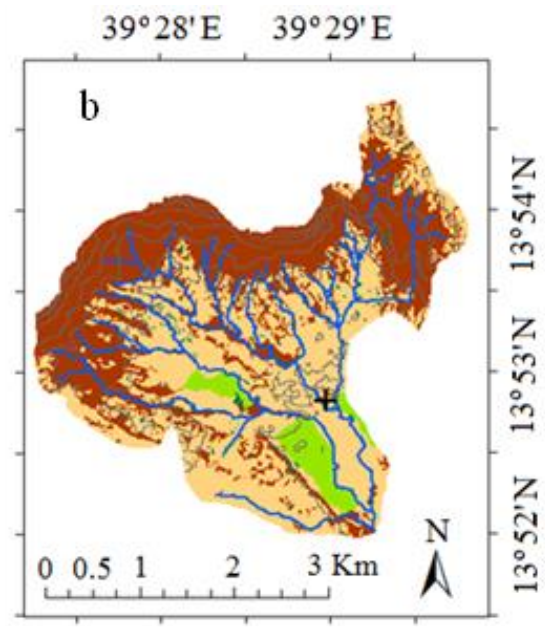

Land use/cover

$\square$ Cultivated land (48\%)
Grass land ( $5 \%)$
Shrub land (46\%)
Wood land (1\%)
- Ephemeral streams
+ Contour (I. $50 \mathrm{~m})$
+ Experimental site

Figure 4.1 Location of the study area. (a) Topography of Ethiopia. (b) Land use of the Gule sub-watershed and location of the experimental site.

Table 4.1 Description of the treatments in the field experiment.

\begin{tabular}{ll}
\hline Treatment & Description \\
\hline T0 (control) & Basal fertilisation $^{\text {a }}$ \\
T1 & Basal fertilization + tied ridges \\
T2 & Basal fertilization + straw mulch $\left(15 \mathrm{Mg} \mathrm{ha}^{-1}\right)$ \\
T3 & Basal fertilization + straw mulch $\left(15 \mathrm{Mg} \mathrm{ha}^{-1}\right)$ and tied ridges \\
T4 & Basal fertilization + straw mulch $\left(15 \mathrm{Mg} \mathrm{ha}^{-1}\right)$ and $4 \mathrm{~L} \mathrm{ha}^{-1}$ of EMs \\
T5 & Basal fertilization + straw mulch $\left(15 \mathrm{Mg} \mathrm{ha}^{-1}\right)$, tied ridges, and $4 \mathrm{~L} \mathrm{ha}^{-1}$ of EMs \\
\hline${ }^{\mathrm{a}}$ Basal fertilization: & 100 kg ha ${ }^{-1}$ urea $(46 \% \mathrm{~N})$ and $100 \mathrm{~kg} \mathrm{ha}^{-1}$ diammonium phosphate $(18 \% \mathrm{~N}, 46 \% \mathrm{P})$ applied to the \\
\multicolumn{2}{c}{ entire field experiment. EMs: effective micro-organisms. }
\end{tabular}




\subsubsection{Experimental design}

The experiment was carried out for two successive rainy seasons (June to September) in 2013 and 2014. The experiment had a completely randomized block design consisting of five treatments and a control. The treatments were selected by stakeholders in a participatory WHT selection workshop (Grum et al., 2016). Each treatment had three replicates with plot size of $3 \times 15 \mathrm{~m}$, for a total of 18 plots (Figure 4.2). The treatments and the application of measures are described in Table 4.1.

The experimental field was ploughed twice by oxen-driven maresha a month and a week before sowing. The experimental plots were then established by hand. Each plot was isolated by earth bunds $50 \mathrm{~cm}$ wide and $40 \mathrm{~cm}$ high to prevent the flow of water from neighbouring plots and to provide access to the plots during inspection.

A basal fertiliser was applied to the entire field (all plots) at rates of $64 \mathrm{~kg} \mathrm{ha}^{-1}$ nitrogen (N) and $46 \mathrm{~kg} \mathrm{ha}^{-1}$ phosphorus (P) in the form of inorganic fertilisers (urea and diammonium phosphate). These rates of fertilisation are blanket recommendations and commonly applied rates in the region (Araya and Stroosnijder, 2010). Wheat-straw mulch was applied for T2-T5 at a rate of $15 \mathrm{Mg} \mathrm{ha}{ }^{-1}$. Wheat straw (Triticum aestivum L.), typically used for feedstocks, consists of cellulose (35\%), hemicellulose (25\%) and lignin (19\%) (Windeatt et al., 2014). Wheat straw contains $0.6 \% \mathrm{~N}$ (Nicholson et al., 1997; Smil, 1999) and 0.1\% P (Smil, 1999). The nutrient inputs from the straw mulch for T2-T5 were thus $90 \mathrm{~kg} \mathrm{~N} \mathrm{ha-1}$ and $15 \mathrm{~kg} \mathrm{P} \mathrm{ha}^{-1}$.

The crop used in the experiment was maize (Zea mays L.). Maize seeds were planted in each plot in rows with $30 \mathrm{~cm}$ between plants and $60 \mathrm{~cm}$ between rows in plots without tied ridges and $70 \mathrm{~cm}$ between rows in plots with ridges. Tied ridges for T1, T3, and T5 were established after maize had fully germinated and emerged. The ridges were $20 \mathrm{~cm}$ high, $3 \mathrm{~m}$ long, and $1.9 \mathrm{~m}$ apart and were tied in the middle. Each plot with tied ridges therefore had seven tied ridges in the rows (Figure 4.2). All plots were manually hoed and weeds were removed one and two months after planting. Dry wheat-straw mulch was spread onto the soil surface in T2-T5 at a rate of $15 \mathrm{Mg} \mathrm{ha}^{-1}$ after the maize had fully germinated and emerged. A diluted solution (1:500) of activated EMs (EMRO, Okinawa, Japan) was also sprayed onto the soil surface in T4 and T5. The EMs consisted of a selected group of micro-organisms, predominantly lactic acid bacteria, yeast, and phototrophic bacteria. The activated EMs were prepared one week before sowing at a ratio of 2:96:2 of molasses, rainwater and inactivated EMs, respectively. The EMs were applied twice, at sowing and mid of the growing season (early August), at a rate of $4 \mathrm{Lha}^{-1}$. 

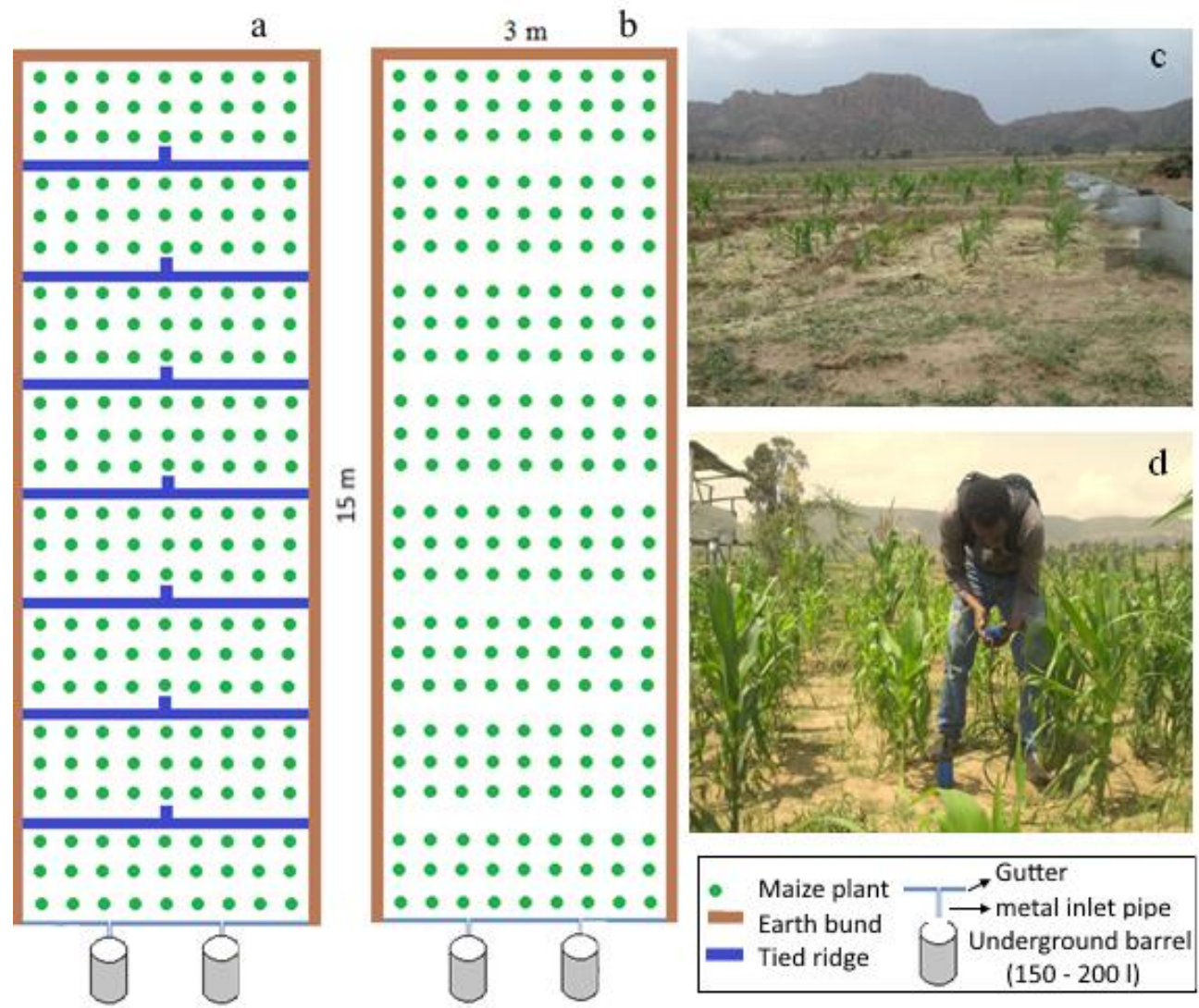

Figure 4.2 Layout of the experimental runoff plots. (a) Experiment plots with tied ridges (T1, T3 and T5). (b) Experiment plots without tied ridges (TO, T2 and T4). (c) Photograph of the field layout with treatments. (d) Soil-moisture measurement by using Trime-PICO64 soil-moisture sensor.

Eroded soil exported with the runoff after each rain was collected in 300-400 L subsurface barrels buried at the end of each plot. The exported soil with runoff was channelled from the plots by a corrugated iron gutter placed directly above the barrels and was then directed into the barrels by a metal inlet pipe (Figure 4.2).

\subsubsection{Data collection and measurements}

Composite soil samples were collected to a depth of $20 \mathrm{~cm}$ before the beginning of the rainy season in 2013 and 2014 for characterising the physical and chemical properties (Table 4.2). Soil samples were also collected using ergonomic hand auger (Eijkelkamp, Giesbeek, Netherlands) from three sampling points in each plot at the end of the 
experimental period to depths of 20 and $40 \mathrm{~cm}$ for the analysis of $\mathrm{pH}$, soil organic carbon (SOC) content, and nutrient ( $\mathrm{N}$ and $\mathrm{P}$ ) contents.

Table 4.2 Selected initial soil properties at the experimental site.

\begin{tabular}{ll}
\hline Properties & Mean \pm SD \\
\hline Soil texture & - \\
$0.063-2 \mathrm{~mm}$, sand (\%) & $64.6 \pm 4.7$ \\
$0.002-0.063 \mathrm{~mm}$, silt (\%) & $12.6 \pm 3.5$ \\
$<0.002 \mathrm{~mm}$, clay (\%) & $22.8 \pm 1.9$ \\
Bulk density $\left(\mathrm{g} \mathrm{cm}^{-3}\right)$ & $1.6 \pm 0.0$ \\
$\mathrm{pH}\left(\mathrm{H}_{2} \mathrm{O}\right)$ & $6.8 \pm 0.2$ \\
Soil organic carbon $\left(\mathrm{g} \mathrm{kg}^{-1}\right)$ & $4.7 \pm 1.9$ \\
Total nitrogen $\left(\mathrm{mg} \mathrm{kg}^{-1}\right)$ & $4.4 \pm 2.0$ \\
Available phosphorus $\left(\mathrm{mg} \mathrm{kg}^{-1}\right)$ & $8.2 \pm 2.1$ \\
\hline
\end{tabular}

Soil texture was determined by the hydrometer method, bulk density by the core method (Blake and Hartge, 1986), and $\mathrm{pH}$ by potentiometry. SOC content was analysed by the Walkley Black method (Nelson and Sommers, 1982), total N (TN) content by the Kjeldahl method (Jackson, 1958), total P (TP) and available-P content by the Olsen method (Olsen and Sommers, 1982).

Rainfall was measured using tipping-bucket data-logging RG3-M HOBO (precision: $0.2 \mathrm{~mm}$ per tip) rain gauge (Onset, Bourne, MA, USA) installed at the site. Soil-moisture content (SMC) was monitored daily using a Trime-PICO64 (time-domain reflectometer or TDR method) soil-moisture sensor (Eijkelkamp, Giesbeek, Netherlands) to a depth of $15 \mathrm{~cm}$ at six sampling points in each plot in 2013 and 2014.

Runoff volume per plot was measured after each rain event. An aliquot of $1 \mathrm{~L}$ was collected from each barrel after thoroughly stirring the collected runoff. The aliquot was used to analyse sediment concentration, soil and nutrient losses in the eroded soil in 2013 and 2014. Each water sample was first filtered through a Whatman Grade 42 filter paper by gravity, and the sediment residue on the filter paper was then dried at room temperature. The dried residue was weighed to determine the sediment concentration in the runoff, and the total amount of eroded soil per plot. The loss of nutrients ( $N$ and $P$ ), was determined from only five of the runoff events distributed over each experimental year due to the expense of the analyses.

\subsubsection{Data analysis}

Statistical analysis was performed using SPSS 22 (IBM Corporation, New York, USA). Normally distributed data were analysed using a least squares one-way analysis of 
variance. The data that were not normally distributed were analysed using non-parametric tests for statistical differences. Significant difference between treatments for a measured variable was tested using the pairwise Mann-Whitney U-test. All statistical tests were considered significant at a probability value of $0.05(p<0.05)$.

The fraction of exported nutrients in eroded soils per runoff event for each treatment was calculated by:

Fraction of nutrient loss $(\%)=\frac{\text { Nutrient loss in eroded soil }}{\text { Nutrient input }} \times 100$

Soil/nutrient loss reduction per runoff event of a treatment relative to the control was calculated by:

$R(\%)=\frac{o_{c}-o_{t}}{o_{c}} \times 100$

where $R$ is the reduction in soil/nutrient loss by a treatment relative to the control (\%), $O_{c}$ is the measured soil $\left(\mathrm{kg} \mathrm{ha}^{-1}\right)$ or nutrient $\left(\mathrm{g} \mathrm{ha}^{-1}\right)$ loss in the control, and $O_{t}$ is the measured soil $\left(\mathrm{kg} \mathrm{ha}^{-1}\right)$ or nutrient $\left(\mathrm{g} \mathrm{ha}^{-1}\right)$ loss in a treatment.

Principal component analysis (PCA) was carried out to identify the factors affecting the soil and nutrient losses using averaged data per treatment and the control for 2013 and 2014 $(n=36)$. The PCA tested seven variables: runoff, soil loss, TN loss, TP loss, SMC, bulk density, and plot slope. Correlations between variables were analysed using Spearman's rank correlation at a significance level of $0.01 \quad(p<0.01)$. Regression analyses were performed between soil loss and runoff and between nutrient loss and soil loss. The regression analyses were carried out separately for the control (TO) and the in-situ WHTs (T1-T5).

\subsection{Results}

\subsubsection{Effect of the treatments on soil and associated nutrient losses}

The effects of treatments on runoff, soil and nutrients losses are summarized in Table 4.3. Runoff was significantly lower in T1-T5 than T0. Median runoff was lowest and highest in T3 $(0.6 \mathrm{~mm})$ and T0 $(4.7 \mathrm{~mm})$, respectively. 
Soil loss per event was significantly lower in all WHTs than the control. Median soil loss was highest in T0 at $90.6 \mathrm{~kg} \mathrm{ha}^{-1}$ and lowest in T3 at $8.3 \mathrm{~kg} \mathrm{ha}^{-1}$. Median soil loss was significantly higher (36.4 $\mathrm{kg} \mathrm{ha}^{-1}$ ) in T1 than T2-T5. Median soil loss per event for the various treatments was in the order $\mathrm{T} 0>\mathrm{T} 1>\mathrm{T} 2=\mathrm{T} 3=\mathrm{T} 4=\mathrm{T} 5$. Seasonal soil loss was also significantly higher in the control than the WHTs and was significantly lower in T2-T5 than T0 and T1.

Table 4.3 Average runoff and soil, total $N$, and total $P$ losses per event over two seasons (2013 and 2014).

\begin{tabular}{|c|c|c|c|c|c|}
\hline & $\begin{array}{l}\text { Runoff } \\
\text { (mm) }\end{array}$ & $\begin{array}{l}\text { Soil loss } \\
\left(\mathrm{kg} \mathrm{ha}^{-1}\right)\end{array}$ & $\begin{array}{l}\text { Seasonal soil } \\
\text { loss }\left(\mathrm{Mg} \mathrm{ha}^{-1}{ }^{*}\right.\end{array}$ & $\begin{array}{l}\text { Total N loss } \\
\left(\mathrm{g} \mathrm{ha}^{-1}\right)\end{array}$ & $\begin{array}{l}\text { Total P loss } \\
\left(\mathrm{g} \mathrm{ha}^{-1}\right)\end{array}$ \\
\hline $\begin{array}{l}\text { Treat- } \\
\text { ment }\end{array}$ & $\begin{array}{l}\text { Median } \\
(\min , \max ) \\
(n=84)\end{array}$ & $\begin{array}{l}\text { Median } \\
(\min , \max ) \\
(n=84)\end{array}$ & $\begin{array}{l}\text { Median } \\
(\min , \max ) \\
(n=3)\end{array}$ & $\begin{array}{l}\text { Median } \\
(\min , \max ) \\
(n=30)\end{array}$ & $\begin{array}{l}\text { Median } \\
(\min , \max ) \\
(n=30)\end{array}$ \\
\hline T0 & $\begin{array}{l}4.7 \\
(0.3,11.2) d\end{array}$ & $\begin{array}{l}90.6 \\
(2.3,865.1) c\end{array}$ & $\begin{array}{l}4.3 \\
(3.6,4.7) d\end{array}$ & $\begin{array}{l}364.1 \\
(36.2,1731.3) c\end{array}$ & $\begin{array}{l}259.2 \\
(14.2,746.9) \mathrm{c}\end{array}$ \\
\hline $\mathrm{T} 1$ & $\begin{array}{l}2.0 \\
(0.2,9.2) \mathrm{c}\end{array}$ & $\begin{array}{l}36.4 \\
(2.0,529.8) b\end{array}$ & $\begin{array}{l}2.1 \\
(1.7,2.2) \mathrm{c}\end{array}$ & $\begin{array}{l}134.3 \\
(8.4,996.2) b\end{array}$ & $\begin{array}{l}96.7 \\
(3.1,393.1) b\end{array}$ \\
\hline $\mathrm{T} 2$ & $\begin{array}{l}0.9 \\
(0.2,8.9) b\end{array}$ & $\begin{array}{l}16.8 \\
(0.7,373.6) a\end{array}$ & $\begin{array}{l}1.0 \\
(0.5,1.3) a b\end{array}$ & $\begin{array}{l}154.7 \\
(5.3,977.9) b\end{array}$ & $\begin{array}{l}95.1 \\
(1.8,313.0) b\end{array}$ \\
\hline T3 & $\begin{array}{l}0.6 \\
(0.1,8.8) a\end{array}$ & $\begin{array}{l}8.3 \\
(0.5,306.4) a\end{array}$ & $\begin{array}{l}0.8 \\
(0.7,0.9) a\end{array}$ & $\begin{array}{l}42.6 \\
(1.3,1019.5) a\end{array}$ & $\begin{array}{l}20.0 \\
(1.0,301.2) \mathrm{a}\end{array}$ \\
\hline $\mathrm{T} 4$ & $\begin{array}{l}1.0 \\
(0.2,8.8) b\end{array}$ & $\begin{array}{l}10.9 \\
(0.8,437.5) a\end{array}$ & $\begin{array}{l}1.3 \\
(1.2,1.4) b\end{array}$ & $\begin{array}{l}208.9 \\
(1.9,1230.8) b\end{array}$ & $\begin{array}{l}104.6 \\
(0.9,399.6) b\end{array}$ \\
\hline T5 & $\begin{array}{l}0.9 \\
(0.1,8.6) b\end{array}$ & $\begin{array}{l}11.7 \\
(0.4,388.1) a\end{array}$ & $\begin{array}{l}0.8 \\
(0.8,1.4) a b\end{array}$ & $\begin{array}{l}98.8 \\
(0.8,613.2) a b\end{array}$ & $\begin{array}{l}62.8 \\
(0.3,451.4) a b\end{array}$ \\
\hline
\end{tabular}

Different letters show significant (Mann-Whitney U-test, $p<0.05$ ) difference between treatments, $\mathrm{a}<\mathrm{b}<\mathrm{c}<\mathrm{d}$.

${ }^{*}$ Seasonal soil loss was computed from runoff events in 2014. T0: Control, T1: Tied ridges, T2: Straw mulch, T3: Tied ridges + straw mulch, T4: Straw mulch + EMs, T5: Tied ridges + straw mulch + EMs.

The WHTs had significant effects on TN and TP losses in the sediments. The TN and TP losses were the highest in the control, with medians of 364.1 and $259.2 \mathrm{~g} \mathrm{ha}^{-1}$, respectively. Nutrient losses were significantly lower in all WHTs than the control. Nutrient losses were lowest in T3 but did not differ significantly from the losses in T5. Nutrient losses in the sediments were generally higher for $\mathrm{N}$ than $\mathrm{P}$. Nutrient losses were generally higher in the treatments with EMs (T4 and T5) than in the corresponding treatments without EMs (T2 and T3). The event-based statistical analysis (Figure 4.3) showed no significant differences in nutrient losses between the treatments with and without EMs.

T3 (90\%) and T1 (60\%) decreased soil losses the most and least, respectively (Table 4.4). The efficiencies of reductions in nutrient losses for the treatments ranged between 56 and $84 \%$ for TN and between 52 and $86 \%$ for TP. T3 decreased the loss of both TN and TP the 
most, by 84 and $86 \%$, respectively, and T1 and T4 decreased the loss of both TP and TN the least, by 52 and $56 \%$, respectively.
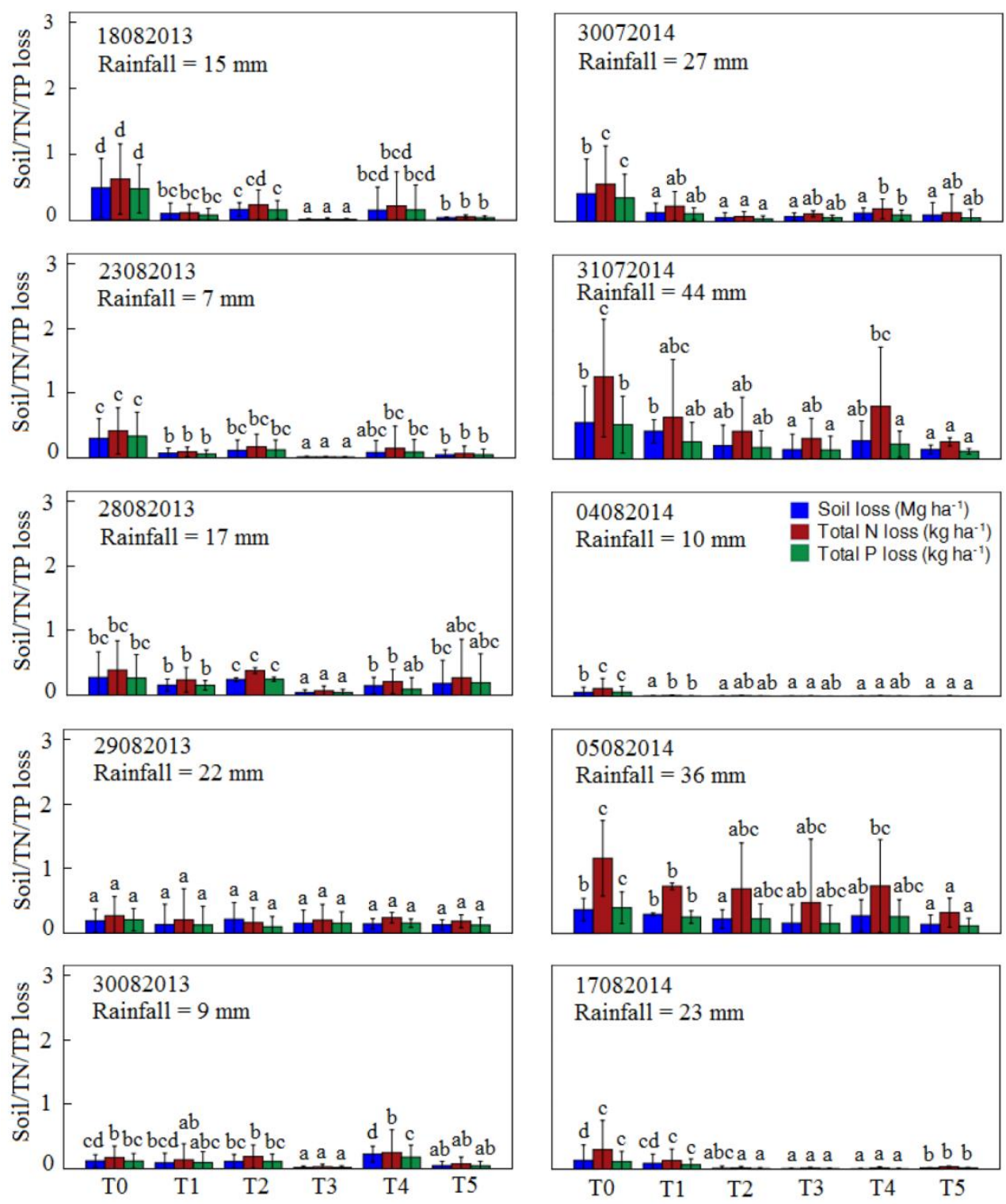

Figure 4.3 Soil, total $N$ and total $P$ losses per event for different treatments $(n=3)$. Different letters show significant (Mann-Whitney U-test, $p<0.05$ ) difference between treatments, $a<b<c<d$. Error bars are standard deviations. T0: Control, T1: Tied ridges, T2: Straw mulch, T3: Tied ridges + straw mulch, T4: Straw mulch + EMs, T5: Tied ridges + straw mulch + EMs. 
Table 4.4 Efficiencies of reduction in runoff, and soil, total $N$ and total $P$ losses compared to control over two seasons (2013 and 2014).

\begin{tabular}{lllll}
\hline & Runoff reduction (\%) & $\begin{array}{l}\text { Soil loss } \\
\text { reduction }(\%)\end{array}$ & $\begin{array}{l}\text { Total } \mathbf{N} \text { loss } \\
\text { reduction }(\%)\end{array}$ & $\begin{array}{l}\text { Total P loss } \\
\text { reduction (\%) }\end{array}$ \\
\cline { 2 - 5 } Treatment & $\begin{array}{l}\text { Median (min, max) } \\
(\boldsymbol{n}=\mathbf{8 4})\end{array}$ & $\begin{array}{l}\text { Median }(\min , \max ) \\
(\boldsymbol{n}=\mathbf{8 4})\end{array}$ & $\begin{array}{l}\text { Median (min, max) } \\
(\boldsymbol{n}=\mathbf{3 0})\end{array}$ & $\begin{array}{l}\text { Median (min, max) } \\
(\boldsymbol{n}=\mathbf{3 0})\end{array}$ \\
\hline T0 & $0(0,0)$ & $0(0,0)$ & $0(0,0)$ & $0(0,0)$ \\
T1 & $49(-29,93)$ & $60(-32,94)$ & $59(-30,95)$ & $52(-14,96)$ \\
T2 & $80(-17,96)$ & $85(-53,98)$ & $70(-55,98)$ & $73(-45,98)$ \\
T3 & $85(0,99)$ & $90(-24,99)$ & $84(-49,100)$ & $86(-11,100)$ \\
T4 & $77(-19,96)$ & $81(-50,99)$ & $56(-21,99)$ & $63(-45,99)$ \\
T5 & $79(-32,98)$ & $82(-32,99)$ & $80(2,98)$ & $80(3,98)$ \\
\hline
\end{tabular}

T0: Control, T1: Tied ridges, T2: Straw mulch, T3: Tied ridges + straw mulch, T4: Straw mulch + EMs, T5: Tied ridges + straw mulch + EMs.

The fractions of nutrients exported with eroded soil compared to inputs (basal fertilisation and straw mulch) during the growing season in 2014 were low in T2-T5 (Table 4.5). The fractions, however, were significantly higher in T1 (tied ridges) and T0. In T0, 14.3 and 9.3\% of the $N$ and $P$ inputs respectively, were exported with the eroded soil. The fractions of $\mathrm{N}$ and $\mathrm{P}$ exported with the eroded soil for $\mathrm{T} 1$ were 5.8 and $3.6 \%$, respectively. The fractions of exported nutrients were significantly lower in T1-T5 than T0. The fractions of exported nutrients were significantly higher in T4 than the other treatments, even though T2-T5, received the same inputs.

Table 4.5 Nutrient inputs ( $N$ and $P$ ) and fractions of exported nutrients in eroded soils (median (min, max)) relative to the inputs in $2014(n=3)$.

\begin{tabular}{|c|c|c|c|c|}
\hline \multirow[b]{2}{*}{ Treatment } & \multicolumn{2}{|l|}{ Nutrient inputs } & \multicolumn{2}{|c|}{ Fractions of $\mathrm{N}$ and $\mathrm{P}$ losses } \\
\hline & Total N (kg ha $\left.{ }^{-1}\right)$ & Total P $\left(\mathrm{kg} \mathrm{ha}^{-1}\right)$ & Total N (\%) & Total P (\%) \\
\hline TO & 64 & 46 & $14.3(13.7,16.1) \mathrm{d}$ & $9.3(7.5,9.9) d$ \\
\hline T1 & 64 & 46 & $5.8(4.0,8.1) \mathrm{c}$ & $3.6(2.9,4.5) \mathrm{c}$ \\
\hline $\mathrm{T} 2$ & 154 & 61 & $1.4(0.7,1.7) \mathrm{a}$ & $1.5(0.7,1.6) \mathrm{a}$ \\
\hline T3 & 154 & 61 & $1.1(1.1,1.4) \mathrm{a}$ & $1.3(1.2,1.3) \mathrm{a}$ \\
\hline T4 & 154 & 61 & $1.9(1.8,2.1) b$ & $1.9(1.7,2.2) b$ \\
\hline T5 & 154 & 61 & $1.2(0.9,1.6) \mathrm{a}$ & $1.1(1.0,1.7) \mathrm{a}$ \\
\hline
\end{tabular}

Different letters show significance (Mann-Whitney U-test, $p<0.05)$ difference between treatments, $\mathrm{a}<\mathrm{b}<\mathrm{c}<\mathrm{d}$. T0: Control, T1: Tied ridges, T2: Straw mulch, T3: Tied ridges + straw mulch, T4: Straw mulch + EMs, T5: Tied ridges + straw mulch + EMs.

\subsubsection{Effect of the treatments on sediment and nutrient concentrations}

Sediment concentrations were significantly $(p<0.05)$ lower in T2-T5 than T0 (Table 4.6). Sediment concentration in T1 did not differ significantly from those in the other treatments (T2-T5) or T0. The concentrations varied little amongst T1-T5 but were highest and lowest in T0 and T4 at 2.39 and $1.20 \mathrm{~g} \mathrm{~L}^{-1}$, respectively. Sediment concentrations in 
the runoff for all treatments were higher at the beginning of the rainy season and decreased towards the end (Figure 4.4).

Table 4.6 Average sediment, total $N$ and total $P$ concentrations over two seasons (2013 and 2014).

\begin{tabular}{|c|c|c|c|}
\hline & $\begin{array}{l}\text { Sediment } \\
\text { concentration }\left(\mathrm{g} \mathrm{L}^{-1}\right)\end{array}$ & $\begin{array}{l}\text { Total } \mathrm{N} \\
\text { concentration }\left(\mathrm{g} \mathrm{kg}^{-1}\right)\end{array}$ & $\begin{array}{l}\text { Total } P \\
\text { concentration }\left(\mathrm{g} \mathrm{kg}^{-1}\right)\end{array}$ \\
\hline Treatment & $\begin{array}{l}\text { Median (min, max) } \\
(n=84)\end{array}$ & $\begin{array}{l}\text { Median (min, max) } \\
(n=30)\end{array}$ & $\begin{array}{l}\text { Median (min, max) } \\
(n=30)\end{array}$ \\
\hline T0 & $2.39(0.10,30.40) b$ & $1.53(1.03,3.27) \mathrm{a}$ & $1.01(0.76,1.22) b$ \\
\hline $\mathrm{T} 1$ & $1.74(0.16,22.07) a b$ & $1.56(0.36,2.79) \mathrm{a}$ & $0.91(0.25,1.18) \mathrm{a}$ \\
\hline $\mathrm{T} 2$ & $1.45(0.10,25.36) \mathrm{a}$ & $1.63(0.21,3.79)$ a & $0.95(0.06,1.37) a b$ \\
\hline T3 & $1.34(0.10,39.86) \mathrm{a}$ & $1.67(0.73,3.51) \mathrm{a}$ & $0.94(0.64,1.42) a b$ \\
\hline T4 & $1.20(0.17,23.63) \mathrm{a}$ & $1.65(0.41,3.15)$ a & $0.95(0.05,1.24) a b$ \\
\hline T5 & $1.26(0.16,27.72) \mathrm{a}$ & $1.52(0.89,3.26)$ a & $0.86(0.19,1.18) \mathrm{a}$ \\
\hline
\end{tabular}

Different letters show significant (Mann-Whitney U-test, $p<0.05)$ differences between treatments, $\mathrm{a}<\mathrm{b}$. T0: Control, T1:

Tied ridges, T2: Straw mulch, T3: Tied ridges + straw mulch, T4: Straw mulch + EMs, T5: Tied ridges + straw mulch + EMs.

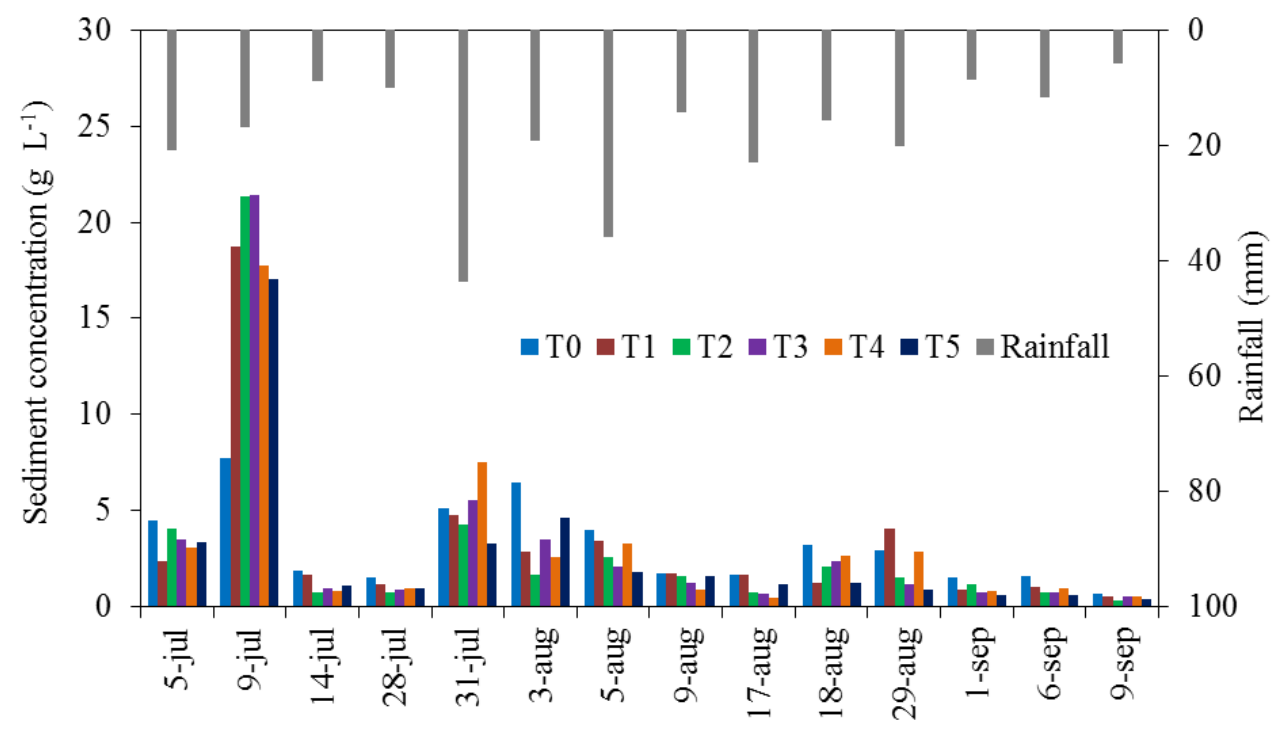

Figure 4.4 Sediment concentrations in runoff for different treatments and rain events in 2014. T0: Control, T1: Tied ridges, T2: Straw mulch, T3: Tied ridges + straw mulch, T4: Straw mulch + EMs, T5: Tied ridges + straw mulch + EMs.

Nutrient concentrations in the sediments were generally less variable amongst the treatments than the sediment concentrations (Table 4.6). P concentrations were significantly lower than in the control only in T1 and T5. The treatments did not significantly affect the $\mathrm{N}$ concentrations in the sediments. $\mathrm{N}$ concentrations were generally higher than $\mathrm{P}$ concentrations in the sediments. 


\subsubsection{Effects of the treatments on maize grain yield and biomass}

The treatments had significant $(p<0.05)$ effects on maize grain yield and biomass but not on plant height (Table 4.7). Grain yield was significantly higher in T2 and T4 than TO. The yields were highest and lowest in T4 and T0 at 3.13 and $2.55 \mathrm{Mg} \mathrm{ha}^{-1}$, respectively. T2 and T4 increased maize grain yield by 20 and $23 \%$, respectively, compared to the control. Grain yield was not significantly higher in T1, T3, and T5 than T0. Biomass was also significantly higher in T2 and T4 than T0. Biomass in T2 and T4 was 13.64 and $13.13 \mathrm{Mg} \mathrm{ha}{ }^{-1}$, respectively. Biomass was lowest in the control at $10.70 \mathrm{Mg} \mathrm{ha}^{-1}$ but was not significantly higher in T1, T3, or T5. Plant height did not differ significantly amongst the treatments. The plants were smallest and tallest in T3 and T5 at 154.4 and $166.5 \mathrm{~cm}$, respectively. In the treatments with tied ridges, there were signs of aeration stresses in the early stages of plant growth in late July 2013 and early August 2014. In these periods, the intensity of rain was relatively higher than the other periods.

Table 4.7 Maize grain yield, biomass, and plant height (Mean \pm SD) over two years in 2013 and 2014 (n=6).

\begin{tabular}{llll}
\hline Treatment & Grain yield $\left(\mathbf{M g ~ h a}^{-1}\right)$ & Biomass $\left(\mathbf{M g ~ h a} \mathbf{~}^{-1}\right)$ & Plant height $(\mathbf{c m})$ \\
\hline T0 & $2.55 \pm 0.31 \mathrm{a}$ & $10.70 \pm 1.50 \mathrm{a}$ & $159.2 \pm 8.1 \mathrm{a}$ \\
T1 & $2.79 \pm 0.41 \mathrm{abc}$ & $11.44 \pm 1.45 \mathrm{ab}$ & $156.1 \pm 13.0 \mathrm{a}$ \\
T2 & $3.06 \pm 0.40 \mathrm{bc}$ & $13.64 \pm 1.30 \mathrm{c}$ & $158.3 \pm 11.7 \mathrm{a}$ \\
T3 & $2.61 \pm 0.35 \mathrm{ab}$ & $12.58 \pm 1.76 \mathrm{abc}$ & $154.4 \pm 7.2 \mathrm{a}$ \\
T4 & $3.13 \pm 0.49 \mathrm{c}$ & $13.13 \pm 1.79 \mathrm{bc}$ & $155.2 \pm 9.9 \mathrm{a}$ \\
T5 & $2.65 \pm 0.46 \mathrm{ab}$ & $12.42 \pm 2.08 \mathrm{abc}$ & $166.5 \pm 13.2 \mathrm{a}$ \\
\hline
\end{tabular}

Different letters show significance $(p<0.05)$ difference between treatments, $a<b<c$.

T0: Control, T1: Tied ridges, T2: Straw mulch, T3: Tied ridges + straw mulch, T4: Straw mulch + EMs, T5: Tied ridges + straw mulch + EMs.

\subsubsection{Relationships amongst runoff, soil loss, nutrient loss, SMC, slope and bulk density}

The PCA identified two components that together explained $69.5 \%$ of the variance of the data (Figure 4.5). The variance was mainly described by PC1, which accounted for $52.2 \%$ of the total variation and was strongly associated with runoff, soil loss, and $\mathrm{N}$ and $\mathrm{P}$ losses, with factor loadings of $0.94,0.93,0.88$, and 0.97 , respectively. The high and positive factor loadings of the variables in PC1 were also complemented by strong and significant correlations $(p<0.01)$ between these variables (Table 4.8 ). PC2 explained $17.3 \%$ of the total variance and was correlated strongly with SMC and moderately with slope, with factor loadings of 0.90 and -0.47 , respectively. 


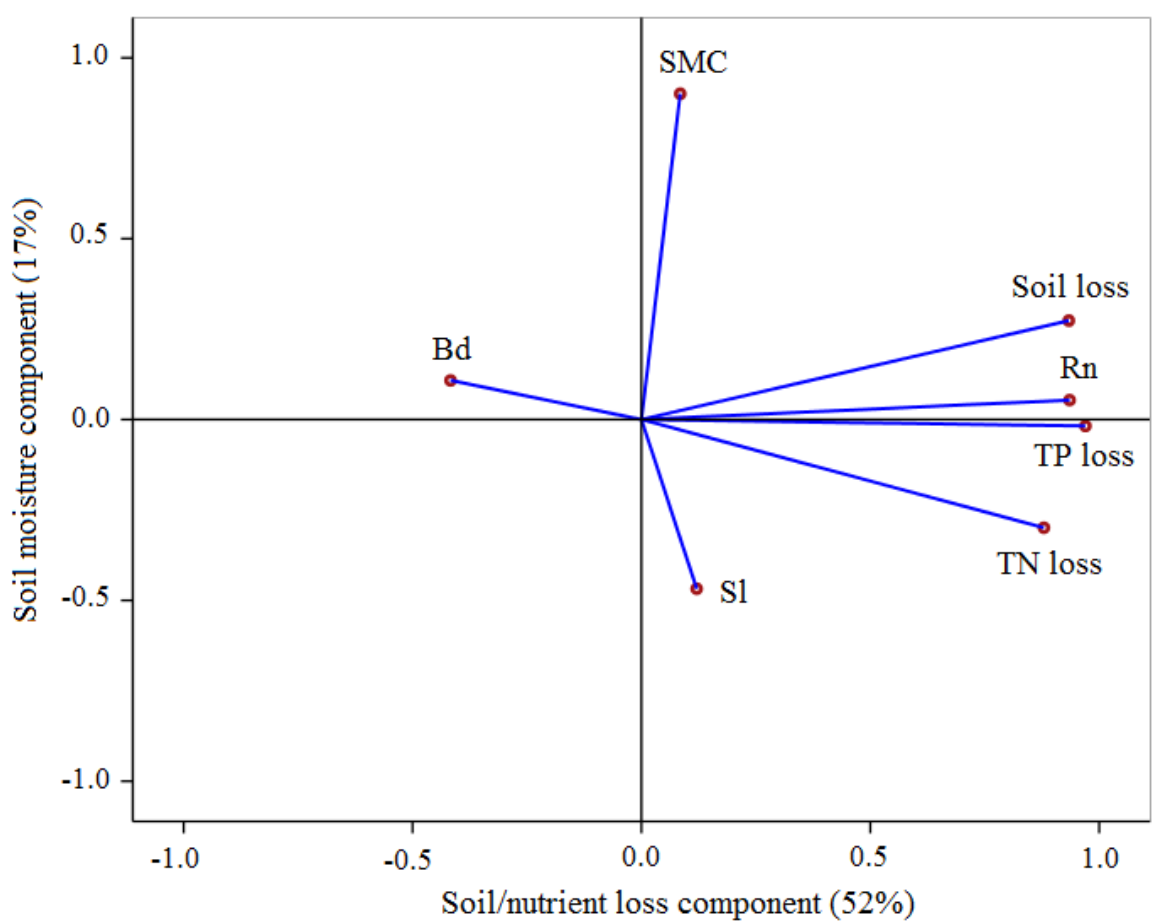

Figure 4.5 Principal component analysis of runoff (Rn), soil-moisture content (SMC), soil loss, total $N(T N)$ loss, total $P(T P)$ loss, slope (SI) and bulk density (Bd), based on average seasonal data $(n=36)$ in 2013 and 2014.

Table 4.8 Regression equations for estimating soil $\left(\mathrm{kg} \mathrm{ha}^{-1}\right)$, total $N\left(g \mathrm{ha}^{-1}\right)$, and total $P\left(g\right.$ ha $\left.{ }^{-1}\right)$ losses in the control (TO) and in-situ WHTs (T1-T5).

\begin{tabular}{|c|c|}
\hline Control (T0) & In-situ WHTs (T1-T5) \\
\hline $\begin{array}{l}\text { Log soil loss }=1.25 \times \log \text { runoff }+1.17 \\
\left(r^{2}=0.52, n=84, p<0.01\right)\end{array}$ & $\begin{array}{l}\text { Log soil loss }=1.33 \times \log \text { runoff }+1.18 \\
\left(r^{2}=0.63, n=420, p<0.01\right)\end{array}$ \\
\hline $\begin{array}{l}\text { Nitrogen loss }=1.70 \times \text { soil loss }+30.72 \\
\left(r^{2}=0.71, n=30, p<0.01\right)\end{array}$ & $\begin{array}{l}\text { Nitrogen loss }=1.90 \times \text { soil loss }-12.11 \\
\left(r^{2}=0.74, n=150, p<0.01\right)\end{array}$ \\
\hline $\begin{array}{l}\text { Phosphorus loss }=0.89 \times \text { soil loss }+25.57 \\
\left(r^{2}=0.96, n=30, p<0.01\right)\end{array}$ & $\begin{array}{l}\text { Phosphorus loss }=0.82 \times \text { soil loss }+6.34 \\
\left(r^{2}=0.84, n=150, p<0.01\right)\end{array}$ \\
\hline
\end{tabular}

T0: Control, T1: Tied ridges, T2: Straw mulch, T3: Tied ridges + straw mulch, T4: Straw mulch + EMs, T5: Tied ridges + straw mulch + EMs.

The correlation analysis between runoff and soil loss per event identified a significant $(p<0.01)$ logarithmic relationship between the two variables (Table 4.8). Fifty-two percent of the variation in soil loss in T0 was explained by the runoff. The explanatory capability improved slightly for the in-situ WHTs (T1-T5), where runoff accounted for $63 \%$ of the variability in soil loss. 
Nutrient losses were positively and significantly $(p<0.01)$ correlated with soil losses in both the control and the in-situ WHTs. Soil loss accounted for 71 and $96 \%$ of the variation in the losses of $\mathrm{N}$ and $\mathrm{P}$ for T0, respectively, and 74 and $84 \%$ for $\mathrm{T} 1-\mathrm{T} 5$, respectively.

\subsection{Discussion}

\subsubsection{Soil and nutrient losses}

The application of the in-situ WHTs significantly decreased the loss of soil compared to T0. Straw mulch (with or without tied ridges) was efficient in reducing soil loss from cultivated land. The positive effect of crop residue mulching on soil loss in cultivated lands have also been documented in other ecosystems in the world (Adekalu et al., 2007; Fernández and Vega, 2016; Gholami et al., 2013; Mwango et al., 2015; Prosdocimi et al., 2016b; Sadeghi et al., 2015a). The good performance of the straw mulch for decreasing soil loss was associated with its good performance in decreasing runoff and sediment concentration compared to the control. This result was also confirmed by other researchers (Gholami et al., 2013; Sadeghi et al., 2015a; Sadeghi et al., 2015b; Prosdocimi et al., 2016b).

Our study did not analyse the costs and social acceptance of straw mulch in the study area. Some researchers have tested the effect of different mulching rates on soil erosion in agricultural fields (Donjadee and Tingsanchali, 2016; Jordán et al., 2010; Lal, 1998). Further research, however, is necessary to determine an optimum rate of mulch application in terms of cost effectiveness and soil erosion control (Cerdà et al., 2016; Jordán et al., 2010).

The efficiency of the decrease in soil loss for the tied ridges alone (T1) was mainly associated with runoff reduction, because the sediment concentration for the tied ridges was not significantly lower than for the control and the other treatments (T2-T5).

T3 and T5 registered the lowest seasonal soil loss $\left(0.8 \mathrm{Mg} \mathrm{ha}^{-1}\right)$ in 2014 . T0 had the highest seasonal soil loss (4.3 $\mathrm{Mg} \mathrm{ha}^{-1}$ ). The seasonal soil losses for T1, T2 and T4 were 2.1, 1.0 and $1.3 \mathrm{Mg} \mathrm{ha}^{-1}$, respectively. This result is similar to a study in northern Ethiopia by McHugh et al.( 2007), who reported soil loss from cultivated land on flat (<3\%) plains of $<2 \mathrm{Mg} \mathrm{ha}^{-1}$. The rate of seasonal soil loss in the control, however, was lower in our study than in other plot-level studies in northern Ethiopia (Araya et al., 2011; Girmay et al., 2009; Nyssen et al., 2008). The lower rate of soil loss in our study was probably associated with the sandy clay loam soil texture, and differences in crop cover and to a lower slope gradient and slightly lower seasonal rainfall. 
The lower sediment concentrations in T2-T5 were associated with the application of straw mulch in these treatments, emphasising the role of mulch in decreasing the effects of raindrop splashes on soil surfaces (Cerdà et al., 2016; Okeyo et al., 2014) and hence slowing the detachment of soil particles. Sediment concentrations tended to decrease towards the end of the rainy season irrespective of treatment. Our results corroborated those of other studies in northern Ethiopia and other regions (Araya et al., 2011; Gebreegziabher et al., 2009; Sirjani and Mahmoodabadi, 2014). The decrease in sediment concentrations in runoff late in the rainy season is due to the increase in crop cover, which dissipates the energy of raindrops and decreases the velocity of water on the soil surface (Gebreegziabher et al., 2009).

The higher efficiency of decreasing nutrient losses by the in-situ WHTs (T1-T5) compared to T0 was mainly associated with the reduction of runoff and soil losses. The treatments had no significant effect on TN concentrations in the sediments. The differences in the nutrient losses in the in-situ WHTs were mainly associated with the amounts of runoff and soil losses in the treatments, consistent with other findings (Ali et al., 2007; Baptista et al., 2015a; Zougmoré et al., 2009), where nutrient losses were primarily a function of the amounts of runoff and soil loss. Although nutrient losses were generally higher in the treatments with EMs than the corresponding treatments without EMs, the effect of EMs was however inconclusive because the differences were not significant either for medians (Table 4.3) or per event (Figure 4.3).

The fractions of exported nutrients in the eroded soils compared to the nutrient inputs were significantly higher in T0 and T1 than T2-T5 (Table 4.5), likely due to the lower nutrient inputs in T0 and T1. The straw mulch application might have increased the nutrient contents in T2-T5. The slightly higher and significant fraction of nutrient exports in T4 than T2 may be an indication of the release (mineralisation) of nutrients from straw mulch due to the microbial activity of the EMs. $\mathrm{N}$ and $\mathrm{P}$ may not be immediately released by the decomposition of the organic matter in wheat-straw mulch due to its high C:N ratio (Bertoldi et al., 1983), but the application of straw mulch can maintain carbon and $\mathrm{N}$ stocks in the soil (Abbasi et al., 2015; Smil, 1999). The availability of soil nutrients, contributed by the straw mulch, would help in the long term to maintain soil quality by minimizing the fraction of nutrient exports in eroded soils.

Several researches demonstrated the dependency of soil erosion rates at various plotscale experiments (e.g. Le Bissonnais et al., 1998; Moreno-de las Heras et al., 2010; Parsons et al., 2006; Sadeghi et al., 2015b). A field experiment by Parsons et al. (2006) revealed the decrease of soil erosion rate with increasing plot length. Moreno-de las Heras et al. (2010) confirmed the decrease of soil erosion rate with plot length in less degraded 
lands. On the contrary, the rate of soil loss substantially increased with increasing plot length for highly degraded lands. These findings confirm the variation of soil erosion rates with the scale of plot experiments. Therefore, the soil erosion rates from this study might slightly differ from field conditions because of the size of the plots and the setup of the experiment.

\subsubsection{Maize grain yield and biomass}

Maize grain yield and biomass were significantly higher in the treatments with straw mulch (with and without EMs) compared to the control. The effect of the mulch on yield may have been due to an increase in soil-moisture and decrease in evaporation in the plots by the mulch during dry periods. The release of $\mathrm{N}$ from mulch decomposition may also have contributed to the higher grain yield and plant biomass in the treatments with mulch. The use of EMs with the mulch, however, did not significantly increase yield. The lack of effect of the EMs on yield may have been due to the slow release of nutrients from the mulch because of its high C:N ratio (Bertoldi et al., 1983). Some studies, however, reported an increase in grain yield by using good organic amendments (e.g. compost and farmyard manure) with EMs (Hu and Qi, 2013; Hussain et al., 1999; Javaid and Bajwa, 2011). Hussain et al. (1999) reported an increase in wheat and rice grain yields by using farmyard manure with EMs. In another study, the long term application of EMs with compost increased wheat grain yield ( $\mathrm{Hu}$ and $\mathrm{Qi}, 2013$ ). Further research is required to ascertain the benefits of EM application with different organic materials for increasing the release of nutrients to the soil and thus for increasing maize yield.

Tied ridges alone or combined with straw did not significantly increase grain yield or plant biomass compared to the control, perhaps because excess water in the root zone with the tied ridges from successive and intensive rains caused aeration stress. Similar symptoms of aeration stress were reported in another study in northern Ethiopia in barley fields during seasons with high rainfall (Araya and Stroosnijder, 2010). Maize is vulnerable to aeration stress during the early stages of growth (Mason et al., 1987). Nutrient deficiency due to restricted nutrient uptake is the primary reason of inhibited plant growth in waterlogged soils (Steffens et al., 2005). Anaerobic soil conditions caused by waterlogging also enhance the release of $\mathrm{N}_{2}$ to the atmosphere (Eickenscheidt et al., 2014). Grain yield might thus be improved if tied ridges are avoided during the early stages of plant growth. The time of application of tied ridges merits further study for the improvement of grain yield in northern Ethiopia. 


\subsubsection{Factors influencing soil and nutrient losses}

The PCA indicated that runoff, soil loss, and nutrient ( $N$ and $P$ ) losses were closely associated with each other, demonstrated by high factor loadings in the PCs (Figure 4.5) and the strong correlations (Table 4.8). Event-based logarithmic soil loss was positively correlated with logarithmic runoff. Soil loss is primarily governed by runoff (Ali et al., 2007), which allows the estimation of soil loss per event using measured runoff. A similar logarithmic relationship was established by Girmay et al. (2009), in which runoff volume alone accounted for $76 \%$ of the variability in annual soil loss.

The positive and direct correlation between the nutrient and soil losses suggested that nutrient losses from farmland could be easily estimated using data for soil loss. Similar associations were reported between soil and nutrient losses from micro-dam catchments in northern Ethiopia (Haregeweyn et al., 2008a). This underlines that any measure taken to decrease soil loss will also proportionally decrease N and P losses (Jie et al., 2013).

\subsection{Conclusions}

In-situ water harvesting techniques are useful for reducing soil erosion and nutrient losses form farmland. The combined use of tied ridges and straw mulch was the best in-situ water harvesting technique for reducing soil loss from farmland with coarse-textured soils and gentle slopes. All in-situ water harvesting techniques significantly reduced soil loss and associated nutrient losses. Straw mulch (with or without effective micro-organisms) significantly increased maize grain yield and biomass, substantiating the role of straw mulch in improving in-situ water harvesting for combatting soil-moisture deficiency during dry periods. The use of straw mulch as an in-situ water harvesting technique would further help in the long term to mitigate nutrient losses from the soil due to the release of nutrients from the straw. Further research, however, is required to identify the stage of plant growth when tied ridges should be installed for improving maize yield in northern Ethiopia. 


\section{Assessing the effect of water harvesting techniques on event-based hydrological responses and sediment yield at a catchment scale in northern Ethiopia using LISEM}

Runoff and sediment yield in semi-arid catchments are highly influenced by infrequent but very heavy rains. These events occur over short temporal scales, so runoff and sediment transport can only be understood using an event-based analysis. We applied a hydrological and erosion model, LISEM, to the Gule catchment $\left(\sim 12 \mathrm{~km}^{2}\right)$ in northern Ethiopia. The objectives of the study were: (a) to evaluate the performance of LISEM in describing event-based hydrological processes and sediment yield in a catchment under the influence of different water harvesting techniques, and (b) to study the effect of the water harvesting techniques on catchment-scale event-based runoff and sediment yield. The model performed satisfactorily (NSE>0.5) for most of the events when discharge was calibrated at the main outlet (Gule) and at a sub-outlet (Misbar). Runoff and sediment yield needed to be calibrated separately for each event because of the variable characteristics of the rains. Runoff coefficients for the Gule catchment and Misbar subcatchment were expectedly low due to the implementation of water harvesting techniques, which can store runoff from the rains and increase infiltration into the soil. Simulated and measured sediment yields were of similar orders of magnitude. The calibration of event-based sediment concentration was less accurate, and LISEM generally overestimated sediment yield compared to the measurements. Catchmentscale model simulations indicated that runoff and sediment yield could be effectively reduced by implementing water harvesting techniques. The model estimated 41 and $67 \%$ reductions in runoff and sediment yield at the Gule outlet, respectively. Similarly, runoff and sediment yield at the Misbar sub-outlet were reduced by 45 and 55\%, respectively. LISEM can thus be used to simulate the effects of different existing or new water harvesting techniques on catchment hydrology and sediment yield. The results of scenario predictions could be useful for land-use planners who intend to implement different measures of catchment management.

Submitted as:

Grum, B., Woldearegay, K., Hessel, R., Baartman, J.E.M., Abdulkadir, M., Yazew, E., Kessler, A., Ritsema, C.J., Geissen, V. Assessing the effect of water harvesting techniques on event-based hydrological responses and sediment yield at a catchment scale in northern Ethiopia using LISEM. Catena. 


\subsection{Introduction}

Land degradation is a global challenge to the environment and sustainable agricultural production. Increased pressure on natural resources caused by high population density has led to land degradation in the Ethiopian highlands (Nyssen et al., 2009a). Erosion by runoff coupled with poor land management in these semi-arid highlands are the main causes of the degradation.

Runoff and erosion are complex at catchment scales and difficult to understand because of their non-linearity and scale dependency (Lesschen et al., 2009). Runoff and sediment yield are also characterised by high temporal and spatial variability within a catchment (Mohamadi and Kavian, 2015; Rai and Mathur, 2008). Sediment yield at catchment levels is controlled by many factors, such as rain intensity, soil and rock properties, vegetation cover, topography, soil-moisture content (SMC), infiltration rate, and natural and artificial geomorphic features (Medeiros et al., 2010). There are several studies about hydrological responses and sediment yield under different measures of land management (e.g. Betrie et al., 2011; Haregeweyn et al., 2008b; Lanckriet et al., 2012; Nyssen et al., 2010; Nyssen et al., 2009a) at catchment level. These studies were, however, carried out at a coarser temporal scale (e.g. daily or annual) and may miss to capture small-scale runoff and erosion processes in events of varying rain intensity (Kandel et al., 2004).

Erosion in semi-arid regions is exacerbated by the heavy but infrequent rains and the low protection of the soil surface due to sparse vegetation cover (Medeiros et al., 2010). Extreme runoffs must therefore be carefully assessed, because these events can control long-term sediment yield (White, 2005), and a few storms may cause most of the yearly total erosion. The design of strategies to combat the negative effects of runoff and soil loss from hillslopes also often require an understanding of the characteristics of individual rains for quantifying the magnitude and timing of peak water and sediment discharges (Ramsankaran et al., 2013).

Runoff and erosion also influence the availability and sustainability of water resources in a catchment. An understanding of event-based runoff and erosion not only helps for managing existing schemes of water harvesting but also for implementing new techniques, such as check dams, percolation ponds, and micro-dams. Recent endeavours in the Tigray region of northern Ethiopia have tried to rehabilitate the land by water harvesting techniques (WHTs), such as stone bunds, infiltration or deep trenches, check dams, and percolation ponds (Desta et al., 2005; Nyssen et al., 2004; Vancampenhout et al., 2006; Walraevens et al., 2015). 
The durability and sustainability of water-storage structures, however, can be threatened by siltation due to excessive erosion from brief but heavy rains (Haregeweyn et al., 2008b; Ramsankaran et al., 2013). Check dams, for example, are useful for stabilising gullies by controlling runoff and peak discharges and by reducing the velocity of flow and settling sediment behind the structures (Nyssen et al., 2009a). These structures, however, can be damaged by peak flows during periods of intense rains. For example, 39\% of 400 looserock check dams in Tigray have been damaged by intensive rainstorms (Nyssen et al., 2004).

The design, implementation, and operation of water harvesting structures requires an understanding of site-specific peak water and sediment discharges during periods of extreme events, which can be attained by applying event-based hydrological and erosion models. Several studies of event-based catchment-scale runoff and sediment yield have been carried out worldwide (e.g. Baartman et al., 2012; Gao and Jesefson, 2012; Hessel et al., 2006; Medeiros et al., 2010; Rai and Mathur, 2008; Ramsankaran et al., 2013). Processbased runoff and sediment yield at a catchment scale in Ethiopia have also been modelled (e.g. Betrie et al., 2011; Gebreyohannes et al., 2013; Haregeweyn et al, 2013). Event-based runoff and sediment yield, however, have not yet been modelled for Ethiopia. The effect of extreme events on catchment hydrology and sediment yield in the Ethiopian highlands is not well understood, especially under the influence of different WHTs. We used the Limburg Soil Erosion Model (LISEM) to study the effect of WHTs on event-based hydrological processes and soil erosion. LISEM is a physically event-based hydrological and erosion model and so is suitable for the planning and evaluation of measures for mitigating soil erosion (De Roo et al., 1996b). The objectives of this study were therefore to (a) evaluate the performance of LISEM in predicting hydrological responses and sediment yield under different WHTs in the Gule catchment in semi-arid northern Ethiopia, and (b) investigate the effect of WHTs on catchment runoff and sediment yield.

\subsection{Materials and Methods}

\subsubsection{Description of study area}

The study was conducted in the Gule catchment in the northern Ethiopian highlands (Figure 5.1), located between $13^{\circ} 51^{\prime} 59^{\prime \prime}-13^{\circ} 54^{\prime} 40^{\prime \prime} \mathrm{N}$ and $39^{\circ} 27^{\prime} 16^{\prime \prime}-39^{\circ} 29^{\prime} 49^{\prime \prime} \mathrm{E}$. The Gule catchment lies within the upper Geba catchment, which drains to the Tekeze River basin. The Gule catchment has a rugged topography, with mountains, hillslopes, and flat valley floors, with altitudes ranging between 2008 and 2408 m a.s.l. 
The catchment has a semi-arid climate, with distinct dry and wet (rainy) seasons. The rainy season is relatively short and occurs between June and September. The dry season (October to May) is characterised by little or no rainfall, except for some rains towards the beginning of the rainy season. Rain gauges installed at the study site recorded mean annual rainfall of $465 \mathrm{~mm}$ between 2013 and 2015. Temperatures in the Gule catchment vary little throughout the year compared to the considerable diurnal variations. Average daily temperature in the Gule catchment ranges between 15 and $25^{\circ} \mathrm{C}$.

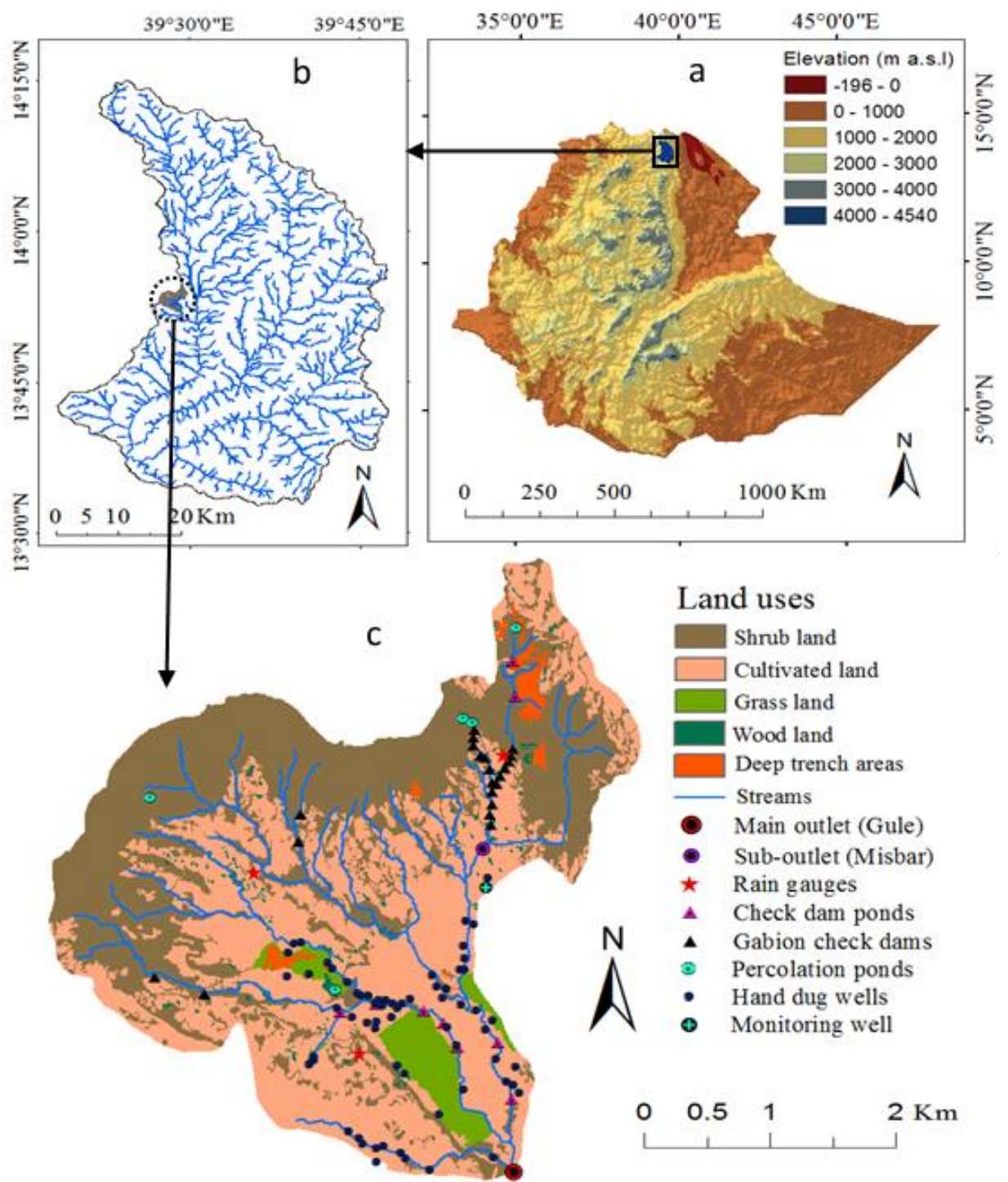

Figure 5.1 Location of the study area. (a) Topography of Ethiopia. (b) Drainage of the upper Geba catchment, and (c) Land uses of the Gule catchment. 
The study area is dominated by different rock and soil types (Figure 5.2): (a) steep slopes and cliff-forming areas dominated by Adigrat sandstone, which is fractured and has a high infiltration capacity, (b) intermediate slopes of mainly siltstone and claystone, which have low permeability, and (c) flat areas dominated by unconsolidated sediments, which have high permeability and infiltration capacity. These unconsolidated sediments are underlain by Edaga Arbi tillite and metamorphic rocks (metavolcanic and metasedimentary), which have low to moderate permeability. The rock and soil properties along the landscapes are generally characterised as rocky in the upper section, gravelly and sandy in the central section, and sandy and silty in the lower section. The soils in the lower sections of the landscape have large capacities to store water, which can reduce subsurface outflow and enhance groundwater storage. The underlying Edaga Arbi tillite layer and metamorphic rocks prevent deep percolation of water and encourage the storage of subsurface water in the weathered rocks and overlying unconsolidated sediments. This setting is geologically ideal for the development of shallow (hand-dug) groundwater wells in the lower section of the catchment.

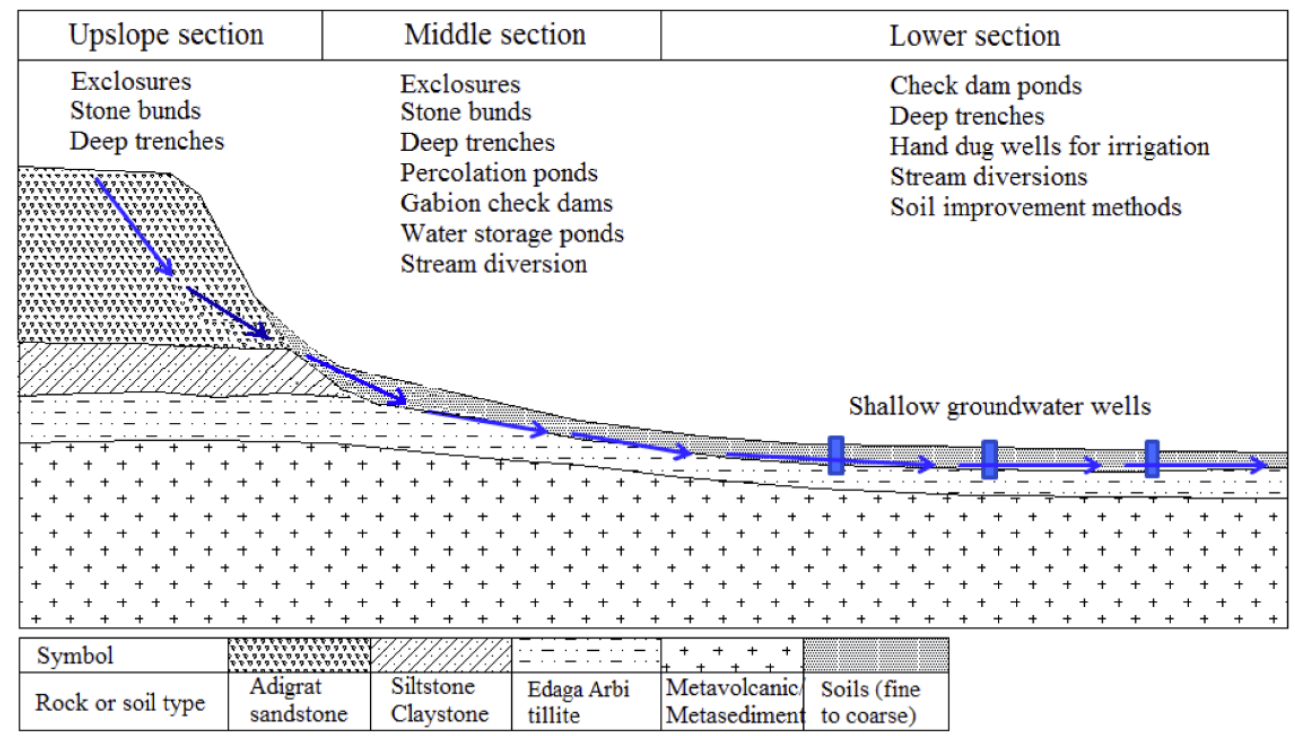

Figure 5.2 Geo-hydrological model and water harvesting techniques implemented at different sections of the catena in Gule catchment, northern Ethiopia.

The Gule catchment has a total area of $\sim 12 \mathrm{~km}^{2}$. The Misbar sub-catchment has an area of $\sim 2.4 \mathrm{~km}^{2}$. The major land uses for the Gule catchment are cultivated land (48\%), shrub land $(46 \%)$, grass land (5\%), and wood land (1\%). The most widely cultivated crops are wheat, barley, millet, teff (Eragrostis tef), maize, and sorghum. The catchment is characterised by fine- to coarse-textured soils with the major textural classes consisting of sandy loam (24\%), sandy clay (21\%), sandy clay loam (14\%), clay loam (13\%), loam (13\%), and silty loam (12\%). 
The catchment is currently well managed with various WHTs such as stone bunds, deep trenches, check dams, and percolation ponds (Figures 5.1 and 5.3). Stone bunds have been constructed along the contours of the slopes mainly in the hilly and shrub-dominated areas. Deep trenches are often dug behind the stone bunds in shrub land, grass land, and farm land to collect runoff and to trap sediments in the trenches. Areas treated with deep trenches cover $\sim 1.4 \%$ of the Gule catchment and $\sim 5.2 \%$ of the Misbar sub-catchment. The Misbar sub-catchment has a total area of $\sim 2.4 \mathrm{~km}^{2}$. Check dams have been constructed across streams or gullies to facilitate the harvesting of rainwater and to control soil erosion by trapping eroded sediment behind the structures (Balooni et al., 2008; Nyssen et al., 2009a). Two types of check dams, namely gabion or stone masonry check dams and concrete check-dam ponds, have been constructed in the catchment (Figure 5.3). Several percolation ponds have also been recently built to enhance the infiltration of collected rainwater and hence enhance groundwater recharge to the existing hand-dug wells. The integrated management of the catchment with these different WHTs has created new groundwater and has enhanced existing wells, which are used for water supply (household and livestock) and for irrigation during the dry season.
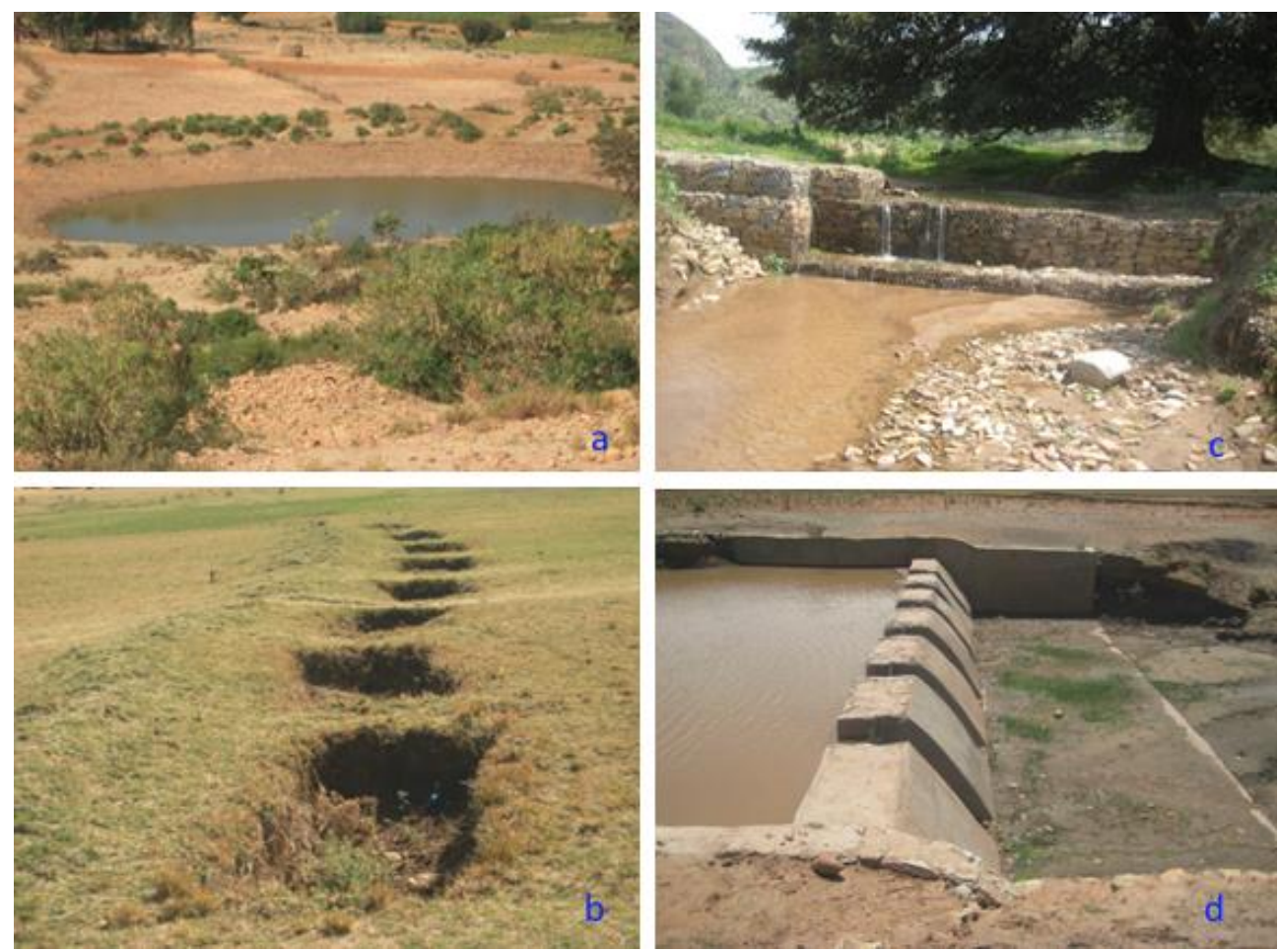

Figure 5.3 Examples of water harvesting techniques implemented in the Gule catchment (a) percolation pond (b) deep trench (c) gabion check dam (d) concrete check-dam pond. 


\subsubsection{LISEM}

LISEM is a physically based hydrological and soil-erosion model developed to simulate event-based runoff, erosion, and sediment transport at catchment levels (De Roo et al., 1999a, 1999b). The model is built in a raster-based geographic information system and can be used to simulate the spatial variability of erosion and sedimentation at a catchment scale. LISEM incorporates several processes to simulate runoff and sediment transport.

The interception and storage of water by plants during a rain is calculated based on the maximum canopy storage and leaf area index (LAI). Infiltration is then calculated using the Holtan (Beasley and Huggins, 1982), SWATRE (Belmans et al., 1983), or Green and Ampt (Green and Ampt, 1911) method, depending on the availability of soil input data. The amount of runoff stored in depressions is estimated based on measured random roughness (RR) of the soil surface. The four-point finite-difference solution of the kineticwave and Manning's equations are used to simulate overland and channel flows. The amount of sediment transport in LISEM is simulated based on the balance between erosion and deposition. Erosion is caused by both splash detachment by raindrops and flow detachment by runoff. See De Roo et al. (1996b) for detailed process descriptions and mathematical equations.

\subsubsection{Model input parameters}

The input parameters for the LISEM were measured for the study area in 2014 and 2015. Soil texture (Figure 5.4) was determined for 62 sample sites distributed over the catchment. The sites were chosen to represent the different soil types in the catchment. Soil texture was first determined in the laboratory using a hydrometer. A soil-texture map was then produced by ordinary kriging interpolation using the known textures at the 62 measurement sites. A $20 \times 20 \mathrm{~m}$ digital elevation model was used to generate slope gradients, local drain directions, and catchment outlet points. Land uses (Figure 5.1) were derived from recent Google Earth images (2011 and 2013) and ground observations. The land-use classes for 2014 and 2015 were then updated to classify the cultivated land into different crop covers (wheat, millet, teff, and fallow).

Most of the LISEM input parameters, such as LAI, plant cover, plant height, RR, and stone fraction, were extrapolated from the land uses, based on 22 measurement sites distributed over the catchment. Stone fraction was derived from land use because farmers remove or leave stones depending on the land use. Land use thus has a larger effect on 
stone cover than soil type. Initial SMC was also measured at the 22 measurement sites, but the measured SMCs were associated with the corresponding soil texture at each measurement site because SMC was more closely associated with soil type than land use. The initial SMC was then extrapolated based on the soil-texture classes at the 22 measurement sites. Median size (d50) of soil texture, saturated hydraulic conductivity (Ksat), and aggregate stability were extrapolated based on the measurements at the 62 sample sites (Figure 5.4). Manning's roughness coefficient ( $n$ ) for the land uses was estimated as described by Chow (1959). The Green and Ampt parameters (porosity and wetting-front soil-suction head) for the soil textures were obtained from Rawls et al. (1993).
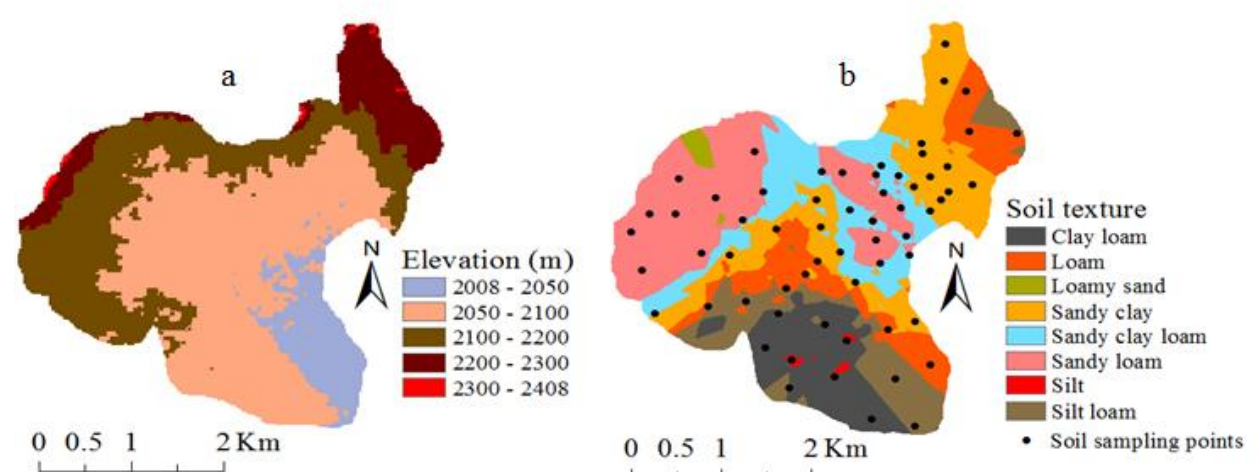

Figure 5.4 Topography (a) and soil texture (b) of the Gule catchment, northern Ethiopia.

\section{Measurement of LISEM input parameters}

LAI: LAls for the land uses were measured every two weeks in 2014 and 2015 during the rainy season (June to September). The total numbers of plants were counted for the cultivated land (wheat, millet, and teff), fallow land, and grass land, and total leaf area was measured over a $50 \times 50 \mathrm{~cm}$ sample plot. First, the average leaf area of a plant was estimated based on measurements from plants in the sample plot. The total leaf area was then determined by multiplying the average leaf area of a plant by the total number of plants in the plot. LAI for shrubs and trees was estimated from representative sample sites using $5 \times 5$ m plots.

Plant cover: Plant cover was measured every two weeks in 2014 and 2015 using the same sample sites for LAl. Five photographs were taken using a digital camera at the measurement sites in the cultivated land and grass land where plants were short. Plant cover for the shrubs and trees was estimated by measuring the proportion of the $5 \times 5 \mathrm{~m}$ plots covered by plants using a measuring tape. The fraction of plant cover for cultivated land and grass land was then analysed by ImageJ (Abramoff et al., 2004) using the digital pictures. 
Plant height: Plant height for each land use was measured at each measurement site every two weeks in 2014 and 2015 using a measuring tape. Plant height for cultivated land, grass land, and shrubs was estimated using averages of representative plant heights at the sample site. The height of trees was estimated, because measurement using a tape was difficult.

Initial SMC: Initial SMC was monitored every 1-2 weeks at the measurement sites using a Trime-PICO64 (time-domain reflectometer) soil-moisture sensor (Eijkelkamp, Giesbeek, Netherlands). SMCs were measured at five soil depths $(0,10,20,40$, and $70 \mathrm{~cm})$ using 3-5 measurements for each measurement site. The SMCs were then averaged for two layers $(0-40 \mathrm{~cm}$ and $40-70 \mathrm{~cm})$ to satisfy the requirements of the two-layered Green and Ampt infiltration model. The two soil layers describe the differences in the soil properties for the study area.

$R R$ : The RR of each land use was measured over two (2014 and 2015) rainy seasons using a constructed pin meter (Jester and Klik, 2005). Five photographs were taken at each measurement site using a digital camera. The roughness of the surface was then determined from the photographs by calculating the standard deviation of the pin positions on the pin board.

Ksat: Soil samples were collected at the 62 sample sites (Figure 5.4) by coring. Ksat was then determined by a laboratory permeameter using the constant-head method.

Soil cohesion: Cohesion of the soil for the soil-texture classes was measured using a Torvane. Soil cohesion was measured 10 times at each of the 22 measurement sites for both dry and wet conditions. Cohesion was measured twice during the rainy seasons in 2014 and 2015.

Stone fraction: The fraction of stone cover for the land uses was estimated based on the areal coverage of stones over a unit area for each land use. Stone fraction was assumed not to vary with time.

\subsubsection{Measurement of rainfall, discharge, and groundwater level}

Rainfall for the study area was measured using three gauging stations (Figure 5.1) installed for this study. Rain intensity was measured at 5-min intervals using a tipping-bucket datalogging RG3-M HOBO (precision: $0.2 \mathrm{~mm}$ per tip) rain gauge (Onset, Bourne, USA).

Discharge was measured at the Gule outlet and Misbar sub-outlet using mini- and barodiver water-level loggers with capacities of $10 \mathrm{~m}$ (Eijkelkamp, Giesbeek, Netherlands). Water depth or stage at the outlets were recorded every 5 min. A discharge rating curve 
was then developed for the Gule outlet for 2014 and 2015 (Figure 5.5). The discharge at this outlet was calculated based on the rating curves. The rating curve for the main outlet was developed using velocities measured by a current meter during some of the rains. Velocity was measured at various depths across the river, depending on the depth of flow. Average velocity for each measured section of the river was the velocity at $60 \%$ of the depth of flow. Velocities and depths of flow during the dry seasons were determined using the floating method to include low flows. Discharge rating curves for the Gule outlet were developed by fitting stage and discharge using a power-law function (Herschy, 1995):

$Q=c_{1}\left(h-h_{0}\right)^{c_{2}}$

where $Q$ is the discharge, $h$ is the stage, $h_{0}$ is the maximum depth of water for zero discharge, and $c_{1}$ and $c_{2}$ are calibration coefficients.

The sub-outlet (Misbar) was deliberately located at an existing broad-crested weir for measuring discharge for the Misbar sub-catchment. The discharge for the sub-outlet was thus estimated using the discharge equation for a broad-crested weir (Kay, 2008). Groundwater level was manually measured weekly using a scale bar (meter) in an open hand-dug well in the lower section of the Gule catchment (Figure 5.1).

\subsubsection{Model implementation}

LISEM version 2.64 was used to simulate event-based hydrological processes and sediment yield at the Gule outlet and Misbar sub-outlet. LISEM requires detailed hydrometeorological and spatial input data. The spatial data were prepared at a pixel size of 20 $\mathrm{m}$, and all simulations were run at $15 \mathrm{~s}$ time steps. Infiltration was modelled using the twolayer Green and Ampt method. The soil was divided into upper $(0-40 \mathrm{~cm})$ and lower $(40$ to $2000 \mathrm{~cm}$, if it exists as in some cases weathered tillite rock was encountered) layers based on the measured soil depths for the catchment.

Calibration was performed using discharge and suspended-sediment concentration (SSC) measured at the Gule and Misbar outlets. Each event was calibrated separately. Discharge for the Gule outlet was calibrated for 25 rains. Discharge for the Misbar sub-outlet was calibrated using 12 rains, which were a subset of the 25 rains used for Gule. Discharge was calibrated by comparing the measured and simulated hydrographs for peak discharge, runoff volume, and timing of peak discharge. We decided to separate base flow from the observed discharge at the outlets, because LISEM does not simulate base flow. Base flow was, however, observed prior to the rains in some of the streams, especially near the main 
outlet. Base flow was separated by the recession method (Tallaksen, 1999). The performance of the discharge calibration was then evaluated using the Nash-Sutcliffe efficiency (NSE) coefficient (Nash and Sutcliffe, 1970). Earlier studies of runoff using LISEM (e.g. De Roo et al., 1996a) indicated that Ksat and Manning's $n$ values were the most uncertain, so discharge was calibrated using these parameters.

Sediment yield was then calibrated using SSCs measured at the Gule and Misbar outlets. Sediment yield was calibrated using 11 and 9 rain events for the Gule and Misbar outlets, respectively. The number of sediment-calibration events was limited by the availability of measured SSCs. We used cohesion, d50, and aggregate stability for the calibration, because these parameters determine erosion rate and transport capacity in LISEM.

The effect of WHTs on runoff and sediment yield for the Gule catchment was determined by simulating LISEM with and without WHTs using the method developed by Hessel and Tenge (2008). The method involves the calibration of LISEM input parameters at pixel scales based on P-factors, i.e. the ratio of runoff and erosion rates in areas with WHTs to the rates in areas without WHTs, to simulate the effect of WHTs at a catchment scale. This is similar to the P-factors which are used, for example, in the RUSLE model (Renard et al., 1996).

Information on the effect of different WHTs on runoff and erosion was collected from the literature and reported as P-factors. Runoff and sediment yields for stone bunds and deep trenches were simulated at pixel scales by changing the LISEM input parameters until the simulation results matched the reported P-factors for each WHT. Pixel scale was used because reported $\mathrm{P}$-factors are usually based on experimental plots that are of similar dimensions as the pixels in our model. Calibrations for gabion check dams using the Pfactor used micro-catchments $\left(\sim 0.5 \mathrm{~km}^{2}\right)$; because gabion check dams have larger catchments than stone bunds and deep trenches. Check-dam and percolation ponds were entered into LISEM as water and sediment-storage structures (buffers), because they impound water and sediment. Simulation was then carried out at the catchment scale by incorporating the calibrated values of the LISEM input parameters and entering waterstorage structures (check-dam and percolation ponds) in areas where the WHTs were implemented. We simulated runoff and sediment yield without WHTs at the catchment scale by removing the calibrated values (at 1-pixel and micro-catchment scales) of the LISEM input parameters and the water-storage structures. The reductions of runoff and sediment yield by the WHTs were then estimated by calculating the differences of the simulations with and without WHTs. 
Table 5.1 Average values of LISEM input parameters for different land uses of the Gule catchment.

\begin{tabular}{llllllll}
\hline Model parameter & Wheat & Millet & Teff & Fallow & Grass land & Shrub land & Wood land \\
\hline Manning's $\mathrm{n}^{\mathrm{a}}$ & 0.04 & 0.04 & 0.03 & 0.04 & 0.03 & 0.13 & 0.15 \\
Leaf area index $\left(\mathrm{m}^{2} \mathrm{~m}^{-2}\right)$ & 3.30 & 5.00 & 3.70 & 0.70 & 1.60 & 2.00 & 6.00 \\
Random roughness $(\mathrm{cm})$ & 0.80 & 1.10 & 1.10 & 1.20 & 0.70 & 0.50 & 0.50 \\
Plant cover (fraction) & 0.52 & 0.44 & 0.29 & 0.10 & 0.81 & 0.31 & 0.91 \\
Plant height (m) & 0.38 & 0.50 & 0.18 & 0.05 & 0.19 & 1.50 & 10.0 \\
Stone cover (fraction) & 0.09 & 0.09 & 0.09 & 0.09 & 0.01 & 0.50 & 0.50 \\
\hline
\end{tabular}

${ }^{\mathrm{a}}$ Estimated from Chow (1959)

Table 5.2 Average values of LISEM input parameters for soil texture of the Gule catchment.

\begin{tabular}{lllllllll}
\hline Model parameter & $\begin{array}{l}\text { Clay } \\
\text { loam }\end{array}$ & Loam & $\begin{array}{l}\text { Loamy } \\
\text { sand }\end{array}$ & $\begin{array}{l}\text { Sandy } \\
\text { clay }\end{array}$ & $\begin{array}{l}\text { Sandy } \\
\text { clay loam }\end{array}$ & $\begin{array}{l}\text { Sandy } \\
\text { loam }\end{array}$ & $\begin{array}{l}\text { Silt } \\
\text { Silt }\end{array}$ & \begin{tabular}{l} 
loam \\
\hline Ksat $\left(\mathrm{cm} \mathrm{d}^{-1}\right)$
\end{tabular} \\
Cohesion $(\mathrm{kPa})$ & 0.51 & 222 & 323 & 297 & 186 & 187 & 194 & 257 \\
Porosity $\left(\mathrm{cm}^{3} \mathrm{~cm}^{-3}\right)$ & 0.46 & 0.39 & 0.41 & 0.50 & 0.54 & 0.45 & 0.69 & 0.67 \\
Initial soil-moisture content $\left(\mathrm{cm}^{3} \mathrm{~cm}^{-3}\right)$ & 0.20 & 0.20 & 0.13 & 0.16 & 0.37 & 0.42 & 0.52 & 0.45 \\
Median texture $(\mu \mathrm{m})$ & 41.0 & 53.0 & 42.0 & 49.0 & 30.0 & 40.0 & 30.0 & 41.0 \\
Aggregate stability (median of drop no.) & 10.5 & 9.30 & 8.50 & 11.3 & 9.00 & 8.00 & 14.3 & 12.5 \\
\hline
\end{tabular}
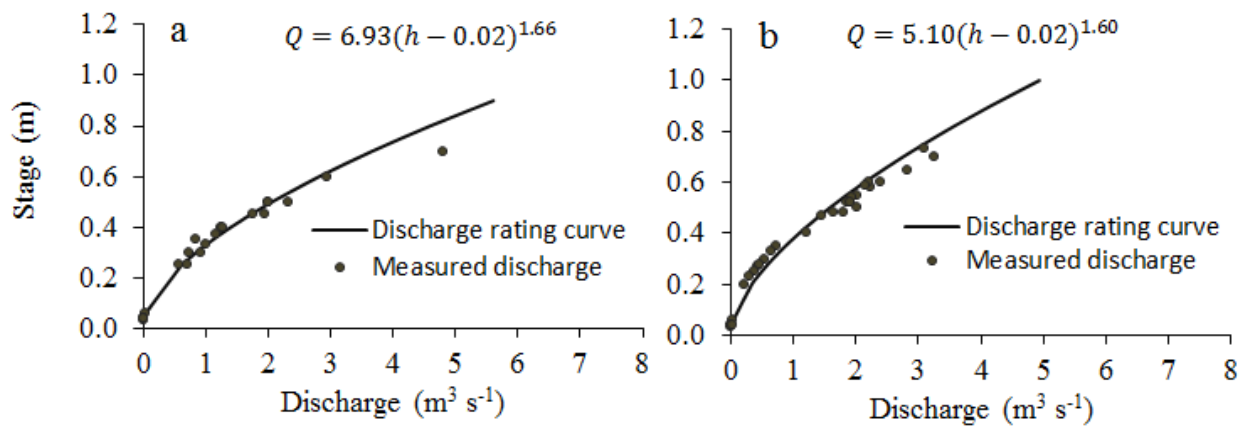

Figure 5.5 Discharge rating curves at the Gule outlet for 2014 (a) and 2015 (b). Q: discharge $\left(m^{3} s^{-1}\right), h$ : water depth or stage $(m)$. 


\subsection{Results}

\subsubsection{Measured field and estimated model input data}

The field measurements for LAI, RR, plant cover, and plant height for the land uses are summarised in Table 5.1. The values for the input parameters are averages of the measurements for the rainy seasons in 2014 and 2015.

Average values of the LISEM input parameters, which were extrapolated based on soil texture, are summarised in Table 5.2. Most of the LISEM input parameters used in the simulations varied with time, depending on the measurement interval, although only the averages are reported in Tables 5.1 and 5.2. D50 for the soil textures for the Gule catchment was variable, but we used a constant value of $41 \mu \mathrm{m}$ for the sediment-yield simulations, because this value was the average for the soil-texture classes and because the values for these classes were not clearly correlated with texture class (e.g. d50 was not higher for sand than loam).

The developed discharge rating curves for the Gule outlet for 2014 and 2015 are shown in Figure 5.5. The fitted rating curves matched the measured discharges reasonably well. The measured maximum depth of flow without discharge (stagnant water) was $2 \mathrm{~cm}$. The rating-curve equations were quite similar for 2014 and 2015, and the coefficients differed only slightly.

\subsubsection{Model calibration}

Table 5.3 summarises the model calibrations for Ksat and Manning's $\mathrm{n}$ and the model performance for calibrated events at the Gule and Misbar outlets. The event-based calibration of LISEM for discharge substantially reduced Ksat compared to the field measurements. The calibrated Ksat values for the events at the Gule outlet were quite variable, ranging between 0.2 and $7.2 \%$ of the measured Ksat inputs. Calibrated Ksat values for the Misbar outlet ranged between 0.5 and $6.0 \%$ of the measured inputs. The calibration of Manning's $n$ for the Gule and Misbar outlets indicated high variability amongst the events. The calibrated $n$ values for the events ranged from 33 to $190 \%$ and 12 to $70 \%$ of the estimated values for the Gule and Misbar outlets, respectively. 
Table 5.3 Measured and calibrated hydrological responses at the Gule and Misbar outlets. P: rainfall, I30: 30-min rain intensity, $R C$ : runoff coefficient, $R V$ : runoff volume.

\begin{tabular}{|c|c|c|c|c|c|c|c|c|c|c|}
\hline \multirow[b]{3}{*}{ Event } & \multirow{2}{*}{\multicolumn{2}{|c|}{$\begin{array}{l}\text { Calibrated } \\
\text { parameters }\end{array}$}} & \multirow[b]{3}{*}{$\begin{array}{l}P \\
(\mathrm{~mm})\end{array}$} & \multirow{3}{*}{$\begin{array}{l}130 \\
\left(\mathrm{~mm} \mathrm{~h}^{-}\right. \\
1)\end{array}$} & \multicolumn{3}{|c|}{ Simulated } & \multicolumn{2}{|c|}{ Measured } & \multirow[b]{3}{*}{ NSE } \\
\hline & & & & & \multirow[b]{2}{*}{$\begin{array}{l}\text { RV } \\
\left(\mathrm{m}^{3}\right)\end{array}$} & \multirow[b]{2}{*}{$\begin{array}{l}\text { RC } \\
(\%)\end{array}$} & \multirow{2}{*}{$\begin{array}{l}\text { Infiltra- } \\
\text { tion } \\
(\mathrm{mm})\end{array}$} & \multirow[b]{2}{*}{$\begin{array}{l}\text { RV } \\
\left(\mathrm{m}^{3}\right)\end{array}$} & \multirow[b]{2}{*}{ RC (\%) } & \\
\hline & $\begin{array}{l}\text { Ksat } \\
\text { (\%) }\end{array}$ & $\begin{array}{l}n \\
(\%)\end{array}$ & & & & & & & & \\
\hline \multicolumn{11}{|c|}{ Gule (main outlet) } \\
\hline 090714 & 1.3 & 65 & 16 & 27 & 3130 & 1.5 & 15.7 & 3422 & 1.7 & 0.66 \\
\hline 310714 & 2.9 & 90 & 44 & 41 & 69071 & 12.6 & 38.1 & 71901 & 13.2 & 0.75 \\
\hline 300714 & 2.3 & 77 & 22 & 39 & 22771 & 8.4 & 19.6 & 26690 & 9.9 & 0.83 \\
\hline 010814 & 0.2 & 190 & 12 & 9 & 4810 & 3.2 & 11.4 & 6959 & 4.6 & -0.35 \\
\hline 030814 & 7.3 & 100 & 25 & 48 & 8848 & 2.8 & 24.0 & 6851 & 2.2 & 0.77 \\
\hline 050814 & 5.5 & 38 & 34 & 66 & 36436 & 8.6 & 30.7 & 36025 & 8.5 & 0.80 \\
\hline 160814 & 1.8 & 110 & 15 & 28 & 5900 & 3.2 & 13.8 & 6851 & 3.8 & 0.89 \\
\hline 170814 & 1.4 & 80 & 22 & 30 & 19898 & 5.8 & 20 & 16678 & 6.1 & 0.45 \\
\hline 180814 & 0.8 & 135 & 13 & 28 & 18865 & 11.7 & 10.9 & 20410 & 12.7 & 0.80 \\
\hline 290814 & 2.6 & 42 & 14 & 33 & 10157 & 5.9 & 12.7 & 19921 & 11.5 & 0.54 \\
\hline 310814 & 0.8 & 110 & 12 & 22 & 15796 & 5.8 & 10.7 & 8392 & 5.6 & 0.90 \\
\hline 030914 & 0.8 & 150 & 10 & 20 & 5629 & 4.4 & 9.5 & 7742 & 6.1 & 0.63 \\
\hline 060914 & 1.5 & 50 & 9 & 18 & 3279 & 2.8 & 8.8 & 4419 & 3.9 & 0.74 \\
\hline 070914 & 0.6 & 95 & 9 & 17 & 12727 & 11.5 & 7.5 & 9549 & 8.6 & 0.83 \\
\hline 100914 & 3.4 & 115 & 24 & 47 & 15987 & 5.3 & 22.5 & 15810 & 5.2 & 0.83 \\
\hline 170914 & 3.5 & 85 & 27 & 37 & 11798 & 3.5 & 25.7 & 13417 & 4.0 & 0.71 \\
\hline 110715 & 0.8 & 190 & 16 & 30 & 14180 & 7.4 & 14.0 & 14692 & 7.6 & 0.76 \\
\hline 230715 & 2.3 & 100 & 21 & 33 & 6191 & 2.4 & 19.6 & 9010 & 3.5 & 0.51 \\
\hline 240715 & 7.2 & 45 & 40 & 70 & 37611 & 7.6 & 36.6 & 41195 & 8.3 & 0.94 \\
\hline 290715 & 0.6 & 60 & 10 & 14 & 9052 & 7.2 & 9.2 & 12978 & 10.3 & 0.48 \\
\hline 020815 & 1.0 & 33 & 19 & 16 & 2823 & 1.1 & 20.2 & 4905 & 2.1 & 0.39 \\
\hline 030815 & 0.3 & 70 & 16 & 27 & 8350 & 4.2 & 14.9 & 10294 & 5.2 & 0.82 \\
\hline 140815 & 4.4 & 110 & 28 & 30 & 9657 & 2.7 & 27.2 & 11126 & 3.2 & 0.63 \\
\hline 150815 & 3.4 & 95 & 18 & 32 & 8276 & 3.6 & 16.5 & 13097 & 6.0 & 0.74 \\
\hline 250815 & 1.1 & 55 & 15 & 13 & 4748 & 2.6 & 13.9 & 3673 & 2.0 & 0.86 \\
\hline Mean & 2.3 & 92 & 20 & 31 & 14187 & 5.4 & 18.2 & 16007 & 6.3 & 0.68 \\
\hline SD & 2.0 & 42 & 9 & 15 & 14592 & 3.2 & 8.4 & 15008 & 3.4 & 0.26 \\
\hline \multicolumn{11}{|c|}{ Misbar (sub-outlet) } \\
\hline 030814 & 4.0 & 34 & 19.2 & 38 & 697 & 1.2 & 18.7 & 1070 & 2.3 & 0.65 \\
\hline 050814 & 5.0 & 26 & 37.2 & 71 & 6836 & 8.4 & 33.7 & 11727 & 13.2 & 0.73 \\
\hline 160814 & 1.4 & 50 & 11.4 & 22 & 594 & 1.7 & 10.7 & 810 & 3.0 & 0.73 \\
\hline 170814 & 1.8 & 20 & 24.2 & 37 & 3417 & 6.5 & 21.8 & 7674 & 13.2 & 0.88 \\
\hline 180814 & 1.8 & 30 & 12.4 & 24 & 903 & 2.9 & 11.5 & 1766 & 5.9 & 0.57 \\
\hline 310814 & 2.2 & 12 & 12 & 20 & 607 & 2.1 & 11.1 & 1202 & 4.2 & 0.64 \\
\hline 100914 & 4.8 & 70 & 25.2 & 47 & 1462 & 2.5 & 24.3 & 1941 & 3.2 & 0.79 \\
\hline 170914 & 6.0 & 21 & 28.2 & 37 & 730 & 1.1 & 27.5 & 2440 & 3.6 & 0.18 \\
\hline 230715 & 3.5 & 20 & 22.4 & 43 & 2210 & 4.5 & 20.4 & 3538 & 6.6 & 0.88 \\
\hline 240715 & 0.5 & 13 & 37.6 & 58 & 3364 & 3.5 & 35.9 & 7759 & 8.6 & 0.52 \\
\hline 140815 & 5.2 & 43 & 43.4 & 54 & 4950 & 7.3 & 40.2 & 8083 & 7.8 & 0.67 \\
\hline 250815 & 3.0 & 40 & 20.5 & 15 & 336 & 0.9 & 18.9 & 426 & 0.9 & 0.76 \\
\hline Mean & 3.3 & 32 & 25 & 39 & 2175 & 3.5 & 22.9 & 4036 & 6.0 & 0.67 \\
\hline SD & 1.8 & 17 & 11 & 17 & 2070 & 2.6 & 9.8 & 3757 & 4.0 & 0.19 \\
\hline
\end{tabular}



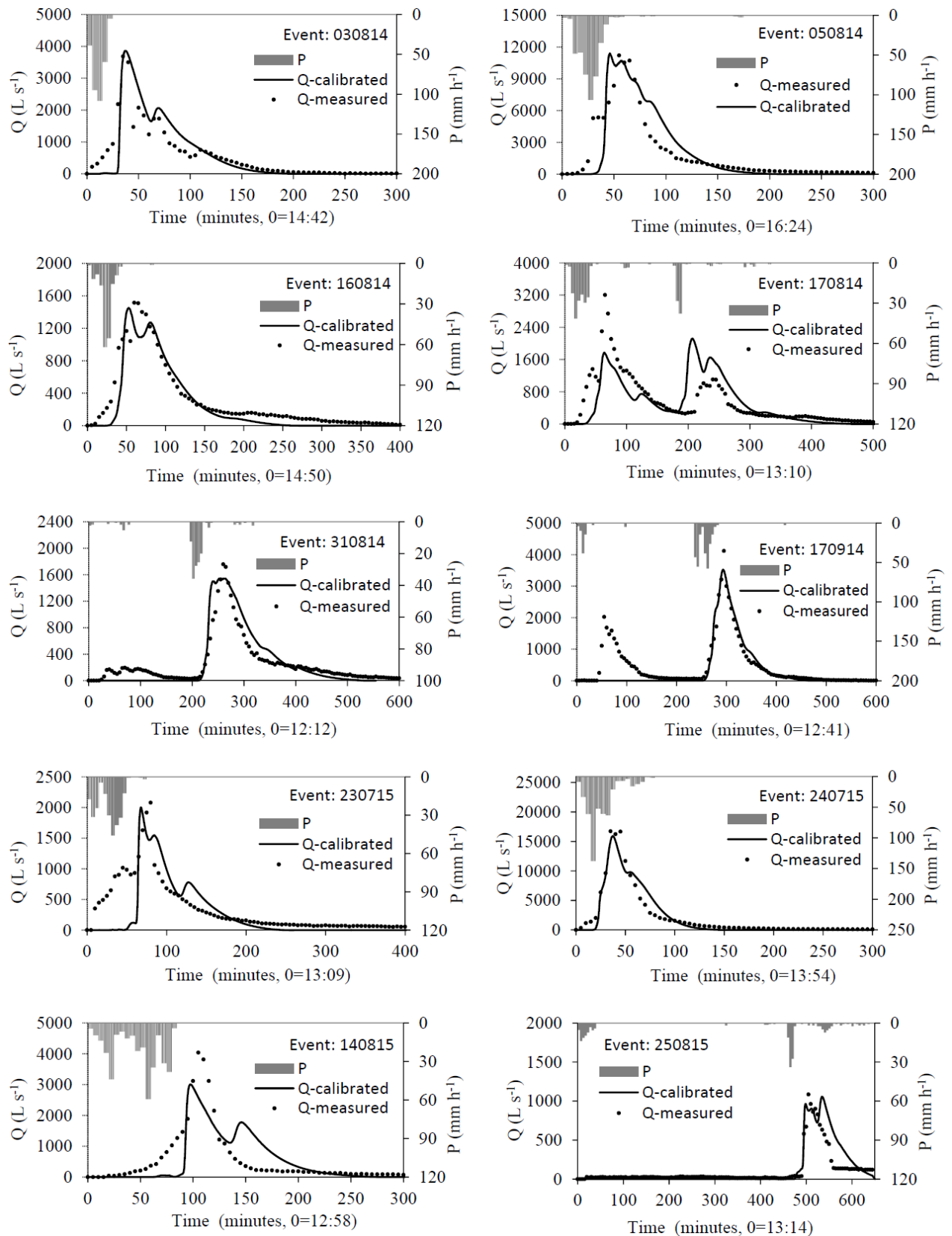

Figure 5.6 Discharge hydrographs at the Gule outlet for selected events in 2014 and 2015. P: rain intensity $\left(m m h^{-1}\right), Q$ : discharge $\left(L s^{-1}\right)$. 

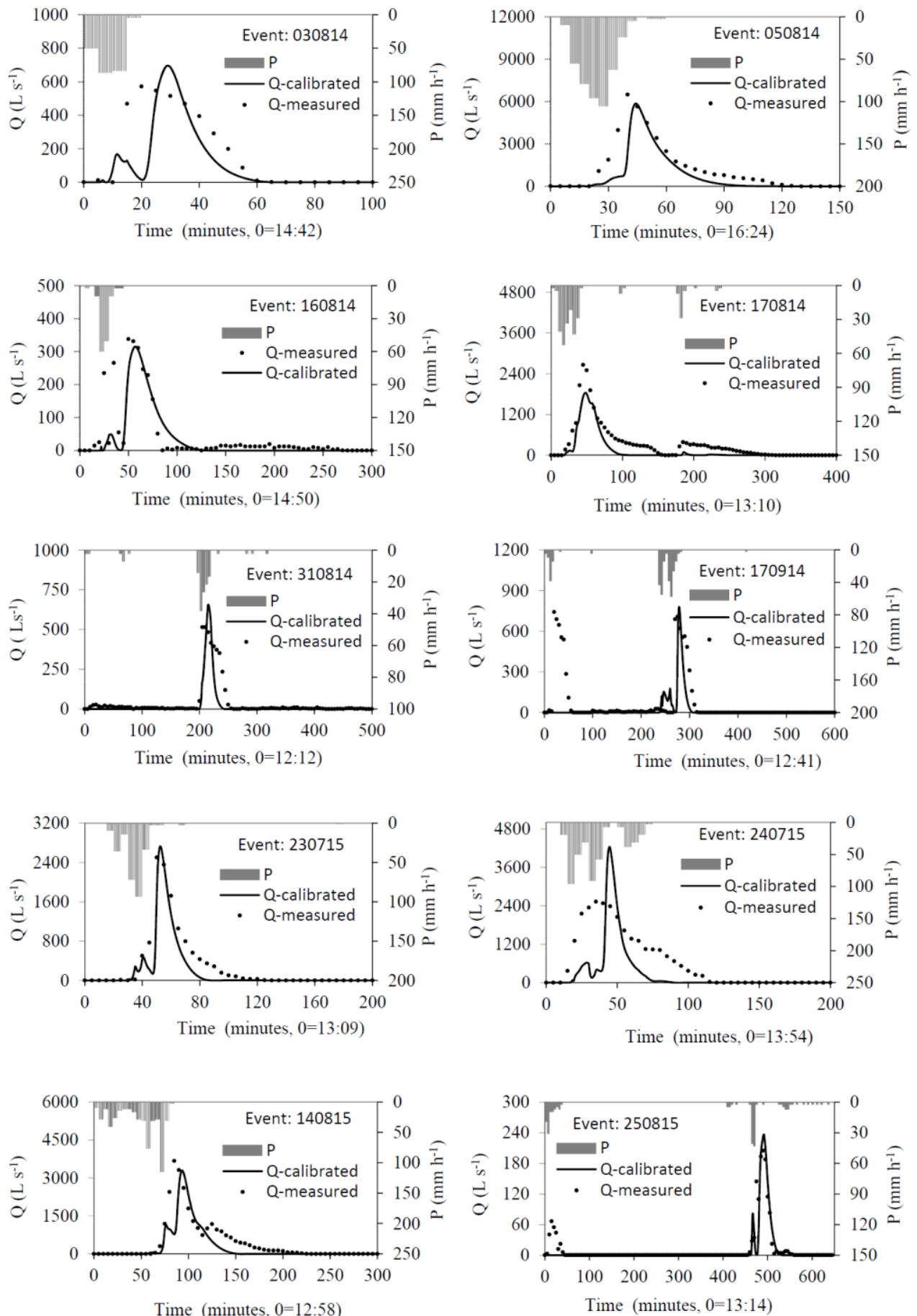

Figure 5.7. Discharge hydrographs at the Misbar sub-outlet for selected events in 2014 and 2015. P: rain intensity $\left(m m h^{-1}\right), Q$ : discharge $\left(L s^{-1}\right)$. 
Measured and simulated discharges after calibration for most events at the Gule and Misbar outlets agreed well (Table 5.3). A satisfactory hydrological model should have an NSE>0.5 (Moriasi et al., 2007). Twenty-one of the 25 calibrated events at the Gule outlet were satisfactory. The model calibration was better for the Misbar sub-outlet, with only 1 of 12 events deemed unsatisfactory (NSE<0.5). The model generally performed less well for the Gule outlet for light rains, i.e. rains with low rainfall and/or 30-min rain intensity (I30). For example, the model predicted discharge poorly for events 010814 and 290715, which had relatively low rainfalls and I30s. The model, however, predicted discharge well for events 060914 and 070914, which had low rainfalls but moderate 130s. The model also performed poorly for events with moderate rainfalls but with low I30s (e.g. 020815). Event 250815 was an exception to this generalisation, in which discharge was predicted well despite the event having a low 130 .

The measured and simulated discharge hydrographs for the Gule and Misbar outlets matched well for most events (Figures 5.6 and 5.7). The model was able to simulate runoff peaks for most single-peak storms but responded differently when an event had more than one peak. The model was able to simulate small runoff peaks following a major peak (e.g. 170814). The model, however, could not capture runoff peaks prior to a larger peak (e.g. 170914). The model simulations also showed some double-peaked hydrographs (e.g. 140815 at Gule and 030814 at Misbar) although these peaks were not observed in reality.
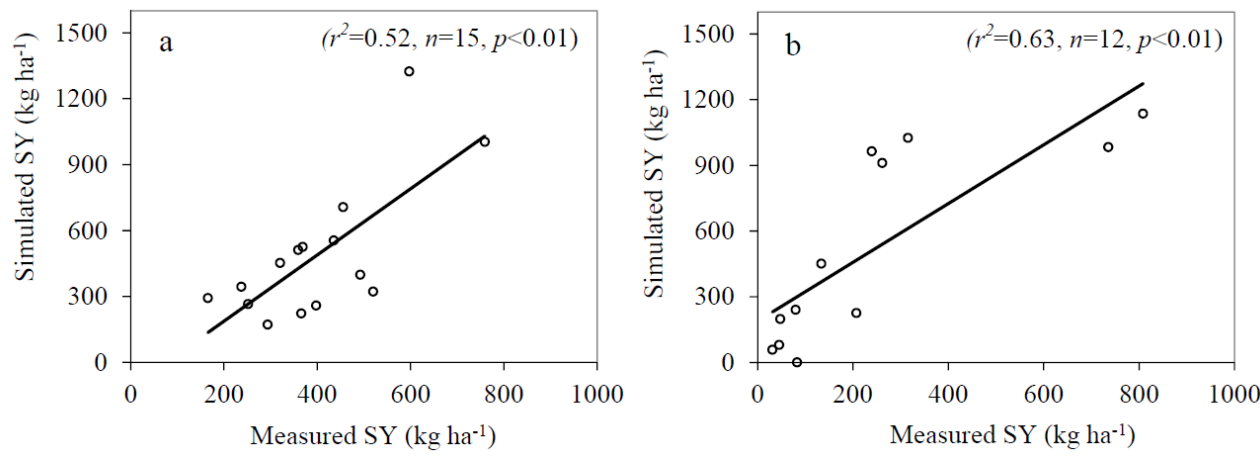

Figure 5.8 Relations between simulated and measured sediment yields at Gule (a) and Misbar (b) outlets. SY: sediment yield.

Aggregate stability, soil cohesion, and d50 were associated with erosion and deposition in the LISEM model. The default values of the sediment parameters overestimated the SSCS compared to the measured values. The calibration of event-based SSCs was unsatisfactory, so the simulated and measured sediment yields calculated based on average sediment concentration in an event were compared. Simulated soil cohesion increased substantially $\left(10^{4}\right.$-fold) for the calibrated events. The simulated d50 increased 3 -fold. Simulated and 
measured values for the Gule $\left(r^{2}=0.57, n=15, p<0.01\right)$ and Misbar $\left(r^{2}=0.77, n=12, p<0.01\right)$ outlets agreed to some extent, despite the tendency of LISEM to overestimate sediment yield (Figure 5.8).

\subsubsection{Hydrological responses}

Table 5.3 shows the measured and simulated runoff volumes, runoff coefficients, and amounts of infiltration for the Gule and Misbar outlets. Runoff volume at both outlets generally increased with rainfall and 130. Simulated runoff volume for the Gule outlet was moderately correlated with rainfall $\left(r^{2}=0.67, n=25, p<0.01\right)$ and $130\left(r^{2}=0.48, n=12, p<0.01\right)$.

The better correlation of runoff volume with rainfall than 130 was most apparent for events 310714 (rainfall=44 mm, I30=41 mm h${ }^{-1}$ ) and 240715 (rainfall=40 mm, I30=70 mm $\mathrm{h}^{-1}$ ). Runoff volume was higher for 310714 than 240715 , even though 130 was higher for 240715 than 310714 . The higher runoff volume for 310714 than 240715 was likely due to the double-peak rainstorm (data not shown) for 310714. Runoff volume increased substantially in the second peak of the event due to the saturation of the soil layer in the previous rainfall peak. Similarly, runoff volume was higher for both 240715 and 310714 than 050814, despite a higher 130 for 050814. Runoff volume for the Misbar sub-outlet was also moderately correlated with rainfall $\left(r^{2}=0.55, n=25 p<0.01\right)$ and $130\left(r^{2}=0.65, n=12\right.$, $p<0.01)$.

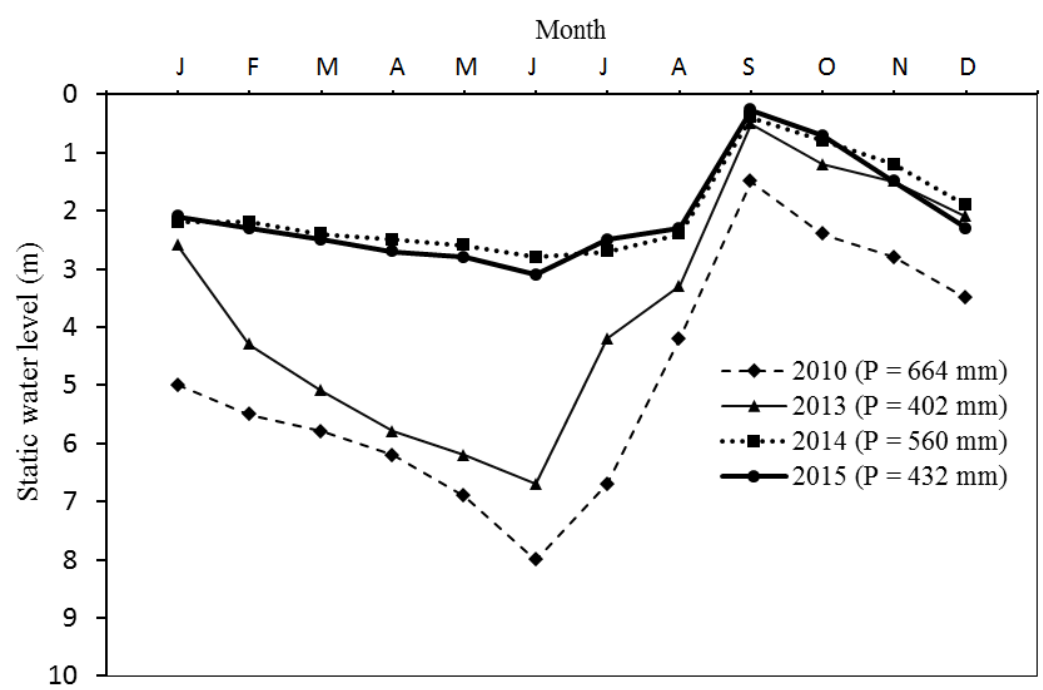

Figure 5.9 Monthly static water level of a shallow groundwater monitoring well downstream of the Misbar sub-outlet. P: annual rainfall $(\mathrm{mm})$. 
Average measured and simulated runoff coefficients were low, at 6.3 and $5.4 \%$ for the Gule outlet and 6 and 3.5\% for the Misbar sub-outlet, respectively. The coefficients were similar for the Gule and Misbar outlets, despite the large difference in catchment areas. The low runoff coefficients for the rains were compensated by the high levels of infiltration in the catchments (Table 5.3). Infiltration during the rains $(n=25)$ was high for the Gule catchment, with a mean of $18.2 \mathrm{~mm}$. Average infiltration was even higher during the rains $(n=12)$ for the Misbar sub-catchment, at $22.9 \mathrm{~mm}$.

The low runoff coefficients for rains for the Gule catchment were likely due mainly to a combination of three factors, namely a fairly fine to coarse soil type (high infiltration), the flatter topography of the lower section of the catchment, and the retention of runoff by the WHTs implemented in the upper and central sections of the catchment. The monthly static water level of the monitoring well located slightly below the Misbar sub-catchment is shown in Figure 5.9. An increase in groundwater level from 2010 to 2015 could not have been due to rainfall and was probably due to the WHTs that were installed between 2011 and 2013. The groundwater level in the well rose substantially especially during the dry months of the year.

\subsubsection{Sediment yield}

Simulated and measured sediment yields per event for the Gule and Misbar outlets are summarised in Table 5.4. Sediment yield varied considerably for the different rains. Average measured sediment yields per event for the Gule and Misbar outlets were 401 and $249 \mathrm{~kg} \mathrm{ha}^{-1}$, respectively. Average sediment yields for extreme events (e.g. 050814), however, were higher, at 759 and $809 \mathrm{~kg} \mathrm{ha}^{-1}$ for Gule and Misbar, respectively. Average simulated sediment yields for the Gule and Misbar outlets were 491 and $523 \mathrm{~kg} \mathrm{ha-1}$, respectively. The simulated and measured sediment yields generally had similar orders of magnitude for the Gule outlet. SSCs for the Gule and Misbar outlets varied moderately amongst the measured events. Average measured SSCs were generally higher for Gule than Misbar. Average SSCs were 27.2 and $14.6 \mathrm{~g} \mathrm{~L}^{-1}$ for the Gule and Misbar outlets, respectively (Table 5.4).

The simulated sediment yields after calibration were generally higher than the measured values. Average measured sediment yield per unit area was higher for the Gule than the Misbar outlet. Sediment yields for the events were well correlated with runoff volume, both for the model simulations and observations (Figure 5.10). The higher slopes of the regression lines of the model simulations compared to the observations demonstrated that simulated sediment yield tended to increase more quickly than the measured 
sediment yield for a similar change in runoff volume. Similarly, the regression lines indicated that sediment yield responded quicker for the Misbar than the Gule outlet for similar changes in runoff volume. The higher response of sediment yield for the Misbar sub-catchment than the Gule catchment highlights the difference in catchment size. Sediment yield with runoff volume is expected to respond slower in larger catchments where physical variations are large.

Table 5.4 Measured and simulated sediment yields at the Gule and Misbar outlets. * SSCs were estimated based on average measured values over the year.

\begin{tabular}{|c|c|c|c|c|c|c|}
\hline \multirow[b]{2}{*}{ Event } & \multicolumn{2}{|c|}{$\begin{array}{l}\text { Simulated } \\
\text { sediment yield }\left(\mathrm{kg} \mathrm{ha}^{-1}\right)\end{array}$} & \multicolumn{2}{|l|}{$\begin{array}{l}\text { Measured } \\
\mathrm{SSC}\left(\mathrm{g} \mathrm{L}^{-1}\right)\end{array}$} & \multicolumn{2}{|c|}{$\begin{array}{l}\text { Measured } \\
\text { sediment yield }\left(\mathrm{kg} \mathrm{ha}^{-1}\right)\end{array}$} \\
\hline & Gule ( $n=15)$ & Misbar (n=12) & Gule ( $n=15)$ & Misbar $(n=12)$ & Gule ( $n=15)$ & Misbar $(n=12)$ \\
\hline 030814 & 172 & 198 & 22.2 & 10.7 & 294 & 48 \\
\hline 050814 & 1004 & 1136 & $24.3^{*}$ & $16.5^{*}$ & 759 & 809 \\
\hline 160814 & 266 & 80 & $24.3^{*}$ & 13.4 & 252 & 45 \\
\hline 170814 & 707 & 983 & 27.4 & 23.0 & 455 & 736 \\
\hline 180814 & 555 & 240 & 20.8 & 10.9 & 435 & 80 \\
\hline 310814 & 345 & 0 & $24.3^{*}$ & $16.5^{*}$ & 237 & 83 \\
\hline 100914 & 512 & 451 & $24.3^{*}$ & $16.5^{*}$ & 359 & 134 \\
\hline 170914 & 453 & 226 & 18.4 & 22.7 & 320 & 207 \\
\hline 230715 & 259 & 964 & 39.3 & 16.2 & 398 & 240 \\
\hline 240715 & 1324 & 1025 & 16.7 & 9.7 & 597 & 315 \\
\hline 290715 & 526 & na & 31.4 & no data & 492 & no data \\
\hline 030815 & 399 & na & 31.5 & no data & 369 & no data \\
\hline 140815 & 223 & 911 & 28.5 & 7.7 & 366 & 261 \\
\hline 150815 & 323 & na & 43.3 & no data & 520 & no data \\
\hline 250815 & 293 & 58 & 31.8 & 11.2 & 166 & 31 \\
\hline Mean (SD) & 491 (317) & $523(442)$ & $27.2(7.3)$ & $14.6(4.9)$ & 401 (151) & $249(262)$ \\
\hline
\end{tabular}

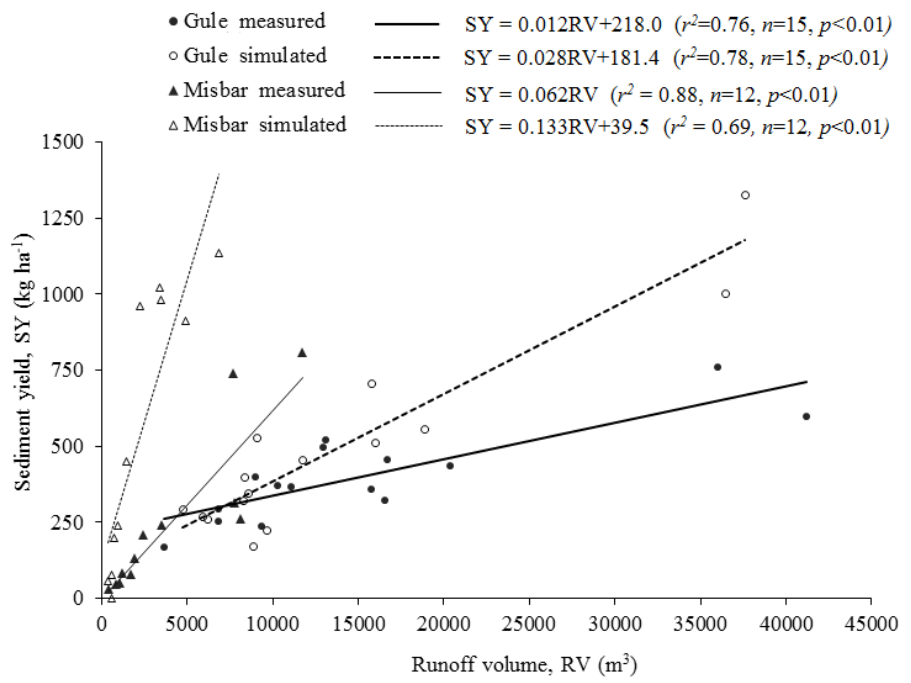

Figure 5.10 Correlations between sediment yield (SY) and runoff volume (RV) at the Gule and Misbar outlets. 


\subsubsection{Effect of WHTs on catchment runoff and sediment yield}

The P-factors obtained from the literature are summarised in Table 5.5. The P-factors varied considerably for the WHTs. A deep trench combined with a stone bund was the most effective technique for reducing runoff and sediment yield. Stone bunds and gabion check dams reduced soil loss more effectively than runoff.

Table 5.6 shows the calibrated multiplication factors for the LISEM input parameters that mostly affect runoff after calibration using the P-factor simulations. Manning's $\mathrm{n}$ and Ksat needed to be changed the most to replicate the P-factors observed for the WHTs. The higher changes to Manning's $n$ due to the implementation of the WHTs reflected the ability of WHTs to reduce soil loss by slowing the flow velocity and trapping eroded soil. The large changes in the values of the LISEM input parameters (mainly Ksat and Manning's n) were expectedly caused by deep trench combined with stone bund, because this technique had the lowest P-factor (Table 5.5).

Table 5.5 Estimated P-factors for runoff and sediment yield due to different water harvesting techniques.

\begin{tabular}{llll}
\hline & \multicolumn{2}{l}{ Runoff } & \\
\cline { 2 - 3 } Water harvesting technique & Literature & Used & References \\
\hline Stone bunds & $0.20-0.35,0.73$ & 0.70 & Al-Seekh and Mohammad (2009), Taye et al. (2013) \\
Deep trenches & 0.31 & 0.30 & Taye et al. (2013) \\
Stone bunds + deep trenches & 0.16 & 0.20 & Taye et al. (2013) \\
Gabion check dams & $0.84-0.91,0.73-0.85$ & 0.80 & Guyassa et al. (2015), Xu et al. (2013) \\
\hline \multirow{3}{*}{ Water harvesting technique } & Sediment yield & & \\
\cline { 2 - 3 } & Literature & Used & References \\
\hline Stone bunds & $0.32,0.36$ & 0.40 & Desta et al. (2005), Taye et al. (2013) \\
Deep trenches & 0.10 & 0.10 & Taye et al. (2013) \\
Stone bunds + deep trenches & 0.04 & 0.05 & Taye et al. (2013) \\
Gabion check dams & $0.33,0.37-0.43$ & 0.40 & Boix-Fayos et al. (2008), Xu et al. (2013) \\
\hline
\end{tabular}

Table 5.6 Calibrated values of LISEM input parameters using the P-factors for the Gule catchment.

\begin{tabular}{lllll}
\hline Water harvesting technique & Ksat & Manning's $\mathbf{n}$ & Random roughness & Aggregate stability \\
\hline Stone bunds & 1.12 & 2.25 & 1.2 & 1.0 \\
Deep trenches & 1.55 & 2.79 & 1.2 & 0.8 \\
Stone bunds + deep trenches & 1.58 & 3.72 & 1.5 & 0.8 \\
Gabion check dams & 1.04 & 1.21 & 1.0 & 1.0 \\
\hline
\end{tabular}

Values are given as multiplication factors

The results of the catchment-level simulations for runoff and sediment yield with and without WHTs for the 12 events for the Gule and Misbar outlets are shown in Table 5.7. The result for event 310814 was not included for the Misbar sub-outlet because of the zero simulated sediment yield for the baseline, i.e. with WHTs (Table 5.4). The catchmentlevel simulation by LISEM with and without WHTs showed that the amount of reduction in runoff volume and sediment yield varied amongst the events. The reduction in runoff and 
sediment yield due to the use of WHTs generally tended to decrease with increasing rainfall. The model predicted an average $41 \%$ reduction in runoff volume for the Gule outlet due to the implementation of WHTs. Similarly, the WHTs reduced sediment yield for the Gule outlet by $67 \%$. The WHTs also decreased runoff volume and sediment yields for the Misbar outlet, by 45 and $55 \%$, respectively.

Table 5.7 Effectiveness of water harvesting techniques (WHTs) on reducing runoff volume and sediment yield for the Gule outlet and Misbar sub-outlet.

\begin{tabular}{|c|c|c|c|c|c|c|}
\hline \multirow[b]{2}{*}{ Event } & \multicolumn{3}{|c|}{ Runoff volume $\left(\mathrm{m}^{3}\right)$} & \multicolumn{3}{|c|}{ Sediment yield $\left(\mathrm{kg} \mathrm{ha}^{-1}\right)$} \\
\hline & Without WHTs & With WHTs & Reduction (\%) & Without WHTs & With WHTs & Reduction (\%) \\
\hline \multicolumn{7}{|c|}{ Gule outlet } \\
\hline 030814 & 19884 & 8848 & 55.5 & 662 & 172 & 74.0 \\
\hline 050814 & 54287 & 36436 & 32.9 & 2754 & 1004 & 63.5 \\
\hline 160814 & 9531 & 5900 & 38.1 & 703 & 266 & 62.2 \\
\hline 170814 & 24421 & 15796 & 35.3 & 1926 & 707 & 63.3 \\
\hline 180814 & 27885 & 18865 & 32.3 & 1435 & 555 & 61.3 \\
\hline 310814 & 14335 & 8590 & 40.1 & 939 & 345 & 63.3 \\
\hline 100914 & 29063 & 15987 & 45.0 & 2105 & 512 & 75.7 \\
\hline 170914 & 22514 & 11798 & 47.6 & 1594 & 453 & 71.6 \\
\hline 230715 & 12623 & 6191 & 51.0 & 928 & 259 & 72.1 \\
\hline 240715 & 51445 & 37611 & 26.9 & 2950 & 1324 & 55.1 \\
\hline 140815 & 17530 & 9657 & 44.9 & 1003 & 223 & 77.8 \\
\hline 250815 & 8716 & 4748 & 45.5 & 912 & 293 & 67.9 \\
\hline Mean & 24354 & 15036 & 41.3 & 1493 & 509 & 67.3 \\
\hline SD & 14884 & 11162 & 8.4 & 787 & 350 & 6.9 \\
\hline \multicolumn{7}{|c|}{ Misbar sub-outlet } \\
\hline 030814 & 1335 & 697 & 47.8 & 531 & 198 & 62.6 \\
\hline 050814 & 11810 & 6836 & 42.1 & 2257 & 1136 & 37.4 \\
\hline 160814 & 1143 & 594 & 48.0 & 336 & 80 & 76.3 \\
\hline 170814 & 4597 & 3608 & 21.5 & 1474 & 1039 & 29.5 \\
\hline 180814 & 2213 & 903 & 59.2 & 914 & 240 & 73.7 \\
\hline 100914 & 2192 & 1462 & 33.3 & 857 & 451 & 47.4 \\
\hline 170914 & 1658 & 730 & 56.0 & 864 & 226 & 73.9 \\
\hline 230715 & 4357 & 2210 & 49.3 & 1838 & 964 & 47.6 \\
\hline 240715 & 5465 & 3364 & 38.4 & 1561 & 1025 & 34.3 \\
\hline 140815 & 9042 & 4950 & 45.3 & 1683 & 911 & 45.9 \\
\hline 250815 & 704 & 336 & 52.3 & 256 & 58 & 77.6 \\
\hline Mean & 4047 & 2535 & 44.8 & 1143 & 575 & 55.1 \\
\hline SD & 3565 & 2119 & 14.1 & 658 & 436 & 18.2 \\
\hline
\end{tabular}

\subsection{Discussion}

\subsubsection{Hydrological processes}

The larger influence of rainfall than 130 on runoff volume in the Gule catchment may have been due to its longer duration of discharge compared to the Misbar sub-catchment. The 
differences in the width (duration) in the discharge hydrographs at the Gule and Misbar outlets were likely due to the differences in the catchment sizes. Discharge hydrographs are expected to be wider for large than small catchments because of the delay of upstream runoff to reach the outlet, which attenuates the discharge peak. Runoff volume for runoffs with narrow hydrographs is mainly controlled by the magnitude of the peak discharges.

LISEM was unable to consistently simulate small runoff peaks for hydrographs with multiple peaks. The difficulty of the model to correctly simulate runoff peaks for complex (multiple-peaked) hydrographs has also been noted by other studies (Hessel et al., 2006, Jetten et al., 1999). The model was, however, able to reproduce small runoff peaks occurring after a rain's major runoff peak. The failure of LISEM to simulate double peaks (e.g. 170914) could be due to the arrival of water from different parts of the catchment at different times or an uneven distribution of rainfall in the catchment. The absence of double peaks in reality, despite the model simulations (e.g. 140815 at Gule and 030814 at Misbar), could have been due to the coincidence of double peaks at the catchment outlets.

The poorer performance of LISEM for light rains could be attributed to the spatial variability and uncertainty of the input data, variability in rainfall over the catchment, or the larger effect of initial storage in ponds and channels (Hessel, 2002). Sheik et al. (2010) noted that runoff prediction was highly influenced by initial SMC in events with low runoff coefficients and rain intensity. SMC was also measured for 1-2 weeks, a measurement interval that might not fully characterise actual moisture conditions in the catchment at the start of a rain. Ksat values for the catchment were also interpolated from 62 field samples in the catchment; these measurement sites may thus not adequately represent the entire catchment. Other unaccounted topographic features such as field boundaries, hedges, and paths (Hessel et al., 2006) may be important, especially for light rains.

The magnitude of the runoff coefficients for the Gule and Misbar catchments were similar despite the differences in catchment area. Many studies have confirmed the decrease of area-specific unit runoff with increasing catchment area (e.g. Cammeraat, 2002; Cantón et al., 2011; Cerdan et al., 2004; Lesschen et al., 2009; Nyssen et al., 2010), which is mainly caused by local storage and infiltration (Cammeraat, 2002).

The most probable reason for the unexpectedly similar runoff coefficients for the Gule and Misbar catchments, despite the differences in catchment areas, is the retention of runoff by the WHTs. The Misbar sub-catchment has a larger area with deep trenches and more check dams and percolation ponds than the entire Gule catchment (Figure 5.1). The 
modelled reduction of runoff by the WHTs was also slightly higher at the Misbar (45\%) than the Gule (41\%) outlet. The recent (2014 and 2015) rise in the level of static water at the monitoring well immediately below the Misbar outlet (Figure 5.1) further indicated an improved infiltration of water due to the implementation of WHTs. Most of the check dams in the Misbar sub-catchment were constructed before the 2013 rainy season and were upgraded in late 2014 . The monthly static-water level at the monitoring well rose substantially in 2014 and 2015 despite no significant increase in annual rainfall during these two years compared to 2010 and 2013. Other studies in northern Ethiopia have also reported the reduction of runoff due to the implementation of WHTs at catchment levels (Lanckriet et al., 2012; Nyssen et al., 2010; Walraevens et al., 2015). For example, the annual runoff coefficient for the May Zeg-Zeg catchment in northern Ethiopia decreased from 8 to $1.6 \%$ after catchment management with stone bunds and check dams. Similarly, the construction of a series of percolation ponds and deep trenches in the Mendae plain in northern Ethiopia enhanced the local infiltration of runoff collected from hillslopes, thereby allowing little or no outflow of water from the ponds (Walraevens et al., 2015).

The calibrated Ksat values were substantially lower than the measured values, consistent with other findings (De Barros et al., 2014; Hessel et al., 2006; Hessel et al., 2003a). The large differences between the calibrated and measured Ksat values highlight the difficulties in characterising Ksat at the catchment level. Ksat tends to be spatially and temporally variable at catchment scales (De Roo, 1996b). Disturbances in soil sampling, the inability of field measurements to account for the effects of sealing or crusting, incomplete saturation of the field, and very large differences in conductivity for very small changes in SMC in very wet soils (Hessel et al., 2003a) may also have contributed to the higher measured Ksat values.

\subsubsection{Sediment yield}

Sediment yields for the Gule and Misbar catchments were quite variable for the different rains. Extremely heavy rains delivered the highest sediment yields. High sediment yields in extreme events are due to the intensive impacts of raindrops, detaching soil particles and causing surface wash and high runoff volumes (Cerdà et al., 2016). The contribution of extreme events to overall sediment yield, especially in semi-arid areas, is thus quite large (Baartman et al., 2012; Coppus and Imeson, 2002; Gonzalez-Hidalgo et al., 2010).

Interestingly, average measured sediment yield per unit area was higher for the Gule catchment than the Misbar sub-catchment, despite Gule's larger catchment area (Table 5.4). The lower sediment yield at the Misbar sub-outlet compared to the Gule outlet 
contradicts the general premise that sediment yield decreases with increasing catchment size. Despite the variations in spatial scales (De Vente and Poesen, 2005), catchment-level studies often indicate decreases in sediment yield with increasing catchment area (Cantón et al., 2011; De Vente and Poesen, 2005; De Vente et al., 2007; Nyssen et al., 2004; Vanmaercke et al., 2014). The lower sediment yield in the larger catchments area was likely due to increased sedimentation at the feet of slopes or in dry channels, flood plains, and other sinks in the larger catchment (De Vente et al., 2007).

The decrease in sediment yield with area should, however, be considered carefully, because factors other than area can also contribute to sediment yield (Vanmaercke et al., 2011). For example, Vanmaercke et al. (2014) showed that $40 \%$ of the variation in sediment yield in Africa was due to seismic activity, topography, vegetation cover, and runoff. Tamene et al. (2006) reported that the variability of sediment yield in northern Ethiopian catchments was mostly associated with topography, gully erosion, surface lithology, and land cover. Haregeweyn et al. (2008b) found an inverse and significant correlation $(r=-0.66)$ between the fraction of catchment area affected by WHTs and sediment yield, which emphasises the role of WHTs as sediment sinks.

In our study, the higher number of check dams and larger coverage of deep trenches in the Misbar than the Gule catchment have likely contributed to the lower rate of measured sediment yield at the Misbar sub-catchment, because the SSCs for the different events were lower at the Misbar than the Gule outlet (Table 5.4). LISEM, however, underestimated the effect of the WHTs in reducing sediment yield in the Misbar subcatchment; the modelled reduction in sediment yield was higher at the Gule outlet (67\%) than at the Misbar sub-outlet (55\%). It was not clear why the modelled effect of WHTs on sediment yield was lower for the Misbar sub-outlet than for the Gule outlet. Evidence worldwide suggests that WHTs such as stone bunds (Nyssen et al., 2009a), check dams (Abedini et al., 2012; Mekonnen et al., 2015a; Nyssen et al., 2009a; Polyakov et al., 2014), percolation ponds (Fiener et a., 2005; Verstraeten and Poesen, 2001), and Fanya juu terraces (Fisseha et al., 2011) can reduce catchment sediment yield. The efficiency of reduction, however, could be improved by combining some of these techniques, despite the demonstrated benefits of individual WHTs in reducing runoff and sediment yield from catchments (Grum et al., 2016; Mekonnen et al., 2015b; Nyssen et al., 2009a).

LISEM tended to overestimate sediment yield for the Gule and Misbar catchments, which has also been reported for tropical catchments (De Barros et al., 2014; Hessel et al., 2006). The poor performance of LISEM in predicting sediment yield arises from the difficulty of modelling sediment transport, because it is highly complicated by the high spatial variability of several factors controlling erosion in a catchment (De Barros et al., 2014; 
Ramsankaran et al., 2013). The model efficiency in our study may also have been affected by the limited number of events used in the analysis, due to the unavailability of measured sediment concentrations for all events.

The measured and calibrated values for soil cohesion differed widely. This result was consistent with a study in Brazil, in which the magnitudes of the measured soil cohesion and aggregate stability had to be substantially increased to calibrate sediment yield (De Barros et al., 2014). This adjustment poses a challenge for adapting physically consistent and realistic values of soil parameters as LISEM inputs for predicting sediment yield. This problem may be due to the lack of representativeness of spatial data for a catchment or a structural problem in LISEM for describing erosion. Hessel (2003a) also indicated that the current analysis of erosion by LISEM does not adequately describe erosion on steep slopes, such as in our study area. The ability of the values of soil cohesion and aggregate stability in LISEM to adequately represent soil physical parameters therefore requires further study (De Barros et al., 2014).

The calibration of LISEM for a small catchment in northern Ethiopia in our study has provided good model performance for runoff and a resemblance between measured and simulated average sediment yields. The prediction capability of LISEM, however, was suboptimal because it was calibrated for separate events, but it remained a useful tool to explore the responses of catchment hydrology and sediment yield to land-use scenarios and the implementation of WHTs (De Roo et al., 1996a, 1996b; Hessel et al., 2003b). Hessel et al. (2003b) has successfully applied LISEM for determining the impact of land-use scenarios in the Danangou catchment on the Chinese Loess Plateau. Baartman et al. (2012) has also used LISEM to investigate the effect of rain intensity and duration on soil erosion in the Prado catchment in southeastern Spain. Based on these experiences and the successful calibration of LISEM for runoff and sediment yield at the Gule catchment, LISEM can be further used for evaluating the effects of land-use changes and the widespread implementation of WHTs in the study area.

\subsection{Conclusion}

The good calibrations at the Gule and Misbar outlets showed that LISEM could be applied in northern Ethiopia to small catchments containing WHTs. The following conclusions can be drawn from this study:

- The performance of LISEM in predicting runoff was better for the smaller subcatchment than the entire catchment, due to the increased spatial complexity with increasing catchment size. 
- $\quad$ LISEM needed to be calibrated separately for each runoff event because of the added complexity of a smaller temporal scale and the variable characteristics of the rains. LISEM failed to reproduce some runoff peaks for multiple-peaked events, especially those peaks that occurred prior to a major peak in an event.

- The calibration of event-based SSC was less accurate, and LISEM tended to overestimate sediment yield compared to measured values.

- The general trend of area-specific decreases in runoff and sediment yield with increasing catchment area was violated in catchments with WHTs, demonstrating the effect of WHTs in reducing runoff and sediment yield in catchments with WHTS.

- $\quad$ LISEM was successfully calibrated for the Gule catchment for runoff and sediment yield and so can be further used to evaluate the effect of land-use scenarios. LISEM can be used to quantify the hydrological responses and sediment yields from the implementation of existing and/or new WHTs at a catchment level. 


\section{Synthesis}




\subsection{General discussion}

This chapter synthesizes the main findings of this $\mathrm{PhD}$ project in the context of the four research questions in order to understand the effects of water harvesting techniques (WHTs) on the availability of rainwater for agricultural use and the mitigation of land degradation in northern Ethiopia. It also presents the major scientific and social contributions, extension and policy implications of this project and highlights future research directions.

The synopsis diagram (Figure 6.1) demonstrates how the in-situ and catchment-scale WHTs were selected, as well as the effects of these WHTs on on-site water regime, soil erosion, catchment hydrology and sediment yield. First, a decision support approach, which integrated a GIS-based multi-criteria analysis (MCA) with a participatory multistakeholder workshop, was developed for the selection of suitable WHTs for a given area. The decision support approach was applied on a case study in northern Ethiopia and resulted in the selection of in-situ and catchment-scale WHTs which were then tested for their effects.

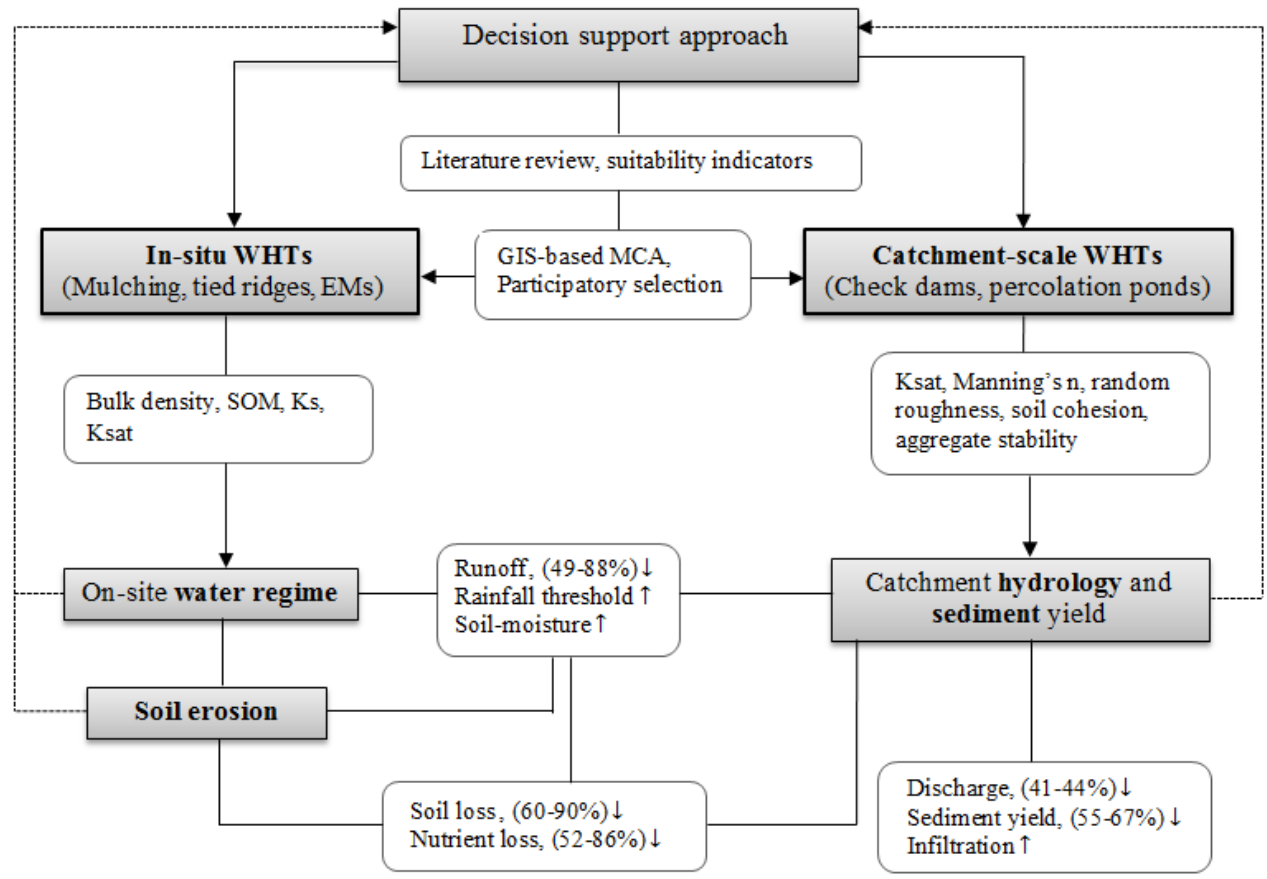

Figure 6.1. Synopsis of the process of water harvesting techniques (WHTs) selection, and on-site and offsite effects of WHTs. EMs: effective micro-organisms, MCA: multi-criteria analysis, SOM: soil organic matter, Ks: unsaturated hydraulic conductivity, Ksat: saturated hydraulic conductivity. 
The selection procedure for WHTs investigated in research question I is discussed in detail in the following section. The decision support could be improved using the lessons acquired during the implementation and performance evaluation of the selected WHTs (Figure 6.1, dotted line with arrows).

A plot-scale experiment was setup to evaluate the performance of the selected in-situ WHTs in improving on-site water availability for agricultural uses. The effects of the in-situ WHTs on runoff and soil-moisture were monitored using the field experiment. Similarly, the effects of the in-situ WHTs on soil properties such as bulk density, soil organic matter (SOM), saturated (Ksat) and unsaturated (Ks) hydraulic conductivities were also measured. The in-situ WHTs, in general, decreased runoff and soil erosion, and increased availability of soil moisture (Figure 6.1). The effect of the in-situ WHTs is discussed in detail in relation to research questions II and III.

The performance of the catchment-scale WHTs (e.g. percolation ponds and check dams), was monitored at catchment level in a case study in northern Ethiopia. Discharge and sediment yield measurements and modelling studies showed that WHTs help to decrease catchment-level runoff and sediment yield (Figure 6.1). The effect of WHTs on catchment hydrology and sediment yield is discussed in detail in relation to research question IV.

\section{How can appropriate site-specific WHTs be selected in arid and semi-arid areas?}

Overall, the decision support approach developed in this project (Chapter 2) emphasizes that the selection and implementation of WHTs requires the integration of scientific and local knowledge as well as maintaining the participation of relevant stakeholders. Similar to our approach, other researchers (Mbilinyiet al., 2005; Ngigi, 2003; Schwilch et al., 2009), also recommend the integration of scientific expertise with local knowledge in order to create a common understanding among the stakeholders and develop sustainable solutions to existing local problems.

A new insight in the decision support approach from this project was the development of suitability indicators (Table 2.1) for bio-physical assessment of WHTs to a specific area. Land users and extension workers can use the information in Table 2.1 to check if existing bio-physical properties of an area fit with the suitability indicators of specific WHTs. The developed database of suitability indicators for WHTs makes it different from other similar efforts (e.g. Critchley and Siegert, 1991; Liniger et al., 2011; Mekdaschi Studer and Liniger, 2013; Oweis et al., 2001; Prinz, 1996) because it contains a comprehensive set of suitability indicators for an extended list of WHTs applied in arid and semi-arid regions. The suitability indicators of WHTs can also be used by researchers or by development agents to identify areas where specific WHTs can be applied at catchment level. This kind 
of assessment however requires multi-criteria evaluation and decision making in which several criteria/constraints are considered to identify suitable areas for WHTs.

It is worth noting that the list of WHTs and the suitability indicators in Table 2.1 are not exhaustive. The table only contains WHTs that are most commonly applied worldwide. For those WHTs which are not included in this study, it may be necessary to look for other sources to assess the bio-physical suitability of the techniques. The suitability ranges in Tab. 2.1 were compiled from the literature (e.g. Critchley and Siegert, 1991; Liniger et al., 2011; Oweis et al., 2001; Prinz, 1996), hence it might be necessary to change the suitability ranges but with justified explanations.

It remains a challenge to identify suitable areas in large catchments in which bio-physical characteristics are expected to significantly vary spatially (Grum et al., 2016; Pandey et al., 2011). In this case, the use of some decision-making tools such as the GIS-based MCA becomes inevitable. The comparative advantage with the use of decision support tools such as the GIS-based MCA in locating suitable areas is that it makes decision making easier in large catchments (Oweis et al., 2001; Pandey et al., 2011). The GIS-based MCA approach of this project was successfully tested in the upper Geba catchment in northern Ethiopia to identify suitable areas for catchment-scale WHTs such as check-dams, percolation ponds and bench terraces. Our approach was able to correctly locate $90 \%$ of 80 existing check dams and $93 \%$ of 92 existing percolation ponds in the catchment. The suitability indices using this GIS-based MCA identified 23 and 35\% of the upper Geba watershed as suitable for the construction of percolation ponds and bench terraces, respectively. This has the potential to greatly increase the effective use and benefit of catchment-scale WHTs in northern Ethiopia.

Although socio-economic suitability indicators of WHTs are not included in Table 2.1, stakeholders can define these indicators/criteria during the evaluation and selection of WHTs (e.g. Table 2.3) in stakeholder workshops (Grum et al., 2016; Mbilinyi et al., 2005; Schwilch et al., 2012b). It is worth noting that the specific criteria listed in Table 2.3 might not necessarily be appropriate for other areas. For example, in northern Ethiopia the stakeholders prioritized selection criteria such as "improving availability of arable land", considering the limited availability of land for agricultural use. This was also reflected in the selection of bench terraces (Table 2.5), which are used to produce new arable land from uncultivated shrub lands on hillslopes. The regional government of Tigray has also recently started promoting the construction of bench terraces on uncultivated shrub lands to provide new arable land to the youth. In other areas, this criterion may not be necessary and hence other criteria might be prioritized for selection of WHTs. 
The selection workshop highlighted the need for combining WHTs to maximize benefits, and to do more research for testing the performance of WHTs. Based on the stakeholders recommendations, the performance of in-situ (Chapter 3 and 4) and catchment-scale WHTs (Chapter 5) was evaluated at field and catchment scales, respectively. Results from these evaluations validated the belief of the stakeholders that combining WHTs helps to maximize benefits (Grum et al., 2016; Mekonnen et al., 2015b). Combination of in-situ WHTs such as tied ridges and straw mulch was more effective in improving on-site water availability (Table 3.4 ) and decreasing soil losses (Tables 4.3 and 4.4 ) compared to the techniques alone. Moreover, catchment-scale assessment of several combinations of WHTs such as stone bunds, check dams, percolation ponds and check dams resulted in reduction of runoff and sediment yield by $41-45 \%$ and $55-67 \%$, respectively (Table 5.7). The benefits of WHTs as highlighted in Chapters 3, 4 and 5 reflect the need for participatory selection of WHTs in which technical knowledge is combined with stakeholders participation in decision making.

\section{What is the role of in-situ WHTs such as tied ridges and straw mulch in improving on- site water availability in semi-arid areas?}

The development of the decision support approach was intended to select WHTs which can be applied at field and catchment scales (Figure 6.1). In addition to the bio-physical suitability of the techniques (Chapter 2, Table 2.1), the decision methodology requires that techniques be ranked and selected by the stakeholders in a participatory selection workshop. The selected WHTs can then be evaluated for effectiveness. The highest ranking in-situ WHT (Table 2.5) was soil-improvement methods (e.g. mulching, compost, EMs, etc.) which was selected for further testing. Furthermore, tied ridges are also tested in this project to evaluate their effectiveness when combined with straw mulch. On-site water availability was evaluated by looking at effects on soil physical properties, runoff, and SMC.

It has been reported that in-situ WHTs can affect the on-site water regime (e.g. Adimassu et al., 2014; Al-Seekh and Mohammad, 2009; Okeyo et al., 2014), as a result of changes in runoff and SMC. This research project confirmed such results for the in-situ WHTs tested, with average runoff reduction efficiency over two years (2013 and 2014) ranging between $49 \%$ and $88 \%$. The most effective technique in reducing runoff was when tied ridges were combined with straw mulch. The improved efficiency of runoff reduction due to the combined use of in-situ WHTs was also found in studies in Cape Verde (e.g. Baptista et al., 2015b). The combined use of tied ridges and straw mulch also significantly improved SMC. This result too is consistent with other studies (e.g. Ramesh and Devasenapathy, 2006; Wang et al., 2009) in India and China which reported improved SMCs in the soil by the use of different crop-residue mulches with ridges or furrows. This research project has now 
verified the beneficial effects of the combined use of these in-situ WHTs for the conditions of northern Ethiopia.

Our results also provide an important insight on the use of the WHTs tested for increasing SMC. While maize yield significantly increased when straw mulch was used alone (Chapter 4, Table 4.7), it did not significantly increase by the combined use of straw mulch with tied ridges, despite an increase in SMC. The increase is likely the result of the improved temporal distribution of moisture in the soil during dry periods (Stroosnijder, 2003). However, in the case of the combination of straw mulching and tied ridges, there were noticeable signs of aeration stress during intensive rain events in late July 2013 and early August 2014, which would hinder crop growth. Similar symptoms of aeration stress were also reported in another study in northern Ethiopia due to the use of tied ridges in barley fields during seasons with high rainfall (Araya and Stroosnijder, 2010). This indicates in general that the application of in-situ WHTs is not always a simple yes/no decision, and in particular that tied ridges should not be applied during the entire plant growth period, especially during times with high rainfall. Tied ridges can possibly help to increase grain yield in northern Ethiopia when it is applied during drier periods, usually towards the end of the rainy season or in drier regions.

The better performance of in-situ WHTs in reducing runoff and increasing SMC when combined supports the stakeholders' understanding that combining WHTs can maximize benefits (Chapter 2). However it is important to note that improving water availability in the soil does not mean that benefits are maximized as shown by the lack of a significant increase in maize yield when tied ridges and straw mulch were combined (Table 4.7). This is a good indication that the decision support approach can be enriched using lessons learnt from the implementation of WHTs. For example, in addition to defining the selection criteria, stakeholders need to think about whether WHTs need to be combined or not, and if so when.

\section{Can in-situ WHTs help to mitigate land degradation by reducing soil and nutrient losses from farmlands?}

Our research demonstrated that all in-situ WHTs in our study were effective in significantly reducing soil loss (Table 4.3). The good performance of straw mulch in this respect is mainly attributed to its capability to reduce runoff and sediment concentration which has also been noted by other researchers (Gholami et al., 2013; Sadeghi et al., 2015a; Sadeghi et al., 2015b; Prosdocimi et al., 2016b). Straw mulch helps to protect the soil from the impact of raindrop splash and consequently reduces the detachment of soil particles (Cerdà et al., 2016; Okeyo et al., 2014). Straw mulch also slows down overland flow (Cerdà et al., 2016; Jordán et al., 2010) and thus reduces its capacity to detach the 
soil as well as its transport capacity. While tied ridges can reduce soil loss from farmland by trapping runoff and eroded soil in the ridge depressions, the reduction of soil loss in this project was primarily the result of reduced runoff as we found no significant effect of tied ridges on sediment concentration (Chapter 4, Table 4.6).

Although no specific analysis was made to quantify the contribution of in-situ WHTs to reducing runoff and sediment yield at catchment outlets, it can be argued that the contributions could be significant if the use of in-situ WHTs in a catchment is large (e.g. Lanckriet et al., 2012). The reduction in soil loss through use of in-situ WHTs also impacted the loss of nutrients from farmland. The in-situ WHTs tested reduced total N (TN) and total $P$ (TP) losses with tied ridges in combination with straw mulch being the most efficient technique (Tables 4.3 and 4.4). Our result is in agreement with studies in other areas that reported a better efficiency of nutrient loss reduction by combining mulch with compost (Baptista et al., 2015a) and stone rows/grass strips with compost (Zougmoré et al., 2009). This positive effect of the combined use of these in-situ WHTs is now confirmed for northern Ethiopian conditions.

Another potential benefit of straw mulch related to nutrient losses that was revealed in our research is the maintenance of nutrient ( $\mathrm{N}$ and $\mathrm{P}$ ) stocks in the soil. For example, despite the fact that wheat straw contains $0.6 \% \mathrm{~N}$ (Nicholson et al., 1997; Smil, 1999) and $0.1 \% \mathrm{P}$ (Smil, 1999), it is not immediately released into the soil due to its high C:N ratio (Bertoldi et al., 1983). The nutrients will, however, be released to the soil over time due to decomposition and mineralization of straw in the soil. Therefore, the use of straw as mulch would also help in the long run to balance the depletion of nutrients from soils. Where immediate release of nutrients is required from mulch, it is advisable to use organic materials such as compost and organic farmyard manure which have relatively lower C:N compared to straw mulch (Bertoldi et al., 1983).

Although mulching was one of the techniques the stakeholders selected for implementation (Chapter 2, Table 2.5) and showed positive results, it will be important to more closely investigate its acceptance by farmers as an in-situ water harvesting option because wheat straw in the study areas is also used as animal feed. Despite the current acreage of maize cultivation in northern Ethiopia is small compared to other crops and only a small amount of wheat-straw mulch is needed, the competition from animal feed might limit its use. Ways to address this include investigating the use of other types of crop residues for mulching, especially if that crop residue is cheap and not used for animal feeding. Furthermore, it is necessary to compare different rates of straw mulch applications and determine the most optimum rate in terms of cost-effectiveness (Cerdà et al., 2016; Jordán et al., 2010). 
IV. What is the effect of catchment-scale WHTs on catchment hydrological responses and sediment yield in northern Ethiopia?

Regarding the effect of catchment-scale WHTs such as check dams, percolation ponds, and deep trenches on catchment-scale hydrological responses and sediment yield, our findings support that catchment management with WHTs helps to increase ground water level in hand-dug wells, and to decrease runoff and sediment yield at catchment outlets. Modelbased analysis using LISEM at the outlet and sub-outlet of the Gule catchment in northern Ethiopia suggested that the current WHTs applied in the catchment decreased eventbased runoff volume by 41 and $45 \%$, respectively (Table 5.7 ). Sediment yield was similarly decreased by WHTs at the outlet and sub-outlet, with 67 and $55 \%$, respectively. Our results are consistent with the findings of other researchers (e.g. Nyssen et al., 2010; Walraevens et al., 2015) in northern Ethiopia.

The reduction in catchment-level runoff and sediment yield has consequences on the availability of water and status of land degradation in a catchment (Nyssen et al., 2010). It can also have either positive or negative implications for downstream water users (Ngigi, 2003; Rockström et al., 2003). On the one hand, it is possible that downstream water availability might improve due to upstream implementation of WHTs, for example, a higher base flow resulting from enhanced infiltration of water. On the other hand, the abstraction of runoff by upstream WHTs might decrease the direct availability of water for downstream users. Not only WHTs need to be implemented at catchment level to improve water availability and reduce the effect of erosion, it is also necessary to integrate different WHTs in the catchment so that benefits are maximized (Mekonnen et al., 2015b). Of equal importance is assessing the impact of WHTs at a watershed or basin level before these techniques can be up-scaled (Ngigi, 2003; SIWI, 2001).

\subsection{Limitations of the study}

Although this PhD study used sound methodologies of decision support, field experiments and modelling, some limitations in relation to scope, experiment setup and model applications can be pointed out.

In Chapter 2, Table 2.1 provides bio-physical suitability indicators for different WHTs which can be applied in arid and semi-arid areas. The suitability indicators listed here are limited only to bio-physical conditions and lacked socio-economic criteria, which are of course necessary to assess socio-economic suitability of WHTs. If the socio-economic suitability indicators were included, it would have been easier for researchers and land users to carry 
out socio-economic suitability assessment of WHTs for implementation or prior to stakeholder workshops during the selection process.

The field experiments (Chapter 3 and 4) were conducted over two rainy seasons in a semiarid climate in northern Ethiopia. If long-term experiments were used and field trials were setup at different slopes and soil types, the results would have been richer and could have provided more insights. The field experiment was conducted for in-situ WHTs on field slopes which ranged between 1.8 and $3.4 \%$ and on a sandy clay loam Cambisols. Although it is highly recommended that in-situ WHTs are applied at ground slopes below $5 \%$ (Ibraimo and Munguambe, 2007; Ngigi, 2003), it is possible that in-situ WHTs may be used in higher ground slopes in which the performance of the techniques could be different from the result reported in this study. Furthermore, the performance of the in-situ WHTs could also differ in other soil types, as was evident, for example, in the study by Baptista et al. (2015b). Therefore, up-scaling of the results presented in Chapter 3 and 4 is limited to farmlands with gentle slopes and coarse-textured soils.

For the catchment scale work, the LISEM model was used to assess the effect of different WHTs on event-based hydrological and erosion processes in the Gule catchment of northern Ethiopia. Due to the variable characteristics of the rain events, each rain event was calibrated separately for discharge and sediment yield, as was also done in other similar studies (Baartman et al., 2012; Hessel et al., 2006; Hessel et al., 2003a). Calibration of LISEM for separate events, however, limits its capability as a predictive model for future events (Hessel et al., 2006). Therefore, it should be noted that the current calibrated LISEM in the study area cannot be used to predict runoff and sediment yield using future climatic conditions. If events were calibrated uniformly, LISEM would have wider applications in the Gule catchment than it has now.

\subsection{Implications for mitigating water shortage and land degradation}

The findings of this research are discussed in light of contributions to science and society, as well as implications for policies and extension.

\subsubsection{Scientific and societal contributions}

One of the most important scientific contributions of this thesis is the development of a decision support approach for the selection of WHTs which underscores the importance of integrating local and scientific knowledge for improving agricultural productivity. This research also shows the crucial importance of decision-making tools such as the GIS-based MCA which uses the weighted linear combination procedure (Eastman et al., 1995) and 
the Analytical Hierarchy Process (AHP) of decision making (Saaty, 2004) as part of the decision support approach.

Furthermore, the results on the effect of field and catchment-scale WHTs contributes to present knowledge on Integrated Watershed Management (IWM), in order to efficiently use available water within the watershed and minimize land degradation by implementing WHTs at field and land-scape levels. The result of this study contributes also to the use of Climate Smart Agriculture (CSA) technologies (FAO, 2010), which aim to make landscapes more resilient to climate change.

The timely use of mulch alone or in combination with tied ridges was found to have various positive effects which can enhance the resilience of farmlands in northern Ethiopia to the effect of climate variability by minimizing the chances of crop failure. Furthermore, in-situ WHTs improve resilience in socio-economic adaptability as a result of increased food security and income (Vohland and Barry, 2009).

Our study has shown that the use of catchment-scale WHTs such as stone bunds, checkdams, percolation ponds, etc. reduce runoff losses from a catchment, hence increasing ground water levels, which was also seen as key by other researchers in northern Ethiopia (e.g. Nyssen et al., 2010; Walraevens et al., 2015). The increase in ground-water storage (sometimes called "water bank" in the Ethiopian context) due to the use of WHTs also enhances the resilience of agricultural systems to climate change.

The model-based assessment of the effect of catchment-scale WHTs using LISEM, also contributes to the understanding of event-based hydrological processes. Although there already existed model-based efforts to quantify runoff and sediment yield at a catchment scale in Ethiopia (e.g. Betrie et al., 2011; Gebreyohannes et al., 2013; Haregeweyn et al., 2013), evidence was lacking on the effect of WHTs on event-based hydrological and erosion processes. The calibrated LISEM in northern Ethiopia can be used for assessing the impact of existing or future land-use scenarios on catchment hydrology and sediment yield.

The societal contribution of this research is evident in the Ethiopian context, where around $85 \%$ of the society is dependent on rain-fed agriculture. Any research contributing to the improvement of the agricultural systems will be welcomed by the society as it enables greater food security. The improved efficiency of water harvesting at farm and catchment level contributes to the improvement of water availability and reductions in loss of soil and nutrients. This in turn can improve crop yield and the livelihood of the residents of northern Ethiopia. 
The use of the participatory approach in the selection and implementation of WHTs not only empowers local stakeholders in decision-making, it can also increase the chance of the selected WHTs being adopted. This enhanced adoption can also pave a way to upscale these techniques to other areas in the country.

\subsubsection{Extension and policy implications}

The findings of this research and other studies conducted elsewhere (Baptista et al., 2015b; Schwilch et al., 2009; Tavares et al., 2014) show that decision making regarding the selection and implementation of land management technologies is most effective as a collective effort in which all relevant stakeholders are involved. Currently in Ethiopia, land management practices such as WHTs are implemented using a top-down approach without proper consultation with the local community. In a top-down approach, land users are considered as executors of decisions made at a higher level regarding the implementation of land management practices (Schwilch et al., 2009). The result often in the failure or non-acceptance of the implemented land management practices (Schwilch et al., 2009). Therefore, it is strongly recommended that the current land management strategy in Ethiopia be consciously revised to a participatory approach in which all relevant stakeholders, including the farmers, are involved at all levels of decision making regarding land management practices. This requires the participation of farmers, researchers and experts from governmental and non-governmental organizations, representatives of government officials, extension workers, and development agents, etc. in the selection of WHTs.

The results of this study demonstrate that in-situ WHTs are useful to improve on-site water availability for plant growth as well as reducing soil loss from farmlands. Farmers therefore need to be advised to use straw mulch for decreasing the prevalence of crop failures during dry spells and mitigating soil degradation. The use of straw mulch further improves maize yield substantiating the role of mulch in increasing water availability in the soil for plant growth. There are other studies in Ethiopia showing that various on-farm conservation agriculture decreases runoff and soil losses from farmlands (e.g. Araya et al., 2011; Gebreegziabher et al., 2009; McHugh et al., 2007). Due to the increased use of such on-farm conservation activities and other agricultural inputs (e.g. fertilizers and improved seeds) total food production has now improved in Ethiopia (Nyssen et al., 2015). Therefore, government policies on agricultural systems need to be re-formulated to upscale the use of on-farm conservation measures beyond field research trials. For better effect, policy makers and researchers need to work together, with farmers, to explore how and where this on-farm conservation measures can be applied. 
Research findings from this study and other similar works in northern Ethiopia (e.g. Nyssen et al., 2010; Walraevens et al., 2015) indicate that catchment management with WHTs and small reservoirs (Haregeweyn et al., 2013; Haregeweyn et al., 2008) have contributed to the reduction of sediment yield and an increase in groundwater tables. These findings along with the positive impacts of in-situ WHTs are promising developments for addressing food insecurity in northern Ethiopia (Nyssen et al., 2010) and improving on the efforts of the government and other actors to rehabilitate degraded land using soil and water conservation measures (Nyssen et al., 2015; Vancampenhout et al., 2006; Walraevens et al., 2015). Considering that the economic backbone of Ethiopia is still highly dependent on agriculture and to realize the agriculture led industrialization policy, lessons learnt in northern Ethiopia need to strengthened and up-scaled to other areas in the country. This requires documentation and preparation of guidelines of best practices and approaches of WHTs so that similar techniques can be applied elsewhere.

One possible approach, which was emphasized in this study (Chapter 5), is the implementation of individual or combined WHTs at different landscapes of a catchment to maximize the effectiveness of the techniques (Mekonnen et al., 2015b). So, preparation of guidelines (in local languages as well) on best practices of WHTs in Ethiopia requires a strong commitment and a collaborative effort among different actors such as policy makers, research institutions and governmental and non-governmental development agents as well as other stakeholders. Current efforts in Ethiopia for sharing best practices of land management are usually through field visits. Although experience sharing through field visits is beneficial, it needs a lot of effort and resource to move people from region to other and hence the intended impact can be undermined due to financial limitations.

The implementation of landscape-based WHTs has further implications on the use of downstream water resources. The retention of sediments by WHTs upstream of a catchment further helps to decrease siltation of downstream water-storage structures such as check-dam ponds, percolation ponds and micro-dams (Haregeweyn et al., 2008b). However, downstream water supplies can also be negatively affected. Therefore, policy makers and land users need to study existing landscape conditions and downstream water uses before they can implement WHTs at catchment level. Looking at the different landscapes of a catchment, erosion prone areas can be protected by implementing appropriate WHTs which can effectively decrease erosion in the catchment as well as reducing sediment yield downstream of the catchment. 


\subsection{Research challenges and future research directions}

This thesis has addressed the selection of WHTs by developing a decision support approach and evaluating the effect of in-situ and catchment-scale WHTs on various hydrological processes and sediment yields at various scales. The following issues, however, need to be further investigated in order to obtain a full-fledged understanding of the effects of implementation of WHTs, which is needed to maximize the benefits locally, and to allow up-scaling to larger catchments.

- Explore the application of the decision support approach using socio-economic suitability indicators. A comprehensive evaluation of the suitability of WHTs considering both bio-physical and socio-economic factors prior to the selection workshop would simplify decision-making for stakeholders.

- Assess the effect of different straw mulch application rates on runoff, soilmoisture, soil and nutrient losses and requirements for additional nutrients based on local conditions.

- Investigate the effectiveness of EMs applied with organic materials of varying C:N ratio to ascertain the release of nutrient to the soil for increasing crop yield.

- Identify the stage of plant growth when tied ridges can be safely installed in order to avoid collection of excess water in the ridge depressions and aeration stress. The evaluation can be done for different crops, as crops have variable sensitivity to aeration stress due to excess water.

- Further explore the capability of LISEM to adequately describe soil erosion processes in steeply sloping catchments and the representativeness of the values of soil erosion parameters in LISEM to adequately represent soil physical parameters. This is necessary before sediment yield modelling results can be directly up-scaled to other areas.

- Evaluate the effect of different catchment-level land-use scenarios (e.g. land-use change and/or the use of new WHTs) on catchment hydrology and sediment yield. Despite the proven benefits of catchment-scale WHTs in reducing runoff and sediment yield in the upper Geba catchment, it will be important to understand the extent of the effects of future WHT interventions on water resource availability in the catchment. This will be of value in planning further catchment-based interventions. 


\subsection{General conclusions}

The thesis developed and demonstrated the benefits of multi-faceted approach to selecting WHTs that can be implemented in arid and semi-arid areas. It further investigated the role of in-situ and catchment-scale WHTs on the capture and availability of rainwater for agricultural production and erosion control in northern Ethiopia. The following general conclusions are drawn based on the results of the study.

- A decision support approach which integrates bio-physical knowledge/tools, socio-economic criteria, GIS-based MCA where needed and participatory, multistakeholder workshops helps to more effectively select appropriate WHTs.

- In-situ WHTs improve water availability by significantly decreasing net runoff loss from farmlands. Straw mulch was the most optimum in-situ WHT for improving maize yield in the semi-arid northern Ethiopia. In relatively water scarce or arid areas, tied ridges combined with straw mulch are an efficient technique for reducing runoff and improving soil-moisture in farmlands.

- In-situ WHTs are useful for mitigating soil degradation by decreasing soil and nutrient losses from farmlands. The efficiency of reduction in soil and nutrient losses increased when straw mulch was applied in combination with tied ridges.

- LISEM can be used to model runoff and sediment yield in catchments under the influence of WHTs. The model performance for runoff prediction by LISEM was satisfactory although LISEM overestimated sediment yield at catchment level.

- Catchment-scale model simulations indicated that runoff and sediment yield can be reduced by implementing WHTs in a catchment. The general trend of areaspecific decrease in unit runoff and sediment yield with increasing catchment area was violated in catchments with WHTs, demonstrating the effect of WHTs in reducing runoff and sediment yield at catchment level. 


\section{Literature cited}

Abbasi, M.K., Tahir, M.M., Sabir, N., Khurshid, M., 2015. Impact of the addition of different plant residues on nitrogen mineralization-immobilization turnover and carbon content of a soil incubated under laboratory conditions. Solid Earth 6, 197-205.

Abedini, M., Md Said, M.A., Ahmad, F., 2012. Effectiveness of check dam to control soil erosion in a tropical catchment (The Ulu Kinta basin). Catena 97, 63-70.

Abramoff, M., Magalhaes, P.J., Ram, S., 2004. Image processing with ImageJ. Biophotonics Int. 11, 36-42.

Abrisqueta, J.M., Plana, V., Mounzer, O.H., Mendez, J., Ruiz-Sánchez, M.C., 2007. Effects of soil tillage on runoff generation in a Mediterranean apricot orchard. Agric. Water Manag. 93, 11-18.

Abrisqueta, J.M., Plana, V., Ruiz-Canales, A., Ruiz-Sánchez, M.C., 2006. Unsaturated hydraulic conductivity of disturbed and undisturbed loam soil. Span. J. Agric. Res. 4, 91-96.

Adekalu, K.O., Olorunfemi, I.A., Osunbitan, J.A., 2007. Grass mulching effect on infiltration, surface runoff and soil loss of three agricultural soils in Nigeria. Biores. Technol. 98, 912-917.

Adimassu, Z., Mekonnen, K., Yirga, C., Kessler, A., 2014. Effect of soil bunds on runoff, soil and nutrient losses, and crop yield in the central highlands of Ethiopia. Land Degrad. Dev. 25, 554-564.

Alcamo, J., Flörke, M., Märker, M., 2007. Future long-term changes in global water resources driven by socio-economic and climatic changes. Hydrol. Sci. J. 52, 247-275.

Ali, I., Khan, F., Bhatti, A.U., 2007. Soil and nutrient losses by water erosion under monocropping and legume inter-cropping on sloping land. Pak. J. Agric. Res. 44, 3-4.

Ali, A., Oweis, T., Salkini, A.B., El-Naggar, S., 2009. Rainwater cisterns: traditional technologies for dry areas. ICARDA, Aleppo, Syria.

Al-Seekh, S.H., Mohammad, A.G., 2009. The effect of water harvesting techniques on runoff, sedimentation, and soil properties. Environ. Manag. 44, 37-45.

Araya, T., Cornelis, W.M., Nyssen, J., Govaerts, B., Bauer, H., Gebreegziabher, T., Oicha, T., Raes, D., Sayre, K.D., Haile, M., Deckers, J., 2011. Effects of conservation agriculture on runoff, soil loss and crop yield under rainfed conditions in Tigray, northern Ethiopia. Soil Use Manag. 27, 404-414. 
Araya, A., Stroosnijder, L., 2010. Effects of tied ridges and mulch on barley (Hordeum vulgare) rainwater use efficiency and production in Northern Ethiopia. Agric. Water Manag. 97, 841-847.

Baartman, J.E., Jetten, V.G., Ritsema, C.J., De Vente, J., 2012. Exploring effects of rainfall intensity and duration on soil erosion at the catchment scale using openLISEM: Prado catchment, SE Spain. Hydrol. Process. 26, 1034-1049.

Balooni, K., Kalro, A.H., Kamalamma, A.G., 2008. Community initiatives in building and managing temporary check-dams across seasonal streams for water harvesting in South India. Agric. Water Manag. 95, 1314-1322.

Baptista, I., Ritsema, C., Geissen, V., 2015a. Effect of integrated water-nutrient management strategies on soil erosion mediated nutrient loss and crop productivity in Cabo Verde drylands. PLos One 10, 1-23.

Baptista, I., Ritsema, C., Querido, A., Ferreira, A.D., Geissen, V., 2015b. Improving rainwater-use in Cabo Verde drylands by reducing runoff and erosion. Geoderma 237238, 283-297.

Batchelor, C., Singh, A., Mohan Rao, R.M., Butterworth, J., 2002. Mitigating the potential unintended impacts of waterharvesting. IWRA International Regional Symposium on Water for Human Survival, New Delhi, India.

Beasley, D., Huggins, L., 1982. ANSWERS users manual. U.S. Environmental Protection Agency. Purdue University, West Lafayette, Indiana.

Belmans, C., Wesseling, J.G., Feddes, R.A., 1983. Simulation model of the water balance of a cropped soil: SWATRE. J. Hydrol. 63, 271-286.

Bertoldi, M.D., Vallini, G., Pera, A., 1983. The biology of composting: A review. Waste Manag. Res. 1, 157-176.

Betrie, G.D., Mohamed, Y.A., Van Griensven, A.A., Srinivasan, R., 2011. Sediment management modelling in the Blue Nile Basin using SWAT model. Hydrol. Earth Syst. Sci. 15, 807-818.

Beven, K., 2004. Robert E. Horton's perceptual model of infiltration processes. Hydrol. Process. 18, 3447-3460.

Biazin, B., Sterk, G., Temesgen, M., Abdulkedir, A., Stroosnijder, L., 2012. Rainwater harvesting and management in rainfed agricultural systems in sub-Saharan Africa: $A$ review. Phys. Chem. Earth, Parts A/B/C 47-48, 139-151.

Blake, G.R., Hartge, K., 1986. Bulk density, in: Klute A. (Eds.), Methods of soil analysis, part 1, physical and mineralogical methods. Am. Soc. Agron., Madison, pp. 363-375.

Boelee, E., Yohannes, M., Poda, J.N., Mccartney, M., Cecchi, P., Kibret, S., Hagos, F., Laamrani, H., 2013. Options for water storage and rainwater harvesting to improve health and resilience against climate change in Africa. Reg. Environ. Change 13, 509519. 
Boers, M., Ben-Asher, J., 1982. A review of rainwater harvesting. Agric. Water Manag. 5, 145-158.

Boix-Fayos, C., Barberá, G.G., López-Bermúdez, F., Castillo, V.M., 2007. Effects of check dams, reforestation and land-use changes on river channel morphology: Case study of the Rogativa catchment (Murcia, Spain). Geomorph. 91, 103-123.

Cammeraat, L.H., 2002. A review of two strongly contrasting geomorphological systems within the context of scale. Earth Surf. Process. Landf. 27, 1201-1222.

Cantón, Y., Solé-Benet, A., De Vente, J., Boix-Fayos, C., Calvo-Cases, A., Asensio, C., Puigdefábregas, J., 2011. A review of runoff generation and soil erosion across scales in semiarid south-eastern Spain. J. Arid Environ. 75, 1254-1261.

Cerdà, A., Flanagan, D.C., Le Bissonnais, Y., Boardman, J., 2009. Soil erosion and agriculture. Soil Tillage Res. 106, 107-108.

Cerdà, A., Gonzalez-Pelayo, O., Gimelnez-Morera, A., Jordan, A., Pereira, P., Novara, A., Brevik, E.C., Prosdocimi, M., Mahmoodabadi, M., Keesstra, S.D., Garcia, Orenes, F., Ritsema, C.J., 2016. Use of barley straw residues to avoid high erosion and runoff rates on persimmon plantations in Eastern Spain under low frequency-high magnitude simulated rainfall events. Soil Res. 54, 154-165.

Cerdan, O., Le Bissonnais, Y., Govers, G., Lecomte, V., Van Oost, K., Couturier, A., King, C., Dubreuil, N., 2004. Scale effect on runoff from experimental plots to catchments in agricultural areas in Normandy. J. Hydrol. 299, 4-14.

Chakraborty, D., Nagarajan, S., Aggarwal, P., Gupta, V.K., Tomar, R.K., Garg, R.N., Sahoo, R.N., Sarkar, A., Chopra, U.K., Sarma, K.S.S., Kalra, N., 2008. Effect of mulching on soil and plant water status, and the growth and yield of wheat (Triticum aestivum L.) in a semi-arid environment. Agric. Water Manag. 95, 1323-1334.

Chiroma, A.M., Alhassan, A.B., Yakubu, H., 2006a. Growth, nutrient composition and straw yield of sorghum as affected by land configuration and wood-chips mulch on a sandy loam soil in Northeast Nigeria. Int. J. Agric. Biol. 8, 770-773.

Chiroma, A.M., Folorunso, O.A., Alhassan, A.B., 2006b. The effects of land configuration and wood-shavings mulch on the properties of a sandy loam soil in Northeast Nigeria.

1. Changes in chemical properties. Tropicultura 24, 129-134.

Chow, V.T., 1959. Open-channel hydraulics. McGraw-Hill, New York.

Cook, H.F., Valdes, G.S.B., Lee, H.C., 2006. Mulch effects on rainfall interception, soil physical characteristics and temperature under Zea mays L. Soil Tillage Res. 91, 227235.

Cooper, P.J.M., Dimes, J., Rao, K.P.C., Shapiro, B., Shiferaw, B., Twomlow, S., 2008. Coping better with current climatic variability in the rain-fed farming systems of sub-Saharan Africa: An essential first step in adapting to future climate change? Agric. Ecosyst. Environ. 126, 24-35. 
Coppus, R., Imeson, A.C., 2002. Extreme events controlling erosion and sediment transport in a semi-arid sub-andean valley. Earth Surf. Process. Landf. 27, 1365-1375.

Critchley, W., Siegert, K., 1991. A manual for the design and construction of water harvesting schemes for plant production. Water Harvesting (AGL/MISC/17/91), FAO, Rome.

Dagnew, D.C., Guzman, C.D., Zegeye, A.D., Tibebu, T.Y., Getaneh, M., Abate, S., Zemale, F.A., Ayana, E.K., Tilahun, S.A., Steenhuis, T.S., 2015. Impact of conservation practices on runoff and soil loss in the sub-humid Ethiopian highlands: The Debre Mawi watershed. J. Hydrol. Hydromech. 63, 210-219.

Damene, S., Tamene, L., Vlek, P.L.G., 2013. Performance of exclosure in restoring soil fertility: A case of Gubalafto district in North Wello zone, northern highlands of Ethiopia. Catena 101, 136-142.

De Barros, C.A.P., Minella, J.P.G., Dalbianco, L., Ramon, R., 2014. Description of hydrological and erosion processes determined by applying the LISEM model in a rural catchment in southern Brazil. J. Soils Sediments 14, 1298-1310.

De Roo, A.P.J., Offermans, R.J.E., Cremers, N.H.D.T., 1999a. LISEM: A single-event, physically based hydrological and soil erosion model for drainage basins. II: Sensitivity analysis, validation and application. Hydrol. Process. 10, 1119-1126.

De Roo, A.P.J., Wesseling, C.G., Ritsema, C.J., 1996b. LISEM: a single-event physically based hydrological and soil erosion model for drainage basins. I: Theory, input and output. Hydrol. Process. 10, 1107-1 117.

De Vente, J., Poesen, J., 2005. Predicting soil erosion and sediment yield at the basin scale: Scale issues and semi-quantitative models. Earth-Sci. Rev. 71, 95-125.

De Vente, J., Poesen, J., Arabkhedri, M., Verstraeten, G., 2007. The sediment delivery problem revisited. Prog. Phys. Geogr. 31, 155-178.

Descheemaeker, K., Nyssen, J., Poesen, J., Raes, D., Haile, M., Muys, B., Deckers, S., 2006a. Runoff on slopes with restoring vegetation: A case study from the Tigray highlands, Ethiopia. J. Hydrol. 331, 219-241.

Descheemaeker, K., Nyssen, J., Rossi, J., Poesen, J., Haile, M., Raes, D., Muys, B., Moeyersons, J., Deckers, S., 2006b. Sediment deposition and pedogenesis in exclosures in the Tigray highlands, Ethiopia. Geoderma 132, 291-314.

Desta, G., Nyssen, J., Poesen, J., Deckers, J., Haile, M., Govers, G., Moeyersons, J., 2005. Effectiveness of stone bunds in controlling soil erosion on cropland in the Tigray highlands, northern Ethiopia. Soil Use Manag. 21, 287-297.

Donjadee, S., Tingsanchali, T., 2016. Soil and water conservation on steep slopes by mulching using rice straw and vetiver grass clippings. Agric. Nat. Res. 50, 75-79.

Dos Anjos, N.F.R., 1998. Source book of alternative technologies for freshwater augmentation in Latin America and the Caribbean. Int. J. Water Res. Dev. 14, 365-398. 
Eastman, R.J., Jin, W., Kyem, P.A., Toledano, J., 1995. Raster procedure for multicriteria/multi-objective decisions. Photogramm. Eng. Remote Sens. 61, 539-547.

Eickenscheidt, T., Heinichen, J., Augustin, J., Freibauer, A., Drösler, M., 2014. Nitrogen mineralization and gaseous nitrogen losses from waterlogged and drained organic soils in a black alder (Alnus glutinosa (L.) Gaertn.) forest. Biogeosci. 11, 2961-2976.

Elewa, H., Qaddah, A., El-Feel, A., 2012. Determining potential sites for runoff water harvesting using remote sensing and geographic information systems-based modeling in Sinai. Am. J. Environ. Sci. 8, 42-55.

Enfors, E.I., Gordon, L.J., 2008. Dealing with drought: the challenge of using water system technologies to break dryland poverty traps. Glob. Environ. Change 18, 607-616.

FAO, 2010. "Climate-Smart" agriculture: policies, practices and financing for food security, adaptation and mitigation. FAO UN, Rome.

FAO, 2001. Lecture notes on the major soils of the world. World Soil Resources Reports 94. FAO UN, Rome.

FAO, 1998. The soil and terrain database for northeastern Africa (CDROM), Rome.

FAO, 1986. Ethiopian highlands reclamation study. Final Report Volume 1. FAO UN, Rome.

Fernández, C., Vega, J.A., 2016. Effects of mulching and post-fire salvage logging on soil erosion and vegetative regrowth in NW Spain. For. Ecol. Manag. 375, 46-54.

Fiener, P., Auerswald, K., Weigand, S., 2005. Managing erosion and water quality in agricultural watersheds by small detention ponds. Agric. Ecosyst. Environ. 110, $132-$ 142.

Fisseha, G., Gebrekidan, H., Kibret, K., Bedadi, B., Yitaferu, B., 2011. Participatory development of soil conservation measures at the Debre-Mewi watershed in the upper catchment of the Blue Nile basin, northwest Ethiopia. J. Biodivers. Environ. Sci. 1, 199-213.

Fox, P., Rockström, J., 2003. Supplemental irrigation for dry-spell mitigation of rainfed agriculture in the Sahel. Agric. Water Manag. 61, 29-50.

Fu, C., Chen, J., Jiang, H., Dong, L., 2013. Threshold behavior in a fissured granitic catchment in southern China: 1 . Analysis of field monitoring results. Water Res. Res. 49, 2519-2535.

Gao, P., Josefson, M., 2012. Event-based suspended sediment dynamics in a central New York watershed. Geomorphol. 139-140, 425-437.

Gates, J.B., Scanlon, B.R., Mu, X., Zhang, L., 2011. Impacts of soil conservation on groundwater recharge in the semi-arid Loess Plateau, China. Hydrogeol. J. 19, 865875.

Gebreegziabher, T., Nyssen, J., Govaerts, B., Getnet, F., Behailu, M., Haile, M., Deckers, J., 2009. Contour furrows for in situ soil and water conservation, Tigray, northern Ethiopia. Soil Tillage Res. 103, 257-264. 
Gebreyohannes, T., De Smedt, F., Walraevens, K., Gebresilassie, S., Hussien, A., Hagos, M., Amare, K., Deckers, J., Gebrehiwot, K., 2013. Application of a spatially distributed water balance model for assessing surface water and groundwater resources in the Geba basin, Tigray, Ethiopia. J. Hydrol. 499, 110-123.

Gerten, D., Heinke, J., Hoff, H., Biemans, H., Fader, M., Waha, K., 2011. Global water availability and requirements for future food production. J. Hydrometeorol. 12, 885899.

Gholami, L., Sadeghi, S.H., Homaee, M., 2013. Straw mulching effect on splash erosion, runoff, and sediment yield from eroded plots. Soil Sci. Soc. Am. J. 77, 268-278.

Girmay, G., Singh, B.R., Nyssen, J., Borrosen, T., 2009. Runoff and sediment-associated nutrient losses under different land uses in Tigray, northern Ethiopia. J. Hydrol. 376, 70-80.

Glendenning, C.J., Vervoort, R.W., 2011. Hydrological impacts of rainwater harvesting (RWH) in a case study catchment: The Arvari River, Rajasthan, India Part 2. Catchment-scale impacts. Agric. Water Manag. 98, 715-730.

Gonzalez-Hidalgo, J.C., Batalla, R.J., Cerdà, A., De Luis, M., 2010. Contribution of the largest events to suspended sediment transport across the USA. Land Degrad. Develop. 21, 83-91.

Green, H.W., Ampt, G.A., 1911. Studies on soil phyics. J. Agric. Sci. 4, 1-24.

Grum, B., Hessel, R., Kessler, A., Woldearegay, K., Yazew, E., Ritsema, C., Geissen, V. 2016. A decision support approach for the selection and implementation of water harvesting techniques in arid and semi-arid regions. Agric. Water Manag. 173, 35-47.

Guyassa, E., Frankl, A., Zenebe, A., Poesen, J., Nyssen, J., 2015. Tropical lakes in a changing environment: Water, land, biology, climate and humans. Book of abstracts, TropiLakes2015.

Haregeweyn, N., Poesen, J., Deckers, J., Nyssen, J., Haile, M., Govers, G., Verstraeten, G., Moeyersons, J., 2008a. Sediment-bound nutrient export from micro-dam catchments in northern Ethiopia. Land Degrad. Develop. 19, 136-152.

Haregeweyn, N., Poesen, J., Nyssen, J., Govers, G., Verstraeten, G., De Vente, J., Deckers, J., Moeyersons, J., Haile, M., 2008b. Sediment yield variability in northern Ethiopia: A quantitative analysis of its controlling factors. Catena 75, 65-76.

Haregeweyn, N., Poesen, J., Verstraeten, G., Govers, G., De Vente, J., Nyssen, J., Deckers, J., Moeyersons, J., 2013. Assessing the performance of a spatially distributed soil erosion and sediment delivery model (Watem/Sedem) in northern Ethiopia. Land Degrad. Develop. 24, 188-204.

Helmreich, B., Horn, H., 2009. Opportunities in rainwater harvesting. Desalination 248, 118-124.

Herschy, R.W., 1995. Streamflow measurement, second edition. Chapman and Hall, London. 
Hessel, R., 2002. Modelling soil erosion in a small catchment on the Chinese Loess plateau. $\mathrm{PhD}$ thesis. Utrecht University, Utrecht.

Hessel, R., Jetten, V., Liu, B., Zhang, Y., Stolte, J., 2003a. Calibration of the LISEM model for a small Loess Plateau catchment. Catena 54, 235-254.

Hessel, R., Messing, I., Liding, C., Ritsema, C., Stolte, J., 2003b. Soil erosion simulations of land use scenarios for a small Loess Plateau catchment. Catena 54, 289-302.

Hessel, R., Tenge, A., 2008. A pragmatic approach to modelling soil and water conservation measures with a catchment scale erosion model. Catena 74, 119-126.

Hessel, R., Van Den Bosch, R., Vigiak, O., 2006. Evaluation of the LISEM soil erosion model in two catchments in the East African Highlands. Earth Surf. Process. Landf. 31, 469486.

Hu, C., Qi, Y., 2013. Long-term effective microorganisms application promote growth and increase yields and nutrition of wheat in China. Eur. J. Agron. 46, 63-67.

Hu, Q., Wu, W., Xia, T., Yu, Q., Yang, P., Li, Z., Song, Q., 2013. Exploring the use of google earth imagery and object-based methods in land use/cover mapping. Remote Sens. 5 , 6026-6042.

Hunting, 1974. Central Tigre development study. Working paper I: soils and land classification, Hemel Hempstead, Hunting Technical Services Ltd.

Hussain, T., Javaid, T., Parr, J.F.J., Jilani, G., Haq, M., 1999. Rice and wheat production in Pakistan with effective microorganisms. Am. J. Altern. Agric. 14, 30-36.

Ibraimo, N., Munguambe, P., 2007. Rainwater harvesting technologies for small scale rainfed agriculture in arid and semi-arid areas. Waternet Project, South Africa.

Ismail, S.M., 2013. Influence of effective microorganisms and green manure on soil properties and productivity of pearl millet and alfalfa grown on sandy loam in Saudi Arabia. Afr. J. Microbiol. Res. 7, 375-382.

IUSS Working Group WRB, 2015. World reference base for soil resources 2014, update 2015. International soil classification system for naming soils and creating legends for soil maps. World Soil Resources Reports No. 106. FAO, Rome.

Jackson, M.L., 1958. Soil chemical analysis. Prentice-Hall Inc., New Jersey, USA.

Jamali, I.A., Olofsson, B., Mörtberg, U., 2013. Locating suitable sites for the construction of subsurface dams using GIS. Environ. Earth Sci. 70, 2511-2525.

Jarvis, A., Reuter, H.I., Nelson, A., Guevara, E., 2006. Hole-filled seamless SRTM data V3, International FAO Centre for Tropical Agriculture (CIAT).

Javaid, A., Bajwa, R., 2011. Field evaluation of effective microorganisms (EM) application for growth, nodulation, and nutrition of mung bean. Turk. J. Agric. For. 35, 443-452.

Jester, W., Klik, A., 2005. Soil surface roughness measurement-methods, applicability, and surface representation. Catena 64, 174-192.

Jetten, V., De Roo, A.D., Favis-mortlock, D., 1999. Evaluation of field-scale and catchmentscale soil erosion models. Catena 37, 521-541. 
Jie, Y., Haijin, Z., Xiaoan, C., Le, S., 2013. Effects of tillage practices on nutrient loss and soybean growth in red-soil slope farmland. Int. Soil Water Conserv. Res. 1, 49-55.

Jin, K., Cornelis, W.M., Gabriels, D., Schiettecatte, W., De Neve, S., Lu, J., Buysse, T., Wu, H., Cai, D., Jin, J., Harmann, R., 2008. Soil management effects on runoff and soil loss from field rainfall simulation. Catena 75, 191-199.

Jordán, A., Zavala, L.M., Gil, J., 2010. Effects of mulching on soil physical properties and runoff under semi-arid conditions in southern Spain. Catena 81, 77-85.

Kandel, D.D., Western, A.W., Grayson, R.B., Turral, H.N., 2004. Process parameterization and temporal scaling in surface runoff and erosion modelling. Hydrol. Process. 18, 1423-1446.

Kay, M., 2008. Practical hydraulics, second edition. Taylor and Francis, Landon and New York.

Kongo, V.M., Jewitt, G.P.W., 2006. Preliminary investigation of catchment hydrology in response to agricultural water use innovations: A case study of the Potshini catchment - South Africa. Phys. Chem. Earth 31, 976-987.

Kraaijvanger, R., Veldkamp, T., 2015. Grain productivity, fertilizer response and nutrient balance of farming systems in Tigray, Ethiopia: A multi-perspective view in relation to soil fertility degradation. Land Degrad. Develop. 26, 701-710.

Lal, R., 1998. Mulching effects on runoff, soil erosion and crop response on Alfisols in Western Nigeria. J. Sustain. Agric. 11, 135-154.

Lanckriet, S., Araya, T., Cornelis, W., Verfaillie, E., Poesen, J., Govaerts, B., Bauer, H., Deckers, J., Haile, M., Nyssen, J., 2012. Impact of conservation agriculture on catchment runoff and soil loss under changing climate conditions in May Zeg-zeg (Ethiopia). J. Hydrol. 475, 336-349.

Le Bissonnais, Y., Benkhadra, H., Chaplot, V., Fox, D., King, D., Daroussin, J., 1998. Crusting, runoff and sheet erosion on silty loamy soils at various scales and upscaling from $\mathrm{m}^{2}$ to small catchments. Soil Tillage Res. 46, 69-80.

Lee, C.T., Ismail, M.N., Razali, F., Muhamud, I.I., Sarmidi, M.R., Khamis, A.K., 2008. Application of effective microorganisms on soil and maize. J. Chem. Nat. Res. Eng. Spēc. Edition, 1-13.

Lesschen, J.P., Schoorl, J.M., Cammeraat, L.H., 2009. Modelling runoff and erosion for a semi-arid catchment using a multi-scale approach based on hydrological connectivity. Geomorphol. 109, 174-183.

Li, X.Y., Gong, J.D., Gao, Q.Z., Li, F.R., 2001. Incoporation of ridge and furrow method of rainfall harvesting with mulching for crop production under semiarid conditions. Agric. Water Manag. 50, 173-183.

Li, X.Y., Gong, J.D., Wei, X.H., 2000. In-situ rainwater harvesting and gravel mulch combination for corn production in the dry semi-arid region of China. J. Arid Environ. $46,371-382$. 
Li, Y.S., Wu, L.H., Zhao, L.M., Lu, X.H., Fan, Q.L., Zhang, F.S., 2007. Influence of continuous plastic film mulching on yield, water use efficiency and soil properties of rice fields under non-flooding condition. Soil Tillage Res. 93, 370-378.

Liniger, H.P., Mekdaschi Studer, R., Hauert, C., Gurtner, M., 2011. Sustainable land management in practice guidelines and best practices for sub-Saharan Africa. TerrAfrica, World Overview of Conservation Approaches and Technologies (WOCAT) and Food and Agriculture Organization of the United Nations (FAO UN).

Mahmoud, E., Abd El-Kader, N., 2015. Heavy metal immobilization in contaminated soils using phosphogypsum and rice straw compost. Land Degrad. Dev. 26, 819-824.

Malczewski, J., 2000. On the use of weighted linear combination method in GIS: Common and best practice approaches. Trans. GIS 4, 5-22.

Mason, W.K., Pritchard, K.E, Small, D.R., 1987. Effects of early season waterlogging on maize growth and yield. Aust. J. Agric. Res. 38, 27-35.

Mati, B.M., 2005. Overview of water and soil nutrient management under smallholder rainfed agriculture in East Africa. Working Paper 105. International Water Management Institute (IWMI), Colombo, Sri Lanka.

Mbilinyi, B.P., Tumbo, S.D., Mahoo, H.F., Mkiramwinyi, F.O., 2007. GIS-based decision support system for identifying potential sites for rainwater harvesting. Phys. Chem. Earth, Parts A/B/C 32, 1074-1081.

Mbilinyi, B.P., Tumbo, S.D., Mahoo, H.F., Senkondo, E.M., Hatibu, N., 2005. Indigenous knowledge as decision support tool in rainwater harvesting. Phys. Chem. Earth, Parts A/B/C 30, 792-798.

McHugh, O.V., Steenhuis, T.S., Berihun, A., Fernandes, E.C.M., 2007. Performance of in situ rainwater conservation tillage techniques on dry spell mitigation and erosion control in the drought-prone north Wello zone of the Ethiopian highlands. Soil Tillage Res. 97, 19-36.

Medeiros, P.H.A., Güntner, A., Francke, T., Mamede, G.L., Carlos De Araújo, J., 2010. Modelling spatio-temporal patterns of sediment yield and connectivity in a semi-arid catchment with the WASA-SED model. Hydrol. Sci. J. 55, 636-648.

Mekdaschi Studer, R., Liniger, H., 2013. Water harvesting: guidelines to good practice. Centre for Development and Environment (CDE), Bern; Rainwater Harvesting Implementation Network (RAIN), Amsterdam; MetaMeta, Wageningen; The International Fund for Agricultural Development (IFAD), Rome.

Mekonnen, M., Keesstra, S.D., Baartman, J.E., Ritsema, C.J., Melesse, A.M., 2015a. Evaluating sediment storage dams: structural off-site sediment trapping measures in northwest Ethiopia. Cuadernos Investigación Geográfica 41, 7-22.

Mekonnen, M., Keesstra, S.D., Stroosnijder, L., Baartman, J.E.M., Maroulis, J., 2015b. Soil conservation through sediment trapping: A review. Land Degrad. Develop. 26, 544556. 
Mengistie, A., 1997. Land surface water harvesting techniques and their application for drought mitigation measures. Suslainabiliiy of water resources under increasing uncertainty. Proceedings of the Rabat Symposium S1, IAHS 240, Rabat, Morroco.

Mering, C., Baro, J., Upegui, E., 2010. Retrieving urban areas on google earth images: application to towns of West Africa. Int. J. Remote Sens. 31, 5867-5877.

Mesfine, T., Girma, A.G., Al-Tawaha, A.R.M., 2005. Effect of reduced tillage and crop residue ground cover on yield and water use efficiency of sorghum (Sorghum bicolor (L.) Moench) under semi-arid conditions of Ethiopia. World J. Agric. Sci. 1, 152-160.

Meze-Hausken, E., 2004. Contrasting climate variability and meteorological drought with perceived drought and climate change in northern Ethiopia. Clim. Res. 27, 19-31.

Miriti, J.M., Esilaba, A.O., Bationo, A., Cheruiyot, H., Kihumba, J., Thuranira, E.G., 2007. Tied-ridging and integrated nutrient management options for sustainable crop production in semi-arid eastern Kenya, in: Bationo, A. (Eds.), Advances in integrated soil fertility management in sub-Saharan Africa: challenges and opportunities. Springer, Dordrecht, pp. 435-441.

Mohamadi, M.A., Kavian, A., 2015. Effects of rainfall patterns on runoff and soil erosion in field plots. Int. Soil Water Conserv. Res. 3, 273-281.

Moreno-de las Heras, M., Nicolau, J.M., Merino-Martín, L., Wilcox, B.P., 2010. Plot-scale effects on runoff and erosion along a slope degradation gradient. Water Res. Res. 46, W04503.

Moriasi, D.N., Arnold, J.G., Van Liew, M.W., Bingner, R.L., Harmel, R.D., Veith, T.L., 2007. Model evaluation guidelines for systematic quantification of accuracy in watershed simulations. Trans. ASABE 50, 885-900.

Motsi, K.E., Chuma, E., Mukamuri, B.B., 2004. Rainwater harvesting for sustainable agriculture in communal lands of Zimbabwe. Phys. Chem. Earth 29, 1069-1073.

Mudatenguha, F., Anena, J., Kiptum, C.K., Mashingaidze, A.B., 2014. In situ rain water harvesting techniques increase maize growth and grain yield in a semi-arid agroecology of Nyagatare, Rwanda. Int. J. Agric. Biol. 16, 996-1000.

Mwango, S.B., Msanya, B.M., Mtakwa, P.W., Kimaro, D.N., Deckers, J., Poesen, J., 2015. Effectiveness of mulching under miraba in controlling soil erosion, fertility restoration and crop yield in the Usambara mountains, Tanzania. Land Degrad. Dev. 27, 12661275.

Nash, J.E., Sutcliffe, J.V., 1970. River flow forecasting through conceptual models, Part I - A discussion of principles. J. Hydrol. 10, 282290.

NEDECO (Netherlands Engineering Consultants), 1998. Tekeze river basin integrated development master plan project. Ministry of Water Resources of Ethiopia, Sectoral reports volume xv, xiv and vii, Addis Ababa, Ethiopia. 
Nelson, D.W., Sommers, L.E., 1982. Total carbon, organic carbon and organic matter., in: Page, A.L., Miller, R.H., Kenney, D.R. (Eds.), Methods of soil analysis, part 2, chemical and microbiological properties. Am. Soc. Agron, Madison, pp. 539-577.

Ngigi, S.N., 2003. What is the limit of up-scaling rainwater harvesting in a river basin? Phy. Chem. Earth 28, 943-956.

Nicholson, F.A., Chambers, B.J., Mills, A.R., Strachan, P.J., 1997. Effects of repeated straw incorporation on crop fertilizer nitrogen requirements, soil mineral nitrogen and nitrate leaching losses. Soil Use Manag. 13, 136-142.

Nyamadzawo, G., Wuta, M., Nyamangara, J., Gumbo, D., 2013. Opportunities for optimization of in-field water harvesting to cope with changing climate in semi-arid smallholder farming areas of Zimbabwe. SpringerPlus 2, 1-9.

Nyssen, J., Clymans, W., Descheemaeker, K., Poesen, J., Vandecasteele, I., Vanmaercke, M., Zenebe, A., Van Camp, M., Haile, M., Haregeweyn, N., Moeyersons, J., Martens, K., Gebreyohannes, T., Deckers, J., Walraevens, K., 2010. Impact of soil and water conservation measures on catchment hydrological response- A case in north Ethiopia. Hydrol. Process. 24, 1880-1895.

Nyssen, J., Clymans, W., Poesen, J., Vandecasteele, I., De Baets, S., Haregeweyn, N., Naudts, J., Hadera, A., Moeyersons, J., Haile, M., Deckers, J., 2009a. How soil conservation affects the catchment sediment budget - A comprehensive study in the north Ethiopian highlands. Earth Surf. Process. Landf. 34, 1216-1233.

Nyssen, J., Frankl, A., Zenebe, A., Deckers, J., Poesen, J., 2015. Land management in the northern Ethiopian highlands: Local and global perspectives; past, present and future. Land Degrad. Dev. 26, 759-764.

Nyssen, J., Poesen, J., Deckers, J., 2009b. Land degradation and soil and water conservation in tropical highlands. Soil Tillage Res. 103, 197-202.

Nyssen, J., Poesen, J., Gebremichael, D., Vancampenhout, K., D’aes, M., Yihdego, G., Govers, G., Leirs, H., Moeyersons, J., Naudts, J., Haregeweyn, N., Haile, M., Deckers, J., 2007. Interdisciplinary on-site evaluation of stone bunds to control soil erosion on cropland in northern Ethiopia. Soil Tillage Res. 94, 151-163.

Nyssen, J., Poesen, J., Moeyersons, J., Haile, M., Deckers, J., 2008. Dynamics of soil erosion rates and controlling factors in the northern Ethiopian highlands towards a sediment budget. Earth Surf. Process. Landf. 33, 695-711.

Nyssen, J., Veyret-picot, M., Poesen, J., Moeyersons, J., Haile, M., Deckers, J., Govers, G., 2004. The effectiveness of loose rock check dams for gully control in Tigray, northern Ethiopia. Soil Use Manag. 20, 55-64.

Okeyo, A.I., Mucheru-Muna, M., Mugwe, J., Ngetich, K.F., Mugendi, D.N., Diels, J., Shisanya, C.A., 2014. Effects of selected soil and water conservation technologies on nutrient losses and maize yields in the central highlands of Kenya. Agric. Water Manag. 137, 52-58. 
Olsen, S.R., Sommers, L.E., 1982. Phosphorus, in: Page, A.L., Miller, R.H., Kenney, D.R. (Eds.), Methods of soil analysis, part 2, chemical and microbiological properties. Am. Soc. Agron., Madison, pp. 403-430.

Ouessar, M., Bruggeman, A., Abdelli, F., Mohtar, R.H., Gabriels, D., Cornelis, W.M., 2009. Modelling water-harvesting systems in the arid south of Tunisia using SWAT. Hydrol. Earth Syst. Sci. 13, 2003-2021.

Ouessar, M., Hessel, R., Kirkby, M., Sghaier, M., Ritsema, C., 2013. Report on the assessment of potential of water harvesting. WAHARA report number 10 , deliverable 1.4, IRA, Tunisia.

Oweis, T., Hachum, A., 2006. Water harvesting and supplemental irrigation for improved water productivity of dry farming systems in West Asia and North Africa. Agric. Water Manag. 80, 57-73.

Oweis, T., Hachum, A., Kijne, J., 1999. Water harvesting and supplementary irrigation for improved water use efficiency in dry areas. SWIM Paper 7. International Water Management Institute (IWMI), Colombo.

Oweis, T., Prinz, D., Hachum, A., 2001. Water harvesting: Indigeous knowledge for the future of drier environments. ICARDA, Aleppo, Syria.

Panagos, P., Borelli, P., Poesen, J., Ballario, C., Lugato, E., Meusberger, K., Montanarella, L., Alewell, C., 2015. The new assessment of soil loss by water erosion in Europe. Environ. Sci. Policy 54, 438-447.

Pandey, A., Chowdary, V.M., Mal, B.C., Dabral, P.P., 2011. Remote sensing and GIS for identification of suitable sites for soil and water conservation structures. Land Degrad. Dev. 22, 359-372.

Parsons, A.J., Brazier, R.E., Wainwright, J., Powell, D.M., 2006. Scale relationships in hillslope runoff and erosion. Earth Surf. Process. Landf. 31, 1384-1393.

Polyakov, V.O., Nichols, M.H., Mcclaran, M.P., Nearing, M.A., 2014. Effect of check dams on runoff, sediment yield, and retention on small semiarid watersheds. J. Soil Water Conserv. 69, 414-421.

Prinz, D., 2001. Water harvesting for afforestation in dry areas. Proceedings, 10th International Conference on Rainwater Catchment Systems. Mannheim, Germany, pp. 195-198.

Prinz, D., 1996. Water harvesting: past and future, in: Pereira, L.S., Feddes, R.A, Gilley, J.R, Lesaffre, B. (Eds.), Sustainability of irrigated agriculture. Springer, Dordrecht, pp.137168.

Prosdocimi, M., Cerdà, A., Tarolli, P., 2016a. Soil water erosion on Mediterranean vineyards: A review. Catena 141, 1-21.

Prosdocimi, M., Jordán, A., Tarolli, P., Keesstra, S., Novara, A., Cerdà, A., 2016b. The immediate effectiveness of barley straw mulch in reducing soil erodibility and surface runoff generation in Mediterranean vineyards. Sci. Total Environ. 547, 323-330. 
Rai, R.K., Mathur, B.S., 2007. Event-based sediment yield modeling using artificial neural network. Water Res. Manag. 22, 423-441.

Ramakrishna, A., Tam, H.M., Wani, S.P., Long, T.D., 2006. Effect of mulch on soil temperature, moisture, weed infestation and yield of groundnut in northern Vietnam. Field Crop. Res. 95, 115-125.

Ramesh, T., Devasenapathy, P., 2006. Physiological response of cowpea in a rainfed alfisol ecosystem to the impulse of soil moisture conservation practices. Gen. Appl. Plant Physiol. 32, 181-190.

Ramsankaran, R., Kothyari, U.C., Ghosh, S.K., Malcherek, A., Murugesan, K., 2013. Physically-based distributed soil erosion and sediment yield model (DREAM) for simulating individual storm events. Hydrol. Sci. J. 58, 872-891.

Rawls, W.J., Brakensiek, D.L., Logsdon, S.D., 1993. Predicting saturated hydraulic conductivity utilizing fractal principles. Soil Sci. Soc. Am. J. 57, 1193-1197.

Reij, C., Mulder, P., Begemann, L., 1988. Water harvesting for plant production. Rechnical Paper Number 91. The World Bank,Washington.

Renard, K.G., Foster, G.R., Weesies, G.A., McNool, D.K., Yoder, D.C., 1996. Predicting soil erosion by water: $A$ guide to conservation planning with the revised universal soil loss equation (RUSLE). Agricultural Handbook Number 703. USDA, Washington DC.

Rockström, J., 2000. Water resources management in smallholder farms in Eastern and Southern Africa: An overview. Phys. Chem. Earth 25, 275-283.

Rockström, J., Barron, J., Fox, P., 2003. Water productivity in rain-fed agriculture: challenges and opportunities for smallholder farmers in drought-prone tropical agroecosystems, in: Kijne, J.W., Barker, R., Molden, D. (Eds.), Water productivity in agriculture: Limits and opportunities for improvement. CAB International, Wallingford, pp. 145-162.

Rockström, J., Barron, J., Fox, P., 2002. Rainwater management for increased productivity among small-holder farmers in drought prone environments. Phys. Chem. Earth 27, 949-959.

Rodrigo Comino, J., Brings, C., Lassu, T., Iserloh, T., Senciales, J.M., Martínez Murillo, J.F., Ruiz Sinoga, J.D., Seeger, M., Ries, J.B., 2015. Rainfall and human activity impacts on soil losses and rill erosion in vineyards (Ruwer Valley, Germany). Solid Earth 6, 823837.

Rust, W., Corstanje, R., Holman, I.P., Milne, A.E., 2014. Detecting land use and land management influences on catchment hydrology by modelling and wavelets. J. Hydrol. 517, 378-389.

Saaty, T.L, 2004. Decision making - The analytic hierarchy and network processes (AHP/ANP). J. Sys. Sci. Sys. Eng., 13, 1-35.

Saaty, T.L., 1980. The analytic hierarchy process. McGraw-Hill, New York. 
Sadeghi, S.H.R., Gholami, L., Homaee, M., Darvishan, K.A., 2015a. Reducing sediment concentration and soil loss using organic and inorganic amendments at plot scale. Solid Earth 6, 445-455.

Sadeghi, S.H.R., Gholami, L., Sharifi, E., Khaledi Darvishan, A., Homaee, M., 2015b. Scale effect on runoff and soil loss control using rice straw mulch under laboratory conditions. Solid Earth 6,1-8.

Saptarshi, P.G., Raghavendra, R.K.. 2009. GIS-based evaluation of micro-watersheds to ascertain site suitability for water conservation structures. J. Indian Soc. Remote Sens. 37, 693-704.

Schuhmann, R., Königer, F., Emmerich, K., Stefanescu, E., Stacheder, M., 2011. Determination of hydraulic conductivity based on (soil) - moisture content of fine grained soils, in: Elango, L. (Eds.), Hydraulic conductivity - issues, determination and applications. InTech, Rijeka, pp. 165-188.

Schwilch, G., Bachmann, F., de Graaff, J., 2012a. Decision support for selecting SLM technologies with stakeholders. Appl. Geogr. 34, 86-98.

Schwilch, G., Bachmann, F., Liniger, H.P., 2009. Appraising and selecting conservation measures to mitigate desertification and land degradation based on stakeholder participation and global best practices. Land Degrad. Dev. 20, 308-326.

Schwilch, G., Bachmann, F., Valente, S., Coelho, C., Moreira, J., Laouina, A., Chaker, M., Aderghal, M., Santos, P., Reed, M.S., 2012b. A structured multi-stakeholder learning process for sustainable land management. J. Environ. Manag. 107, 52-63.

SEI (Stockholm Environment Institute), 2013. Targeting AGwater Management Interventions (TAGMI). http://iwmi-tagmi.cloudapp.net. Accessed on March 11, 2016.

Sheikh, V., Van Loon, E., Hessel, R., Jetten, V., 2010. Sensitivity of LISEM predicted catchment discharge to initial soil moisture content of soil profile. J. Hydrol. 393, 174185.

Singh, J.P., Singh, D., Litoria, P.K., 2009. Selection of suitable sites for water harvesting structures in Soankhad watershed, Punjab using remote sensing and geographical information system (RS\&GS) approach: A case study. J. Indian Soc. Remote Sens. 37, 21-35.

Sirjani, E., Mahmoodabadi, M., 2014. Effects of sheet flow rate and slope gradient on sediment load. Arab. J. Geosci. 7, 203-210.

SIWI (Stockholm International Water Institute), 2001. Water harvesting for upgrading of rainfed agriculture: problem analysis and research needs. SIWI Report 11. SIWI, Stockholm.

Smil, V., 1999. Crop residues: Agriculture's largest harvest. BioSci. 49, 299-308.

Steffens, D., Hütsch, B.W., Eschholz, T., Lošák, T., Schubert, S., 2005. Water logging may inhibit plant growth primarily by nutrient deficiency rather than nutrient toxicity. Plant Soil Environ. 51, 545-552. 
Strahler, A.N., 1957. Quantitative analysis of watershed geomorphology. Am. Geophys. Union Trans. 38, 913-920.

Stroosnijder, L., 2003. Technologies for improving green water use efficiency in West Africa. Water conservation technologies for sustainable dryland agriculture in subSaharan Africa symposium and workshop. Bloemfontein, South Africa.

Taddese, G., 2001. Land degradation: A challenge to Ethiopia. Environ. Manag. 27, 815824.

Tallaksen, L.M., 1995. A review of baseflow recession analysis. J. Hydrol. 165, 349-370.

Tamene, L., Park, S.J., Dikau, R., Vlek, P.L.G., 2006. Analysis of factors determining sediment yield variability in the highlands of northern Ethiopia. Geomorphol. 76, 7691.

Tavares, J.P., Ferreira, A.D., Reis, E.A., Baptista, I., Amoros, R., Costa, L.R., et al. 2014. Appraising and selecting strategies to combat and mitigate desertification based on stakeholder knowledge and global best practices in Cape Verde archipelago. Land Degrad. Dev. 25, 45-57.

Taye, G., Poesen, J., Van Wesemael, B., Vanmaercke, M., Teka, D., Deckers, J., Goosse, T., Maetens, W., Nyssen, J., Hallet, V., Haregeweyn, N., 2013. Effects of land use, slope gradient, and soil and water conservation structures on runoff and soil loss in semiarid northern Ethiopia. Phys. Geogr. 34, 236-259.

Tejada, M., Benítez, C., 2014. Effects of crushed maize straw residues on soil biological properties and soil restoration. Land Degrad. Develop. 25, 501-509.

Temesgen, M., Hoogmoed, W.B., Rockström, J., Savenije, H.H.G., 2009. Conservation tillage implements and systems for smallholder farmers in semi-arid Ethiopia. Soil Tillage Res. 104, 185-191.

Teshome, A., de Graaff, J., Ritsema, C., Kassie, M., 2016. Farmers' perceptions about the influence of land quality, land fragmentation and tenure systems on sustainable land management in the north western Ethiopian highlands. Land Degrad. Dev. 27, 884898.

Teshome, A., Rolker, D., de Graaff, J., 2013. Financial viability of soil and water conservation technologies in northwestern Ethiopian highlands. Appl. Geogr. 37, 139149.

UNDP (United Nations Development Program), 2006. Beyond scarcity: Power, poverty and the global water crisis. Human Development Report 2006. United Nations Development Programme.

Vancampenhout, K., Nyssen, J., Gebremichael, D., Deckers, J., Poesen, J., Haile, M., Moeyersons, J., 2006. Stone bunds for soil conservation in the northern Ethiopian highlands: Impacts on soil fertility and crop yield. Soil Tillage Res. 90, 1-15.

Vanmaercke, M., Poesen, J., Broeckx, J., Nyssen, J., 2014. Sediment yield in Africa. EarthSci. Rev. 136, 350-368. 
Vanmaercke, M., Poesen, J., Verstraeten, G., De Vente, J., Ocakoglu, F., 2011. Sediment yield in Europe: Spatial patterns and scale dependency. Geomorphol. 130, 142-161.

Verstraeten, G., Poesen, J., 2001. Modelling the long-term sediment trap efficiency of small ponds. Hydrol. Process. 15, 2797-2819.

Vohland, K., Barry, B., 2009. A review of in situ rainwater harvesting (RWH) practices modifying landscape functions in African drylands. Agric. Ecosys. Environ. 131, 119127.

Vörösmarty, C.J., Green, P., Salisbury, J., Lammers, R.B., 2000. Global water resources: Vulnerability from climate change and population growth. Sci. 289, 284-288.

Wakindiki, I., Ben-Hur, M., 2002. Indigenous soil and water conservation techniques: Effects on runoff, erosion, and crop yields under semi-arid conditions. Aust. J. Soil Res. 40, 367-379.

Walraevens, K., Gebreyohannes, T., Amare, K., Hussein, A., Berhane, G., Baert, R., Ronsse, S., Kebede, S., Hulle, V.L., Deckers, J., Martens, K., Camp, M.V., 2015. Water balance components for sustainability assessment of groundwater-dependent agriculture: Example of the Mendae plain (Tigray, Ethiopia). Land Degrad. Dev. 26, 725-736.

Wang, H., Gao, J.E., Zhang,S.L., Zhang, M.J., Li, X.H., 2013. Modeling the impact of soil and water Conservation on surface and ground water based on the SCS and visual Modflow. Plos One 8, e79103.

Wang, Y., Xie, Z., Malhi, S.S., Vera, C.L., Zhang, Y., Wang, J., 2009. Effects of rainfall harvesting and mulching technologies on water use efficiency and crop yield in the semi-arid Loess Plateau, China. Agric. Water Manag. 96, 374-382.

White, S., 2005. Sediment yield prediction and modelling. Hydrol. Process. 19, 3053-3057.

Windeatt, J.H., Ross, A.B., Williams, P.T., Forster, P.M., Nahil, M.A., Singh, S., 2014. Characteristics of biochars from crop residues: Potential for carbon sequestration and soil amendment. J. Environ. Manag. 146, 189-197.

WOCAT, 2007. Where the land is greener: Case studies and analyis of soils and water conservation initiatives world wide, in: Liniger, H., Critchely, W. (Eds.), World Overview of Conservation Approaches and Technologies (WOCAT), CTA, Wageningen; FAO, Rome; UNEP, Nairobi and CDE, Bern.

World Bank, 2007. Agriculture for Development. World development report overview.The World Bank, Washington

$\mathrm{Xu}$, Y.D., Fu, B.J., He, C.S., 2013. Assessing the hydrological effect of the check dams in the Loess Plateau, China, by model simulations. Hydrol. Earth Syst. Sci. 17, 2185-2193.

Yosef, B.A., Asmamaw, D.K., 2015. Rainwater harvesting: An option for dry land agriculture in arid and semi-arid Ethiopia. Int. J. Water Res. Environ. Eng. 7, 17-28.

Zougmoré R., Mando A., Stroosnijder L., 2009. Soil nutrient and sediment loss as affected by erosion barriers and nutrient source in semi-arid Burkina Faso. Arid Land Res. Manag. 23, 85-101. 


\section{English summary}

Rainfed agriculture is widely practiced in northern Ethiopia with $85 \%$ of the livelihood of the society depending on subsistence agriculture, mainly crop production. Crop production in semi-arid and arid northern Ethiopia is highly influenced by the erratic rainfall pattern and sometimes insufficient rainfall for crop growth. The temporal variability of rainfall and the occurrence of dry spell, especially in drought-prone areas such as the northern Ethiopian highlands are the main causes for crop failures and low yields. The negative effects of these climatic adversities can be minimized by using water management strategies that improve the temporal availability and distribution of water for crop growth. Since rain is the principal source of water for subsistence agriculture in northern Ethiopia, it is necessary to implement water management options that most effectively utilize rainwater.

The efficient use of rainwater for different agricultural systems can be increased by implementing water harvesting techniques (WHTs), which are able to bridge water deficiencies during dry spells and hence decrease the prevalence of crop failures. The landscape of the northern Ethiopian highlands is characterized by a rugged topography, usually with steep slopes; hence hydrology is primarily influenced by landscape morphology. For this reason, it is important to distinguish different positions in the landscape such as slopes and valley-floors as wells as upstream and downstream in order to select appropriate WHTs for different parts of the landscape. The objectives of the study are therefore to develop a decision support approach for selection of WHTs and evaluate the on-site and off-site effects of the selected WHTs on hydrological and erosion processes.

After the general introduction (Chapter 1), Chapter 2 discusses the development of a decision support approach that facilitates the selection of WHTs by integrating sitespecific bio-physical and socio-economic conditions. The selection procedure mainly involves identification and assessment of WHTs based on local and global best practices, pre-selection, bio-physical suitability analysis and final selection with stakeholders. Once selected, the WHTs can be implemented in the target area and tested for their performances. 
This decision support approach was validated with a case study for WHTs in the upper Geba watershed in northern Ethiopia. Using the decision support methodology, eight potential WHTs were pre-selected for implementation in the upper Geba watershed. Next, using the suitability indicators for WHTs and a GIS-based MCA, suitable areas were identified for three of these WHTs, namely check dams, percolation ponds and bench terraces and suitability maps were generated. The MCA was validated by comparing the predicted suitable areas with the already existing locations of WHTs in the watershed. The result was that $90 \%$ of the existing check dams and $93 \%$ of the percolation ponds in the upper Geba watershed were correctly identified by the approach. At the final selection workshop, the selection of WHTs to take to further testing was made based on a participatory ranking of the candidate WHTs using economic, ecological and socio-cultural criteria.

Chapter 3 assessed the benefits of individual and combined use of in-situ WHTs such as tied ridges and straw mulch and effective micro-organisms (EMs) in improving on-site water availability for crop production. A plot-scale experiment was setup to monitor the effect of the in-situ WHTs on soil properties, runoff and soil-moisture content (SMC). Soil properties such as bulk density, soil organic matter, saturated and unsaturated hydraulic conductivities did not change after the application of the in-situ WHTs. However the WHTs did impact both runoff and SMC.

Event-based runoff was significantly reduced by the use of the in-situ WHTs. The efficiency of runoff reduction per event for the various in-situ WHTs in general ranged between 49 and $88 \%$. Tied ridges alone reduced average runoff from farmland by $56 \%$. The application of straw mulch, with and without EMs in farmland, decreased runoff by 49 and 53\%, respectively. Next to the individual benefits of straw mulch and tied ridges for decreasing runoff from farmland, the efficiency of runoff reduction was even more improved when the two techniques were combined. Combined tied ridges and straw mulch with and without EMs significantly reduced average runoff per event by 78 and $88 \%$, respectively.

While SMC in the farmland did not increase when tied ridges were used alone, it was improved when straw mulch was applied alone or in combination with tied ridges. SMC was significantly higher when the two techniques (straw mulch and tied ridges) were combined. The higher efficiency in soil-moisture retention is primarily attributed to the cumulative effect of water storage by tied ridges and straw mulch, as well as the reduction of water evaporation from the soil by straw mulch.

Chapter 4 focuses on the role of in-situ WHTs in reducing soil erosion and nutrient losses from farmland. Effect on maize yield was also investigated. The field experiment 
demonstrated that in-situ WHTs are useful for mitigating land degradation by decreasing soil erosion, consequently reducing soil and nutrient losses. For example, tied ridges alone reduced average soil loss per event by $60 \%$. Straw mulch (with and without EMs) reduced average soil loss per event by $83 \%$. Similarly, the combined use of straw mulch with tied ridges reduced average soil loss by $86 \%$. Nutrient losses ( $\mathrm{N}$ and $\mathrm{P}$ ) were also reduced by the use of in-situ WHTs in farmlands. Tied ridges decreased total $\mathrm{N}$ and P losses by 59 and $52 \%$, respectively. Total $N$ and $P$ losses also decreased by 63 and $68 \%$, respectively, due to the use of straw mulch. Combining tied ridges with straw mulch was even more efficient with 82 and $83 \%$ of reductions in total $\mathrm{N}$ and $\mathrm{P}$ losses, respectively.

Maize grain yield in the field experiment significantly increased only for straw mulch used alone. Maize yield did not significantly increase with tied ridges alone or combined with straw mulch. The increase in yield with straw mulch is most likely attributed to the improved temporal distribution of soil-moisture and the reduction of water evaporation from the soil layer. The lack of any significant yield increase from tied ridges in combination with straw mulch is most probably due to excess water in the root zone when this combination was used during periods with intensive rain events, causing aeration stress and disrupting the normal growth of the maize.

Chapter 5 deals with a catchment-scale study on the effect of WHTs on hydrological responses and sediment yield. The study was conducted in the Gule catchment (area 12 $\mathrm{km}^{2}$ ), in northern Ethiopia, which is well managed with WHTs such as stone bunds, deep trenches, check dams and percolation ponds. The effects of the WHTs on event-based runoff and sediment yield were monitored for two years (2014 and 2015) at two outlets, namely Gule (main outlet) and Misbar (sub-outlet). The effect of the WHTs on ground water level was also monitored by measuring static water levels in a hand-dug well located within the catchment.

Field measurements showed that WHTs in the catchment help to increase ground water level in hand-dug wells, and decrease runoff and sediment yield at the outlets. Modelbased assessment using LISEM after calibration for event-based runoff and sediment yield using measurements at the outlets, also showed a reduction in catchment-level runoff and sediment yield due to WHTs. The model-based simulation at the Gule and Misbar outlets showed that the current WHTs applied in the catchment are able to decrease the eventbased runoff volume by 41 and $45 \%$, respectively. Similarly, sediment yield was reduced at both the Gule outlet and Misbar sub-outlet, by 67 and 55\%, respectively. The reduction in catchment-level runoff helps to improve the availability of water in a catchment, for example, by raising ground water levels in hand-dug wells, as was demonstrated in our study. The reduction in catchment-level sediment yield due to WHTs further indicates that 
WHTs are useful for mitigation of land degradation caused by water erosion. The benefits from WHTs at catchment level can be maximized by optimizing the locations of the WHTs in the catchment. The locations of WHTs, for example, can be made based on landscapes to improve the efficiency of water harvesting. Some WHTs such as stone bunds, deep trenches, and percolation ponds need to be located in the upper part of the catchment in order to enhance ground water recharge so that the infiltrated water can be harvested downstream with, for example, check-dam ponds and hand-dug wells.

This project developed and validated a decision support approach, which is suitable for northern Ethiopia for selecting and implementing effective WHTs. This decision approach helps to select WHTs that improve availability of water at farmlands and catchments, hence decreasing overreliance on subsistent rainfed agriculture. This project has verified that in semi-arid areas, such as the northern Ethiopian highlands, in-situ WHTs such as tied ridges and straw mulch can be used to improve rainwater capture and on-site water availability for crop growth. These in-situ WHTs also decrease the loss of soil from farmlands. Furthermore, the project shows that catchment management with WHTs is also useful to decrease runoff and sediment yield at catchment outlets under conditions found in northern Ethiopia. 


\section{Acknowledgements}

The long journey, which was seemingly never ending, has come to a conclusion. Despite all the hardship, I always echo the old English proverb made famous by Shakespeare, "All is well that ends well". The journey was, however, never easy and without the support and encouragement of the people who were close to me, the "end" would have been different. I am therefore indebted to the following people for their unconditional support during my PhD study as well as for their valuable encouragement and advice when I needed.

First, I would like to thank my promoter Prof. Coen Ritsema, the Soil Physics and Land Management group leader, for willingly accepting me as a PhD student to the group, for his valuable discussions during proposal writing, and for his assistance in resolving administrative issues during my stay in Wageningen. My deep and heartfelt gratitude goes to my other promoter and supervisor Prof. Violette Geissen for her never-ending support and guidance during proposal writing, research set-up, arrangement of equipment purchase for field work, daily supervision on progress of the study, guidance on the use of statistical analysis tools and PhD thesis writing. I would also like to thank her for her keen and cheerful support in arranging and resolving any administrative issues in relation to the PhD study, at all costs. Her valuable encouragement and support during good and desperate times was indispensable. My gratitude goes as well to Dr. Rudi Hessel for his guidance on the use of LISEM, assistance during proposal writing and for thoroughly reading and revising all the chapters of the thesis. He had always time to read and revise my manuscripts and I have learnt a lot from his critical comments and suggestions. I was really blessed to have him in my supervision team. I am also thankful to Dr. Aad Kessler who had helped me a lot during writing the proposal and chapters of the thesis. I really appreciate your critical and honest comments and suggestions on the contents and structure of the chapters. I thank Jantiene Baartman too for her technical support on the use of LISEM.

I would like to express my heartfelt gratitude to my local supervisor Dr. Kifle Woldearegay for his incessant support during the field research work and writing of the thesis. It was really easy and inspiring working with you. I thank Dr. Dereje Assefa, Dr. Mohammed Abdulkadir and Dr. Eyasu Yazew for their support and co-authorship in the PhD work. 
Special thanks for Berihu Aregawi and Kelali Haftu too for their assistance during the field work.

I am very grateful for the European Union's (EU) Seventh Framework Program (FP7/20072013) for funding my PhD study and research through the Water Harvesting for Rainfed Africa (WAHARA) project (contract number 265570).

I would like to thank Mekelle University, School of Civil Engineering for granting me the study leave for pursuing my PhD study as well as providing field equipment and laboratory for conducting my research. I thank all my colleagues in the School of Civil Engineering for their friendly support and encouragement during my PhD study.

I am thankful to the staff and students of the Soil Physics and Land Management group at Wageningen University for their support and friendship during my stay away from home. I am greatly indebted to Klaas Oostindie for his assistance in assembling and outlining my PhD thesis book, for nicely formatting some figures and providing a design for the cover page of the thesis book. I am thankful to Demie Moore for helping me in editing the English of the synthesis and English summary of the thesis. I am indebted to thank my friends in Wageningen University, particularly Kaveh, Célia, Ammar, Mohamed, Xiaomei, Karrar, Samuel, Mulatie, Walle, Akalu, Zenebe, Lingtong, Everton, Ricardo, Isaurinda, Vera, Sija, Rens and many others from the "Atlas Gang" group for their friendship and support during my stay in Wageningen.

My heartfelt gratitude goes to the cheerful Marnella van der Tol and Annelies van de Bunte for their uninterrupted support in administrative arrangements. Special thanks to Anita Kok and Esther van den Brug for their support in administrative and financial matters.

My sincere gratitude goes to my mother Mitsilal Alemayehu, my late father Grum Woldegiorgis, my aunt Alganesh Alemayehu and her husband Negassi Assefa, brothers and sisters for their endless love and caring throughout my life.

My sincere and heartfelt gratitude goes to my lovely wife HanaMariam Gebru, for her love and caring, continuous support, and for handling household issues during my absence. I thank you for your patience and encouragement during hardships and desperate conditions. My thanks and apologies go to my children Saron and Eliana for your tolerance during my absence and for not giving you ample time even when I was in Mekelle. 


\section{Curriculum Vitae}

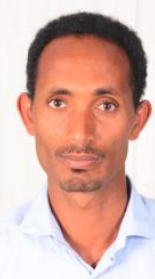

Berhane Grum Woldegiorgis was born on March 28, 1980 in Digum, Ethiopia.

He has got his bachelor's degree (BSc.) in Civil Engineering from Mekelle University in July 2006. In August 2006, he was employed by Mekelle University, in the department of Civil Engineering as instructor, with rank of graduate assistant.

In September 2007, he got a scholarship from the Swedish International Development Agency (SIDA) to pursue his graduate program in Environmental Engineering and Sustainable Infrastructure in the Royal Institute of Technology (KTH), in which he got his masters' degree (MSc.) in August 2009.

Starting from September 2009 till April 2012, he continued to work in Mekelle University, in the department of Civil Engineering as lecturer and researcher. He has been teaching courses mainly engineering mechanics, hydraulics I, hydraulics II and open channel hydraulics. He was also a member of the Mekelle University and the Flemish International University Council (MU-IUC) research project funded by the Belgium government, in which he worked as hydrologist.

In April 2012, Berhane Grum was admitted to a PhD program at Wageningen University in the Land Degradation and Development (currently Soil Physics and Land Management) research group. His PhD research topic was on "Effect of Water Harvesting Techniques on Hydrological processes and Sediment Yield in northern Ethiopia". The research work was relevant to the semi-arid northern Ethiopia in which the existing rainfed agriculture is highly affected by climatic variability and availability of water. The PhD study was funded by the European Union's Seventh Framework Program (FP7/2007-2013), under the Water Harvesting for Rainfed Africa (WAHARA) project.

He has participated and presented his research results at international meetings and symposiums. He participated in the "Agro Environ Symposium 2012" in Wageningen, the Netherlands. He also presented his study in the WAHARA Annual Plenary meeting in July 2015, which took place in Ouagadougou, Burkina Faso and in the SENSE-WIMEK 
symposium on "Hazard, risk and sustainability in the soil environment" in October 2015, at Wageningen, the Netherlands. In addition to his PhD study, he was also partly involved in teaching courses in Mekelle University and doing research entitled "potential of water harvesting from road catchments" under the UPGro catalyst project.

Berhane is married and has two children, a 6-years and 3-years old daughters.

Email contact: berhanegr@gmail.com ; biire2005@yahoo.com

Publications

Peer reviewed papers

Grum, B., Hessel, R., Kessler, A., Woldearegay, K., Yazew, E., Ritsema, C., Geissen, V. 2016. A decision support approach for the selection and implementation of water harvesting techniques in arid and semi-arid regions. Agricultural Water Management 173, 35-47.

Grum, B., Assefa, D., Hessel, R., Woldearegay, K., Kessler A., Ritsema C., Geissen, V. 2016. Effect of in situ water harvesting techniques on soil and nutrient losses in semi-arid northern ethiopia. Land Degradation and Development, online early view.

Grum, B., Assefa, D., Hessel, R., Woldearegay, K., Ritsema, C., Aregawi, B., Geissen, V. Improving on-site water availability by combining in-situ water harvesting techniques in semi-arid northern Ethiopia. Agricultural Water Management. Under review.

Grum, B., Woldearegay, K., Hessel, R., Baartman, J.E.M., Abdulkadir, M., Yazew, E., Kessler, A., Ritsema, C., Geissen, V. Assessing the effect of water harvesting techniques on event-based hydrological responses and sediment yield at a catchment scale in northern Ethiopia using LISEM. Catena. Under review.

Proceedings/Reports/Master's thesis

Woldearegay, K., Van Steenbergen. F., Agujetas, M., Grum, B., Van Beusekom, M. 2015. Water harvesting from roads: climate resilience in Tigray, Ethiopia. IRF Europe \& Central Asia Regional Congress September 15-18, 2015-Istanbul Turkey.

Grum, B., Woldearegay, K., Van Steenbergen. F., Puertas, D.G., Van Beusekom, M., Agujetas, M. 2014. Reconnaisance Report: Potentials of water harvesting from road catchments: the case of Freweign-Hawzien-Abreha Weatsbeha route, Tigray, Northern Ethiopia. http://roadsforwater.org.

Grum, B., Setegn, S., Janssen, P-E., 2009. Application of SWAT model for water balance and climate change impact assessment in Geba watershed, Ethiopia. Master's thesis. KTH, the Royal Institute of Technolohgy, Sweden, Stockholm. 


\title{
SENSE
}

Netherlands Research School for the

Socio-Economic and Natural Sciences of the Environment

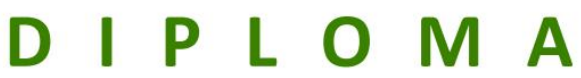

For specialised PhD training

The Netherlands Research School for the

Socio-Economic and Natural Sciences of the Environment

(SENSE) declares that

\section{Berhane Grum Woldegiorgis}

\author{
born on 28 March 1980 in Digum, Ethiopia
}

has successfully fulfilled all requirements of the

Educational Programme of SENSE.

Wageningen, 9 May 2017

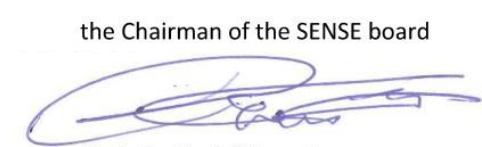

Prof. dr. Huub Rijnaarts

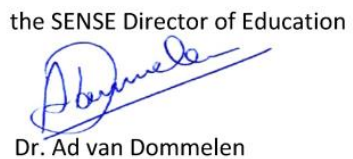

Dr. Ad van Dommelen

The SENSE Research School has been accredited by the Royal Netherlands Academy of Arts and Sciences (KNAW)

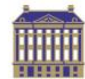

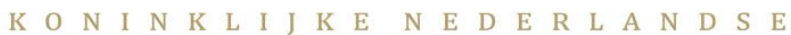

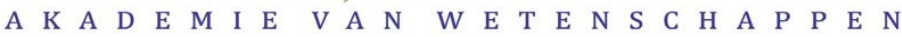




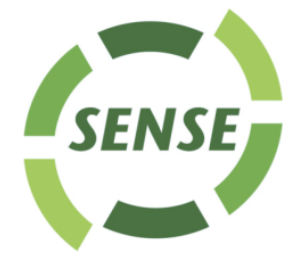

The SENSE Research School declares that Mr Berhane Grum Woldegiorgis has successfully fulfilled all requirements of the Educational PhD Programme of SENSE with a work load of $36.3 \mathrm{EC}$, including the following activities:

\section{$\underline{\text { SENSE PhD Courses }}$}

- Environmental research in context (2012)

- Linear models (2012)

- Generalised linear models (2012)

- Mixed linear models (2012)

- Hands-on soil and water field measurements (2012)

- Research in context activity: 'Contributing analysis to reviewing of intergovernmental panel on climate change (IPCC) chapter under coordination of the Netherlands Environmental Assessment Agency (PBL)' (2013)

- Basic statistics (2015)

- Geostatistics (2015)

- Statistical uncertainty analysis of dynamic models (2015)

- Introduction to R for statistical analysis (2015)

\section{Other PhD and Advanced MSc Courses}

- Information literacy PhD including EndNote introduction, Wageningen University (2012)

- Techniques for writing and presenting a scientific paper, Wageningen University (2012)

- Statistical down scaling model (SDSM), Mekelle University (2015)

\section{Management and Didactic Skills Training}

- Teaching undergraduate course 'Open channel hydraulics' (2013) and (2016)

- Assisting in graduate course 'Hydrodynamics' (2013)

- Assisting in graduate course 'Statistics for road and transport engineers' (2014) and (2016)

\section{Oral Presentations}

- The role of check dams for sediment storage and gully rehabilitation. SENSE-WIMEK Symposium Hazard, Risk and Sustainability in the Soil Environment, 14 October 2015, Wageningen, the Netherlands

- Effect of water harvesting techniques in the upper Geba catchment, northern Ethiopia. Water Harvesting for Rainfed Africa (WAHARA) project meeting, 6-9 July 2015,

Ougadougou, Burkina Faso

SENSE Coordinator PhD Education

Dr. ing. Monique Gulickx 